\title{
The nature, extent and survivorship of biofouling organisms at different hull locations on various vessel types
}

by

Ashley D. M. Coutts

A thesis submitted to the Victoria University of Wellington in fulfilment of the requirements for the degree of

Doctor of Philosophy in Marine Biology

Victoria University of Wellington

Te Whare Wānanga o te Ūpoko o te Ika a Māui 


\section{STATEMENT OF AUTHORSHIP BY PHD CANDIDATE}

Except where specific reference is made in the main text of the thesis, this thesis contains no material extracted in whole or in part from a thesis, dissertation, or research paper presented by me for another degree or diploma. No other person's work (published or unpublished) has been used without due acknowledgement in the main text of the thesis. This thesis has not been submitted for an award of any other degree or diploma in any other tertiary institution. All chapters are the product of investigations in collaboration with other researchers, and co-authors are listed at the start of each chapter. In all cases I am the principal author and contributor of the research. I certify that this thesis is less than 100,000 words, including all scholary apparatus.

Ashley David Murdoch Coutts

Date 


\section{PREFACE}

This thesis was motivated by the outcomes and limitations of my Masters research which investigated the nature, extent and factors that contribute to a vessel's degree of biofouling. While my Masters research was one of the first studies in the world to address this issue for modern day merchant vessels, the investigation was restricted to biofouling on the uniform areas of vessel hulls. While undertaking that investigation, I observed greater levels of biofouling in niche areas of vessels. Therefore, this thesis is a continuation of my Masters and aims to investigate the nature, extent and survivorship of biofouling organisms on various vessel types at different hull locations. The thesis consists of a general introduction, five technical chapters and a general discussion. At the time of submitting the thesis, all five technical chapters have been published in peerreviewed international journals and their citations provided in the Preface of each chapter. Each chapter is linked and provides a logical progression of investigation as outlined in each Chapter's Preface. The general discussion attempts to provide further explanations surrounding the nature, extent and survivorship of biofouling and nonindigenous marine species (NIMS) on vessel hulls. Furthermore, the general discussion outlines the latest biofouling management measures (to the author's knowledge) that have or are being developed around the world and highlight how the results of this thesis have and will continue to contribute to such developments. Finally a simplistic, but pragmatic risk assessment for identifying and managing potentially high risk vessels for NIMS is offered followed by some overall thesis recommendations. 


\begin{abstract}
The importance of vessel biofouling as a vector for the dispersal of non-indigenous marine species (NIMS) is only just beginning to receive international attention. At the time of commencing this study, there was a considerable lack of knowledge surrounding which vessels, hull locations, levels and types of biofouling pose the greatest biosecurity risk. Therefore, the aim of this study was to investigate the nature, extent and survivorship of biofouling organisms on various vessel types at different hull locations and offers a pragmatic risk assessment approach for managing this threat.
\end{abstract}

The results of this thesis found that the recruitment, persistence, distribution, abundance and species composition of biofouling on vessel hulls is influenced by many factors including: 1) the presence/absence, age and type of anti-fouling coating; 2) voyage duration and route; and 3) port residency period. Therefore, higher levels of biofouling (species richness, percentage cover, and biomass), including NIMS are more likely to accumulate and persist on vessels (and in hull locations) that: 1) lack and/or possess old, ineffective, damaged, inappropriate or unsuitable anti-fouling coatings; 2) spend prolonged periods stationary in ports; 3) travel at slow speeds (i.e. <10 knots); 4) have short voyage durations; and 5) remain at similar latitudes.

Prevention is clearly better than a cure, hence the correct application and maintenance of suitable anti-fouling coatings to the entire submerged hull surface of vessel hulls, including niche areas is the most cost-effective way of minimising the unwanted translocation of biofouling organisms and NIMS. However, the results of this thesis demonstrate that if biofouling organisms colonise and establish on a vessel's hull, voyage speed alone is not capable of providing a reliable secondary level of defence against the unwanted dispersal of NIMS. Clearly, the survivorship of biofouling organisms was highest amongst vessels that travelled at slow and medium speeds (e.g. $<10$ knots). Therefore, given that accumulation of biofouling follows a successional process and NIMS are more likely to be associated with higher levels of biofouling, vessels that travel at slow and medium speeds are more likely to pose the greatest risk of translocating NIMS on a vessel by vessel scale. However, despite the observation that faster vessels reduce the diversity, quantity and quality of sessile biofouling organisms in laminar flow areas of the hull, a wide range of sessile, sedentary and mobile organisms were still cable of survival in areas protected from harsh 
hydrodynamically forces commonly referred to as niche areas, particularly within seachests. 


\section{ACKNOWLEDGEMENTS}

Firstly, I would like to thank my amazing supervisors, Michael Taylor (Cawthron), Jonathan Gardner (Victoria University of Wellington) and Chad Hewitt (University of Tasmania, Australian Maritime College) for their advice, guidance and contributions to this thesis. Moreover, I would like to especially thank Barrie Forrest and Richard Piola (Cawthron Institute) who enticed me back to Cawthron to finish my PhD. Without them I would never have reached the finishing line. Furthermore, there are many other very special people that have contributed significantly to the various chapters throughout this thesis.

Chapter 2: I wish to thank Peter Cover (Australian Maritime College) with his assistance with constructing and testing of the custom designed hydrodynamic keel in the flume tank. Furthermore, thank you to Ian Rinkin, Heidi Grief and Scott Bickford for their assistance with the voyage trials and data collection. A special thanks to Richard Piola, Barrie Forrest and Grant Hopkins (Cawthron Institute) for their assistance with the data analysis and comments on early drafts. Thanks must also go to the Australian Maritime College, Centre for Research on Introduced Marine Pests (CRIMP), and the Australian Quarantine and Inspection Services (AQIS) for funding this portion of research.

Chapter 3: I would like to acknowledge the assistance of the two diving companies, Divers Services Ltd and New Zealand Diving and Salvage Ltd, who provided the underwater hull inspection video assessments of the vessels used in this study. Furthermore, we thank Michael Pryce (New Zealand Ship and Marine Society) for providing valuable information on each of the vessels. Thanks also to DMP Statistical Solutions (University of Auckland) for statistical advice. Useful comments on the manuscript were provided by Barrie Forrest, Tim Dodgshun (Cawthron Institute), Chad Hewitt (New Zealand Ministry of Fisheries), and John Lewis (Defence Science and Technology Organisation, Melbourne, Australia). Thank you to the New Zealand Foundation for Research, Science and Technology for funding this research.

Chapter 4: I would like to acknowledge the assistance of Mike Bailey and Brian Woodhill (Plasticraft Limited) for manufacturing many of the early prototypes and the 
settlement plates. Thank you also to Kevin Heasman and Simon Tannock (Cawthron Institute) for their assistance with the development of the various prototypes. The final prototype could not have been achieved without the further assistance of Paul Mills and Aaron Lane (Magnets New Zealand Limited). Likewise, a very special thank you to James Brodie (Marlborough Commercial Diving Service) for his tireless assistance in the field and constant encouragement to continue when many of the prototypes failed. Finally special thanks to the New Zealand Foundation for Research, Science and Technology for funding this research.

Chapter 5: A very special thank you goes to James and Val Brodie (Marlborough Commercial Diving Services) for their tireless assistance in the field and hospitality. Thank you to the following owners/operators of the vessels who participated in the experiments including: Ross Simonson, Peter McManaway, Jane and Graeme Spall, Ian Halstead, Garry Kenny, Willie and Robyn O’Donnell, Interislander and Strait Shipping. Thank you to Michael Taylor, Barrie Forrest, Grant Hopkins and Richard Piola (Cawthron Institute), Chad Hewitt (University of Tasmania, Australian Maritime College) and Jonathan Gardner (Victoria University of Wellington) for their assistance with the experimental design, data analysis and comments on the manuscript. Finally a special thanks to the New Zealand Foundation for Research, Science and Technology for funding this research.

Chapter 6: I wish to thank Darryl Nicholson and Ray Busch (Nicholson Marine Coatings Limited) and the Engineering Staff of Nalder and Biddle Limited and Kernohan Engineering Limited. Thank you to Hal Upton, Bill Sanders, and Captain Michael Barnett (Lyttelton Port Company), Ralph and Andrew Stark (Stark Brothers Limited), Bernice Meyle and Geoff Mansell (Royal New Zealand Navy) and Keith Drake (Babcock Marine Services). I am indebted to Rick Webber (Museum of New Zealand, Te Papa Tongarewa) for his identification of crab and shrimp specimens. Thanks also to Colin McLay (University of Canterbury) for identification of crab specimens and Graham Fenwick (National Institution of Water and Atmospheric Research) for identification of amphipods. Finally, thank you to the New Zealand Foundation for Research, Science and Technology for funding this research. 
Lastly and most importantly, I wish to thank my parents (Rod and Dawn Coutts), sister and brother-n-law (Vivienne and David Stapleton) and my beautiful wife (Angela Coutts) for all their support, encouragement and patience throughout this eternal commitment. I promise I will never do anything like this again. 


\section{TABLE OF CONTENTS}

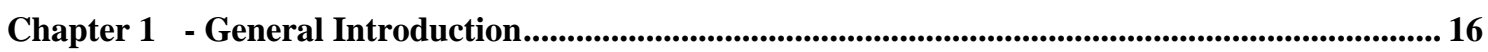

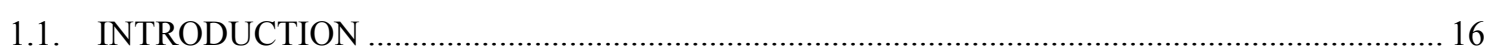

1.2. BIOFOULING AND CHANGES TO VESSEL DESIGN ........................................................ 17

1.3. VESSEL BIOFOULING CONTINUES TO PLAY A ROLE IN THE DISPERSAL OF NIMS .... 19

1.3.1. The New Zealand Fishing Industry Code of Practice........................................................... 21

1.3.2. Hull inspections for vessels visiting New Zealand's Sub-Antarctic Islands ........................... 21

1.3.3. The Darwin (Australia) Marina Hull and Internal Seawater System Inspection and Treatment Regime

1.3.4. The Australian Quarantine and Inspection Service voluntary biofouling management requirements for vessels less than 25 metres in length......................................................... 22

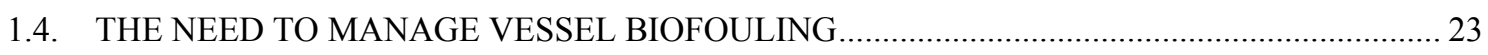

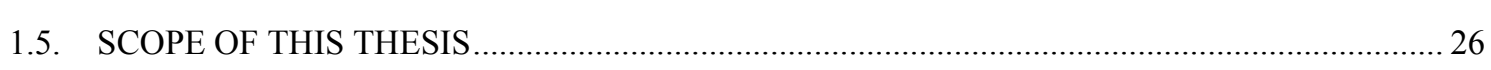

1.5.1. Chapter 2 - Effect of vessel voyage speed on the survival and translocation of biofouling

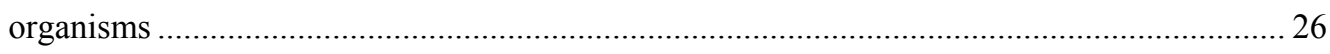

1.5.2. Chapter 3 - Which hull locations pose the greatest risk of containing non-indigenous marine

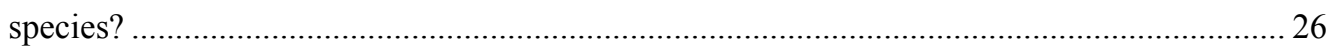

1.5.3. Chapter $4-$ A novel method for assessing the en route survivorship of biofouling organisms 27

1.5.4. Chapter 5 - The survivorship of biofouling organisms on different vessel types at various hull

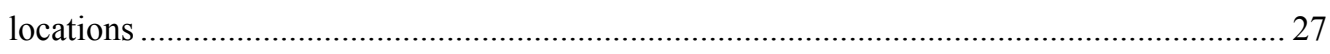

1.5.5. Chapter 6 - An assessment of the nature and extent of biofouling inside vessel sea-chests..... 28

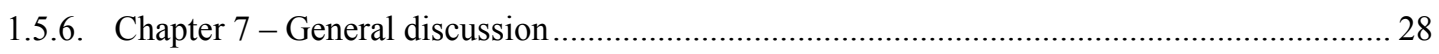

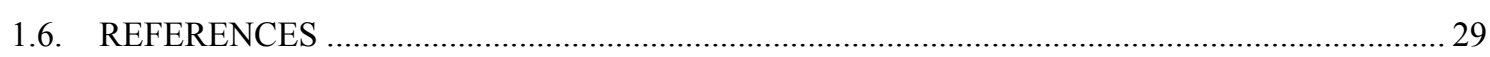

Chapter 2 - Effect of vessel voyage speed on the survival and translocation of biofouling

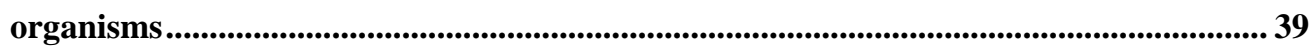

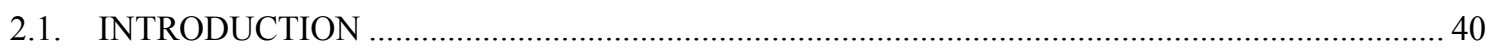

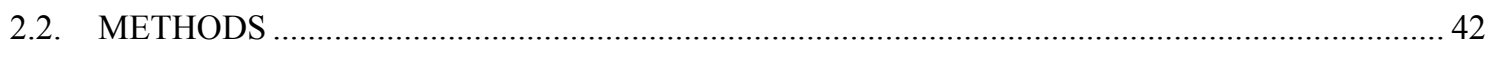

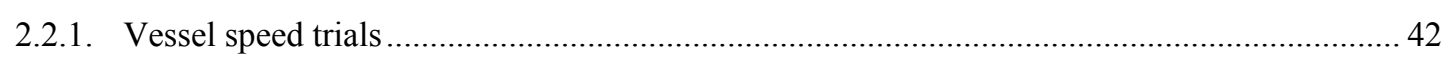

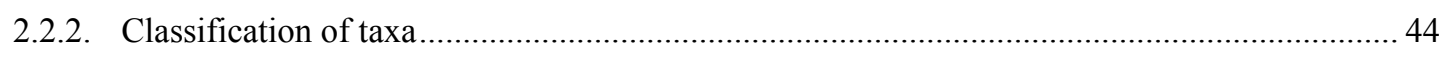

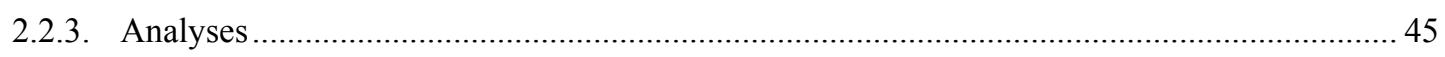

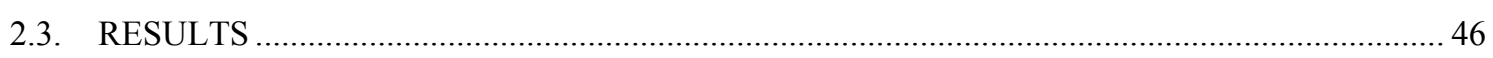

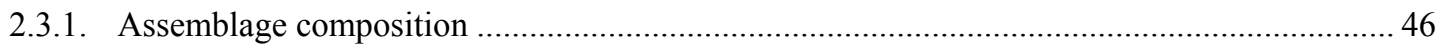

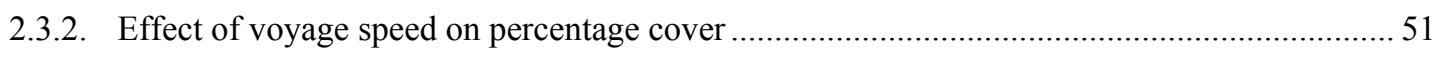

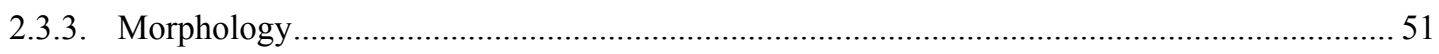

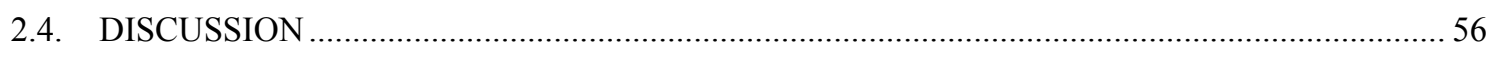

2.4.1. Hydrodynamic flow, vessel speed and the boundary layer .................................................... 56

2.4.2. Morphology, vessel speed and survivorship ....................................................................... 57

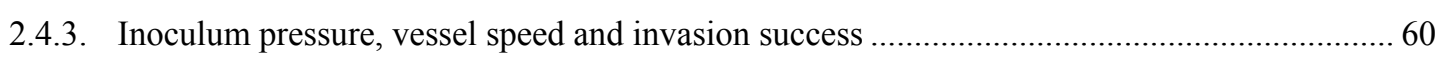

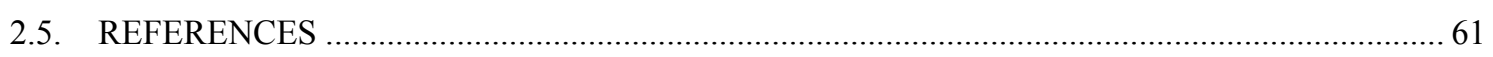


Chapter 3 - Which hull locations are more likely to contain non-indigenous marine species? ...... 68

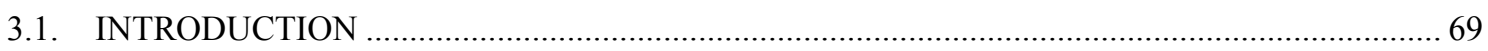

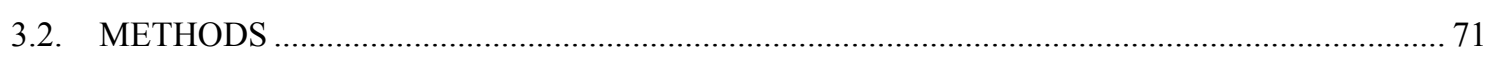

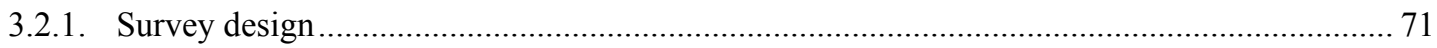

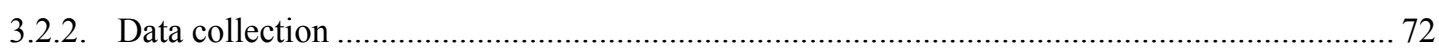

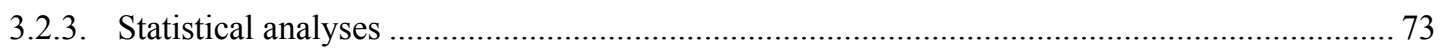

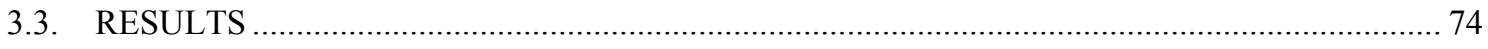

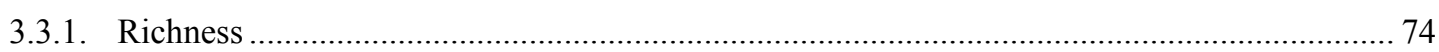

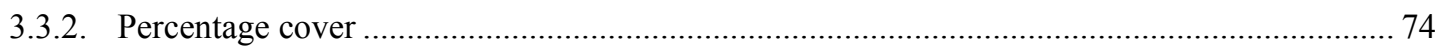

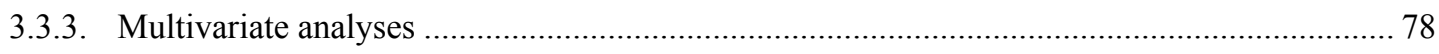

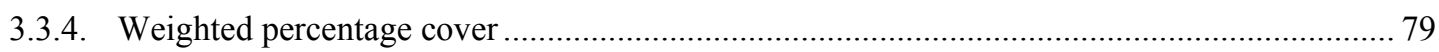

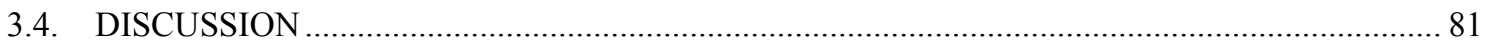

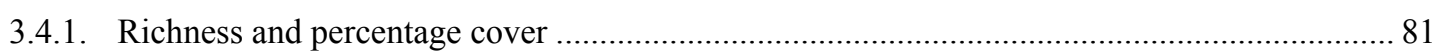

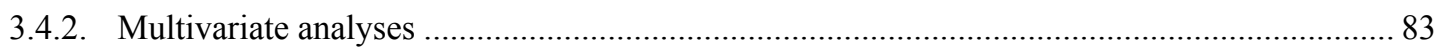

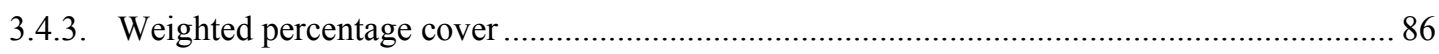

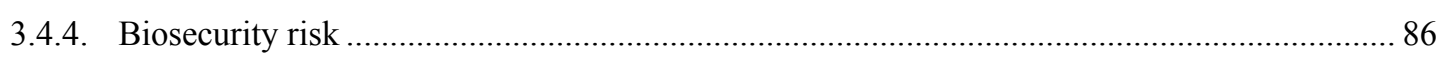

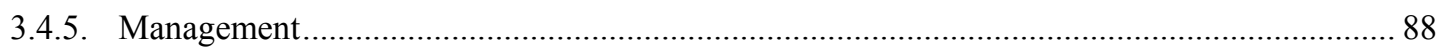

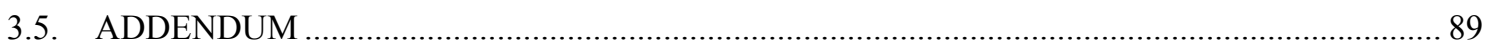

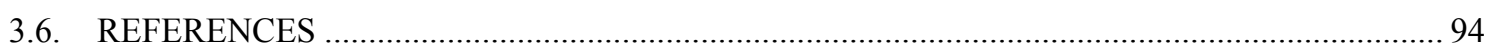

Chapter 4 - A novel method for assessing the en route survivorship of biofouling organisms ..... 101

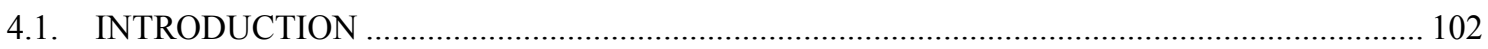

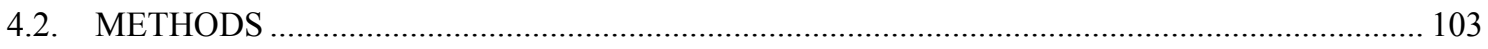

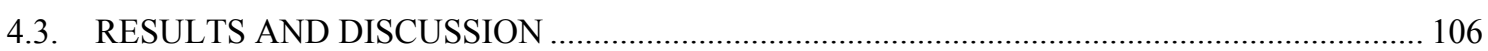

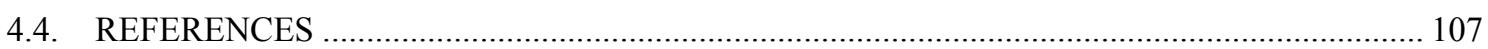

Chapter 5 - The survivorship of biofouling organisms on various vessel types at different hull

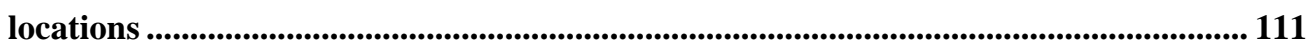

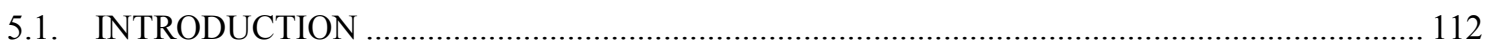

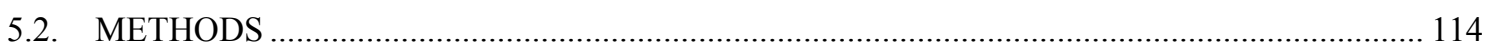

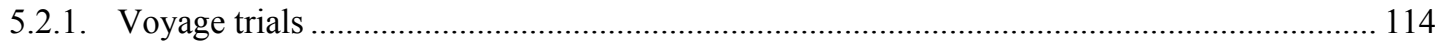

5.2.2. Voyage details and environmental conditions................................................................ 116

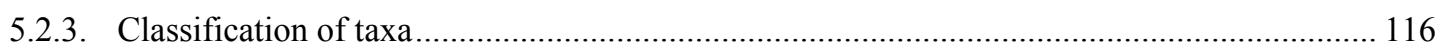

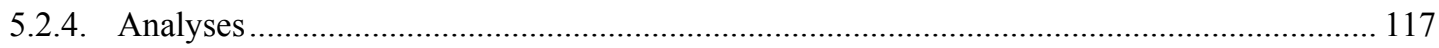

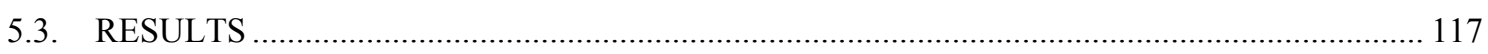

5.3.1. Voyage profiles and environmental conditions ........................................................... 117

5.3.2. Pre-voyage assemblage composition.......................................................................... 120

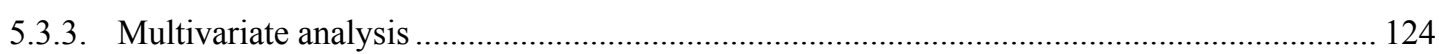

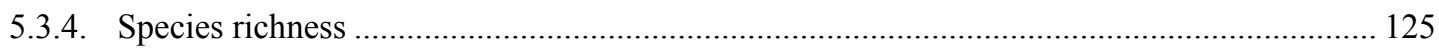

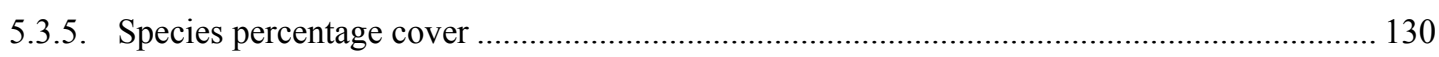

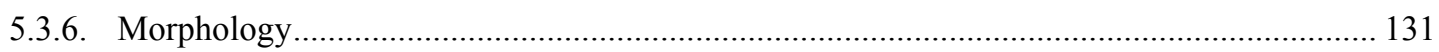




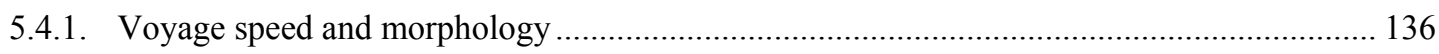

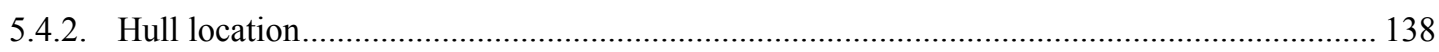

5.4.3. Environmental factors and conditions .......................................................................... 139

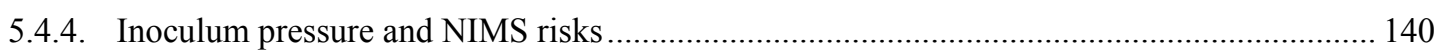

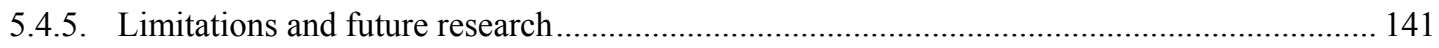

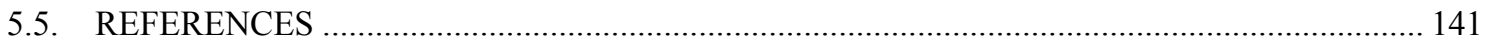

Chapter 6 - A preliminary assessment of the nature and extent of biofouling inside vessel seachests ................................................................................................................................... 148

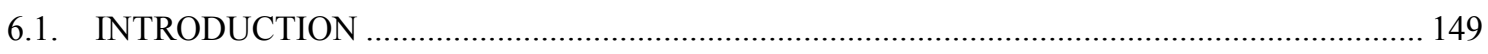

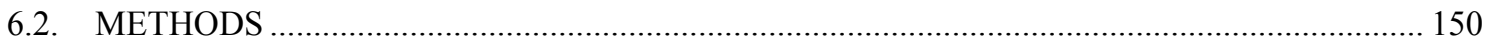

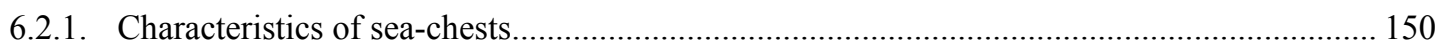

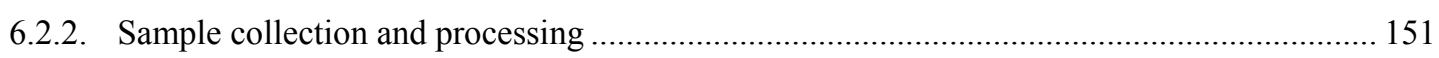

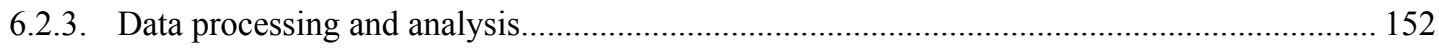

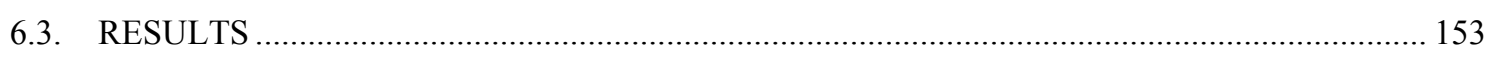

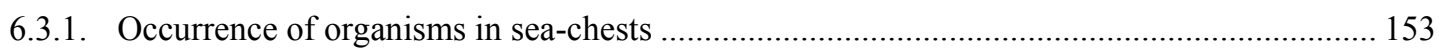

6.3.2. Community composition of organisms in sea-chests ............................................................ 158

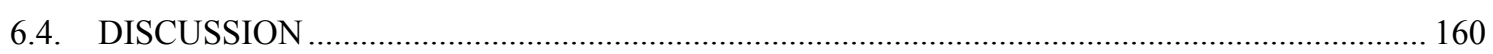

6.4.1. Factors influencing patterns of occupancy inside sea-chests ................................................ 160

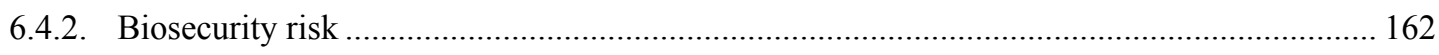

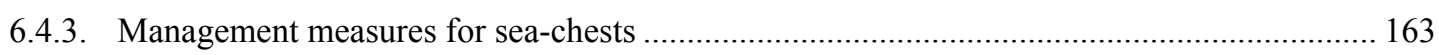

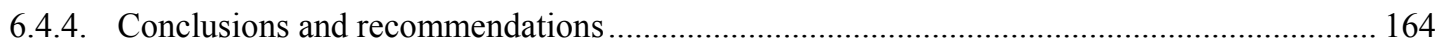

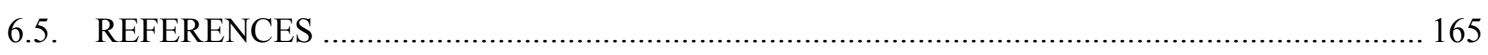

Chapter 7 - General discussion and recommendations ........................................................................... 171

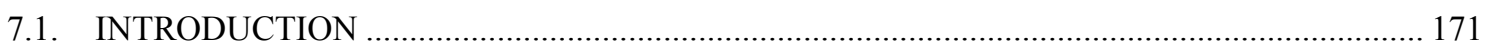

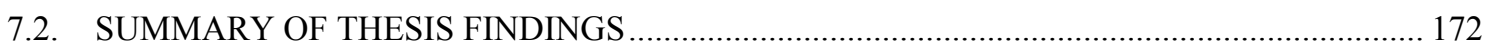

7.2.1. Chapter 2 - Effect of vessel voyage speed on the survival and translocation of biofouling

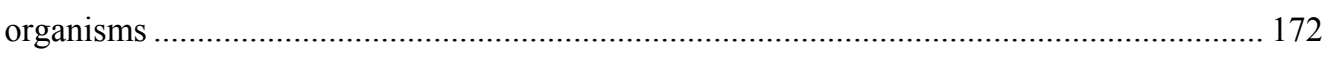

7.2.2. Chapter 3 - Which hull locations are more likely to contain non-indigenous marine species 172

7.2.3. Chapter 4 - A novel method for assessing the en route survivorship of biofouling organisms

7.2.4. Chapter 5 - The survivorship of biofouling organisms on various vessel types at different hull locations

7.2.5. Chapter 6 - A preliminary assessment of the nature and extent of biofouling inside vessel sea-

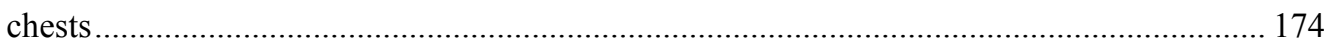

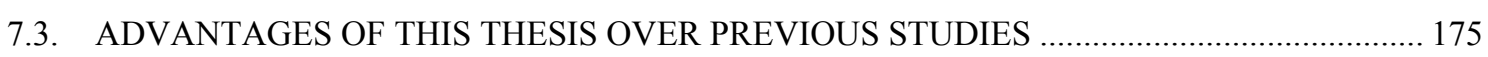

7.4. PUTTING THESIS FINDINGS IN PERSPECTIVE WITH THE WIDER LITERATURE .......... 176

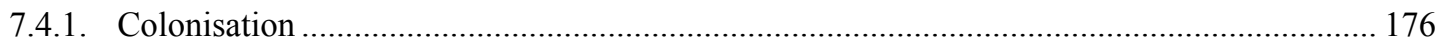

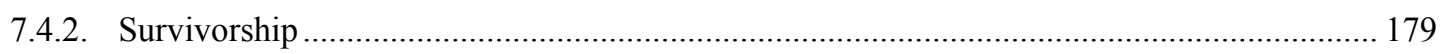




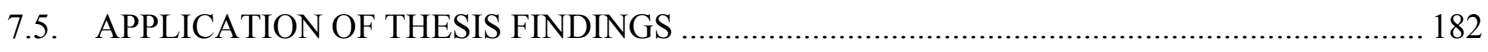

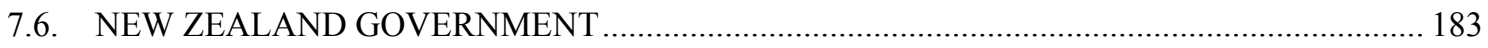

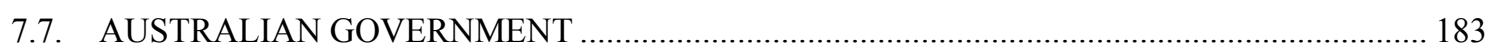

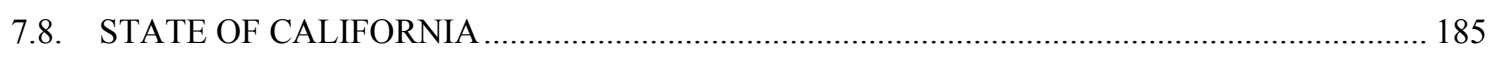

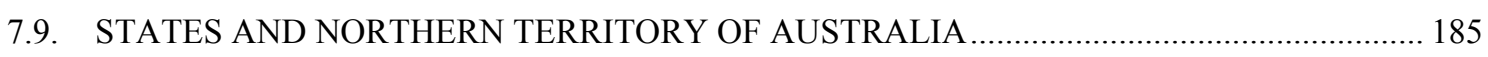

7.10. AN URGENT NEED FOR FURTHER BIOFOULING MANAGEMENT MEASURES ............. 187

7.11. A PROPOSED RISK ASSESSMENT FOR TARGETING HIGH RISK VESSELS...................... 187

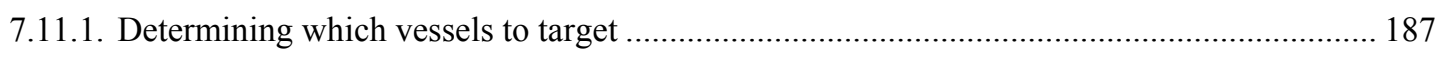

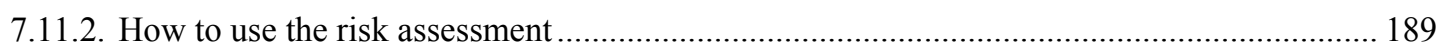

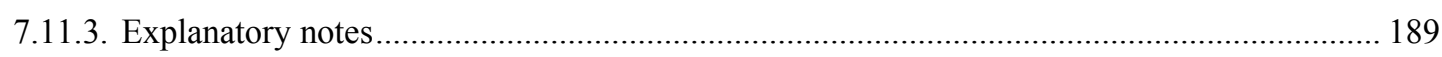

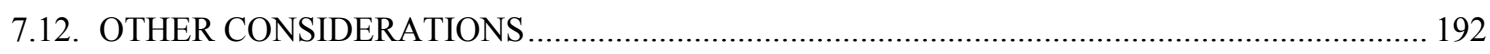

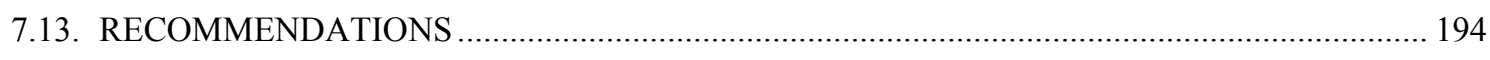

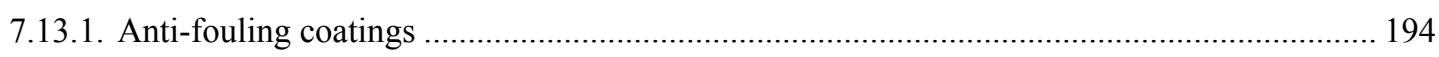

7.13.2. Pragmatic risk assessments and vessel biofouling management requirements ....................... 194

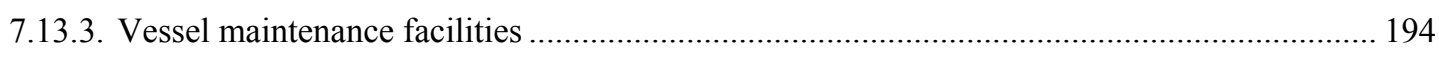

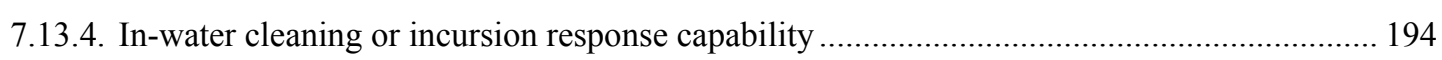

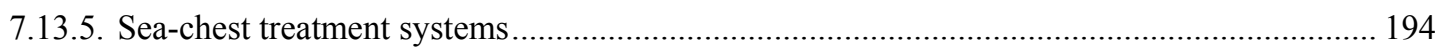

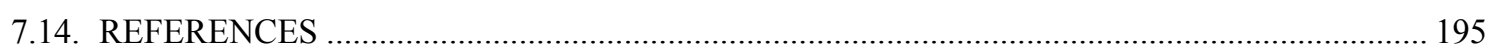




\section{LIST OF TABLES}

Table 1 Summary of biofouling organisms identified on settlement plates used for vessel speed trials; including their origin (indigenous, established, cryptogenic, unknown), morphological characteristics, height of protrusion from the plate surface, and average percentage cover pre- and post-voyage $(20 \mathrm{~min})$ across different voyage speeds $(5,10$ and $18 \mathrm{knots})$. Values represent the average $( \pm 1 \mathrm{SE})$.

Table 2 Summary of a) repeated measures analysis of variance for species richness and percentage cover of biofouling organisms exposed to vessel speeds of 5,10 and 18 knots over three separate trial periods, and Tukey's post-hoc comparisons for b) species richness and c) percentage cover, showing probabilities of differences between individual treatment groups for the Within Subjects interaction Time x Speed. Significant $P$ values are in bold.

Table 3 Summary of two-way analysis of variance of the effects of voyage speed on percentage cover relative to species morphological characteristics. Significant $P$ values are in bold.

Table 4 Biofouling taxa used in the study, categorised according to the general development of biofouling on artificial structures, as described previously.

Table 5 Average $( \pm 1$ SE) percentage cover per quadrat of bare metal, anti-fouling coating, and 12 biofouling taxa for each of the 30 merchant vessels used in the study. Vessels have been sorted from least to greatest degree of biofouling according to the presence of biofouling category $(\mathrm{A}<\mathrm{B}<\mathrm{C}<\mathrm{D})$. Vessel type 1, container vessels; 2, bulk carriers; 3, "other" vessel types. Average abundance of biofouling per vessel refers to average percentage cover of all biofouling per vessel (excluding bare metal and anti-fouling coating). Taxa rich refer to total number of taxa present upon each vessel. Totals refer to average $( \pm 1 \mathrm{SE})$ percentage covers for all vessels pooled.

Table 6 Average $( \pm 1 \mathrm{SE})$ percentage cover per quadrat of bare metal, anti-fouling coating, and biofouling taxa for each of the eight hull locations used in the study. Hull locations have been sorted according to the results of a cluster analyses (see Figure 11). Taxa have been sorted according to biofouling category (A, B, C, and D). Average \% cover refers to biofouling taxa (i.e. biofouling categories B, C, and D only). (DDSS = dry-docking support strips; OutDDSS = outside dry-docking support strips).

Table 7 Summary of known research that has focussed on biofouling and non-indigenous marine species on merchant vessels (this includes reference to bulk carriers, chemical tankers, cargo, commercial, and container vessels) since Coutts and Taylor (2004).

Table 8 A summary of the vessel voyage trials and conditions experienced by biofouling organisms relative to controls.

Table 9 Summary of biofouling organisms identified amongst settlement plates used for the vessel survivorship trials over two trials (T1 and T2); including their status in New Zealand waters, morphological characteristics, average percentage cover $( \pm 1 \mathrm{SE})$ during pre-, post-, and $7 \mathrm{~d}$ postvoyage assessment periods for each of three vessel speed categories (slow, medium and fast). refers to a species absence on settlement plates.

Table 10 Summary of two-way analysis of variance of the effect of voyage speed on the change in: a) species richness; and b) percentage cover between pre- and post-voyage data (with T1 and T2 pooled) relative to species morphological characteristics

Table 11 Organisms identified inside 53 sea-chests from 42 vessels sampled in New Zealand; Origin: Organisms classified according to their origin relative to New Zealand waters as classified by Cranfield et al. (1998). Life-habit: Organisms' life-habit at the time of collection. N refers to the number of vessels with the organism present. $\dagger$ refers to only shells of the organisms present. .... 155 


\section{LIST OF FIGURES}

Figure 1 The biofouling invasion process and examples of selective filters that NIMS must overcome to be successfully translocated and establish in a new location (see Lewis and Coutts 2010)............25

Figure 2 Schematic diagrams showing the front, side, and enlarged views of the custom designed hydrodynamic keel attached to the bottom of a 6 metre powerboat used to assess the effect of various voyage speeds on the survivorship of biofouling species. Diagrams are not drawn to scale.

Figure 3 nMDS plot of the pre- and post-voyage composition and dominance of biofouling organisms on plates exposed to vessel voyage speeds of 5,10 and 18 knots. Each point represents a single replicate settlement plate. Lines encircle treatment groups having a Bray-Curtis similarity of $\geq 65$ $\%$. Also listed are the dominant species (including bare space) contributing to up to $99 \%$ of the similarity within each group (based on simper analysis) and their morphological grouping (Sol = solitary; $\mathrm{Col}=$ colonial; $\mathrm{En}=$ encrusting; $\mathrm{Er}=$ erect; $\mathrm{S}=$ soft; $\mathrm{F}=$ flexible; $\mathrm{H}=$ hard)................. 47

Figure 4 Species richness and percentage cover recorded for biofouling organisms exposed to vessel voyage speeds of 5, 10 and 18 knots: a) comparison of species richness pre- and post-voyage trials $(n=12) ; \mathrm{b})$ assessment of on-going species richness, comparing richness post-voyage and 7 days post- voyage trials $(n=3)$; c) comparison of percentage cover pre- and post-voyage trials $(n=12)$; d) assessment of on-going percentage cover, comparing cover post-voyage and 7 days post-voyage trials $(n=3)$. Values represent the average $( \pm 1 \mathrm{SE})$.

Figure 5 Pre- and post-voyage species richness recorded for biofouling organisms, classified according to various morphological characteristics, subjected to speeds of a) 5, b) 10 and c) 18 knots $(n=12)$. Values represent the average $( \pm 1 \mathrm{SE})$......

Figure 6 Pre- and post-voyage species percentage cover recorded for biofouling organisms, classified according to various morphological characteristics, subjected to speeds of a) 5, b) 10 and c) 18 knots $(n=12)$. Values represent the average $( \pm 1 \mathrm{SE})$.

Figure 7 Effect of voyage speed on the percentage cover of species with different morphological characteristics. Data are the percentage change in percentage cover (i.e. difference between pre- and post-voyage percentage cover divided by the pre-voyage percentage cover, for each morphological characteristic, for each speed. 0 knots refers to data controls. Regression lines are indicative only. 55

Figure 8 Position of various hull locations sampled during this study. (DDSS = dry-docking support strips; OutDDSS = outside dry-docking support strips)

Figure 9 Average $( \pm 1 \mathrm{SE})$ richness within each hull location for the three vessel types used in the study. (DDSS = dry-docking support strips; OutDDSS = outside dry-docking support strips; SC grating = sea-chest gratings. White bars = container vessels, striped = bulk carriers, and black = "other" vessels......

Figure 10 Percentage covers of the four biofouling categories (see Table 4) within each hull location for the three vessel types used in the study. (DDSS = dry-docking support strips; OutDDSS = outside dry-docking support strips; SC gratings = sea-chest gratings. Biofouling category: $\mathrm{A}=$ white, $\mathrm{B}=$ dots, $\mathrm{C}=$ strips and $\mathrm{D}=$ black

Figure 11 Dendogram showing the similarity in the average percentage cover per quadrat of bare metal, anti-fouling coating, and the 12 biofouling taxa for each of the 30 merchant vessels used in this study. See Table 5 for supporting data.

Figure 12 Dendogram showing the similarity in the average percentage cover per quadrat of bare metal, anti-fouling coating, and the 12 biofouling taxa for each hull location used in this study. See Table 6 for supporting data. (DDSS = dry-docking support strips; OutDDSS = outside dry-docking support strips; SC gratings = sea-chest gratings).....

Figure 13 Average $( \pm 1 \mathrm{SE})$ weighted percentage cover within each hull location for the three vessel types used in the study. See materials and methods section for definitions of weighted percentage cover (DDSS = dry-docking support strips; OutDDSS = outside dry-docking support strips; SC gratings = sea-chest gratings. White bars = container vessels, striped = bulk carriers, and black = "other" vessels

Figure 14 Diagram (not to scale) of the dimensions of the MAGPLATEs from a) top view, b) side view, and c) bottom view.

Figure 15 Voyage trials were conducted on vessels that operated from Picton Harbour (South Island) throughout the Queen Charlotte Sound and across Cook Strait to Wellington (North Island), New Zealand. Use in conjunction with Table 8.

Figure 16 nMDS plots of the T1 pre- (0), post- (1) and $7 \mathrm{~d}$ post-voyage (2) composition and dominance of biofouling organisms on plates subjected to slow, medium and fast vessel voyage speeds at three different hull locations $(\mathrm{E}=$ exposed, $\mathrm{D}=\mathrm{DDSS}$, and $\mathrm{P}=$ protected). Each point represents the 
average composition and dominance of biofouling organisms within a given hull location. Lines encircle treatment groups having a Bray-Curtis similarity of $\geq 75 \%$ and $\geq 90 \%$.

Figure $17 \mathrm{nMDS}$ plots of the T2 pre- (0), post- (1) and $7 \mathrm{~d}$ post-voyage (2) composition and dominance of biofouling organisms on plates subjected to slow, medium and fast vessel voyage speeds at three different hull locations $(\mathrm{E}=$ exposed, $\mathrm{D}=\mathrm{DDSS}$, and $\mathrm{P}=$ protected). Each point represents the average composition and dominance of biofouling organisms within a given hull location. Lines encircle treatment groups having a Bray-Curtis similarity of $\geq 80 \%$ and $\geq 90 \%$.

Figure 18 Average percentage changes and ( $\pm 1 \mathrm{SE})$ in species richness recorded during pre-, post- and $7 \mathrm{~d}$ post-voyage assessments over three vessel voyage speeds (slow, medium, and fast) for both trials a) $\mathrm{T} 1$ and b) T2.

Figure 19 Prevalence of various biofouling organisms encountered on settlement plates during the T1 trials amongst three vessel voyage speeds: a) slow, b) medium, and c) fast during pre-, post- and $7 \mathrm{~d}$ post-voyage assessments. The dashed line refers to the total number of settlement plates used per trial (i.e. three vessels $\mathrm{x}$ three hull locations $\mathrm{x}$ three replicate plates $=27$ )...

Figure 20 Prevalence of various biofouling organisms encountered on settlement plates during the T2 trials amongst three vessel voyage speeds: a) slow, b) medium, and c) fast during pre-, post- and $7 \mathrm{~d}$ post-voyage assessments. The dashed line refers to the total number of settlement plates used per trial (i.e. three vessels $x$ three hull locations $x$ three replicate plates $=27$ ).....

Figure 21 Changes in species percentage cover recorded during pre-, post- and $7 \mathrm{~d}$ post-voyage assessments over three vessel voyage speeds (slow, medium, and fast) for both trials a) T1 and b) $\mathrm{T} 2$.

Figure 22 Average percentage cover of various biofouling organisms encountered on settlement plates during the T1 trials amongst three vessel voyage speeds: a) slow, b) medium, and c) fast during pre, post- and $7 \mathrm{~d}$ post-voyage assessments.

Figure 23 Average percentage cover of various biofouling organisms encountered on settlement plates during the T1 trials amongst three vessel voyage speeds: a) slow, b) medium, and c) fast during pre, post- and $7 \mathrm{~d}$ post-voyage assessments.

Figure 24 Schematic diagram of a vessel's sea-chest system.

Figure 25 Species accumulation curves for: all 42 vessels (a and b); 24 domestic vessels (c and d); nine semi-international vessels (e and f); and nine international vessels ( $g$ and $h$ ). Left hand side grafts are expected species accumulation curves using Monte Carlo simulations (solid lines) with Mao Tau $95 \%$ confidence intervals (dashed lines). Right hand side graphs are Chao2 nonparametric richness estimators (solid lines with $95 \%$ confidence intervals (dashed lines).

Figure 26 Average ( $\pm 1 \mathrm{SE})$ number of indigenous, introduced, non-indigenous and unknown organisms according to vessel origin (domestic, semi-international and international).

Figure 27 Dendrogram illustrating the Bray-Curtis percentage similarity between the community composition of organisms in sea-chests of the 42 vessels surveyed. The dashed line represents the $50 \%$ similarity threshold. Int $=$ international vessels; S-Int $=$ semi-international vessels; Dom $=$ domestic vessels.

Figure 28 Multi-dimensional scaling plot illustrating the similarity between patterns of organisms (reclassified into 22 higher taxonomic groups) in sea-chests of 27 fishing vessels relative to geographical area of operation (e.g. Sth-NZ = southern New Zealand, All-NZ = all of New Zealand, $\mathrm{WW}=$ world-wide, $\mathrm{PAC}=$ Pacific Ocean, $\mathrm{SP}=$ South Pacific). The dashed circle represents a group of vessels that operated in a similar geographical area.

Figure 29 A proposed decision-tree for risk assessing high risk or targeting vessels for non-indigenous marine species. Yes also requires vessel owners/operators supplying authentic documentation to support their answers. No could mean the condition was met, but no authentic supporting documentation is produced. 190 


\section{Chapter 1 - General Introduction}

\subsection{INTRODUCTION}

The human-mediated introduction of non-indigenous aquatic species into new locations where they did not naturally exist can have catastrophic ecological, economic and social consequences (Carlton 1996, 2001; Hewitt 2003; Pimentel et al. 2005). One of the most renowned examples is the European Zebra Mussel (Dreissena polymorpha) and its introduction into the Great Lakes of the United States of America and Canada in 1988, and subsequent spread through most waterways of eastern United States of America. The mussel out-competes native species and blocks water intakes of vessels and power stations, and costs an estimated USD \$1 billion per annum in remedial engineering and preventative measures (Schormann et al. 1990; Hebert et al. 1991; Hedgpeth 1993; Pimentel et al. 2005).

While the dispersal of marine species has occurred naturally since the dawn of time, in modern times many organisms have been translocated by a diversity of humanmediated mechanisms including: vessel biofouling, dry and semi-dry ballast and ballast water; intentional transfers of aquaculture and mariculture organisms; aquarium trade; biological material for packing; and scientific research (e.g. Carlton 1985, 1987, 1992; Cohen and Carlton 1995; Thresher et al. 1999; Ruiz et al. 2000; Minchin and Gollasch 2002; Hewitt et al. 2004a and b). Of these, the worldwide movement of vessels has been identified as the single most important vector for the dispersal of marine species, both historically and in modern times (e.g. Ruiz et al. 1997; Fofonoff et al. 2003; Hewitt and Campbell 2008).

The anthropogenic movement of marine species, hereafter referred to as non-indigenous marine species (NIMS), undoubtably commenced as biofouling attached to the exterior of vessels while humans circumnavigated the globe during their exploratory phase. The frequency at which species were translocated probably increased significantly between the $14^{\text {th }}$ and $19^{\text {th }}$ century owing to the volume of slow-moving wooden sailing ships in use (Thresher et al. 1999; Ruiz et al. 2000). Such vessels would have facilitated the dispersal of neritic and port-dwelling organisms as the wooden hulls were likely 
excessively biofouled and riddled with shipworms (teredinid bivalves) and gribbles (limnoriid isopods) (see discussions in Carlton 1987; Schormann et al. 1990; Carlton and Hodder 1995; Taylor 1999). Furthermore, given the lack of effective anti-fouling coatings, it was common practice to careen vessels on a beach at high tide for cleaning and maintenance which probably also contributed significantly to the dispersal of biofouling and boring organisms (e.g. Carlton 1996; Campbell and Hewitt 1999). Additionally, the transfer of dry and semi-dry ballast from one location to another exacerbated this situation. The subsequent substitution of water for dry and semi-dry ballast (largely beginning in the 1880s with the advent of steel hulled vessels) resulted in a shift from epibenthic and biofouling organisms to species with a planktonic existence (e.g. Carlton 1987, 1996; Ruiz et al. 2000; Hewitt et al. 2004a). Despite numerous changes to vessel design, modern biofouling of externally exposed surfaces of vessel hulls, including hydrodynamically protected "niche areas"” (e.g. sea-chests", internal piping, rudders, propeller shafts), continues to occur.

\subsection{BIOFOULING AND CHANGES TO VESSEL DESIGN}

A number of significant technological changes aimed at improving vessel efficiency and performance occurred between the 1800s and 1900s and were thought to have mitigated the dispersal of NIMS. However, despite such technological changes to vessel design, engines, and structural integrity, the rate of species introductions appeared to accelerate (e.g. Cohen and Carlton 1998; Ruiz et al. 2000). For example, by the 1800s, the opium trade necessitated changes to vessel designs to increase vessel speeds in order to avoid the monsoons on passage between India and Europe (Macintyre 1972). With this, the "clipper" sailing vessel was born and soon became the dominant vessel type on the high seas. The clippers utilised lighter wood and copper-cladding on the exterior of their hulls to inhibit biofouling and prevent the deleterious effects boring organisms, and both of these changes aided in increasing vessel speed (Lubbock 1921; Macintyre 1972). By the 1860s the softwood hulled clippers were deteriorating too quickly, prompting the use of iron hulls which could be considered to be the most revolutionary

\footnotetext{
${ }^{1}$ Niche areas generally refer to locations on a vessel's hull that accumulate higher levels of biofouling relative to the mainstream areas of the hull due to the absence and/or in-effectiveness of anti-fouling coatings.

2 Sea-chests are recesses built into a vessel's hull below the waterline that house the intake pipes for sea-water used for ballast, engine cooling and fire fighting.
} 
change in ship design (Macintyre 1972; Bach 1976). The switch from wooden to iron hulls facilitated the use of steam power, screw propellers, novel anti-fouling coatings (i.e. not copper cladding) and the use of ballast water rather than solid dry and semi-dry ballast, all of which combined to further increase vessel speeds and longevity (Macintyre 1972; Bach 1976; Fitchett 1980; Campbell and Hewitt 1999). These advances are considered to have significantly reduced the unwanted accumulation and dispersal of biofouling organisms (Lewis 2002a).

The next most significant innovation in vessel design occurred in the 1920 s with steam engines and coal being superseded by motor engines and oil, which further improved vessel speed and efficiency (Dunn 1973). Arguably the most revolutionary change in anti-fouling technology occurred in the 1960s with the discovery of organotin compounds which were highly effective biocides. Subsequent developments led to the formulation of self-polishing copolymer (SPC) anti-fouling coatings based on tributyltin (TBT) copolymers. Up until the 1970s, most antifoulants were based on copper, and the effective life of these coatings rarely exceeded 24 months, requiring vessels to be removed from the water to have their excessively biofouled hulls cleaned (Lewis 2002b). However, SPC TBT coating systems could provide effective anti-fouling performance for more than 5 years (Christie and Dalley 1987; Evans 1981), and reduced the likelihood of biofouling organism translocations (Coutts 1999; Nehring 2001). Hence, SPC TBT coatings dominated the global shipping market between 1970 and early 2000 .

Technological improvements in anti-fouling coatings led to the belief that vessel biofouling had ceased to be a significant dispersal mechanism for NIMS and the focus quickly turned towards ballast water (e.g. Carlton 1985; Carlton et al. 1995). The significance of ballast water as a potential dispersal mechanism was first realised following several studies that found numerous living organisms representing all major aquatic phyla and trophic groups within ballast tanks of vessels (e.g. Medcof 1975; Carlton 1982; Carlton and Geller 1993; Locke et al. 1993; Carlton et al. 1995). Furthermore, a number of high profile invasions occurred during this period (19802000) including: the zebra mussel (Dreissena polymorpha) into Lake St Clair, Canada (Hebert et al. 1989); the American Atlantic coast comb jelly (Mnemiopsis leidyi) into the Black and Azov Seas (Vinogradov et al. 1989; Studenikina et al. 1991), south 
eastern Europe (Dumont and Shiganova 2002); the toxic dinoflagellate (Gymnodinium catenatum) and the northern Pacific seastar (Asterias amurensis) into the Derwent Estuary, Tasmania (Byrne et al. 1997); the Japanese seaweed Undaria pinnatifida in Wellington Harbour, New Zealand (Hay and Luckens 1987) and Rheban, Tasmania (Sanderson 1990); and the Mediterranean fanworm (Sabella spallanzanii) in Port Phillip Bay, Victoria (Currie et al. 2000), all of which at the time were thought to have been transferred via ballast water.

In response to these continuing invasions, the dispersal of harmful aquatic organisms via ballast water was raised with the International Maritime Organization (IMO) in 1988. However, it took a further 16 years of negotiations before the IMO finally supported a diplomatic conference: the International Convention for the Control and Management of Ships' Ballast Water and Sediments in February 2004, a new international convention to prevent the spread of harmful aquatic organisms carried by ships' ballast water. However, at the time of writing, the Convention will not come into effect until 12 months after ratification by 30 States, representing $35 \%$ of world merchant shipping tonnage. Fortunately a range of ballast water management guidelines and regulatory practices were unilaterally introduced by various countries (e.g. Argentina, Australia, Canada, Chile, Israel, New Zealand, United States of America, United Kingdom) between 1989 and 2001 in an attempt to mitigate the spread of future NIMS introductions. However, it is not known how successful these measures have been.

\subsection{VESSEL BIOFOULING CONTINUES TO PLAY A ROLE IN THE DISPERSAL OF NIMS}

Despite many countries implementing ballast water management requirements, the detection of new NIMS continued. For example, since 1998 when New Zealand implemented mandatory ballast water management requirements, a number of newly established NIMS have been detected including the Asian paddle crab Charybdis japonica (Auckland 2000; Webber 2001), the colonial ascidian Didemnum vexillum (Whangamata 2001; Mather 2002), the clubbed sea squirt Styela clava (Auckland 2005; Davis and Davis 2006), the colonial ascidian Eudistoma elongatum (Houhora Harbour, Northland, 2005; Smith et al. 2007), and the Mediterranean fanworm S. spallanzanii (Lyttleton 2008; The New Zealand Herald 2008). While it is possible that some of these 
species were introduced many years ago and underwent a "lag phase" before detection, it is also likely that others were recently introduced via vessel biofouling rather than ballast water (see discussion in Hewitt et al. 2004b).

Numerous retrospective analyses of the life histories of established NIMS around the world have also concluded that more species are likely to have been introduced as biofouling organisms than via ballast water (e.g. Cranfield et al. 1998; Thresher et al. 1999; Gollasch 2002; Hewitt 2002; Fofonoff et al. 2003; Hewitt et al. 2004a, 2007; Hewitt and Campbell 2008). For example, the most recent assessment on a global scale by Hewitt and Campbell (2008) estimated that 55-69\% of the 1780 NIMS detected in ports and harbours around the world have life-history characteristics that make them able to have been introduced as biofouling on vessel hulls. Furthermore, despite technological advances in vessel designs, the rate of species introductions via vessel biofouling appears to have increased (Campbell and Hewitt 1999; Hewitt et al. 2004a). Moreover, many recent studies have identified a wide diversity of biofouling organisms on vessel hulls, highlighting the potential for such modern-day vessels to translocate NIMS around the world (e.g. Coutts 1999; Floerl 2002; Gollasch 2002; Godwin 2003; Davidson et al. 2009).

Finally, the discovery that TBT causes shell deformation in oysters, reduces resistance to infection in fish, causes imposex (i.e. the development of sex organs that are opposite to the normal condition) in some gastropod species, is absorbed throughout the food chain, and has been found to be highly toxic to humans, resulted in the IMO adopting Resolution A.895 (21) “Antifouling Systems Used on Ships” in 1999. The International Convention on the Control of Harmful Anti-fouling Systems on Ships (AFS Convention 2001) prohibited the application of organotin compounds on ships after January 2003 with a complete prohibition by January 2008. Hence, in the absence of TBT and with increasing reliance on less effective anti-fouling coatings, concerns have been raised that there could be an increase in NIMS introductions around the world (e.g. Nehring 2001; Drake and Lodge 2007).

Despite compelling evidence for on-going introductions of NIMS, vessel biofouling remains largely unmanaged at the international level despite calls for this issue to be taken up by the IMO (UNEP/CBD/COP/8/3, 2005). At the time of writing (2010), the 
author is only aware of four management regimes that are in place around the world which attempt to mitigate the introduction of NIMS via vessel biofouling. These are described in the following subsections, and highlight that New Zealand and Australia are leading the way in terms of managing risks from vessel biofouling.

\subsubsection{The New Zealand Fishing Industry Code of Practice}

The New Zealand Fishing Industry Code of Practice was adopted in December 1996, following the removal of 90 tonnes of foreign organisms from the hull of the $F$. $V$. Yefim Gorbenko (a Russian Bartm Class fishing trawler) during her dry-docking in Auckland in November 1995 (Hay and Dodgshun 1997). The vessel had been laid-up in Port Novorossiysk in the Black Sea for 18 months prior to fishing within New Zealand waters for 12 months before dry-docking. Such a discovery prompted the New Zealand Fishing Industry Association to develop a Code of Practice which essentially recommends any company responsible for chartering a foreign owned or sourced fishing vessel to ensure the vessel is free of biofouling pests prior to arrival in New Zealand waters (see Pfahlert 1997).

\subsubsection{Hull inspections for vessels visiting New Zealand's Sub-Antarctic Islands}

The introduction and rapid spread of the highly invasive kelp, U. pinnatifida into and around New Zealand's coastal environment prompted the New Zealand's Department of Conservation (DoC) to implement a permit scheme for managing the species' anthropogenic spread to New Zealand's pristine sub-Antarctic Islands. Hull checks are required for all vessels used for travel by DoC and DoC-permitted parties visiting the waters around the sub-Antarctic islands. Hull inspections must be carried out by an approved inspector and permits will only be granted for vessels that are completely clean of biofouling, including all visible marine plant and animal material. Vessel inspection documentation must be provided to the Southern Islands Area office within 10 days of departure for the sub-Antarctic islands and are only valid for 28 days from the date of inspection (Hewitt et al. 2004b; Dodgshun et al. 2007). 


\subsubsection{The Darwin (Australia) Marina Hull and Internal Seawater System Inspection and Treatment Regime}

In March 1999, an infestation of the highly invasive black-striped mussel, Mytilopsis sallei was found in Cullen Bay Marina, Darwin, Australia (Field 1999; Willan et al. 2000). It was concluded that the species was most likely introduced via biofouling on a visiting international yacht (Field 1999). This prompted the Northern Territory Government to develop a hull and internal seawater systems inspection regime for NIMS of visiting international vessels wishing to enter Darwin's marinas. Any vessel unable to demonstrate that the hull has been cleaned or anti-fouled in Australia must undergo a hull and internal seawater systems inspection and if necessary treatment to kill any NIMS (www.nt.gov.au/d/Fisheries/index.cfm?header=Vessel\%20Inspections).

\subsubsection{The Australian Quarantine and Inspection Service voluntary biofouling management requirements for vessels less than 25 metres in length}

The likely introduction M. sallei in Cullen Bay, Darwin in 1999 via biofouling on a yacht and the subsequent border interceptions by the Darwin (Australia) Marina Hull and Internal Seawater System Inspection and Treatment Regime prompted the Australian Quarantine and Inspection Service (AQIS) to implement voluntary biofouling management requirements for vessels less than $25 \mathrm{~m}$ in length on 1 October 2005. The protocol also includes apprehended illegal foreign fishing vessels and abandoned vessels. The protocol encourages vessel owners/operators to:

- apply an effective anti-fouling coating suited to the operation of the vessel

- inspect, and if necessary, clean the vessel including niche areas (e.g. internal seawater systems, sea-chests, rudder stock and propeller shafts), anchors, chains and other ancillary gear immediately prior to arrival in Australia

- once inspected and cleaned at an overseas port, depart immediately and travel directly to Australia to minimise re-contamination

- maintain a voyage and biofouling maintenance log and other documentation that supports any biofouling mitigation activities undertaken.

Upon arrival in Australia, AQIS may conduct an in-water inspection to determine the level and nature of biofouling present to determine whether the operator's maintenance 
regime has been effective in minimising the biofouling accumulation on the vessel, to guard against the presence of quarantinable biofouling pests.

\subsection{THE NEED TO MANAGE VESSEL BIOFOULING}

Given the weight of evidence that vessel biofouling continues to be an active contributor to the inadvertent spread of NIMS, there is an urgent need to develop and implement national and international measures to manage vessel biofouling around the world. Unfortunately it is not presently known which vessels, trading routes/pathways or levels of biofouling (i.e. biomass, richness, diversity, percentage cover) pose the greatest risk of translocating NIMS.

Generally, the greater the quality ${ }^{3}$, quantity, diversity, and frequency of NIMS that survive translocation over a wide geographical range, the greater the likelihood of their establishment (Lockwood et al. 2009; although see also Grevstad, 1999). Therefore, the greatest risks could lie with the cumulative influence of thousands of fast-moving merchant vessels with their relatively small aggregations of biofouling confined to niche areas of their hulls that visit ports and harbours worldwide everyday (e.g. Rainer 1995; Coutts 1999; James and Hayden, 2000; Lewis 2002a; Lewis et al. 2003; Coutts et al. 2003; Coutts and Taylor 2004; Australian Shipowners Association 2006; Coutts and Dodgshun 2007; Drake and Lodge 2007; Mineur et al. 2007; Davidson et al. 2009). Alternatively, the greatest risks could lie with the less numerous slow-moving vessels (e.g. yachts, barges, oil exploration rigs, floating dry-docks, decommissioned or specialised vessels) that are renowned for accumulating relatively high levels of biofouling over their entire hull (e.g. Foster and Willan 1979; Hay 1990; Hay and Dodgshun 1997; Brock et al. 1999, Coles et al. 1999; DeFelice 1999; Field 1999; Apte et al. 2000; Godwin and Eldredge 2001; Coutts 2002; Floerl 2002; Godwin 2003; Davidson et al. 2008). It is therefore important that further research be undertaken that contributes to identifying which vessels and characteristics contribute to the translocation of NIMS via biofouling.

\footnotetext{
${ }^{3}$ Quality in this context refers to the general health and condition of organisms after translocation (i.e. upon arrival in a recipient location).
} 
To assess the risks posed by vessel biofouling and develop pragmatic management policies, an understanding of the biofouling "invasion pathway" and the "selective filters" that dictate the success of biofouling organisms that transition through each stage of the invasion process is necessary. For instance, for biofouling organisms or NIMS to be translocated from a donor location and become established in a recipient location, they must successfully complete the following processes: 1) colonise a vessel's hull in a donor region; 2) survive translocation from the donor to the recipient location; 3) adults, offspring and/or fragments transfer from the vessel to the surrounding recipient environment; 4) colonise available substrata or habitat in the recipient location; and 5) undergo on-going reproduction in the recipient location to establish a viable population. Furthermore, at each stage of the invasion process there are a variety of selective filters or hurdles that biofouling organisms must overcome to proceed to the next stage (Figure 1; Lewis and Coutts 2010).

One of the greatest hurdles biofouling organisms must overcome is to successfully colonise a vessel's hull, because vessels are usually protected with anti-fouling coatings. While there are many types of anti-fouling coatings designed to suit different vessels and their behaviours (e.g. voyage speed, frequency of movement, maintenance regimes, etc; see Lewis 2002a for review), generally there are two broad types, namely biocidal and non-biocidal coatings. The most commonly used type is biocidal which incorporates toxic chemicals within the coatings to kill or deter the colonisation of biofouling larvae and propagules. Their efficacy and lifespan are mainly influenced by: 1) type of biocide used; 2) the type of coatings that house the biocides; 3 ) the method of biocidal release; 4) their correct application; and 5) the vessel's activity. Vessels that adopt the correct coating suited to their vessel's intended behaviour are more likely to remain relatively free of biofouling (excluding niche areas) for most of their in-service period.

In light of the impacts of NIMS and the excessive costs associated with the many failed attempted control and eradication programs around the world, "prevention is clearly better than a cure". Therefore, anti-fouling coatings are the best approach for mitigating the invasion process via vessel biofouling. However, unfortunately not all vessels: a) use anti-fouling coatings, b) adopt the correct coating, or c) renew their coatings within the recommended period. Additionally, there are areas of the vessel that are not coated 
with anti-foulant or possess old, ineffective or damaged coatings which allow biofouling organisms to colonise and persist (James and Hayden 2000; Lewis 2002a).

Invasion process

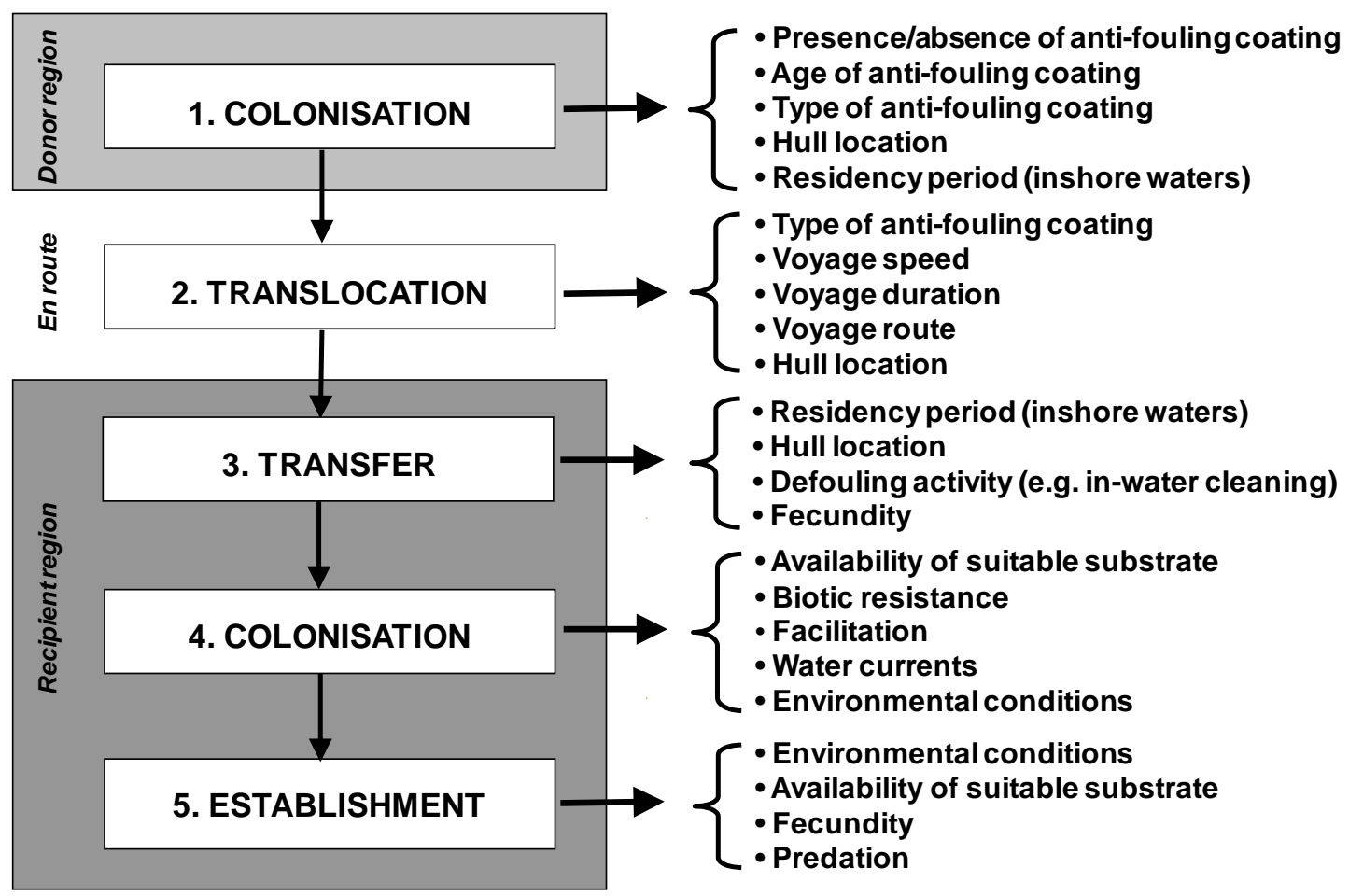

Figure 1 The biofouling invasion process and examples of selective filters that NIMS must overcome to be successfully translocated and establish in a new location (see Lewis and Coutts 2010).

The next and arguably the last defence against the unwanted dispersal of NIMS via vessel biofouling is the possibility that biofouling organisms are unable to survive translocation from the donor to recipient region. There are many selective filters which influence the survival of NIMS during the journey, including: 1) type of anti-fouling coating, 2) voyage speed, 3) voyage duration, 4) voyage route, and 5) settlement location on the hull, etc (Figure 1). While it appears that survivorship of biofouling species is generally higher amongst slow-moving vessels with short voyage durations that ply similar latitudes and in hull locations protected from harsh hydrodynamic forces, more research into their influence on survivorship is needed to assist with the development of effective management policies for mitigating the dispersal of NIMS via vessel biofouling. 


\subsection{SCOPE OF THIS THESIS}

\subsubsection{Chapter 2 - Effect of vessel voyage speed on the survival and translocation of biofouling organisms}

My Masters research investigated the nature and extent of biofouling on merchant vessels visiting northern Tasmania and determined that average voyage speed when combined with average voyage duration and age of anti-fouling coating influenced the degree of biofouling present on the vessels surveyed (Coutts 1999). However, interestingly average voyage speed alone had no detectable influence on the vessel's degree of biofouling. This was particularly surprising given that the sampling design was confined to uniform or exposed areas where biofouling would be most influenced by hydrodynamic forces. However, it possible that the biofouling species recorded in these areas were most probably suited to such harsh environments. Therefore, I hypothesised that vessel or voyage speed will have an effect on a vessel's degree of biofouling if a variety of biofouling organisms are used and if other dominant factors such as age of anti-fouling coating and voyage duration are excluded. Given the potential influence of voyage speed as a selective filter in the invasion process, this chapter used manipulative experiments to assess the influence of voyage speed on the persistence and survival of common biofouling organisms in situ. The specific aims of the study were to: 1) quantify the effects of voyage speed on the survivorship, species richness and percentage cover of biofouling organisms; 2) compare patterns of survival as a function of the morphological characteristics of each organism; and 3) predict which vessel types are more likely to pose the greatest risk of translocating NIMS based on their typical voyage speed.

\subsubsection{Chapter 3 - Which hull locations pose the greatest risk of containing non- indigenous marine species?}

During my Masters research I determined the distribution, abundance and frequency of biofouling organisms amongst merchant vessels. This required an experimental design that was restricted to sampling the uniform areas on the vessel hulls (i.e. flat sides and inside and outside dry-docking support strips ${ }^{4}$; DDSS) to enable direct comparisons to be made between vessels. However, I noticed that higher levels of biofouling occurred

\footnotetext{
${ }^{4}$ Dry-docking support strips refer to the positions under a vessel that cannot be coated with fresh anti-fouling during a dry-docking because of the position of docking blocks.
} 
in niche areas and hypothesized that such hull locations were more likely to house NIMS than uniform areas of the hull. Furthermore, the results of the previous chapter established that voyage speed does influence the survivorship of biofouling species and biofouling organisms may be capable of colonising and persisting in niche areas that are protected from harsh hydrodynamic forces. Therefore, this chapter is a continuation from both my Masters research and Chapter 2 and aimed to: 1) quantify the nature and extent of biofouling within niche areas of merchant vessel hulls, and 2) determine which hull locations in which NIMS were more likely to occur.

\subsubsection{Chapter 4 - A novel method for assessing the en route survivorship of biofouling organisms}

Given Chapter 2 established that vessel voyage speed is capable of influencing the survivorship of biofouling species and Chapter 3 established that there were higher levels of biofouling and likelihood of NIMS within niche areas, I wanted to design a method of assessing the en route survivorship of biofouling organisms on different hull locations on various vessel types. The development of such a novel method would enable other covariates and confounding of multiple correlated influences to be excluded. Relatively few studies have actually assessed the intrinsic survivorship of biofouling organisms on a vessel's hull (i.e. Carlton and Hodder 1995) or have undertaken an experimental assessment of biofouling from a biological invasion perspective. In part, this is due to the constraints of accessing and manipulating biofouling communities in situ. Access to commercial vessels has hitherto been restricted to one-off evaluations in dry-dock or through significant efforts of individual researchers to overcome the occupational health and safety concerns and increased security precautions in port environments (e.g. Rainer 1995; Coutts 1999; James and Hayden 2000). Therefore, Chapter 4 describes the design, methods and results of the technique used to attach pre-fouled settlement plates to vessel hulls at different hull locations.

\subsubsection{Chapter 5 - The survivorship of biofouling organisms on different vessel types at various hull locations}

The aim of this chapter was to determine the survivorship of biofouling organisms on different vessel types at various hull locations. In light of the previous chapters, I hypothesized that survivorship of biofouling organisms is likely to be higher in 
unprotected areas on slow-moving vessels. The aim of this chapter was to quantify the effects of voyage speed on the survivorship and persistence, richness and percentage cover of biofouling species: 1) amongst different vessel types; 2) at various hull locations; and 3) according to their morphological characteristics (i.e. growth form, profile and structure) for each species.

\subsubsection{Chapter 6 - An assessment of the nature and extent of biofouling inside vessel sea-chests}

Chapters 3 and 5 both established that survivorship of biofouling species is likely to be higher in niche areas on vessel hulls, particularly amongst fast-moving vessels. While Chapter 3 reported that sea-chest gratings were more likely to house NIMS than most other hull locations, the contents and risk of the sea-chests themselves could not be determined. Sea-chest cavities potentially offer biofouling organisms a unique environment that differs from other hull locations, including niche areas because they are capable of completely sheltering organisms from harsh en route hydrodynamic forces. Furthermore, anecdotal evidence and discussion of sea-chest systems as potential dispersal mechanisms for marine species has been recognised in the scientific literature for several decades (e.g. Newman 1963; Hoese 1973; Carlton 1985; SlackSmith and Brearly 1987; Richards 1990; Carlton et al. 1995; Cohen and Carlton 1995; Carlton 2001; Lewis 2002a; Coutts et al. 2003; Davis and Davis 2004; Lee and Chown 2007). However, the potential for sea-chests to disperse NIMS was probably first highlighted when Coutts et al. (2003) documented the occurrence of two recognized pest species, the European clam Corbula gibba and the European green crab Carcinus maenas, inside the sea-chests of a ferry in southern Australia. Despite such findings, a better understanding of the potential for sea-chests to house and disperse aquatic organisms has not yet emerged. Therefore, the purpose of this chapter was to determine the nature and extent of organisms inside sea-chests and to establish their role as a potential dispersal mechanism for NIMS.

\subsubsection{Chapter 7 - General discussion}

The purpose of this chapter is to provide further explanations surrounding the nature, extent and survivorship of biofouling and non-indigenous marine species (NIMS) on vessel hulls. Furthermore, the general discussion outlines the latest biofouling management measures (to the author's knowledge) that have been, or are being, 
developed around the world and highlight how the results of this thesis have and will continue to contribute to such developments. Finally a simplistic, but pragmatic risk assessment for identifying and managing potentially high risk vessels for NIMS is offered followed by some overall thesis recommendations.

\subsection{REFERENCES}

AFS Convention, 2001. The International Convention on the Control of Harmful Antifouling Systems on Ships. International Maritime Organization, London.

Apte, S., Holland, B. S., Godwin, L. S., Gardner, J. P. A., 2000. Jumping ship: a stepping stone event mediating transfer of non-indigenous species via a potentially unsuitable environment. Biological Invasions 2: 75-79.

Australian Shipowners Association, 2006. Assessment of introduced marine pest risks associated with niche areas in commercial shipping, June 2006. 24 p.

Bach, J., 1976. A Maritime History of Australia. Book Club Associates; Sydney. 481 pp.

Brock, R., Bailey-Brock, J. H., Goody, J., 1999. A case study of efficacy of freshwater immersion in controlling introduction of alien marine fouling communities: the USS Missouri. Pacific Science 53: 233-231.

Byrne, M., Morrice, M. G., Wolf, B., 1997. Introduction of the northern Pacific asteroid Asterias amurensis to Tasmania: reproduction and current distribution. Marine Biology 127: 637-685.

Campbell, M. L., Hewitt, C. L., 1999. Vectors, shipping and trade. In: Hewitt, C. L., Campbell, M. L., Thresher, R. E., Martin, R. B., (Eds) Marine biological invasions of Port Phillip Bay, Victoria. CSIRO Marine Research, Hobart, Tasmania. Pp. 4560. 
Carlton, J. T., 1982. Final report of seawater ballast studies aboard the Martha R. Ingram. In: Mann, R. (Eds). Biology of ship's ballast water: the role of ballast water in the transoceanic dispersal of marine organisms. Chapter D-VI, from "Final project report. National foundation division of applied research" Grant No. DAR8008450 Woods Hole Oceanographic Institute, Massachusetts, USA.

Carlton, J. T., 1985. Transoceanic and interoceanic dispersal of coastal marine organisms: the biology of ballast water. Oceanography and Marine Biology Annual Review 23: 313-371.

Carlton, J. T., 1987. Patterns of transoceanic marine biological invasions in the Pacific. Bulletin of Marine Science 41: 452-465.

Carlton, J. T., 1992. Dispersal of living organisms into aquatic ecosystems as mediated by aquaculture and fisheries activities. In: Rosenfield, A., Mann, R. (Eds.). Dispersal of Living Organisms into Aquatic Ecosystems, College Park, University of Maryland. 13-45.

Carlton, J. T., 1996. Pattern, process, and prediction in marine invasion ecology. Biological Conservation 78: 97-106.

Carlton, J. T., 2001. Introduced species in U. S. coastal waters: environmental impacts and management priorities, Arlington, Virginia, USA, Pew Oceans Commission, $28 \mathrm{p}$.

Carlton, J. T., Geller, J. B., 1993. Ecological roulette: the global transport of nonindigenous marine organisms. Science 261: 78-82.

Carlton, J. T., Hodder, J., 1995. Biogeography and dispersal of coastal marine organisms: experimental studies on a replica of a $16^{\text {th }}$-century sailing vessel. Marine Biology 121: 721-730.

Carlton, J. T., Reid, D. M., van Leeuwen, H., 1995. Shipping study: the role of shipping in the introduction of non-indigenous aquatic organisms to the coastal waters of the United States (other than the Great Lakes) and an analysis of control options. U.S. Coast Guard, Connecticut, Department of Transportation, Washington, D.C.: 1213. 
Cohen, A. N., Carlton, J. T., 1998. Accelerating invasion rate in a highly invaded estuary. Science 279: 555-558.

Cohen, A. N., Carlton., J. T., 1995. Biological Study. Nonindigenous Aquatic Species in a United States Estuary: A Case Study of the Biological Invasions of the San Francisco Bay and Delta. United States Fish and Wildlife Service, Washington, D. C. and the National Sea Grant College Program, Connecticut Sea Grant, NTIS No. PB96-166525.

Coles, S. L., DeFelice, R. C., Godwin, L. S., 1999. The impact of nonindigenous marine species transported to Pearl Harbor on the hull of the USS Missouri. Hawaii Biological Survey Contribution No. 1999-014, Bishop Museum, Hawaii.

Coutts, A. D. M., 1999. Hull fouling as a modern vector for marine biological invasions: investigation of merchant vessels visiting northern Tasmania. Unpublished MSc. thesis, Australian Maritime College, Launceston, Australia. 283 pp.

Coutts, A. D. M., 2002. A biosecurity investigation of a barge in the Marlborough Sounds. Cawthron Report No. 744. 59 pp.

Coutts, A. D. M., Moore, K. M., Hewitt, C. L., 2003. Ships' sea-chests: an overlooked transfer mechanism for non-indigenous marine species? Marine Pollution Bulletin 46: 1504-1515.

Coutts, A. D. M., Taylor, M. D., 2004. A preliminary investigation of biosecurity risks associated with biofouling on merchant vessels in New Zealand. New Zealand Journal of Marine and Freshwater 38: 215-229.

Coutts, A. D. M, Dodgshun, T. J., 2007. The nature and extent of fouling in vessel seachests: a protected mechanism for marine bioinvasions. Marine Pollution Bulletin 54: 876-886.

Cranfield, H. J., Gordon, D. J., Willan, R. C., Marshall, B. C., Battershill, C. N., Francis, M. P., Nelson, W. A., Glasby, C. J., Read, G. B., 1998. Adventive marine species in New Zealand. NIWA Technical Report No. 34. 
Christie, A. O., Dalley, R., 1987. Barnacle fouling and its prevention. Barnacle Biology 419-433.

Currie, D. R., McArthur, M. A., Cohen, B. F., 2000. Reproduction and distribution of the invasive European fanworm Sabella spallanzanii (Polychaeta: Sabellidae) in Port Phillip Bay, Victoria, Australia. Marine Biology 136: 645-656.

Davidson, I. C., McCann, L. D., Fofonoff, P. W., Sytsma, M. D., Ruiz, G. M., 2008. The potential for hull-mediated species transfers by obsolete ships on their final voyages. Diversity and Distributions 14: 518-529.

Davidson, I. C., Brown, C. W., Sytsma, M. D. Ruiz, G. M., 2009. The role of containerships as transfer mechanisms of marine biofouling species, Biofouling 25: 645-655.

Davis, M. H., Davis, M. E., 2006. Styela clava (Tunicata: Ascidiacea) a new edition to the fauna of New Zealand. Newsletter of the Porcupine Marine Natural History Society 20: 23-28.

DeFelice, R. C., 1999. Fouling marine invertebrates on the floating drydock USS Machinist in Pearl Harbour to its move to Apra Harbour, Guam. Hawai'i Biological Survey, Bernice P. Bishop Museum Honolulu, Hawaii. Contribution No. 1999-013 to the Hawaii Biological Survey.

Dodgshun, T. J., Taylor, M. D., Forrest, B. M., 2007: Human-mediated pathways of spread for nonindigenous marine species in New Zealand. New Zealand Department of Conservation Research and Development Series 266. Department of Conservation, Wellington. $44 \mathrm{p}$.

Drake, J. M., Lodge, D. M., 2007. Hull fouling is a risk factor for intercontinental species exchange in aquatic ecosystems. Aquatic Invasions 2: 121-131.

Dumont, H., Shiganova, T., 2002. The Invasion of the Black, Mediterranean and Caspian Seas by the American Ctenophore, Mnemiopsis leidyi Agassiz: a Multidisciplinary Perspective. A NATO ARW Workshop.

Dunn, L., 1973. Merchant Ships of the World in Colour 1910-1929. Macmillan; New York. 215 pp. 
Evans, L. V., 1981. Marine algae and fouling: A review, with particular reference to ship-fouling. Botanica Marina 24: 167-171.

Field, D., 1999. Disaster averted? Black striped mussel outbreak in northern Australia. Fish Farming International 26: 30-31.

Fitchett, T. K., 1980. The long haul. Ships on the England-Australia run. Rigby, Adelaide. 95 pp.

Floerl, O., 2002. Intracoastal spread of fouling organisms by recreational vessels. PhD thesis. James Cook University, Townsville, Australia. Pp.283.

Fofonoff, P. W., Ruiz, G. M., Stevens, B., Carlton, J. T., 2003. In ships or on ships? Mechanisms of transfer and invasion for nonnative species to the coasts of north America. In: Ruiz, G. M., Carlton, J. T., (Eds), Invasive species: vectors and management strategies, Island Press, pp. 152-183.

Foster, B. A., Willan, R. C., 1979. Foreign barnacles transported to New Zealand on an oil platform. New Zealand Journal Marine Freshwater Research 13: 143-149.

Godwin, L. S., 2003. Hull fouling of maritime vessels as a pathway for marine species invasions to the Hawaiian Islands. Biofouling 19 (Supplement): 123-131.

Godwin, L. S., Eldredge, L. G. 2001. South Oahu Marine Invasions Shipping Study (SOMISS). Technical Report No. 20. Honolulu, Hawaii Biological Survey, Bishop Museum. 104 p.

Gollasch, S., 2002. The importance of ship hull fouling as a vector of species introductions into the North Sea. Biofouling 18: 105-121.

Grevstad, F., 1999. Factors influencing the chance of population establishment: implications for release strategies in biocontrol. Ecological Applications 9: 14391447.

Hay, C. H., 1990. The dispersal of sporophytes of Undaria pinnatifida by coastal shipping in New Zealand, and implications for further dispersal of Undaria in France. British Phycological Journal 25: 301-313. 
Hay, C., Dodgshun, T., 1997. Ecosystem transfer - the case of the Yefim Gorbenko. Seafood New Zealand May 13-14.

Hay, C. H., Luckens, P. A., 1987. The Asian kelp Undaria pinnatifida (Phaeophyta: Laminariales) found in a New Zealand harbour. New Zealand Journal of Botany 25: 329-332.

Hebert, P. D. N., Muncaster, B. W., and Mackie, G. L., 1989. Ecological and genetic studies on Dreissena polymorpha (Pallas): a new mollusc in the Great Lakes. Canadian Journal of Fisheries Aquatic Sciences 46:1587-1591.

Hebert, P. D. N., Wilson, C. C., Murdoch, M. H., Lazar, R., 1991. Demography and ecological impacts of the invading mollusc Dreissena polymorpha. Canadian Journal of Zoology 69: 405-406.

Hedgpeth, J. W., 1993. Foreign invaders. Science 261: 34-35.

Hewitt, C. L., 2002. The distribution and diversity of tropical Australian marine bioinvasions. Pacific Science 56: 213-222.

Hewitt, C. L., 2003. The diversity of likely impacts of introduced marine species in Australian waters. Records of the South Australian Museum Monograph Series 7: $3-10$.

Hewitt, C. L., Campbell, M. L., Thresher, R. E., Martin, R. B., Boyd, S., Cohen, B. F., Currie, D. R., Gomon, M. F., Keogh, M. J., Lewis, J. A., Lockett, M. M., Mays, N., McArthur, M.A., O’Hara, T. D., Poore, G. C. B., Ross, D. J., Storey, M. J., Watson, J. E., Wilson, R. S., 2004a. Introduced and cryptogenic species in Port Phillip Bay, Victoria, Australia. Marine Biology 144: 183-202.

Hewitt, C. L., Willing, J., Bauckham, A., Cassidy, A. M., Cox, C. M. S., Jones, L., Wotton, D. M., 2004b. New Zealand Marine Biosecurity: delivering outcomes in a fluid environment. New Zealand Journal of Marine and Freshwater Research 38: $429-438$.

Hewitt, C. L., Campbell, M. L., Schaffelke, B., 2007. Introductions of seaweeds: accidental transfer pathways and mechanisms. Botanica Marina 50: 326-337. 
Hewitt, C. L., Campbell, M. L., 2008. Assessment of relative contribution of vectors to the introduction and translocation of marine invasive species. Report for the Department of Agriculture, Fisheries and Forestry. National Centre for Marine Conservation and Resource Sustainability Australian Maritime College, an institute of the University of Tasmania. pp. 45.

Hoese, D. F., 1973. The introduction of the gobiid fishes Acanthogobius flavimanus and Tridentiger trigonocephalus into Australia. Koolewong 2: 3-5.

James, P., Hayden, B., 2000. The potential for the introduction of exotic species by vessel hull fouling: A preliminary study. NIWA Technical Report No. 16.

Lee, J. E., Chown, S. L., 2007. Mytilus on the move: transport of an invasive bivalve to the Antarctic. Marine Ecology Progress Series 339: 307-310.

Lewis, J. A., 2002a. Hull fouling as a vector for the translocation of marine organisms. Phase I Study: Hull fouling research. Department of Agriculture, Fisheries and Forestry Australia. Strategic Ballast Water Research and Development Programme, Canberra, Report No. 1. 142 pp.

Lewis, J. A., 2002b. Hull fouling as a vector for the translocation of marine organisms: Report 2 - The significance of the prospective ban on tributyltin anti-fouling paints on the introduction and translocation of marine pests in Australia. Ballast Water Research Series Report No. 15. Department of Agriculture, Fisheries and Forestry, Canberra. 129 pp.

Lewis, J. A., Coutts, A. D. M., 2010. Biofouling invasions. In: Durr, S and Thomason, J., (Eds). Biofouling. Blackwell Publishing Ltd, Oxford. 348-365 pp.

Lewis, P. N., Hewitt, C. L., Riddle, M., McMinn, A., 2003. Marine introductions in the Southern Ocean: an unrecognised hazard to biodiversity. Marine Pollution Bulletin 46: 213-223.

Locke, A., Reid, D. M., van Leeuwen, H. C., Sprules, W. G., Carlton, J. T., 1993. Ballast water exchange as a means of controlling discharge of freshwater organisms by ships. Canadian Journal of Fisheries Aquatic Science 50: 2086-2093. 
Lockwood, J. L., Cassey, P., Blackburn, T. M., 2009. The more you introduce the more you get: the role of colonization pressure and propagule pressure in invasion ecology. Diversity and Distributions 15: 904-910.

Lubbock, B., 1921. Colonial Clippers. Brown, Son and Ferguson; Glasgow, Scotland. $384 \mathrm{pp}$.

Macintyre, D., 1972. The Adventure of Sail. Ferndale editions; London. 256 pp.

Mather, P., 2002. A complex Didemnid ascidian from Whangamata, New Zealand. Journal of Marine Biology Association United Kingdom. 82: 625-628.

Medcof, J. C., 1975. Living marine animals in ship's ballast water. Proceedings of the Natural Shellfisheries Association 65: 11-12.

Minchin, D., Gollasch, S., 2002. Vectors - how exotics get around. In: Leppakoski, E., Gollasch, S., Olenin, S., (Eds.). Invasive Aquatic Species of Europe: Distribution, Impact and Management. London, Kluwer. 183-192 pp.

Mineur, F., Johnson, M. P., Maggs, C. A., 2007. Hull fouling on commercial ships as a vector of macroalgal introduction. Marine Biology 151: 1299-1307.

Nehring, S., 2001. After the TBT era: alternative anti-fouling paints and their ecological risks. Senckenbergiana Maritime 3: 341-351.

Newman, W., 1963. On the introduction of an edible Oriental shrimp (Caridea, Palaemonidae) to San Francisco Bay. Crustaceana 5: 119-132.

Pfahlert, J., 1997. Avoiding vessel hull contamination of the New Zealand environment by fishing boats. Seafood New Zealand, May 1997, p 15.

Richards, A., 1990. Muricids: A Hazard to Navigation? Hawaiian Shell News May, p. 10.

Pimentel, D., Zuniga, R., Morrison, D., 2005. Update on the environmental and economic costs associated with alien-invasive species in the United States. Ecological Economics 52: 273-288. 
Rainer, S., 1995. Potential for the introduction and translocation of exotic species by hull fouling: a preliminary assessment. Technical Report No. 1. Hobart, Tasmania. Centre for Research on Introduced Marine Pests. 18 p.

Ruiz, G. M., Carlton, J. T., Grosholz, E. D., Hines, A. H., 1997. Global invasions of marine and estuarine habitats by non-indigenous species: mechanisms, extent, and consequences. American Zoologist 37: 621-632

Ruiz, G. M., Fofonoff, P. W., Carlton, J. T., Wonham, M. J., Hines, A. H., 2000. Invasion of coastal marine communities in North America: apparent patterns, processes, and biases. Annual Reviews in Ecology and Systematics 31: 481-531.

Sanderson, J. C., 1990. A preliminary survey of the distribution of the intro macroalgae Undaria pinnatifida on the east coast of Tasmania, Australia. Botanica marina 33: 153-157.

Schormann, J., Carlton, J. T., Dochoda, M. R., 1990. The ship as a vector in biotic invasions. Marine Technology and the Environment 19: 147-152.

Slack-Smith, S. M., Brearly, A., 1987. Musculista senhousia (Benson, 1842); a mussel recently introduced into the Swan River estuary, Western Australia (Mollusca: Mytilidae). Records of the Western Australian Museum 13, 225-230.

Smith, P. J., Page, M., Handley, S. J., McVeagh, S. M., Ekins, M., 2007. First record of the Australian ascidian Eudistoma elongatum in northern New Zealand. New Zealand Journal of Marine and Freshwater Research 41: 347-355.

Studenikina, E. I., Volovik, S. P., Miryozan, I. A., Luts, G. I., 1991. The ctenophore Mnemiopsis leidyi in the Sea of Azov. Oceanology 3: 722-725.

Taylor, M., 1999. Building defences against marine pests. Seafood New Zealand. February 1999: 28-30.

The New Zealand Hearld., 2008. Fanworm discovered in Lyttelton. Wednesday 28 May, 2008. 
Thresher, R. E., Hewitt, C. L., Campbell, M. L., 1999. Synthesis: Introduced and cryptogenic species in Port Phillip Bay. In: Hewitt, C. L., Campbell, M. L., Thresher, R. E, Martin, R. B., (Eds.), Marine biological invasions of Port Phillip Bay, Victoria. Centre for Research on Introduced Marine Pests. Technical Report No. 20: 283-295.

Vinogradov, M. E., Shushkina, E. A. Musaeva, E. I., Sorokin, P. Y., 1989. Ctenophore Mnemiopsis leidyi (A.Agassiz) (Ctenophora: Lobata) - new settlers in the Black Sea. Oceanology 29: 293-298.

Webber, R., 2001. Space invaders, crabs that turn up in NZ unannounced. Seafood New Zealand November 2001: 80-84.

Willan, R. C., Russell, B. C., Murfet, N. B., Moore, K. L., McEnnulty, F. R., Horner, S. K., Hewitt, C. L., Dally, G. M., Campbell, M. L., Bourke, S. T., 2000. Outbreak of Mytilopsis sallei (Recluz, 1849) (Bivalvia: Dreissenidae) in Australia. Molluscan Research 20: 25-30. 


\section{Chapter 2 - Effect of vessel voyage speed on the survival and translocation of biofouling organisms}

\section{PREFACE}

The data for this chapter were collected during my Masters research in 1997. However, the data were not processed, analysed or included in my Masters thesis (Coutts 1999). I chose to include this work because it provided a logical link and continuation from my Masters research and, furthermore, a good starting point for my $\mathrm{PhD}$. I was responsible for processing and analysing the data and writing of the initial manuscript. However, the final data analysis was largely coordinated by my co-author Richard Piola (Cawthron Institute) and other co-authors contributed to the final content of the manuscript. An abbreviated version of this chapter has been peer reviewed and published in the international peer-reviewed journal Biofouling according to the following citation:

Coutts, A. D. M., Piola, R. F., Hewitt, C. L., Connell, S. D., Gardner, J. P. A., 2010. Effect of vessel voyage speed on survival of biofouling organisms: implications for translocation of non-indigenous marine species. Biofouling 26: 1-13.

\section{ABSTRACT}

This study experimentally determined the effect of different vessel voyage speeds $(5,10$ and 18 knots $=2.6,5.1$, and $9.3 \mathrm{~ms}^{-1}$, respectively) and morphological characteristics including growth form (solitary or colonial), profile (erect or encrusting) and structure (soft, hard or flexible) on the survival of a range of common biofouling organisms. A custom built hydrodynamic keel attached to the bottom of a 6 metre aluminium powerboat was used to subject pre-fouled settlement plates for this purpose. Vessel speeds of 5 and 10 knots had little effect on the species richness of biofouling assemblages tested, however richness decreased by $50 \%$ following 18 knots treatments. Species percentage cover decreased with increasing speed across all speed treatments 
and this decrease was most pronounced at 10 and 18 knots, with cover reduced by 24 and $85 \%$ respectively. Survival was greatest for organisms with colonial, encrusting, hard and/or flexible morphological characteristics, and this effect increased with increasing speed. This study suggests that there is predictive power in forecasting future introductions if we can gain a better understanding of the extent to which such traits explain the world-wide distributions of non-indigenous species. Future introductions are a certainty and can only provide an increasing source of new information on which to test the validity of these predications.

\subsection{INTRODUCTION}

Understanding dispersal and connectivity among populations is an area of intense study and an ongoing challenge in ecology (Elsdon et al. 2008) and is of particular importance in understanding the worldwide spread of non-indigenous marine species (NIMS) associated with shipping (e.g. Ruiz et al. 1997; Fofonoff et al. 2003; Hewitt et al. 2004; Hewitt and Campbell 2008). The most common mechanisms by which shipping facilitates the transfer of NIMS are via vessel ballast water discharges, or through the translocation of biofouling organisms attached to the exterior of hulls, ancillary equipment, anchors or inside internal seawater systems (e.g. Schormann et al. 1990; Carlton et al. 1995; Coutts and Dodgshun 2007). Historically, biofouling was the key mechanism for translocating species and recent research indicates that it is still the single most important mechanism for the dispersal of NIMS in many locations around the world. For example, Hewitt and Campbell (2008) estimated that more than $55 \%$ and possibly as many as $69 \%$ of the 1781 recognised NIMS detected around the world have life-history characteristics (e.g. adult life habit and reproductive capability) that make them likely to be associated with biofouling on vessel hulls.

For biofouling organisms (or NIMS) to become successful invaders, they must successfully negotiate the "invasion pathway": 1) colonisation; 2) translocation; 3) transfer; 4) colonisation; and 5) establishment. There are a variety of factors or selective filters that influence the success of biofouling organisms that transition through each stage of the invasion process (Figure 1; see also Hewitt et al. 2007, 2009; Lewis and Coutts 2010). Arguably, two of the most influential selective filters are the chemical effects of anti-fouling coatings and the physical effects of hydrodynamic 
forces before the NIMS arrive at the recipient environment. While there has been considerable research on the effects of toxic biocides or chemicals incorporated in antifouling coatings on biofouling organisms (e.g. Piola and Johnston 2006; Dafforn et al. 2008; Piola and Johnston 2008), few studies have explicitly examined the effect of the physical stress of hydrodynamic forces associated with vessel speed on the survival of biofouling organisms.

Our knowledge of the types of biofouling organisms that are capable of surviving the translocation stage is limited to post-voyage in situ assessment of vessel biofouling communities, inspections in maintenance facilities, and retrospective analyses of survivorship relative to the vessels' voyage speed, duration, route, etc. (see Lewis 2002 for summary). Field observations detailing differential biofouling on fast- versus slowmoving vessels suggest that speed is likely to be key factor affecting the spread of NIMS. Most fast-moving (e.g. $\geqslant 15$ knots) vessels in regular use such as merchant vessels tend to have relatively low levels of biofouling which are confined to protected niche areas of the hull (e.g. James and Hayden 2000; Coutts and Taylor 2004; Australian Shipowners Association 2006). In contrast, slow-moving (e.g. $\leqslant 5$ knots) vessels can support substantial biofouling communities across large areas of their hulls, even after long voyages of several weeks (e.g. Foster and Willan 1979; DeFelice 1999; Apte et al. 2000; Davidson et al. 2008).

Voyage speed can affect biofouling assemblages through differential survivorship and growth. For example, high-flow conditions can reduce the ability of sessile and sedentary invertebrates to feed and also reduce the photosynthetic rate of algae (Koehl 1984). To gain a better understanding of these processes with respect to the invasion process, there is a need for studies examining the species-specific effects of vessel speed on survivorship, and assess whether there are any general patterns associated with morphological characteristics.

The author is aware of only three studies that have attempted to quantify the pre- and post-voyage survivorship of various biofouling organisms on vessel hulls (i.e. Carlton and Hodder 1995; Brock et al. 1999; Davidson et al. 2008). These studies clearly demonstrated that many biofouling organisms are capable of surviving such long 
voyages at slow speeds ( $\sim 4.0$ to 6.5 knots), including voyages with transits through freshwater environments (e.g. Panama Canal).

In this study, the influence of voyage speed on the survival of common biofouling organisms in situ was experimentally tested. This experiment was achieved by towing settlement plates with diverse assemblages at a range of speeds to assess both acute and chronic survival of species with differing morphologies. The specific aims of the study were to: 1) quantify the effects of voyage speed on the survivorship, species richness and percentage cover of biofouling organisms; 2) compare patterns of survival with morphological characteristics (i.e. growth form, profile and structure) for each species; and 3) determine which vessel types pose the greatest risk of NIMS transfers based on their typical voyage speed.

\subsection{METHODS}

Biofouling assemblages were obtained from the Beauty Point Marina on the Tamar River, northern Tasmania, Australia $\left(41^{\circ} 09^{\prime} 23.84^{\prime \prime} \mathrm{S} ; 146^{\circ} 49^{\prime} 27.87^{\prime \prime} \mathrm{E}\right)$. Fortyeight black acrylic settlement plates $(150 \times 250 \times 4.5 \mathrm{~mm})$ were used as independent replicate experimental units, with one side of each settlement plate being roughened with sandpaper to promote settlement. Each replicate was attached to the underside of plastic backing plates (approximately $1 \times 1$ metre) with the roughened side facing outwards, and suspended horizontally below a floating barge and maintained at a constant depth of $2 \mathrm{~m}$. Biofouling assemblages were allowed to develop naturally over a period of 10 weeks between October and December (Austral spring). The average wet biomass weight of biofouling on the settlements was determined by weighing a random selection of 12 control plates after the 10 week period.

\subsubsection{Vessel speed trials}

Field-based vessel speed trials commenced on 10 December 1997 in Dalrymple Bay, Tamar River (adjacent to the Beauty Point Marina). A custom-built hydrodynamic keel attached beneath a $6 \mathrm{~m}$ aluminium powerboat was used to subject replicate experimental assemblages to differing vessel voyage speeds (Figure 2). The flow regime around the keel was investigated in a flume tank prior to commencement of field tests to gain a better understanding of the hydrodynamic regime acting on the keel in the field. 

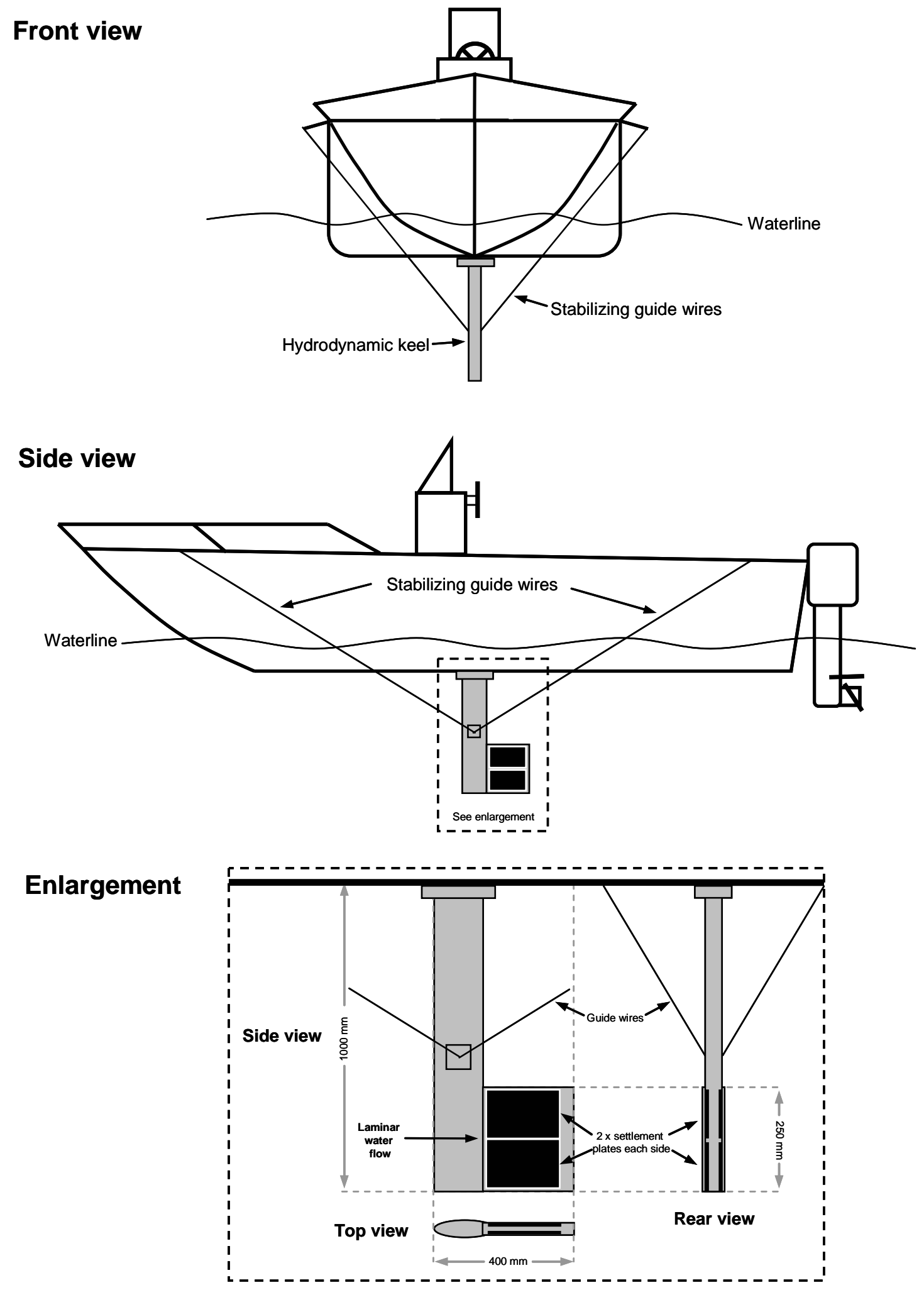

Figure 2 Schematic diagrams showing the front, side, and enlarged views of the custom designed hydrodynamic keel attached to the bottom of a 6 metre powerboat used to assess the effect of various voyage speeds on the survivorship of biofouling species. Diagrams are not drawn to scale. 
The experimental design involved measuring survival (richness and percentage cover), size, and type of species after exposing plates to four voyage speeds: 0 (Control), 5 (slow), 10 (medium) and 18 knots (fast) (representing 2.6, 5.1, and $9.3 \mathrm{~ms}-1$ ) at three assessment periods (0,20 minutes and 7 days). The effect of each of these treatments was determined using three independent replicate trials of four replicate plates. Hence, a total of 48 plates were used (i.e. 3 trials x 4 speeds $x 4$ replicate plates).

For each of the 12 voyage trials, the four randomly selected pre-fouled settlement plates were attached vertically to the keel by divers using flush fitting screws (Figure 2). A further four randomly selected pre-fouled settlement plates were relocated from the plastic backing plates to an adjacent control backing plate beneath the Beauty Point Marina to act as static controls (controls). Each trial had a total voyage duration of 20 min at the target speed while the controls remained stationary. An ST50 Autohelm speed log (Raymarine Ltd, Portsmouth, Hampshire, United Kingdom) attached beneath the vessel was used to monitor and maintain the speed of water movement past the plates during the trials. Prior to each voyage speed, the four settlement plates attached to the keel and the four control plates were photographed and the protrusion height of species at randomly selected points in the fouling assemblage were measured and recorded.

On completion of each voyage trial, the keel and control plates were re-photographed and three each of the keel and control plates were taken back to a laboratory to identify biofouling organisms present and to determine their post-voyage survival relative to pre-voyage states (via evidence of post-voyage feeding activity in the laboratory). The remaining two settlement plates (i.e. one each of the keel and control plate) were removed from the keel and the control backing plate and reattached to the original plastic backing plates for a period of 7 days (post-voyage) after which the on-going survivorship of biofouling organisms on both was assessed. The control plates were used as the baseline for the effect of voyage speed and any handling effects on biofouling communities during the voyage trials.

\subsubsection{Classification of taxa}

Biofouling organisms greater than $1 \mathrm{~mm}$ in size were identified to the lowest practical taxonomic level based on available literature and identification records. Species were 
classified as indigenous (a species that originates in Australia) and established (a nonindigenous species that has established in Australia). Species that were only able to be identified to genus level or higher were classified as status unknown and species with an unknown origin were classified as cryptogenic (sensu Carlton et al. 1996).

Assessment of the effect of voyage speed on the survivorship of biofouling species was achieved by recording the number of species and their percentage cover per plate present in the pre- and post-voyage photographs. Estimates of the number of species and their percentage cover data were derived from a uniform grid of 50 point counts (Drummond and Connell 2005) that was aligned in an identical position over the plate during each assessment. A $20 \mathrm{~mm}$ perimeter along the edge of each plate/photograph was omitted from counting to control for possible boundary effects. In order to determine links between an species' attachment/survival and basic morphology characteristics, all species were grouped into six discrete morphological categories based on growth form (solitary or colonial), profile (erect or encrusting) and structure (soft, hard or flexible; Table 1). Species richness and percentage cover data were calculated to determine the effect of voyage speed on the average abundance of each morphological group.

\subsubsection{Analyses}

Preliminary analyses determined that significant differences occurred between controls and treatments for both richness and percentage cover, hence controls were removed from all further analyses except where stated otherwise. Multivariate analysis of assemblage composition and cover was performed using PRIMER Version 5 (PRIMERE Ltd, Lutton, Ivybridge, United Kingdom). All data were arcsine square-root transformed so that highly dominant species played some role in determining cluster patterns, but did not cause undue bias at the expense of less dominant taxa (Clarke and Warwick 2001). A two-dimensional non-metric multi-dimensional scaling (nMDS) ordination was produced from a Bray-Curtis similarity matrix. Using group average clustering, treatment groupings that formed at $a \geqslant 65 \%$ Bray-Curtis similarity threshold were superimposed on the nMDS ordination plot (Clarke 1993). A SIMPER analysis (Clarke 1993) was then used to identify the major taxa contributing to withingroup similarity (based on cumulative contributions up to $99 \%$ ) and between-group dissimilarity. 
Univariate analyses were used to test for differences in assemblages among speed treatment groups. Repeated measures analysis of variance (RM-ANOVA) was used to test for the effect of vessel speed and trial number on assemblage species richness and percentage cover, with time (pre- and post-voyage) as the repeated effect. Differences in the $7 \mathrm{~d}$ post-voyage survivorship (i.e. on-going survivorship) of species exposed to different vessel speeds were also assessed using a one-factor (speed) RM-ANOVA comparing differences in richness/cover between the post-voyage and $7 \mathrm{~d}$ post-voyage assemblages. The pre-voyage vs post-voyage comparisons used 12 replicates ( 3 trials $\mathrm{x}$ 4 plates) while the post-voyage vs 7 days post-voyage comparisons used only three replicates ( 3 trials $x 1$ plates). Differences in the richness and cover of biofouling organisms on procedural controls were used to compare pre- and post-handling assemblages using a two-factor (speed and trial) RM-ANOVA of which no handling effect was observed. Tukey's post-hoc analyses were conducted on significant results to determine the location of differences among treatments.

To determine which morphological characteristics were most susceptible/resilient to voyage speed, change in percentage cover between pre- and post-voyage divided by the pre-voyage percentage cover was calculated for each morphological characteristic for each speed $(0,5,10$ and 18 knots). All data was arcsine square-root transformed and SYSTAT Version 11 used to undertake a two-way ANOVA to compare differences between each morphological grouping (i.e. sessile vs. colonial; erect vs. encrusting; soft vs. flexible, soft vs. hard and flexible vs. hard). This data were also used to compare differences between each morphological grouping by plotted percentage change (y-axis) against speed (x-axis; controls, 5, 10 and 18 knots) for each morphological characteristic and regression lines applied as indicative indicators.

\subsection{RESULTS}

\subsubsection{Assemblage composition}

Settlement plates accumulated an average of $28.0 \pm 1.6( \pm 1 \mathrm{SE}) \mathrm{g}$ of wet weight biofouling biomass per plate over the ten week period. A total of 13 taxa in four phyla were identified: bryozoans (Bryozoa), serpulid and sabellid worms (Annelida), colonial and solitary ascidians (Chordata), and a colonial hydroid (Cnidaria) (Table 1). These included several species recognised as established NIMS in Australian waters, such as 
the bryozoan Membranipora membranacea, the colonial ascidians Botrylloides leachi, Botryllus schlosseri and Diplosoma listerianum, and the solitary ascidian Corella eumyota.

The composition of assemblages across the pre-voyage plates and 5 and 10 knots postvoyage plates appeared uniform in the diversity and percentage cover of taxa, with a high Bray-Curtis similarity value ( $\geq 65 \%$ ) among treatments (Figure 3). In contrast, all post-voyage 18 knots plates showed marked differences in assemblage compositions to all other treatments, reflecting an increase in the presence of bare space and the removal of numerous dominant pre-voyage species such as the tubeworm Sabellid sp. A and the solitary ascidian C. eumyota (Figure 3).

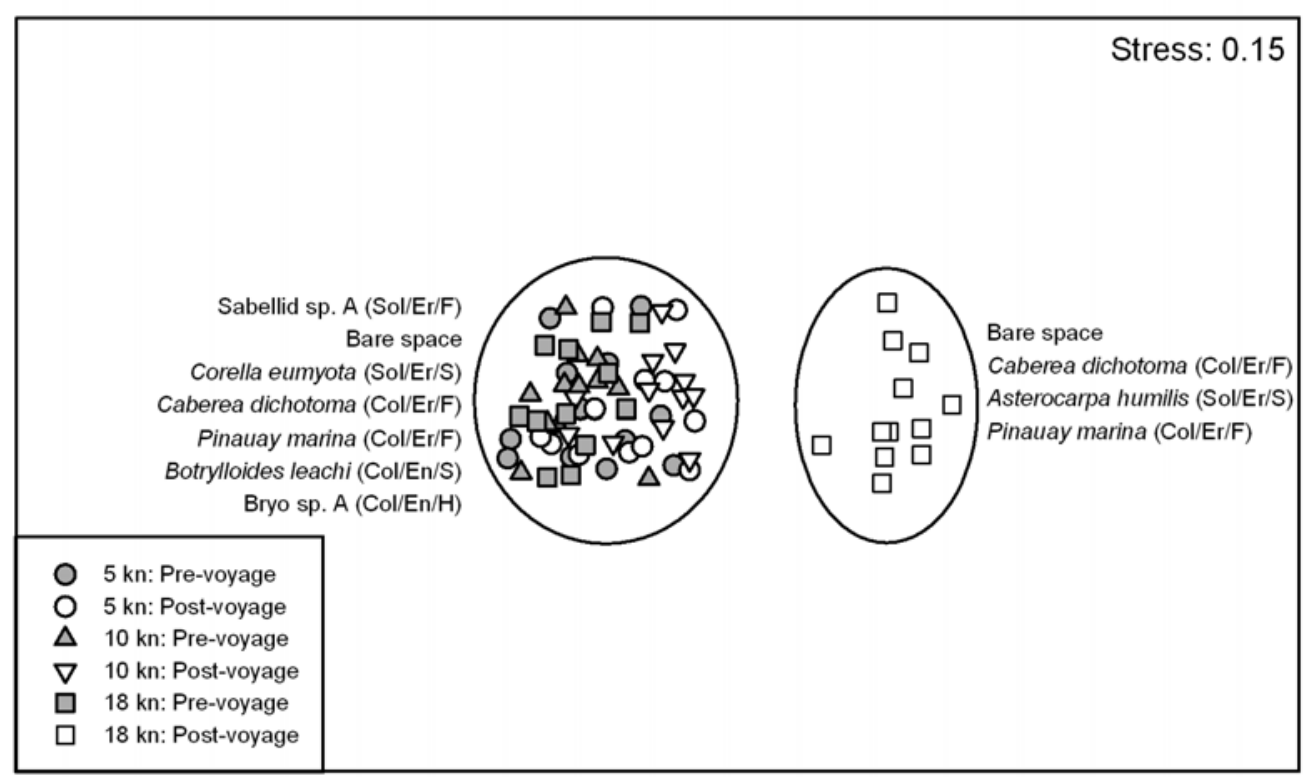

Figure 3 nMDS plot of the pre- and post-voyage composition and dominance of biofouling organisms on plates exposed to vessel voyage speeds of 5, 10 and 18 knots. Each point represents a single replicate settlement plate. Lines encircle treatment groups having a Bray-Curtis similarity of $\geq 65 \%$. Also listed are the dominant species (including bare space) contributing to up to $99 \%$ of the similarity within each group (based on simper analysis) and their morphological grouping (Sol = solitary; Col = colonial; En = encrusting; $\mathrm{Er}=$ erect; $\mathrm{S}=$ soft; $\mathrm{F}=$ flexible; $\mathrm{H}=$ hard).

There was no change in species richness of pre- and post-handled control plates. A significant Time $\mathrm{x}$ Speed interaction was observed among treatment groups exposed to 
differing voyage speeds $\left(\mathrm{F}_{[2,27]}=33.894, P<0.001\right.$; Table $\left.2 \mathrm{a}\right)$. Post-hoc tests revealed that, while there was no significant difference in the pre-voyage species richness on 5 , 10 and 18 knots plates, post-voyage 18 knots plates had significantly fewer species when compared to all pre-voyage assemblages and post-voyage 5 knots plates (Tukey's $P<0.05$; Table $2 \mathrm{~b}$; Figure $4 \mathrm{a})$. There was no evidence of recovery in species richness $7 \mathrm{~d}$ post-voyage $\left(\mathrm{F}_{[2,6]}=0.250, P=0.787\right.$; Figure $\left.4 \mathrm{~b}\right)$.
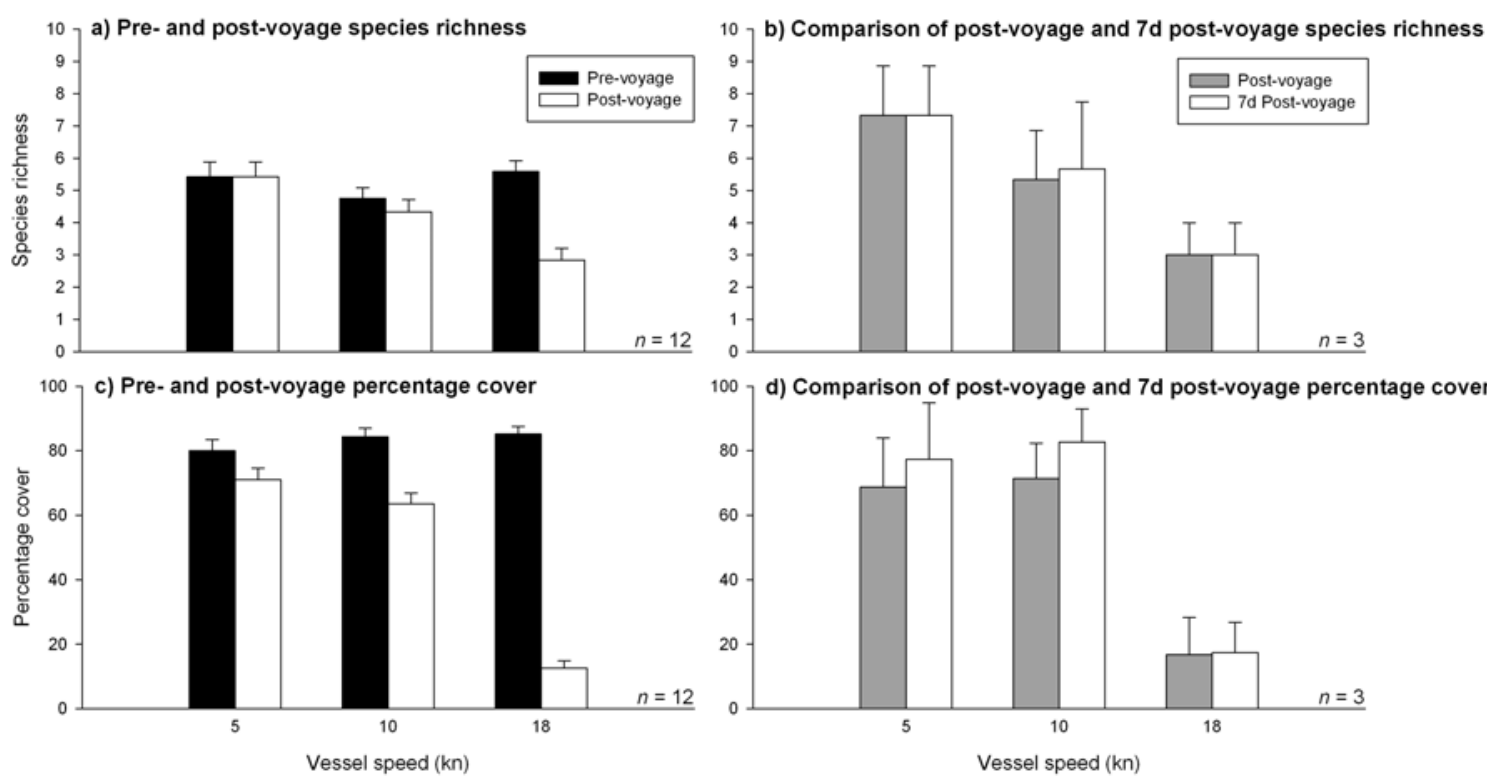

Figure 4 Species richness and percentage cover recorded for biofouling organisms exposed to vessel voyage speeds of 5, 10 and 18 knots: a) comparison of species richness pre- and post-voyage trials $(n=12)$; b) assessment of on-going species richness, comparing richness post-voyage and 7 days post- voyage trials $(n=3)$; c) comparison of percentage cover pre- and post-voyage trials $(n=12)$; d) assessment of on-going percentage cover, comparing cover post-voyage and 7 days post-voyage trials $(n=3)$. Values represent the average $( \pm 1 \mathrm{SE})$. 
Table 1 Summary of biofouling organisms identified on settlement plates used for vessel speed trials; including their origin (indigenous, established, cryptogenic, unknown), morphological characteristics, height of protrusion from the plate surface, and average percentage cover pre- and postvoyage (20 $\mathrm{min})$ across different voyage speeds (5, 10 and 18 knots). Values represent the average ( $\pm 1 \mathrm{SE})$.

\begin{tabular}{|c|c|c|c|c|c|c|c|c|c|c|}
\hline \multirow{2}{*}{$\begin{array}{l}\text { Taxonomic } \\
\text { classification }\end{array}$} & \multirow[t]{2}{*}{ Species } & \multirow[t]{2}{*}{ Origin } & \multirow[t]{2}{*}{ Morphology } & \multirow{2}{*}{$\begin{array}{l}\text { Height } \\
\text { (mm) }\end{array}$} & \multicolumn{2}{|c|}{5 knots } & \multicolumn{2}{|c|}{10 knots } & \multicolumn{2}{|c|}{18 knots } \\
\hline & & & & & $0 \mathrm{~min}$ & $20 \mathrm{~min}$ & $0 \mathrm{~min}$ & $20 \mathrm{~min}$ & $0 \mathrm{~min}$ & $20 \mathrm{~min}$ \\
\hline \multicolumn{11}{|l|}{ ANNELIDA } \\
\hline Serpulidae & Pomatocerus sp. & Unknown & Solitary/Encrusting/Hard & $2.4 \pm 0.8$ & $2.0 \pm 0.0$ & $2.0 \pm 0.0$ & $2.0 \pm 0.0$ & $2.0 \pm 0.0$ & $2.0 \pm 0.0$ & $2.0 \pm 0.0$ \\
\hline Spirorbidae & Spirobid sp. A & Unknown & Solitary/Encrusting/Hard & $1.0 \pm 0.0$ & $2.0 \pm 0.0$ & $2.0 \pm 0.0$ & - & -- & - & - \\
\hline Sabellidae & Sabellid sp. A & Unknown & Solitary/Erect/Flexible & $5.5 \pm 1.7$ & $54.0 \pm 4.9$ & $46.8 \pm 5.1$ & $63.0 \pm 3.2$ & $48.5 \pm 3.6$ & $60.8 \pm 1.3$ & $2.0 \pm 0.0$ \\
\hline \multicolumn{11}{|l|}{ BRYOZOA } \\
\hline Scrupocellariidae & Caberea dichotoma & Established & Colonial/Erect/Flexible & $17.4 \pm 4.7$ & $4.7 \pm 0.9$ & $4.2 \pm 0.9$ & $3.8 \pm 0.9$ & $3.8 \pm 1.0$ & $4.8 \pm 0.7$ & $4.5 \pm 0.5$ \\
\hline Membraniporidae & Membranipora membranacea & Cryptogenic & Colonial/Encrusting/Hard & $1.2 \pm 0.4$ & $2.0 \pm 0.0$ & $2.0 \pm 0.0$ & $4.0 \pm 0.0$ & $4.0 \pm 0.0$ & $2.0 \pm 0.0$ & $2.0 \pm 0.0$ \\
\hline- & Bryo sp. A & Unknown & Colonial/Encrusting/Hard & $1.2 \pm 0.4$ & $4.5 \pm 1.2$ & $4.0 \pm 0.8$ & $4.0 \pm 1.2$ & $3.5 \pm 1.0$ & $4.8 \pm 1.5$ & $4.7 \pm 0.7$ \\
\hline \multicolumn{11}{|l|}{ CNIDARIA } \\
\hline Tubulariidae & Pinauay (Ectopleura) marina & Established & Colonial/Erect/Flexible & $33.7 \pm 8.9$ & $9.3 \pm 4.6$ & $7.7 \pm 4.5$ & $10.8 \pm 2.7$ & $9.3 \pm 2.4$ & $11.4 \pm 4.8$ & $9.0 \pm 4.1$ \\
\hline \multicolumn{11}{|l|}{ CHORDATA } \\
\hline Styelinae & Asterocarpa humilis & Native & Solitary/Erect/Soft & $5.0 \pm 1.4$ & $3.0 \pm 1.0$ & $3.0 \pm 1.0$ & $2.0 \pm 0.0$ & $2.0 \pm 0.0$ & $3.4 \pm 0.8$ & $2.9 \pm 0.6$ \\
\hline Rhodosomitidae & Corella eumyota & Native & Solitary/Erect/Soft & $11.9 \pm 2.7$ & $7.0 \pm 1.2$ & $6.6 \pm 1.2$ & $7.3 \pm 1.7$ & $3.4 \pm 0.7$ & $5.8 \pm 1.0$ & - \\
\hline Urochordata & Solitary sp. A & Unknown & Solitary/Erect/Soft & $2.5 \pm 0.7$ & $2.0 \pm 0.0$ & $2.0 \pm 0.0$ & $2.0 \pm 0.0$ & $2.0 \pm 0.0$ & - & - \\
\hline Botryllidae & Botrylloides leachi & Established & Colonial/Encrusting/Soft & $2.0 \pm 0.7$ & $4.9 \pm 1.3$ & $4.9 \pm 1.3$ & $2.5 \pm 0.5$ & $2.5 \pm 0.5$ & $4.0 \pm 1.3$ & $3.3 \pm 1.3$ \\
\hline Botryllidae & Botryllus schlosseri & Unknown & Colonial/Encrusting/Soft & $2.2 \pm 0.6$ & $6.7 \pm 2.4$ & $6.7 \pm 2.4$ & $2.0 \pm 0.0$ & $2.0 \pm 0.0$ & $3.7 \pm 1.3$ & $2.0 \pm 0.0$ \\
\hline Didemnidae & Diplosoma listerianum & Established & Colonial/Encrusting/Soft & $1.7 \pm 0.6$ & $28.0 \pm 0.0$ & $28.0 \pm 0.0$ & $12.0 \pm 0.0$ & $10.0 \pm 0.0$ & $4.0 \pm 0.0$ & $4.0 \pm 0.0$ \\
\hline
\end{tabular}


Table 2 Summary of a) repeated measures analysis of variance for species richness and percentage cover of biofouling organisms exposed to vessel speeds of 5, 10 and 18 knots over three separate trial periods, and Tukey's post-hoc comparisons for b) species richness and c) percentage cover, showing probabilities of differences between individual treatment groups for the Within Subjects interaction Time $\mathrm{x}$ Speed. Significant $P$ values are in bold.

a)

\begin{tabular}{|c|c|c|c|c|c|c|c|c|}
\hline \multirow[t]{2}{*}{ Source } & \multicolumn{4}{|c|}{ Species richness } & \multicolumn{4}{|c|}{ Percentage cover } \\
\hline & $\mathrm{df}$ & MS & $\mathrm{F}$ & $P$ & $\mathrm{df}$ & MS & $\mathrm{F}$ & $P$ \\
\hline \multicolumn{9}{|l|}{ Between subjects } \\
\hline Speed treatment & 2 & 9.347 & 2.789 & 0.079 & 2 & 5371.2 & 26.873 & $<0.001$ \\
\hline Trial number $^{5}$ & 2 & 7.764 & 2.316 & 0.119 & 2 & 104.0 & 0.520 & 0.600 \\
\hline Speed $\times$ Trial & 4 & 1.431 & 0.427 & 0.788 & 4 & 59.7 & 0.299 & 0.876 \\
\hline Error & 27 & 3.352 & & & 27 & 199.9 & & \\
\hline \multicolumn{9}{|l|}{ Within subjects } \\
\hline Time & 1 & 20.056 & 51.571 & $<0.001$ & 1 & 21012.5 & 515.527 & $<0.001$ \\
\hline Time $\times$ Speed & 2 & 13.181 & 33.894 & $<0.001$ & 2 & 6880.2 & 168.800 & $<0.001$ \\
\hline Time $\times$ Trial & 2 & 0.181 & 0.464 & 0.634 & 2 & 14.0 & 0.343 & 0.712 \\
\hline Time $x$ Speed $x$ Trial & 4 & 0.181 & 0.464 & 0.761 & 4 & 47.2 & 1.157 & 0.351 \\
\hline Error & 27 & 0.389 & & & 27 & 40.8 & & \\
\hline
\end{tabular}

b)

\begin{tabular}{|c|c|c|c|c|c|c|c|}
\hline \multicolumn{2}{|l|}{ Speed } & \multicolumn{2}{|c|}{5 knots } & \multicolumn{2}{|c|}{10 knots } & \multicolumn{2}{|c|}{18 knots } \\
\hline & Time & $0 \mathrm{~min}$ & $20 \mathrm{~min}$ & $0 \mathrm{~min}$ & $20 \mathrm{~min}$ & $0 \mathrm{~min}$ & $20 \mathrm{~min}$ \\
\hline 5 knots & $\begin{array}{r}0 \mathrm{~min} \\
20 \mathrm{~min}\end{array}$ & $\begin{array}{c}- \\
1.000\end{array}$ & - & & & & \\
\hline 10 knots & $\begin{array}{r}0 \mathrm{~min} \\
20 \mathrm{~min} \\
\end{array}$ & $\begin{array}{l}0.837 \\
0.397 \\
\end{array}$ & $\begin{array}{l}0.837 \\
0.397 \\
\end{array}$ & $\begin{array}{c}- \\
0.583 \\
\end{array}$ & - & & \\
\hline 18 knots & $\begin{array}{r}0 \text { min } \\
20 \text { min }\end{array}$ & $\begin{array}{c}1.000 \\
<0.001\end{array}$ & $\begin{array}{c}1.000 \\
<0.001\end{array}$ & $\begin{array}{l}0.671 \\
\mathbf{0 . 0 1 9}\end{array}$ & $\begin{array}{l}0.248 \\
0.105\end{array}$ & $\begin{array}{c}- \\
<0.001\end{array}$ & - \\
\hline
\end{tabular}

c)

\begin{tabular}{|c|c|c|c|c|c|c|c|}
\hline \multirow[t]{2}{*}{ Speed } & \multirow[b]{2}{*}{ Time } & \multicolumn{2}{|c|}{5 knots } & \multicolumn{2}{|c|}{10 knots } & \multicolumn{2}{|c|}{18 knots } \\
\hline & & $0 \mathrm{~min}$ & $20 \mathrm{~min}$ & $0 \mathrm{~min}$ & $20 \mathrm{~min}$ & $0 \mathrm{~min}$ & $20 \mathrm{~min}$ \\
\hline 5 knots & $\begin{array}{r}0 \mathrm{~min} \\
20 \mathrm{~min}\end{array}$ & $\begin{array}{c}- \\
0.021\end{array}$ & - & & & & \\
\hline 10 knots & $\begin{array}{r}0 \mathrm{~min} \\
20 \mathrm{~min}\end{array}$ & $\begin{array}{l}0.925 \\
\mathbf{0 . 0 0 9}\end{array}$ & $\begin{array}{l}0.053 \\
0.556\end{array}$ & $\begin{array}{c}- \\
<0.001\end{array}$ & - & & \\
\hline 18 knots & $\begin{array}{r}0 \mathrm{~min} \\
20 \mathrm{~min}\end{array}$ & $\begin{array}{c}0.855 \\
<0.001\end{array}$ & $\begin{array}{c}0.034 \\
<0.001\end{array}$ & $\begin{array}{c}1.000 \\
<0.001\end{array}$ & $\begin{array}{c}0.000 \\
<0.001\end{array}$ & $\begin{array}{c}- \\
<0.001\end{array}$ & - \\
\hline
\end{tabular}

\footnotetext{
${ }^{5}$ Trial was treated as a "random" factor in this analysis to test whether there was a significant within subject Trial $\mathrm{x}$ Speed interaction. A re-analysis with trial treated as a "fixed" factor did not change the significance of any of these results.
} 


\subsubsection{Effect of voyage speed on percentage cover}

The effect of speed on percentage cover varied significantly between treatment groups $\left(\mathrm{F}_{[2,27]}=26.87, \mathrm{P}<0.001\right.$; Table $\left.2 \mathrm{a}\right)$, with the overall cover on 18 knots treatment plates being $33 \%$ less than that recorded on 5 and 10 knots plates (Tukey's $P<0.001$ ). A significant Time $\mathrm{x}$ Speed interaction was observed $\left(\mathrm{F}_{[2,27]}=168.80, P<0.001\right.$; Table 2a) due to the greater post-voyage decrease in percentage cover on 18 knots treatment plates $(85 \%)$ relative to 5 and 10 knots treatments (11 and $24 \%$ respectively; Figure 4c). Overall, post-voyage assemblage cover was significantly reduced at all speed treatments, though differences were much more pronounced in 10 and 18 knots treatments (Tukey's $P<0.001$; Table 2c) compared to the 5 knots treatment (Tukey's $P$ $=0.021$; Table $2 \mathrm{c}$ ). While an increase in the average cover of organisms in 5, 10 and 18 knots treatment assemblages was observed after $7 \mathrm{~d}$ (12, 16 and $4 \%$ respectively), the increases were not statistically significant $\left(\mathrm{F}_{[2,6]}=2.583, P=0.155\right.$; Figure $\left.4 \mathrm{~d}\right)$.

\subsubsection{Morphology}

The average height of protrusion of biofouling organisms ranged from 1.0 (Spirorbid sp. A) to $33.7 \mathrm{~mm}$ (Pinauay marina; Table 1). Organisms with the lowest height-profiles were least affected by the faster voyage speeds (Table 1), although some erect but flexible species such as P. marina and C. dichotoma (average heights of 33.7 and 17.4 $\mathrm{mm}$ respectively) remained relatively unaffected. Species that were solitary had erect morphologies (both flexible and soft) such as C. eumyota and Sabellid sp. A were most often removed from assemblages travelling at 10 knots (average reductions of 53 and 23 $\%$ respectively) and 18 knots (100 and $97 \%$ respectively; Figure 4, 5b and c, 6b and c; Table 1).

Sabellid sp. A was the only species that underwent a marked reduction (13\%) in cover on plates at 5 knots (Table 1). The cover of colonial species with encrusting or soft characteristics, such as B. schlosseri and B. leachi was also reduced (46 and $18 \%$ respectively) at speeds of 18 knots (Figure 5c, 6c; Table 1). In contrast, taxa with solitary and encrusting, colonial and encrusting (both hard and soft), or colonial, erect and flexible morphologies were not markedly affected by any of the three voyage speeds (Figure 5, 6; Table 1). Overall, voyage speed resulted in greater changes in percentage cover amongst morphological characteristics than others: solitary > colonial; 
erect $>$ encrusting; soft $>$ hard; soft $>$ flexible with no significant difference between flexible and hard (Table 3; Figure 7). Of note, colonial morphologies recovered within 7 days with percentage cover on average increasing by $5.5 \%$ relative to pre-voyage percentage covers. Conversely, percentage covers of solitary species declined by an average of $1.1 \%$.

Table 3 Summary of two-way analysis of variance of the effects of voyage speed on percentage cover relative to species morphological characteristics. Significant $P$ values are in bold.

\begin{tabular}{l|rrrr}
\hline \multirow{2}{*}{ Source } & \multicolumn{4}{|c}{ Change in percentage cover } \\
\cline { 2 - 5 } & df & MS & \multicolumn{1}{c}{$\mathrm{F}$} & \multicolumn{1}{c}{$P$} \\
\hline \hline Solitary vs Colonial & & & & \\
Speed treatment & 3 & 0.029 & 94.484 & $<0.001$ \\
Morphology & 1 & 0.007 & 23.878 & $<0.001$ \\
Speed x Morphology & 3 & 0.001 & 2.803 & $\mathbf{0 . 0 4 5}$ \\
$\quad$ Error & 85 & 0.000 & & \\
\hline Erect vs Encrusting & & & & \\
Speed treatment & 3 & 0.029 & 134.975 & $<0.001$ \\
Morphology & 1 & 0.011 & 52.069 & $<0.001$ \\
Speed x Morphology & 3 & 0.002 & 7.586 & $<0.001$ \\
Error & 84 & 0.000 & & \\
\hline Soft vs Flexible & & & & \\
Speed treatment & 3 & 0.018 & 54.928 & $<0.001$ \\
Morphology & 1 & 0.010 & 31.066 & $<0.001$ \\
Speed x Morphology & 3 & 0.004 & 11.086 & $<0.001$ \\
Error & 83 & 0.000 & & \\
\hline Soft vs Hard & & & & \\
Speed treatment & 3 & 0.019 & 69.689 & 0.000 \\
Morphology & 1 & 0.014 & 51.187 & $<0.001$ \\
Speed x Morphology & 3 & 0.002 & 7.588 & $<0.001$ \\
Error & 72 & 0.000 & & \\
\hline Hard vs Flexible & & & & \\
Speed treatment & 3 & 0.007 & 11.298 & $<0.001$ \\
Morphology & 1 & 0.001 & 1.046 & 0.310 \\
Speed x Morphology & 3 & 0.001 & 1.649 & 0.186 \\
Error & 67 & 0.001 & & \\
\hline
\end{tabular}



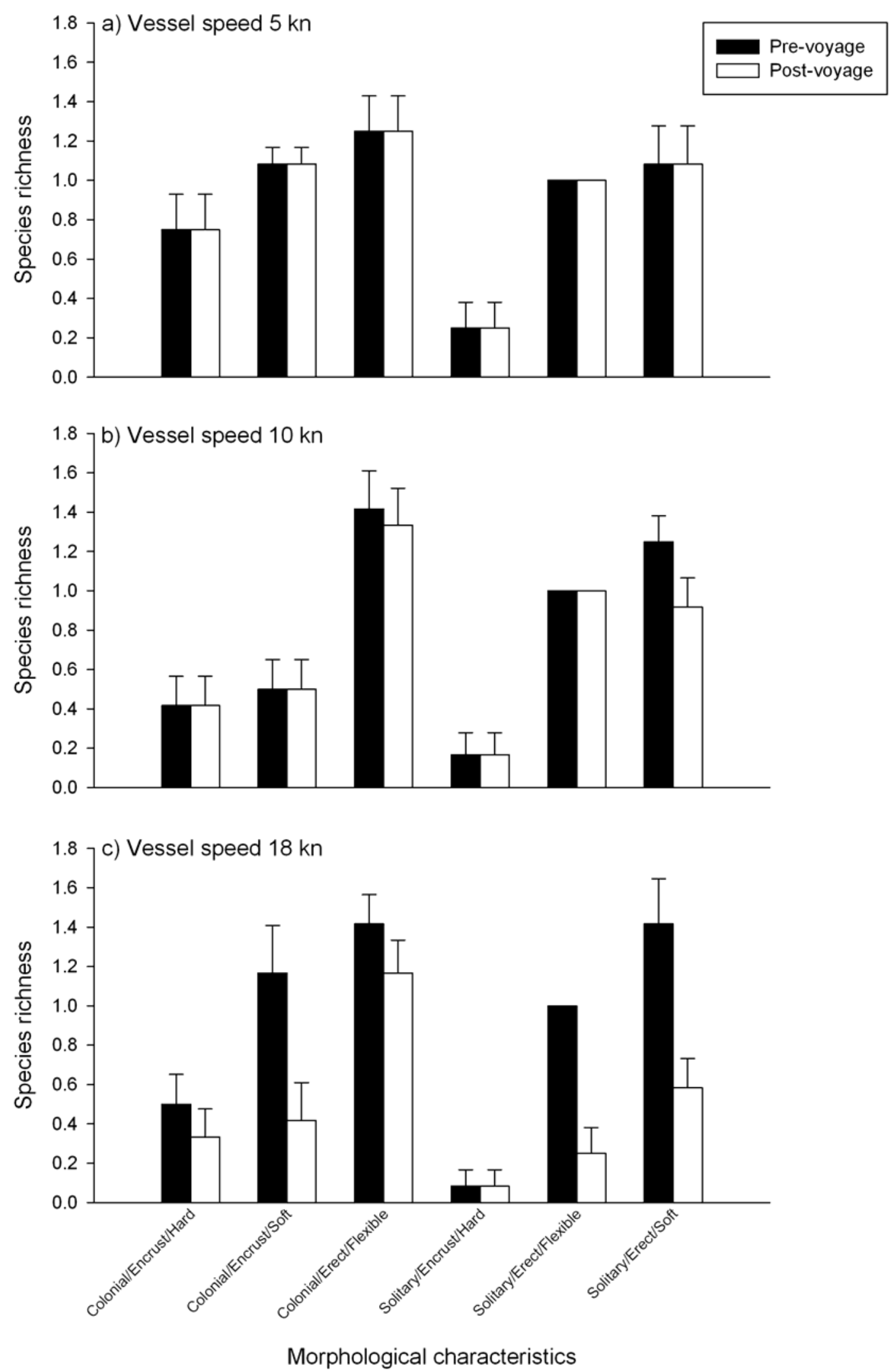

Figure 5 Pre- and post-voyage species richness recorded for biofouling organisms, classified according to various morphological characteristics, subjected to speeds of a) 5 , b) 10 and c) 18 knots $(n=12)$. Values represent the average $( \pm 1 \mathrm{SE})$. 

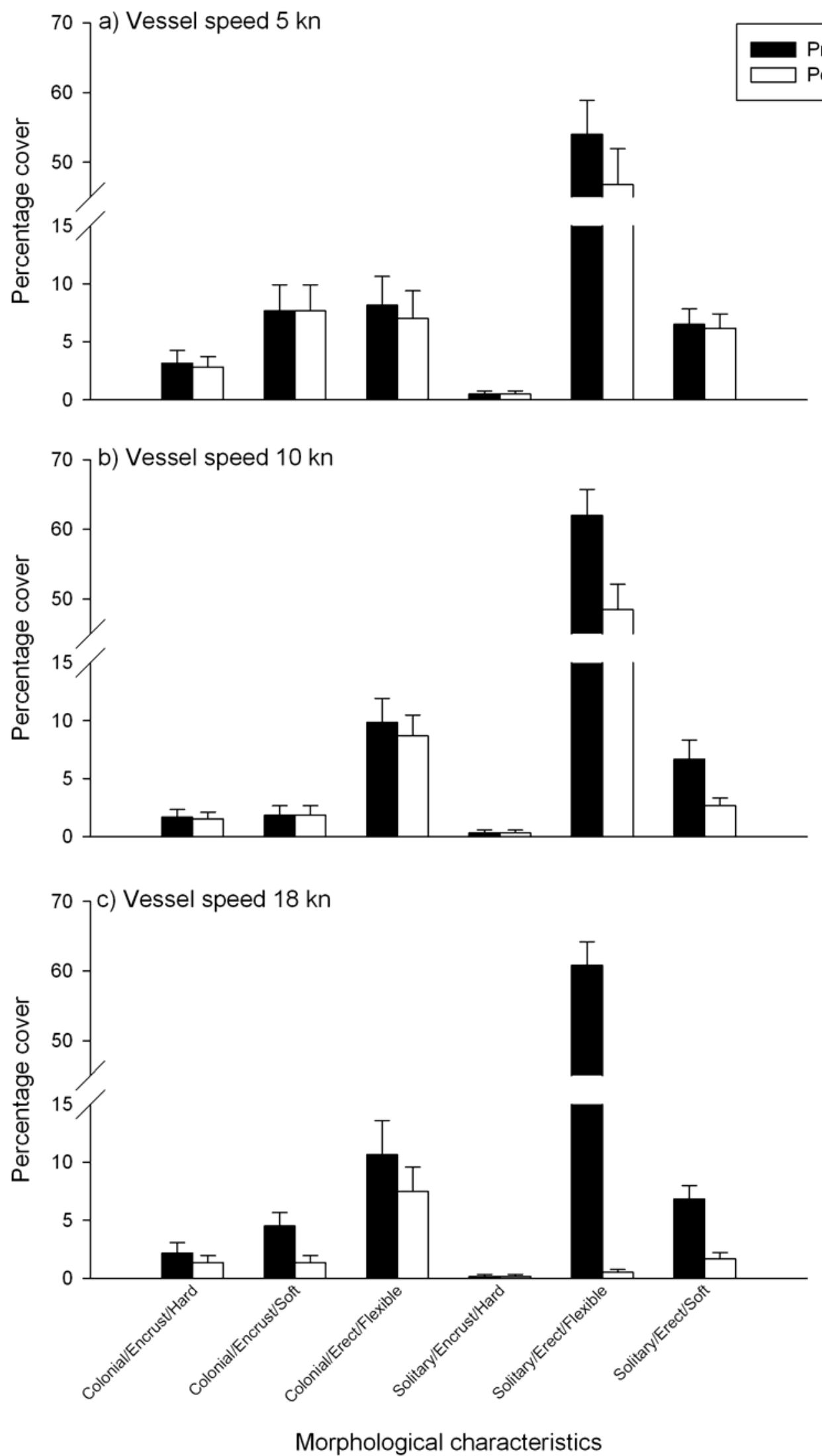

Figure 6 Pre- and post-voyage species percentage cover recorded for biofouling organisms, classified according to various morphological characteristics, subjected to speeds of a) 5, b) 10 and c) 18 knots $(n=12)$. Values represent the average ( $\pm 1 \mathrm{SE})$. 


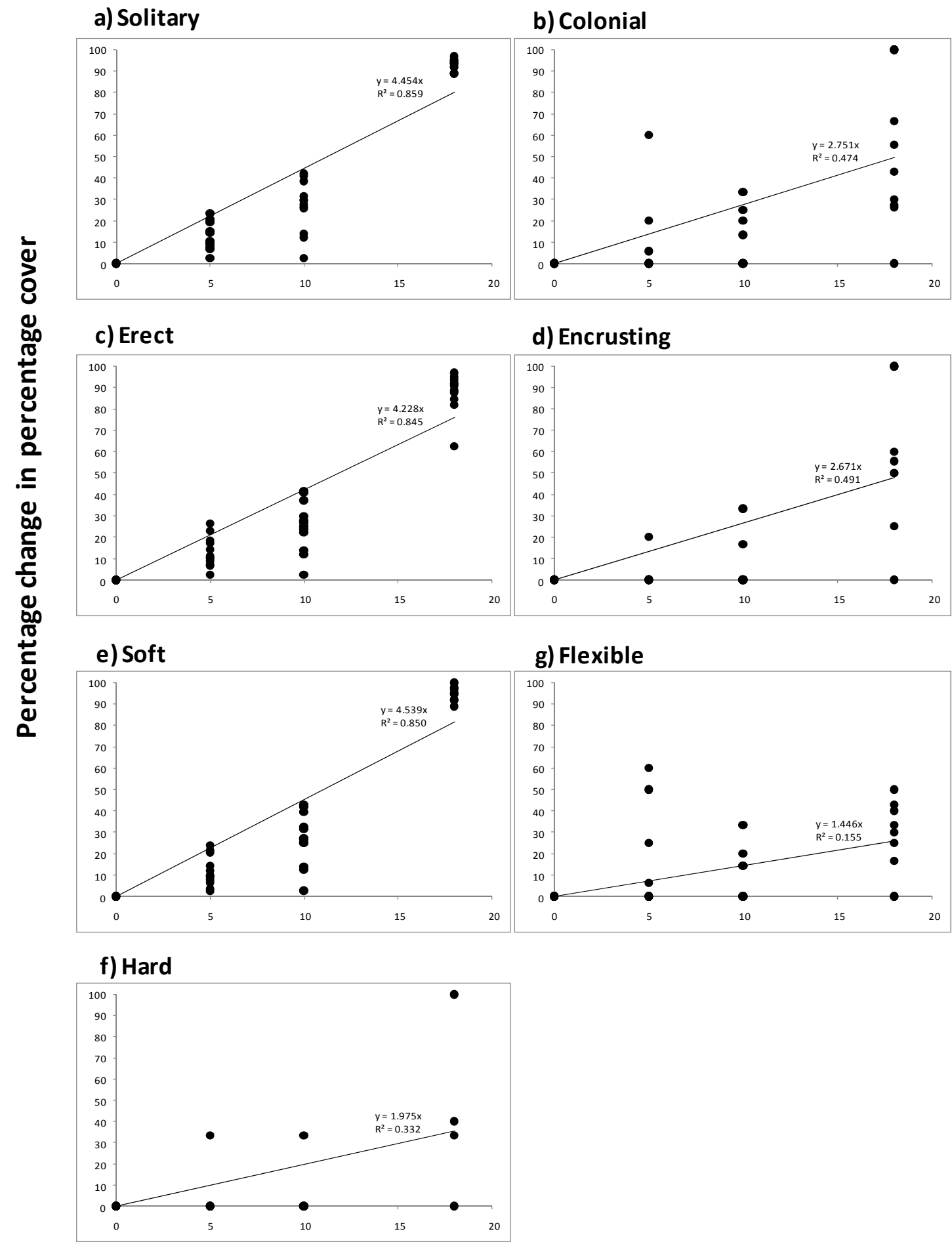

\section{Speed (knots)}

Figure 7 Effect of voyage speed on the percentage cover of species with different morphological characteristics. Data are the percentage change in percentage cover (i.e. difference between pre- and post-voyage percentage cover divided by the pre-voyage percentage cover, for each morphological characteristic, for each speed. 0 knots refers to data controls. Regression lines are indicative only. 


\subsection{DISCUSSION}

\subsubsection{Hydrodynamic flow, vessel speed and the boundary layer}

Species richness was reduced at the highest speeds (18 knots) and the percentage cover of biofouling species decreased with increasing speed, but most notably at 18 and 10 knots. All species that survived the voyage period showed few signs of morbidity and delayed mortality. Morphological characteristics explained many of the observed patterns, with greater loss of solitary species of soft body form and erect stature (i.e. protruding $6-12 \mathrm{~mm}$ ). Survival rates were greater for colonial species than were either encrusting or flexible.

Fluid dynamics provides insight to the observed differences in mortality associated with speed. As water flows over a solid surface, water in direct contact with the substratum experiences friction with the surface and does not move relative to it (known as the noslip condition). Water layers above the no-slip condition are also hindered creating a boundary layer with a different flow regime, that is to a point where water flow equals the mainstream flow (Schlichting 1979; Jumars and Nowell 1984). If an organism is sufficiently flat (e.g. encrusting bryozoans) or small (e.g. newly settled larvae), such a boundary layer may act as a refuge against the otherwise strong mechanical forces of the mainstream flow (Koehl 1984; Denny 1994). Numerous physical factors can affect the level of protection afforded by such boundary layers, including the velocity of the water flow (i.e. the faster the flow, the thinner the boundary layer), the distance of the organism from the leading edge of the substratum, and the complexity of the substratum (e.g. crevices and other organisms may offer protection; Koehl 1982, 1984).

Three types of hydrodynamic forces act upon an attached biofouling organism: drag, lift and acceleration (Denny 1994). Furthermore, the magnitude with which hydrodynamic forces act upon an organim is influenced by their shape, size and texture (Denny et al. 1985; Gerard 1987; Johnson and Koehl 1994). For example, it is well known that many soft-bodied organisms have morphological plasticity and will adopt a morphology that increases flexibility and reduces drag in high flow environments (e.g. Fowler-Walker et al. 2006). Such effects on survival and morphology occur in response to the effect of flow on drag; the magnitude of the drag is proportional to the velocity of the flow (i.e. vessel speed, and the length of the object), and gets larger as organisms increase in size 
or encounter faster flows. It is therefore intuitive and not surprising to have observed lower abundance and cover of biofouling organisms as target vessel voyage speeds increased.

Flume tank observations of the hydrodynamic flow surrounding the keel indicated that settlement plates experienced a stable laminar boundary layer of approximately $8 \mathrm{~mm}$ thick at 3 knots (the maximum speed achievable under flume chamber conditions). During field trials, greater speeds, real-world hydrodynamics, and the disruptive influence of biofouling organisms on the settlement plates were all likely to have altered these stable laminar flows into a thinner, unstable turbulent boundary layer (Smits 1982; Schultz et al. 2003). We predict that the actual boundary layer and hydrodynamic forces acting on the experimental keel and settlement plate surface are likely to resemble those found toward the bow of a vessel where the strength of hydrodynamic forces are greater than at other locations on the hull (e.g. stern or in niche areas; Schultz and Swain 2000; Zvyagintsev and Moshchenko 2002; Schultz et al. 2003; Piola unpub data). On this basis, the results of this study could be considered a worse-case scenario for the survivorship and/or translocation of biofouling organisms on vessel hulls (i.e. higher levels of biofouling are expected to survive on an actual vessel). Although, our study did not subject organisms to accelerative hydrodynamic forces often experienced by biofouling organisms on vessels (i.e. when the vessel "punches or slams" into waves) which is known to have a significant effect on the persistence of wave-swept organisms (Denny et al. 1985; Denny 1995).

\subsubsection{Morphology, vessel speed and survivorship}

The present study found that morphology was a strong determinant for the types of organisms that survived during the fast speed trials. Organisms most resilient to vessel speeds included those with low-profile encrusting forms, hard calcareous protection, and/or flexible morphologies. For example, the soft-bodied encrusting colonial ascidians B. leachi, B. schlosseri and D. listerianum probably survived the various voyage speeds because they protruded less than an average of $2.2 \mathrm{~mm}$ from the settlement plate surface. That is, they were likely to be in the low-energy region of the boundary layer. Such soft colonial organisms may be susceptible to "peeling away" from the substratum if moving water is able to get underneath a loose leading edge, however this would depend upon the strength of the colony tissues, their adhesion to the 
substratum, and the surface texture of the settlement substratum (Edlund and Koehl 1998). Hard encrusting taxa such as M. membranacea, the tubiculous polychaetes Pomatocerus sp., and Spirorbid sp. A, have a calcareous body structure that afforded protection and rigidity against hydrodynamic forces. In contrast, the flexible but erect colonies of the hydroid $P$. marina and the bryozoan $C$. dichotoma were largely unaffected by voyage speed despite having stationary standing heights of between $\sim 17$ and $34 \mathrm{~mm}$ respectively. The flexibility of their colonial branching structure probably resulted in a state of anisotropy (i.e. conforming to the direction of hydrodynamic flow) when the vessel was in motion, reducing drag and allowing the organisms to reside (at least partially) in the keel's boundary layer (Koehl 1984; Denny et al. 1985; Denny et al. 1998).

The taxa most vulnerable to increases in vessel speed were erect soft-bodied organisms such as the solitary ascidian C. eumyota and the erect tubeworm Sabellid sp. A. These species' morphologies lacked the low-profile flow avoidance or the flexibility to ensure anisotropy, and also lacked the structural strength to withstand the forces of motion. However, another solitary ascidian that was also classified as solitary, erect and soft, Asterocarpa humilis, remained largely unaffected by treatment, even at speeds of 18 knots. The test (outer body covering) of other ascidians in the genera Asterocarpa (e.g. A. cerea) are described as tough but flexible (Millar 1982). This species may be sufficiently flexible to deform and achieve anisotropy when the vessel was in motion, resulting in improved survival compared to other less flexible solitary ascidians.

The adhesive strength of the organism is an important factor determining the en route survivorship of biofouling organisms. For example, the adhesive strength of barnacles, oysters, encrusting bryozoa and serpulids is sufficiently great to allow attachment and growth to all areas of a vessel, including high-velocity areas such as bows and propeller shafts and blades (see Lewis 2002). This is likely to be the case because the natural habitat of many common biofouling organisms is the intertidal zone of rocky shores where they are often subjected to strong wave action and at times must endure severe accelerative hydrodynamic forces (Koehl 1984; Denny et al. 1985; Denny 1995). Variation in wave-swept shore environments has been a potent selective force on the evolution of body shapes and biomechanical designs that are serendipitously preadapted to conditions for biofouling. 
Vessel type and patterns of use have a strong influence on the morphotypes and survival success of biofouling organisms present. For example, organisms that are subject to frequent and strong hydrodynamic forces are likely to alter the magnitude of those forces on themselves by a process of "least resistant" growth (ontogeny) throughout their life (e.g. Wainwright et al. 1976; Hunter 1988). In contrast, biofouling organisms on a vessel that remains stationary for prolonged periods are likely to exhibit isotropical ontogeny (i.e. relatively uniform in all directions). In this situation, survival will be higher for organisms that are capable of conforming to the direction of flow during movement, or are able to quickly change the level of drag they experience by changing their morphology (e.g. via muscle contraction, deformation or rapid growth) in response to their water-flow habitats (e.g. Koehl 1977). Prolonged vessel residency periods may also afford organisms the time to develop and mature sufficiently so that their adhesive strength and resilience to detachment is improved.

Several of the species recorded in this study that are also well known NIMS in various regions of the world (e.g. M. membranacea, B. leachi, B. schlosseri and D. listerianum) exhibited growth morphologies that were conducive to withstanding voyages at speed (colonial and encrusting), and as such remained largely unaffected by vessel voyage speeds of up to 18 knots. Morphology may indeed be one of the primary selective mechanisms for determining successful NIMS via the vector of biofouling, with colonial, encrusting, hard and/or flexible organisms better able to withstand the strong physical selective pressures (i.e. hydrodynamic forces) experienced during vessel journeys. Furthermore, colonial morphotypes like the species mentioned have a further advantage over solitary morphotypes given their propensity for asexual reproduction from as little as a single surviving zooid. Hence, such a trait may have contributed to the successful spread of colonial ascidians around the world such as Didemnum vexillum (see Lambert 2009; Stefaniak et al. 2009).

While it is clear from this study that vessel speed can be important influence on translocation success for biofouling NIMS, it is important to acknowledge that its interaction with other factors is critical. For example, the type of anti-fouling coating used on a vessel will affect both the initial recruitment onto the hull as well as the survivorship of biofouling organisms. Anti-fouling coatings containing toxic biocides are designed to prevent the initial colonisation of biofouling taxa, whereas fouling 
release coatings (e.g. silicon coatings) allow organisms to colonise and accumulate, but rely on a voyage speed of more than 20 knots to remove growth (Brady 2001; Candries et al. 2001). Fouling release coatings in particular have an extraordinarily high potential to facilitate the introduction of NIMS if used incorrectly. Watermann et al. (1999) found that removal of up to $90 \%$ of biofouling on silicone coatings was directly dependant on the speed that the vessel was travelling. This study highlights the important need for suitable anti-fouling strategies on all vessels, given that once biofouling organisms colonise and establish on a vessel hull, voyage speed alone will not eliminate biofouling risk.

\subsubsection{Inoculum pressure, vessel speed and invasion success}

Inoculum pressure (including both propagule and colonisation pressure) is increasingly recognised as one of the primary factors likely to influence the successful translocation of NIMS over wide geographical ranges (Carlton and Geller 1993; Carlton 1996; Ruiz et al. 2000; Kolar and Lodge 2001). Invasion success is generally thought to be positively associated with the quality, quantity, diversity and frequency of inoculum releases (e.g. larvae, spores, mature adults) in a recipient environment (Ruiz and Carlton 2003; Lockwood et al. 2009). At present, little is known regarding which combination of vessels, pathways and/or biofouling profiles (e.g. biomass, species richness, percentage cover) pose the greatest risk for NIMS translocations. For example, the greatest inoculum pressure could lie with fast-moving merchant vessels, which may only accumulate relatively small aggregations of biofouling confined to niche areas of their hulls, but have the capacity to visit a large number of ports and harbours worldwide over relatively short time periods and in aggregate represent a significant cumulative pressure (e.g. James and Hayden 2000; Coutts and Taylor 2004; Australian Shipowners Association 2006; Coutts and Dodgshun 2007; Drake and Lodge 2007). Alternatively, greater risks could lie with slow-moving vessels (e.g. yachts, barges, oil rigs, decommissioned vessels) that are less numerous and travel less frequently, but are renowned for accumulating high levels of biofouling over a higher proportion of subsurface structures and spend greater time in both donor and recipient ports (e.g. Foster and Willan 1979; Hay and Dodgshun 1997; DeFelice 1999; Apte et al. 2000; Coutts 2002; Floerl 2002; Davidson et al. 2008). 
While this study suggests that faster moving (10-18 knots) vessels are capable of translocating biofouling species, it is slower moving vessels that travel $\leq 5$ knots that translocate both larger numbers of organisms as well as a greater number of species (i.e. propagule and colonisation pressure), including soft-bodied organisms that may be less resilient to transfer at higher vessel speeds. This finding is supported by numerous real world observations that show slow-moving vessels are able to transport NIMS over large distances for extended periods of time (e.g. Foster and Willan 1979; Coutts 2002; Apte et al. 2000; Davidson et al. 2008). Theoretically therefore, if survivorship is greater on slow-moving vessels, which in turn increases inoculum pressure in ports and harbours, slow-moving vessels will pose the greatest risks on a vessel by vessel scale. While the presence of biofouling organisms after the voyage trials does not necessarily guarantee survivorship, reproduction, and establishment in a new region, a greater diversity and percent cover of organisms means a greater potential for successful translocation to occur (i.e. higher risk).

\subsection{REFERENCES}

Apte, S., Holland, B. S., Godwin, L. S., Gardner, J. P. A., 2000. Jumping ship: a stepping stone event mediating transfer of non-indigenous species via a potentially unsuitable environment. Biological Invasions 2: 75-79

Australian Shipowners Association., 2006. Assessment of introduced marine pest risks associated with niche areas in commercial shipping, June 2006. 24 p.

Brady, R. F., 2001. A fracture mechanical analysis of fouling release from nontoxic antifouling coatings. Progress in Organic Coatings 43: 188-192.

Brock, R., Bailey-Brock, J. H., Goody, J., 1999. A case study of efficacy of freshwater immersion in controlling introduction of alien marine fouling communities: The USS Missouri. Pacific Science 53: 223-231.

Candries, M., Anderson, C. D., Atlar, M., 2001. Foul release systems and drag: observations on how the coatings work. Journal of Protective Coatings \& Linings 18: $38-43$. 
Carlton, J. T., 1996. Biological invasions and cryptogenic species. Ecology 77: 16531655.

Carlton, J. T., Geller, J. B., 1993. Ecological roulette: The global transport of nonindigenous marine organisms. Science 261: 78-82.

Carlton, J. T., Hodder, J., 1995. Biogeography and dispersal of coastal marine organisms: experimental studies on a replica of a 16th-century sailing vessel. Marine Biology 121: 721-730.

Carlton, J. T., Reid, D. M., van Leeuwen, H., 1995. Shipping study: the role of shipping in the introduction of non-indigenous aquatic organisms to the coastal waters of the United States (other than the Great Lakes) and an analysis of control options. U.S. Coast Guard, Connecticut, Department of Transportation, Washington, D.C.: $1-213$.

Carlton, J. T., Ruiz, G. M., Grosholz, E. D., Hines, A. H., 1997. Global invasions of marine and estuarine habitats by non-indigenous species: mechanisms, extent and consequences. American Zoology 376: 621-632.

Clarke, K. R., 1993. Non-parametric multivariate analyses of changes in community structure. Australian Journal of Ecology 18: 117-143.

Clarke, K. R., Warwick, R. M., 2001. Change in marine communities: an approach to statistical analysis and interpretation. $2^{\text {nd }}$ Edition. PRIMER-E, Plymouth, United Kingdom, 172 pp.

Coutts, A. D. M., 2002. A biosecurity investigation of a barge in the Marlborough Sounds. Cawthron Report No. 744.59 pp.

Coutts, A. D. M., Taylor, M. D., 2004. A preliminary investigation of biosecurity risks associated with biofouling on merchant vessels in New Zealand. New Zealand Journal of Marine and Freshwater Research 38: 215-229.

Coutts, A. D. M., Dodgshun, T. J., 2007. The nature and extent of organisms in vessel sea-chests: a protected mechanism for marine bioinvasions. Marine Pollution Bulletin 54: 876-886. 
Dafforn, K. A., Glasby, T. M., Johnston, E. L., 2008. Differential effects of tributyltin and copper antifoulants on recruitment of non-indigenous species. Biofouling 24: 23-33.

Davidson, I. C., McCann, L. D., Fofonoff, P. W., Sytsma, M. D., Ruiz, G. M., 2008. The potential for hull-mediated species transfers by obsolete ships on their final voyages. Diversity and Distributions 14: 518-529.

DeFelice, R. C., 1999. Fouling marine invertebrates on the floating drydock USS Machinist in Pearl Harbour to its move to Apra Harbour, Guam. Hawai'i Biological Survey, Bernice P. Bishop Museum Honolulu, Hawaii. Contribution No. 1999-013 to the Hawaii Biological Survey.

Denny, M. W., 1985. Wave forces on intertidal organisms: a case study. Limnology and Oceanography 30: 1171-1187.

Denny, M. W., 1994. Roles of hydrodynamics in the study of life on wave-swept shores. In: Wainwright PC, Reilly SM, (Eds), Ecomorphology: Integrative Organismal Biology. University of Chicago Press, pp. 169-204.

Denny, M. W., 1995. Predicting physical disturbance: mechanistic approaches to the study of survivorship on wave-swept shores. Ecological Monographs 65: 371-418.

Denny, M. W., Daniel, T., Koehl, M. A. R., 1985. Mechanical limits to size in waveswept organisms. Ecological Monographs 55: 69-102.

Denny, M. W., Gaylord, B. P., Helmuth, B., Daniel, T. L., 1998. The menace of momentum: Dynamic forces on flexible organisms. Limnology and Oceanography 43: 955-968.

Drake, J. M., Lodge, D. M., 2007. Hull fouling is a risk factor for intercontinental species exchange in aquatic ecosystems. Aquatic Invasions 2: 121-131.

Drummond, S. P., Connell, S. D., 2005. Quantifying percentage cover on subtidal organisms on rocky coasts: a comparison of the costs and benefits of standard methods. Marine and Freshwater Research 56: 865-876. 
Edlund, A. F., Koehl, M. A. R., 1998. Adhesion and reattachment of compound ascidians to various substrata: weak glue can prevent tissue damage. Journal of Experimental Biology 201: 2397-2402.

Elsdon, T. S., Wells, B. K., Campana, S. E., Gillanders, B. M., Jones, C. M., Limburg, K. E., Secor, D. H., Thorrold, S. R., Walther, B. D., 2008. Otolith chemistry to describe movements and life-history parameters of fishes: Hypotheses, assumptions, limitations and inferences. Oceanography and Marine Biology: An Annual Review 46: 297-330

Floerl, O., 2002. Intracoastal spread of fouling organisms by recreational vessels. $\mathrm{PhD}$ thesis. James Cook University, Townsville. p. 283.

Fofonoff, P. W., Ruiz, G. M., Stevens, B., Carlton, J. T., 2003. In ships or on ships? Mechanisms of transfer and invasion for nonnative species to the coasts of North America. In: Ruiz, G. M., Carlton, J. T., (Eds), Invasive species: vectors and management strategies, Island Press, pp. 152-183.

Foster, B. A., Willan, R. C., 1979. Foreign barnacles transported to New Zealand on an oil platform. New Zealand Journal Marine Freshwater Research 13: 143-149.

Fowler-Walker, M. J., Wernberg, T., Connell, S. D., 2006. Differences in kelp morphology between wave sheltered and exposed localities: morphologically plastic or fixed traits? Marine Biology 148: 755-767.

Gerard, V. A., 1987. Hydrodynamic streamlining of Laminaria saccharina Lamour in response to mechanical stress. Journal of Experimental Marine Biology and Ecology 107: 237-244.

Hay, C. H., Dodgshun, T. J., 1997. Ecosystem transplant? The case of the Yefim Gorbenko. Seafood New Zealand, May 1997, 13-14.

Hewitt, C. L., Campbell, M. L., Thresher, R. E., Martin, R. B., Boyd, S., Cohen, B. F., Currie, D. R., Gomon, M. F., Keogh, M. J., Lewis, J. A., Lockett, M. M., Mays, N., McArthur, M. A., O’Hara, T. D., Poore, G. C. B., Ross, D. J., Storey, M. J., Watson, J. E., Wilson, R. S., 2004. Introduced and cryptogenic species in Port Phillip Bay, Victoria, Australia. Marine Biology 144(1): 183-202. 
Hewitt, C. L., Campbell, M. L., Schaffelke, B., 2007. Introductions of marine macroalgae - accidental transfer pathways and mechanisms. Botanica Marina 50:326-337.

Hewitt, C. L., Campbell, M. L., 2008. Assessment of relative contribution of vectors to the introduction and translocation of marine invasive species. Report for the Department of Agriculture, Fisheries and Forestry. National Centre for Marine Conservation \& Resource Sustainability Australian Maritime College, an institute of the University of Tasmania. p. 45.

Hewitt, C. L., Gollasch, S., Minchin, D., 2009. Chapter 6 - Ballast water, sediments and hull fouling. In: Rilov, G., Crooks, J., (Eds), Biological Invasions in Marine Ecosystems: Ecology, Conservation and Management Perspectives. Springer, Heidelberg, Germany, pp 117-129.

Hunter, T., 1988. Mechanical design of hydroids: flexibility, flow forces, and feeding in Obelia longissima. $\mathrm{PhD}$ thesis, University of California, Berkeley.

James, P., Hayden, B., 2000. The potential for the introduction of exotic species by vessel hull fouling: A preliminary study. NIWA Technical Report No. 16.

Johnson, A. J., Koehl, M. A. R., 1994. Maintenance of dynamic strain similarity and environmental stress factor in different flow habitats: Thallus allometry and material properties of a giant kelp. Journal of Experimental Biology 195: 381-410.

Jumars, P. A., Nowell, A. R. M., 1984. Fluid and sediment dynamic effects on marine benthic community structure. American Zoologist 24: 45-55.

Koehl, M. A. R., 1977. Mechanical design of cantilever-like sessile organisms: sea anenomes. Journal of Experimental Biology 69: 87-105.

Koehl, M. A. R., 1982. The interaction of moving water and sessile organisms. Scientific American 247: 124-132.

Koehl, M. A. R., 1984. How do benthic organisms withstand moving water? American Zoologist 24: 57-70. 
Kolar, C. S., Lodge, D. M., 2001. Progress in invasion biology: predicting invasions. Trends in Ecology and Evolution 16: 199-204.

Lambert, G., 2009. Adventures of a sea squirt sleuth: unraveling the identity of Didemnum vexillum, a global ascidian invader. Aquatic Invasions 4: 5-28.

Lewis, J. A., 2002. Hull fouling as a vector for the translocation of marine organisms. Phase I Study: Hull fouling research. Department of Agriculture, Fisheries and Forestry Australia. Strategic Ballast Water Research and Development Program, Canberra, Report No. 1. 142 pp.

Lewis, J., Coutts, A. D. M., 2010. Biofouling invasions. In: Durr, S., Thomason, J. (Eds). Biofouling. Blackwell Publishing Ltd, Oxford. 348-365 pp.

Lockwood, J. L., Cassey, P., Blackburn, T. M., 2009. The more you introduce the more you get: the role of colonization pressure and propagule pressure in invasion ecology. Diversity and Distributions 15: 904-910.

Millar, R. H., 1982. The Marine Fauna of New Zealand: Ascidiacea. New Zealand Oceanographic Institute Memoir 85: 117p

Piola, R. F., Johnston, E. L., 2006. Differential resistance to extended copper exposure in four introduced bryozoans. Marine Ecology and Progress Series 311: 103-114.

Piola, R. F., Johnston, E. L., 2008. The potential for translocation of marine species via small-scale disruptions to antifouling surfaces. Biofouling 24: 145-155.

Ruiz, G. M., Carlton, J. T., Grosholz, E. D., Hines, A. H., 1997. Global invasions of marine and estuarine environments by non-indigenous species: mechanisms, extent and consequences. American Zoologist 37: 621-632.

Ruiz, G. M., Fofonoff, P. W., Carlton, J. T., Wonhom, M. J., Hines, A. H., 2000. Invasion of coastal marine communities in North America: apparent patterns, processes and biases. Annual Review of Ecology and Systematics 31: 481-531.

Ruiz, G. M., Carlton, J. T., 2003. Invasion vectors: a conceptual framework for management. In: Ruiz GM, Carlton JT, (Eds), Invasive Species: Vectors and Management Strategies. Island Press, Washington. Pp. 459-504. 
Schlichting, H., 1979. Boundary-Layer Theory, $7^{\text {th }}$ Edition. McGraw-Hill, New York.

Schultz, M. P., Swain, G. W., 2000. The influence of biofilms on skin friction drag. Biofouling 15: 129-139.

Schultz, M. P., Finlay, J. A., Callow, M. E., Callow, J. A., 2003. Three models to relate detachment of low form fouling at laboratory and ship scale. Biofouling 19: 17-26.

Schormann, J., Carlton, J. T., Dochoda, M. R., 1990. The ship as a vector in biotic invasions. Marine Technology and the Environment 19: 147-152.

Smits, A. J., 1982. Turbulence stimulation and the initial boundary-layer development on two ship forms. Journal of Ship Research 26: 166-175.

Stefaniak, L., Lambert, G., Gittenberger, A., Zhang, H., Lin, S., Whitlatch, B., 2009. Genetic conspecificity of the worldwide populations of Didemnum vexillum Kott, 2002. Aquatic Invasions 4: 29-44.

Wainwright, S.A., Biggs, W. D., Currey, J. D., Gosline, J. M., 1976. Mechanical design in organisms. Halstead Press, New York, 423 pp.

Watermann, B., 1999. Alternative antifouling techniques: present and future. Report. Limno Mar, Hamburg, Germany. 6 pp.

Zvyagintsev, A.Yu., Moshchenko, A. V. 2002. The role of small-scale turbulence in the distribution of macrofouling organisms on the hulls of ocean-going ships. Russian Journal of Marine Biology 28:405-410. 


\section{Chapter 3 - Which hull locations are more likely to contain non-indigenous marine species?}

\section{PREFACE}

This chapter builds on my Masters research which focused on the nature and extent and survivorship of biofouling organism in uniform areas of vessels. Furthermore, the previous chapter suggests that vessel speed is likely to influence the accumulation and persistence of biofouling, particularly amongst uniform areas of vessels. The present chapter investigates the nature and extent of biofouling in niche areas where biofouling accumulation, persistence and presence of non-indigenous marine species maybe greater. This work has been published in a refereed journal and is presented below in identical form. The citation for the original publication is:

Coutts, A. D. M., Taylor, M. D., 2004. A preliminary investigation of biosecurity risks associated with biofouling on merchant vessels in New Zealand. New Zealand Journal of Marine and Freshwater Research 38: 215-229.

I was responsible for the collection, processing and writing of most of this paper. My co-author and thesis supervisor Michael Taylor had input into a number of facets of the paper, particularly the data analyses, and structure of the manuscript. Furthermore, peer reviewer comments contributed significantly to the final quality and direction of the paper.

\footnotetext{
ABSTRACT

Biofouling on international vessels is an important mechanism for the inadvertent transfer of non-indigenous marine species around the globe. This chapter describes the nature and extent of biofouling on 30 merchant vessels (ranging from 1,400 to 32,000 gross registered tonnes) based on analysis of hull inspection video footage collected by two New Zealand commercial diving companies. A new method for measuring
} 
biofouling communities is applied, which aims to incorporate the potential for various hull locations to house non-indigenous marine species. Our analysis revealed that outof-service vessels and vessels plying trans-Tasman routes possessed greater levels of biofouling than more active vessels. Dry-docking support strips and sea-chest gratings generally had the highest levels of biofouling and may pose relatively high biosecurity risks. Any future biosecurity surveillance should target these hull locations for nonindigenous marine species.

\subsection{INTRODUCTION}

The frequency at which non-indigenous marine species (NIMS) are being spread around the world appears to be dramatically increasing (Cohen and Carlton 1995; Ruiz et al. 1997; Hewitt et al. 1999; Ruiz et al. 2000). Vessels are considered exacerbators for the inadvertent transfer of NIMS around the world (Carlton 1987; Nehring 2001; Minchin and Gollasch 2002). Shipping can disperse NIMS via a variety of mechanisms including ballast and bilge water discharges, vessel biofouling (including de-fouling activities), sea-chests, sea-sieves, anchors, chain lockers, and piping (Schormann et al. 1990; Carlton et al. 1995). However, vessel biofouling is beginning to be acknowledged, particularly in the Southern Hemisphere, as one of the most important mechanisms for the dispersal of NIMS (Cranfield et al. 1998; Thresher et al. 1999; Gollasch 2002; Hewitt 2002).

Although New Zealand does not presently have any regulations mandating the hygiene of vessel hulls, it does propose to develop a management regime for vessel biofouling of visiting international vessels. In 2002, there were c. 3,421 international vessel visits to New Zealand: 2,581 merchant vessels; 794 pleasure craft; 34 passenger ships; and 12 barges/tugs (Biosecurity Council 2003). To successfully manage the biosecurity risks associated with vessel biofouling on visiting international vessels, it is imperative to know which vessels and pathways pose the greatest biosecurity risks. However, it is not currently known which vessels, pathways, or level of biofouling (e.g. species richness, diversity, biomass) constitute the greatest biosecurity risk.

Simplistically, the greatest biosecurity risk could expect to be those visiting international vessels that possess the greatest levels of biofouling. For instance, slowmoving vessels (i.e. recreational, fishing, barges, oil exploration rigs, floating dry- 
docks, etc) typically spend prolonged periods of time stationary, thus are renowned for accumulating extensive biofouling over their entire hull, including NIMS that are capable of surviving slow voyages to new locations (e.g. Foster and Willan 1979; Hay 1990; Hay and Dodgshun 1997; DeFelice 1999; Field 1999; Apte et al. 2000; Godwin and Eldredge 2001; Coutts 2002). However, their frequency of visits to foreign locations is typically fewer than the pattern of foreign voyages for faster-moving merchant vessels.

The biosecurity risks of frequently visiting merchant vessels may also be relatively high as high levels of biofouling, including NIMS, have been observed within niche areas of the hull (e.g. around the bilge keels, propellers, and rudders) as a result of variation in hydrodynamic flows and in the effectiveness of the anti-fouling coating (Rainer 1995; Coutts 1999; James and Hayden 2000; Schultz and Swain 2000; Lewis et al. 2003). Furthermore, such small pockets of biofouling may be provided with a greater window of opportunity to successfully reproduce and establish compared with the slowermoving vessels described above, owing to the relatively high number of ports frequented by merchant vessels (Minchin and Gollasch 2003).

Assessing the biosecurity risks of a given vessel is a complex task. It is not just the area of the hull that is covered by biofouling organisms or the total biomass of organisms as has been suggested (e.g. Rainer 1995). It might also consider whether any NIMS are present, and other factors such as diversity (number of species present combined with a measure of their relative abundance). This chapter quantifies the nature and extent of biofouling within niche areas of the hulls of various merchant vessels operating in and visiting New Zealand. The potential of different areas of the hull to house biofouling is then used as a basis for interpreting biosecurity risk. The approach assumes that: 1) a greater diversity of biofouling taxa (i.e. in terms of both taxa richness and relative abundance) equates to a higher likelihood of NIMS being present; and 2) more established biofouling communities constitute a greater biosecurity risk than undeveloped communities. The results have application for biosecurity managers in their need for efficient biofouling surveillance methods and for techniques to assess biosecurity risk at the border. 


\subsection{METHODS}

\subsubsection{Survey design}

Underwater videos of the hulls of 30 merchant vessels (17 container vessels, 7 bulk carriers, 2 tankers, 2 roll-on/roll-off vessels, 1 supply vessel, and 1 passenger ferry) were randomly selected from libraries held by two New Zealand commercial diving companies (Divers Services Limited and New Zealand Diving and Salvage Limited). The vessels selected were either resident in New Zealand or visited New Zealand on a regular basis and ranged from 1,400 to 32,000 gross registered tonnes. The vessels had been videoed between 1992 and 1999 using Panasonic Hydrovision (two-chip highresolution) video cameras, immediately before in-water cleaning in Auckland, Tauranga, or Wellington. Information on vessel type was obtained from Maritime Data Services and the New Zealand Ship and Marine Society. Where possible, information on the maintenance history and voyage details of the vessels was obtained from records held by the diving companies. All vessels had been out of dry-dock for a minimum of 2 years.

Video footage targeted for quantitative sampling included areas of the hull (hull location) lacking anti-fouling coating (propeller), areas that often had damaged coatings (bulbous bow), and areas containing ineffective anti-fouling coating (bilge keel, rudder, rope guard, and sea-chest gratings) (Figure 8). Areas with inactive or old anti-fouling coating such as dry-docking support strips (DDSS; the positions under a vessel that cannot be coated with fresh anti-fouling during a dry-docking because of the position of docking blocks) were also included in this study. The area surrounding the DDSS (OutDDSS) on the bottom of vessels was also included for comparative purposes (Figure 8). Quantitative sampling of the bow thrusters and sides of the hull was not possible owing to insufficient video footage of these areas.

During viewing, the video was randomly paused five times within each of the eight hull locations on as many of the vessels as possible. The procedures employed by the divers operating the video cameras indicated that each quadrat corresponded to c. $0.45 \times 0.45$ metre area of the hull. Taxa richness (number of biofouling taxa) and percentage cover data was derived using 50 random points marked on a 0.33 metre television monitor. 


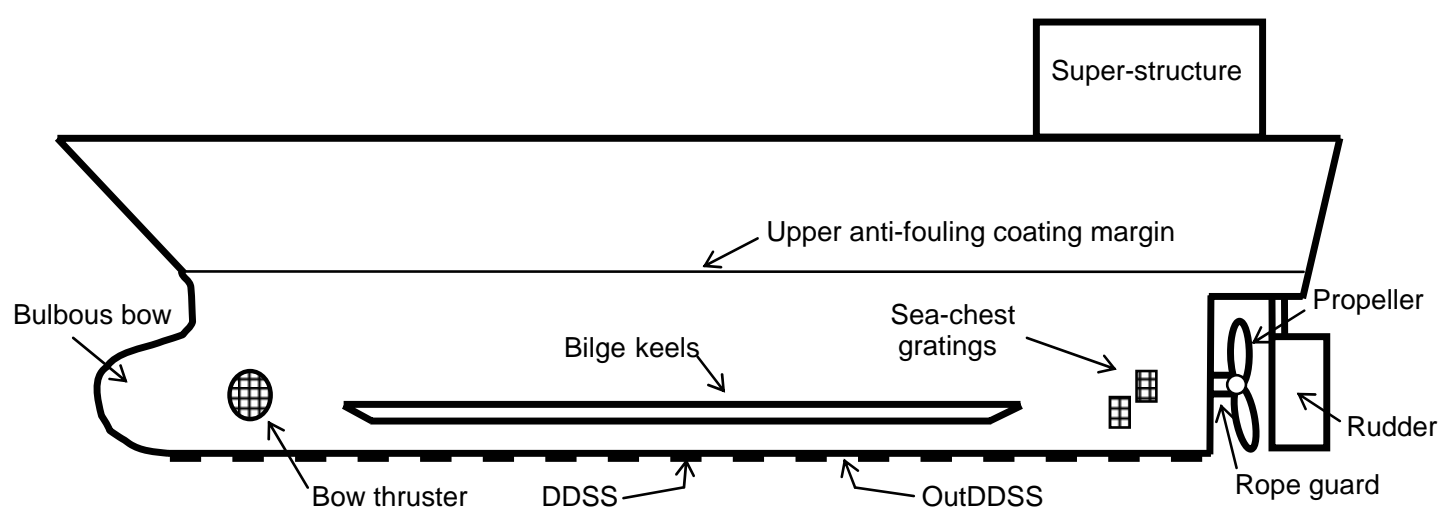

Figure 8 Position of various hull locations sampled during this study. (DDSS = drydocking support strips; OutDDSS = outside dry-docking support strips).

Bare metal, anti-fouling coating, and 15 biofouling taxa (i.e. higher taxonomic groups) corresponding to four biofouling categories, as shown in Table 4, were used as a basis for describing the nature and extent of biofouling within and among the vessels. Only those hull locations described above were analysed, hence levels of biofouling outside these locations such as along the waterline or the flat sides where certain taxa such as algae are more likely to be present were not considered (see Coutts 1999).

\subsubsection{Data collection}

The four biofouling categories correspond to a combination of the development (i.e. presence/absence, succession, and growth) of biofouling generally observed on artificial structures (e.g. Marine Corrosion Sub-Committee 1944; Bishop et al. 1949; Pyefinch 1950; Woods Hole Oceanographic Institution 1952; Skerman 1960; Coutts 1999). Fine green and brown algae are classified as $<5 \mathrm{~mm}$ in length while filamentous green and red algae are defined as $>5 \mathrm{~mm}$ in length. Diatom and bacterial slimes could not be distinguished from bare metal and anti-fouling coating with any certainty and hence were not included in the study as separate taxa. Furthermore, owing to insufficient clarity of the video footage, no mobile biofouling organisms were observed and were therefore not included in the study. 
Table 4 Biofouling taxa used in the study, categorised according to the general development of biofouling on artificial structures, as described previously.

\begin{tabular}{l|l|l|l}
\hline \multicolumn{4}{c}{ Biofouling Category } \\
\hline \multicolumn{1}{c|}{ A } & \multicolumn{1}{c}{ B } & \multicolumn{1}{c}{ C } & \multicolumn{1}{c}{ D } \\
\hline Bare metal & Fine green algae & Acorn barnacles & Solitary ascidians \\
Anti-fouling coating & Fine brown algae & Tubeworms & Colonial ascidians \\
& Filamentous green algae & Coralline algae & Sea anemones \\
& Filamentous red algae & Bryozoans & Mussels \\
& & Hydroids & Oysters \\
& & Macroalgae & \\
\hline
\end{tabular}

The percentage cover data were also used to identify vessels and hull locations that contained a relatively high percentage cover of the higher taxonomic groups (i.e. biofouling categories $\mathrm{C}$ and $\mathrm{D}$ in Table 4). The percentage cover data for all taxa in categories $\mathrm{C}$ and $\mathrm{D}$ were weighted by one, whereas the percentage cover data for categories A and B was weighted by zero. This weighted percentage cover data were used as a simplistic basis for interpreting biosecurity risk under the assumptions described previously.

\subsubsection{Statistical analyses}

Patterns in the weighted percentage cover and richness data were investigated using general linear mixed models (GLMs), after a $\log (\mathrm{X}+1)$ transformation of the data to satisfy normality and independence of error terms (PROC MIXED; SAS/STAT 1990). Vessels were grouped into three different vessel types (i.e. container vessels, bulk carriers, and "other" vessels). "Vessel type", "hull location", and the "vessel type" and "hull location" interaction term were analysed as fixed factors. "Vessel" was declared a random factor nested within "vessel type". "Vessel type" was grouped by the "vessel type" and "hull location" interaction term after initial examination of both the richness and weighted percentage data revealed differences in the underlying variation for each combination of the interaction term. "Vessel" variability was investigated using the restricted maximum likelihood method (REML) and models of best fit were selected on the basis of the highest value of Akaike's information criterion (AIC). With a significant $(P<0.05)$ interaction term, each "vessel type" was analysed independently. 
Sources of variation in the final models were investigated using Tukey-Kramer pairwise comparisons of means (SAS/STAT 1990).

The role of hull location in determining biofouling patterns was also investigated using multivariate analyses. Vessels were pooled and the data square root-transformed to stabilise variance. Then the average percentage cover of each of the biofouling categories listed in Table 4 was determined for quadrats within each hull location. The Bray-Curtis measure (Bray and Curtis 1957) was then used to calculate dissimilarities among means and a visual assessment of the results provided by dendograms using the PRIMER program (Plymouth Routines In Multivariate Ecological Research; Clarke 1993).

\subsection{RESULTS}

\subsubsection{Richness}

Twelve of the 15 higher taxonomic groups listed in Table 4 were encountered during sampling (i.e. except for filamentous red algae, macroalgae, and sea anemones). The highest richness value was 11 taxa on a trans-Tasman container vessel (i.e. vessel 6; Table 5), eight of which were on the rudder. The final GLM for the richness data selected: hull location $(P<0.001$, d.f. $=7 / 215)$; and vessel type $(P<0.001$, d.f. $=$ 2/215). Pairwise comparisons of means revealed significant differences $(P<0.05)$ between the OutDDSS and the bulbous bow, propeller, rudder, and rope guard, and between the DDSS and the propeller, rudder, and rope guard; OutDDSS had the lowest average richness values overall, whereas propellers, rudders, and rope guards generally had higher values (Figure 9). Significant differences were also found between the "other" vessels, and container vessels and bulk carriers; "other" vessels had higher average richness values than the remaining vessel types for most hull locations (Table $5)$.

\subsubsection{Percentage cover}

An average of $54.1 \%$ of the quadrat areas surveyed were not visibly fouled $(50.5 \%$ anti-biofouling coating; $3.6 \%$ bare metal; Table 5). Biofouling category A (bare metal and anti-fouling coating) was noticeably most abundant for the OutDDSS strata 
amongst all three vessel types (Table 6; Figure 10). Average percentage cover of biofouling varied amongst hull locations (propellers $>$ bulbous bows $>$ bilge keels $>$ rudders $>$ rope guards $>$ DDSS $>$ sea-chest gratings $>$ OutDDSS; Table 6). Biofouling category B taxa (i.e. fine and filamentous algae) were most dominant on propellers; a combination of both category A (anti-fouling coating) and B (algae) taxa were particularly dominant on bulbous bows, bilge keels, rudders, and rope guards (Table 6; Figure 10).

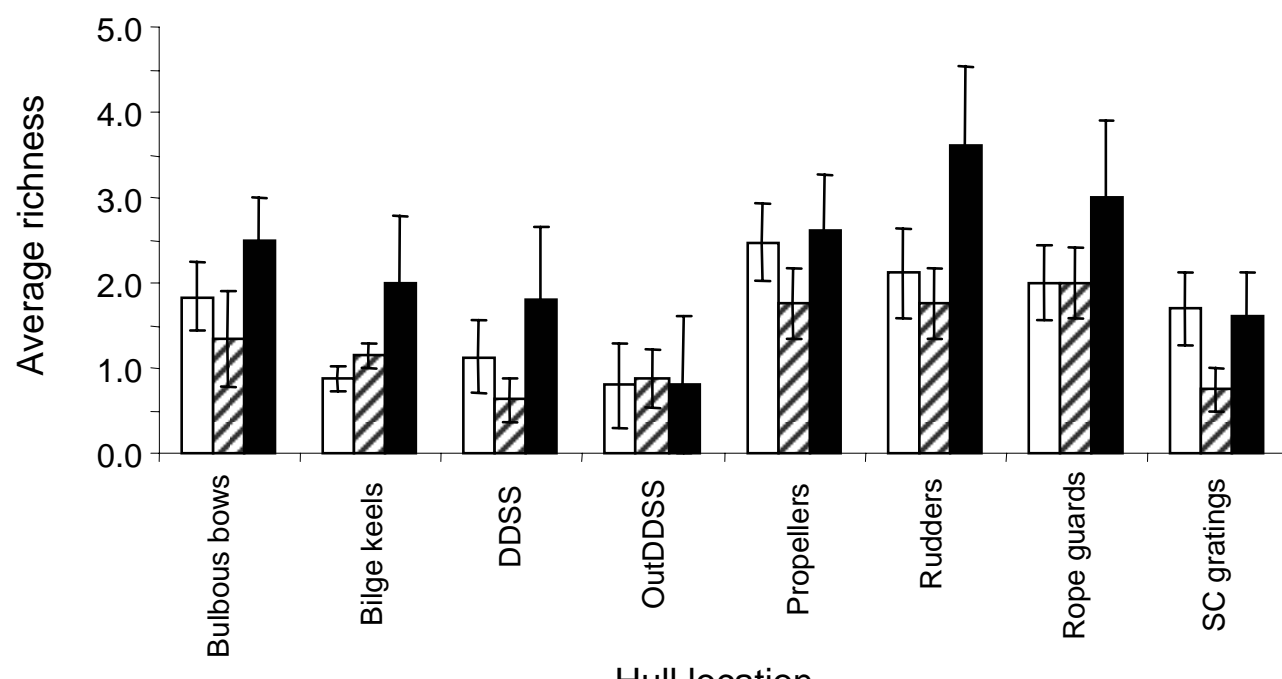

Figure 9 Average $( \pm 1 \mathrm{SE})$ richness within each hull location for the three vessel types used in the study. (DDSS = dry-docking support strips; OutDDSS = outside drydocking support strips; SC grating = sea-chest gratings. White bars = container vessels, striped $=$ bulk carriers, and black $=$ "other" vessels.

Fine green and filamentous algae were relatively uncommon within DDSS, OutDDSS, and on sea-chest gratings. Rather, these locations had a greater percentage cover of category C taxa, acorn barnacles and tubeworms in particular (Table 6; Figure 10). Category D taxa were most abundant within DDSS, but were also present on bulbous bows, rudders, rope guards, sea-chest gratings, and OutDDSS. However, category D taxa were largely confined to just four vessels (i.e. 6, 9, 14, and, 22; Table 5). Vessels 6 and 9 were container vessels, which had spent several months out-of-service in Auckland Harbour immediately before in-water cleaning, whereas vessel 14 was a domestic tanker and vessel 22 a domestic supply vessel. With the exception of these vessels, category D taxa were limited to the bilge keel, rudder, rope guard, and sea-chest gratings on the "other" vessel type. 
Table 5 Average $( \pm 1$ SE) percentage cover per quadrat of bare metal, anti-fouling coating, and 12 biofouling taxa for each of the 30 merchant vessels used in the study. Vessels have been sorted from least to greatest degree of biofouling according to the presence of biofouling category $(\mathrm{A}<\mathrm{B}<\mathrm{C}<\mathrm{D})$. Vessel type 1, container vessels; 2, bulk carriers; 3, "other" vessel types. Average abundance of biofouling per vessel refers to average percentage cover of all biofouling per vessel (excluding bare metal and anti-fouling coating). Taxa rich refer to total number of taxa present upon each vessel. Totals refer to average $( \pm 1 \mathrm{SE})$ percentage covers for all vessels pooled.

\begin{tabular}{|c|c|c|c|c|c|c|c|c|c|c|c|c|c|c|c|c|c|}
\hline Vessel & $\begin{array}{l}\text { Vessel } \\
\text { type }\end{array}$ & $\begin{array}{c}\text { Average } \\
\text { abundance } \\
\text { of } \\
\text { biofouling } \\
\text { per } \\
\text { vessel } \\
\end{array}$ & $\begin{array}{l}\text { Taxa } \\
\text { rich }\end{array}$ & $\begin{array}{l}\text { Bare } \\
\text { metal }\end{array}$ & $\begin{array}{c}\mathbf{A F} \\
\text { coating }\end{array}$ & $\begin{array}{l}\text { Brown } \\
\text { surface } \\
\text { algae }\end{array}$ & $\begin{array}{l}\text { Green } \\
\text { surface } \\
\text { algae }\end{array}$ & $\begin{array}{c}\text { Filament } \\
\text { green } \\
\text { algae }\end{array}$ & $\begin{array}{c}\text { Acorn } \\
\text { barnacles }\end{array}$ & Tubeworms & $\begin{array}{c}\text { Coralline } \\
\text { algae }\end{array}$ & $\begin{array}{l}\text { Encrusting } \\
\text { bryozoans }\end{array}$ & Hydroids & $\begin{array}{c}\text { Solitary } \\
\text { ascidians }\end{array}$ & $\begin{array}{l}\text { Colonial } \\
\text { ascidians }\end{array}$ & Mussels & Oysters \\
\hline 1 & 1 & $1.99 \pm 0.67$ & 1 & $14.37 \pm 6.38$ & $59.82 \pm 9.80$ & & $25.82 \pm 6.81$ & & & & & & & & & & \\
\hline 19 & 1 & $\begin{array}{l}2.81 \pm 0.64 \\
1.61 \pm 0.50\end{array}$ & 2 & $0.50 \pm 0.50$ & $\begin{array}{l}63.47+5.38 \\
78.53+5.82\end{array}$ & $\begin{array}{l}36.19 \pm .632 \\
15.82 \pm 5.34\end{array}$ & & $5.15 \pm 2.78$ & & & & & & & & & \\
\hline 16 & 1 & $3.02 \pm 0.61$ & 3 & $12.50 \pm 5.30$ & $45.76 \pm 6.71$ & $13.51 \pm 4.36$ & $19.83 \pm 5.06$ & $5.96 \pm 2.87$ & & & & & & & & & \\
\hline 8 & 1 & $3.19 \pm 0.71$ & 2 & $8.80 \pm 3.70$ & $50.56 \pm 7.14$ & & $9.18 \pm 3.98$ & & $32.24 \pm 5.62$ & & & & & & & & \\
\hline 2 & 1 & $3.60 \pm 0.66$ & 3 & $12.50 \pm 5.30$ & $40.71 \pm 5.25$ & & $35.60 \pm 5.42$ & $8.00 \pm 3.53$ & $3.18 \pm 1.64$ & & & & & & & & \\
\hline 3 & 1 & $3.80 \pm 0.59$ & 3 & $5.70 \pm 2.65$ & $45.03 \pm 5.57$ & & $16.80 \pm 4.00$ & $18.90 \pm 4.01$ & $13.56 \pm 3.33$ & & & & & & & & \\
\hline 30 & 2 & $2.96 \pm 0.74$ & 4 & & $61.40 \pm 7.69$ & $0.29 \pm 0.23$ & $16.34 \pm 6.21$ & $5.60 \pm 2.96$ & $0.29 \pm 0.23$ & & & & & & & & \\
\hline 17 & 2 & $3.27 \pm 0.69$ & 4 & & $57.53 \pm 7.34$ & $15.90 \pm 5.44$ & $17.47 \pm 5.52$ & $6.59 \pm 3.02$ & $2.51 \pm 1.25$ & & & & & & & & \\
\hline 23 & 1 & $3.15 \pm 0.61$ & 4 & $3.49 \pm 1.72$ & $56.67 \pm 6.57$ & $\begin{array}{l}29.15 \pm 5.63 \\
205+51\end{array}$ & $\begin{array}{l}9.04 \pm 2.71 \\
05.20\end{array}$ & $1.49 \pm 1.49$ & $1.31 \pm 0.57$ & & & & & & & & \\
\hline${ }_{26}^{11}$ & 2 & $\begin{array}{l}4.17 \pm 0.63 \\
2060.042\end{array}$ & $\begin{array}{l}4 \\
4\end{array}$ & $\begin{array}{l}2.20 \pm 1.87 \\
3.87+2.26\end{array}$ & $\begin{array}{l}43.68 \pm 5.61 \\
6033+595\end{array}$ & $\begin{array}{r}23.85 \pm 5.15 \\
158+26\end{array}$ & $\begin{array}{l}10.55 \pm 2.89 \\
1.87+30\end{array}$ & $\begin{array}{l}6.30 \pm 2.83 \\
700+287\end{array}$ & $13.53 \pm 3.00$ & & & & & & & & \\
\hline $\begin{array}{l}26 \\
27\end{array}$ & 1 & $\begin{array}{l}2.06 \pm 0.42 \\
2.690 .54\end{array}$ & $\begin{array}{l}4 \\
4\end{array}$ & $\begin{array}{l}3.87 \pm 2.26 \\
3.95+1.83\end{array}$ & $\begin{array}{l}69.33 \pm 5.95 \\
6033+6.39\end{array}$ & $\begin{array}{l}15.86 \pm 3.65 \\
1855+424\end{array}$ & $\begin{array}{l}1.87 \pm 1.30 \\
9.38+390\end{array}$ & $\begin{array}{l}7.99 \pm 2.87 \\
4.55+2.39\end{array}$ & $\begin{array}{l}1.08 \pm 0.55 \\
2040+136\end{array}$ & & & & & & & & \\
\hline 7 & 1 & $0.83 \pm 0.24$ & 3 & $7.07 \pm 3.17$ & $82.08 \pm 5.52$ & $18.65 \pm 4.24$ & $5.43 \pm 2.52$ & & $2.89 \pm 1.30$ & $2.52 \pm 1.16$ & & & & & & & \\
\hline 18 & 2 & $2.79 \pm 0.51$ & 4 & & $63.70 \pm 4.91$ & $7.65 \pm 3.27$ & $5.70 \pm 3.24$ & & $20.45 \pm 3.53$ & $2.50 \pm 1.21$ & & & & & & & \\
\hline 21 & 1 & $3.44 \pm 0.64$ & 5 & $4.15 \pm 1.91$ & $50.36 \pm 5.97$ & $21.24 \pm 4.89$ & $7.71 \pm 2.45$ & $12.42 \pm 4.91$ & $1.14 \pm 0.71$ & $2.06 \pm 0.89$ & & & & & & & \\
\hline 29 & 3 & $3.98 \pm 0.65$ & 5 & & $48.29 \pm 6.01$ & $8.34 \pm 2.53$ & $5.83 \pm 2.52$ & $8.05 \pm 3.00$ & $8.34 \pm 2.53$ & & $4.29 \pm 1.62$ & & & & & & \\
\hline 25 & 3 & $4.33 \pm 0.80$ & 4 & $2.86 \pm 1.45$ & $39.38 \pm 6.24$ & $30.97 \pm 6.42$ & & & $21.80 \pm 5.73$ & $0.63 \pm 0.39$ & $2.86 \pm 1.27$ & & & & & & \\
\hline 12 & 1 & $3.34 \pm 0.51$ & 5 & $3.45 \pm 1.78$ & $52.15 \pm 5.52$ & $\begin{array}{l}9.77 \pm 2.42 \\
600 \div 17\end{array}$ & $\begin{array}{l}11.49 \pm 3.70 \\
11.0+32\end{array}$ & $8.75 \pm 2.71$ & $8.90 \pm 2.61$ & & $4.46 \pm 2.21$ & & & & & & \\
\hline 4 & 1 & $\begin{array}{l}2.37 \pm 0.41 \\
342+0.64\end{array}$ & $\begin{array}{l}5 \\
6\end{array}$ & $\begin{array}{l}1.40 \pm .98 \\
177+1.26\end{array}$ & $\begin{array}{l}64.10 \pm 6.07 \\
55.59+6.18\end{array}$ & $\begin{array}{l}6.09 \pm 2.17 \\
481+2.24\end{array}$ & $\begin{array}{l}11.90 \pm 3.23 \\
158+53\end{array}$ & $\begin{array}{l}6.26 \pm 2.14 \\
1.05+46\end{array}$ & $6.18 \pm 2.17$ & $061+032$ & $\begin{array}{l}0.41 \pm 0.29 \\
0800.34\end{array}$ & & & & & & \\
\hline $\begin{array}{l}28 \\
15\end{array}$ & $\begin{array}{l}3 \\
2\end{array}$ & $\begin{array}{l}3.42 \pm 0.64 \\
5.440 .85\end{array}$ & $\begin{array}{l}6 \\
5\end{array}$ & $\begin{array}{l}1.75 \pm 1.26 \\
665+2.86\end{array}$ & $\begin{array}{l}53.59 \pm 6.18 \\
22.97+31\end{array}$ & $\begin{array}{l}4.81+2.24 \\
5.85+2.52\end{array}$ & $\begin{array}{l}15.78+5.533 \\
1.67+3.89\end{array}$ & $\begin{array}{l}15.05 \pm 4.66 \\
31.84+6.11\end{array}$ & $7.34 \pm 2.24$ & $\begin{array}{l}0.61 \pm 0.32 \\
19.60+58\end{array}$ & $0.80 \pm 0.34$ & & & & & & \\
\hline 24 & 1 & $\begin{array}{l}\begin{array}{r}.44 \pm 0.83 \\
4.09 \pm 0.78\end{array}\end{array}$ & 5 & $9.94 \pm 4.48$ & $36.83 \pm 6.41$ & $27.87 \pm 6.65$ & $22.57 \pm 5.24$ & $\begin{array}{l}13.84 \pm 0.11 \\
0.40 \pm 0.40\end{array}$ & $1.97 \pm 1.18$ & & & $0.42 \pm 0.20$ & & & & & \\
\hline 13 & 2 & $2.69 \pm 0.49$ & 5 & $0.45 \pm 0.36$ & $64.64 \pm 5.87$ & $5.10 \pm 2.47$ & $23.10 \pm 4.33$ & $1.86 \pm 1.40$ & $2.65 \pm 1.41$ & & & & $2.20 \pm 1.06$ & & & & \\
\hline 5 & & $4.54 \pm 0.73$ & 5 & $3.47 \pm 1.61$ & $37.55 \pm 4.97$ & & $23.81 \pm 4.58$ & $11.28 \pm 4.17$ & $12.24 \pm 4.73$ & & $11.00 \pm 3.47$ & & $0.65 \pm 0.47$ & & & & \\
\hline 10 & 1 & $4.16 \pm 0.72$ & 6 & $0.10 \pm 0.10$ & $45.98 \pm 6.90$ & $4.44 \pm 1.89$ & $35.20 \pm 6.21$ & $10.75 \pm 3.81$ & $1.30 \pm 0.72$ & & $1.98 \pm 1.26$ & & & & & $0.36 \pm 0.36$ & \\
\hline 9 & 1 & $6.67 \pm 0.78$ & 8 & $2.50 \pm 1.78$ & $11.01 \pm 2.32$ & & $37.85 \pm 6.07$ & $7.57 \pm 3.71$ & & $3.52 \pm 1.02$ & & $0.65 \pm 0.28$ & $15.97 \pm 2.37$ & $2.19 \pm 0.69$ & $18.59 \pm 2.64$ & $0.40 \pm 0.40$ & \\
\hline${ }_{14}^{22}$ & 3 & $4.76 \pm 0.53$ & 9 & $0.53 \pm 0.37$ & $\begin{array}{l}37.87 \pm 5.22 \\
450+52\end{array}$ & $8.51 \pm 2.72$ & & $\begin{array}{l}1.09 \pm 0.84 \\
526+20\end{array}$ & $14.82 \pm 2.53$ & $9.40 \pm 2.29$ & $7.89 \pm 3.28$ & $5.71 \pm 1.54$ & $8.52 \pm 1.87$ & & $0.11 \pm 0.11$ & $5.88 \pm 1.78$ & 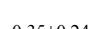 \\
\hline $\begin{array}{c}14 \\
6\end{array}$ & $\begin{array}{l}3 \\
1\end{array}$ & $\begin{array}{l}.422 \pm 0.54 \\
5.72 \pm 0.55\end{array}$ & 11 & $0.23 \pm 0.23$ & $\begin{array}{l}\text { 55.5955.37 } \\
25.045 .80\end{array}$ & & $\begin{array}{c}13.03 \pm 3.305 \\
1.66 \pm 0.81\end{array}$ & $\begin{array}{l}5.2662 .30 \\
4.63 \pm 2.11\end{array}$ & $\begin{array}{c}19.00 \pm 2.70 \\
0.77 \pm 0.40\end{array}$ & $10.46 \pm 1.80$ & $\begin{array}{l}3.89 \pm 1.64 \\
0.51 \pm 0.51\end{array}$ & $8.27 \pm 1.73$ & $24.29 \pm 3.34$ & $9.76 \pm 2.34$ & $12.56 \pm 2.38$ & $\begin{array}{l}10.6993 \pm .04 \\
1.19 \pm 0.91\end{array}$ & $\begin{array}{l}0.35 \pm 0.24 \\
0.23 \pm 0.16\end{array}$ \\
\hline Total & 30 & $3.51 \pm 0.115$ & 12 & $3.55 \pm 0.44$ & $50.51 \pm 1.18$ & $11.55 \pm 0.76$ & $13.58 \pm 0.79$ & $6.79 \pm 0.58$ & $6.40 \pm 0.47$ & $1.75 \pm 0.28$ & $1.26 \pm 0.21$ & $0.48 \pm 0.09$ & $1.71 \pm 0.22$ & $0.39 \pm 0.09$ & $1.07 \pm 0.17$ & $0.67 \pm 0.15$ & $0.02 \pm 0.01$ \\
\hline
\end{tabular}


Table 6 Average $( \pm 1 \mathrm{SE})$ percentage cover per quadrat of bare metal, anti-fouling coating, and biofouling taxa for each of the eight hull locations used in the study. Hull locations have been sorted according to the results of a cluster analyses (see Figure 11). Taxa have been sorted according to biofouling category (A, B, C, and D). Average \% cover refers to biofouling taxa (i.e. biofouling categories B, C, and D only). (DDSS = drydocking support strips; OutDDSS = outside dry-docking support strips).

\begin{tabular}{|c|c|c|c|c|c|c|c|c|}
\hline $\begin{array}{l}\text { Biofouling category/ } \\
\text { taxonomic group }\end{array}$ & Propellers & Bulbous bows & Bilge keels & Rudders & Rope guards & DDSS & $\begin{array}{l}\text { Sea-chest } \\
\text { gratings }\end{array}$ & OutDDSS \\
\hline $\begin{array}{l}\text { A) } \\
\text { Bare metal } \\
\text { Anti-fouling coating }\end{array}$ & $\begin{array}{c}25.67 \pm 2.55 \\
0\end{array}$ & $\begin{array}{c}0.09 \pm 0.09 \\
43.93 \pm 3.41\end{array}$ & $\begin{array}{c}0 \\
43.40 \pm 3.22\end{array}$ & $\begin{array}{c}0 \\
52.06 \pm 2.70\end{array}$ & $\begin{array}{c}0 \\
53.46 \pm 2.65\end{array}$ & $\begin{array}{c}0 \\
58.33 \pm 3.50\end{array}$ & $\begin{array}{c}0 \\
70.03 \pm 2.48\end{array}$ & $\begin{array}{c}0.53 \pm 0.53 \\
83.26 \pm 2.55\end{array}$ \\
\hline $\begin{array}{l}\text { B) } \\
\text { Brown surface algae } \\
\text { Green surface algae } \\
\text { Filamentous green algae }\end{array}$ & $\begin{array}{c}35.08 \pm 3.12 \\
18.06 \pm 2.12 \\
5.38 \pm 1.45\end{array}$ & $\begin{array}{c}6.24 \pm 1.63 \\
16.89 \pm 2.42 \\
28.47 \pm 3.20\end{array}$ & $\begin{array}{c}7.06 \pm 1.79 \\
38.48 \pm 3.35 \\
6.76 \pm 1.77\end{array}$ & $\begin{array}{c}14.87 \pm 2.04 \\
16.94 \pm 2.24 \\
9.61 \pm 1.67\end{array}$ & $\begin{array}{c}12.48 \pm 1.80 \\
10.32 \pm 1.65 \\
7.49 \pm 1.58\end{array}$ & $\begin{array}{l}8.73 \pm 2.42 \\
3.32 \pm 1.26 \\
2.56 \pm 1.13\end{array}$ & $\begin{array}{l}3.45 \pm 0.87 \\
1.04 \pm 0.42 \\
0.41 \pm 0.32\end{array}$ & $\begin{array}{l}1.50 \pm 0.78 \\
3.85 \pm 1.27 \\
0.78 \pm 0.49\end{array}$ \\
\hline $\begin{array}{l}\text { C) } \\
\text { Acorn barnacles } \\
\text { Tubeworms } \\
\text { Coralline algae } \\
\text { Encrusting bryozoans } \\
\text { Hydroids }\end{array}$ & $\begin{array}{l}3.16 \pm 0.80 \\
0.81 \pm 0.34 \\
6.75 \pm 1.34 \\
0.49 \pm 0.33 \\
2.06 \pm 0.70\end{array}$ & $\begin{array}{c}1.04 \pm 0.38 \\
0.38 \pm 0.30 \\
0 \\
0.06 \pm 0.06 \\
1.23 \pm 0.67\end{array}$ & $\begin{array}{c}2.44 \pm 0.65 \\
0.39 \pm 0.18 \\
0 \\
0.25 \pm 0.14 \\
0.37 \pm 0.17\end{array}$ & $\begin{array}{l}3.20 \pm 0.65 \\
0.78 \pm 0.23 \\
0.04 \pm 0.04 \\
0.23 \pm 0.11 \\
0.80 \pm 0.28\end{array}$ & $\begin{array}{l}7.51 \pm 1.23 \\
0.39 \pm 0.21 \\
1.64 \pm 0.66 \\
0.65 \pm 0.30 \\
2.10 \pm 0.62\end{array}$ & $\begin{array}{c}13.09 \pm 2.07 \\
5.80 \pm 1.69 \\
0.19 \pm 0.18 \\
1.01 \pm 0.40 \\
3.01 \pm 0.84\end{array}$ & $\begin{array}{c}16.65 \pm 1.92 \\
0.88 \pm 0.38 \\
0.66 \pm 0.31 \\
0.35 \pm 0.17 \\
3.14 \pm 0.89\end{array}$ & $\begin{array}{l}2.46 \pm 0.78 \\
4.54 \pm 1.20 \\
0.13 \pm 0.13 \\
0.69 \pm 0.26 \\
0.83 \pm 0.30\end{array}$ \\
\hline $\begin{array}{l}\text { D) } \\
\text { Solitary ascidians } \\
\text { Colonial ascidians } \\
\text { Mussels } \\
\text { Oysters }\end{array}$ & $\begin{array}{c}0.36 \pm 0.22 \\
1.05 \pm 0.43 \\
0 \\
0\end{array}$ & $\begin{array}{c}0 \\
1.97 \pm 0.93 \\
0 \\
0\end{array}$ & $\begin{array}{c}0 \\
0 \\
0.30 \pm 0.17 \\
0.31 \pm 0.16\end{array}$ & $\begin{array}{l}0.05 \pm 0.05 \\
0.57 \pm 0.23 \\
0.36 \pm 0.16 \\
0.36 \pm 0.17\end{array}$ & $\begin{array}{l}0.40 \pm 0.26 \\
1.12 \pm 0.41 \\
2.38 \pm 0.72 \\
2.38 \pm 0.72\end{array}$ & $\begin{array}{l}1.21 \pm 0.48 \\
2.41 \pm 0.86 \\
0.06 \pm 0.06 \\
0.06 \pm 0.06\end{array}$ & $\begin{array}{l}0.21 \pm 0.17 \\
1.08 \pm 0.39 \\
1.99 \pm 0.77 \\
1.99 \pm 0.77\end{array}$ & $\begin{array}{c}0.82 \pm 0.39 \\
0.77 \pm 0.30 \\
0 \\
0\end{array}$ \\
\hline Average \% cover (taxa only) & $5.64 \pm 0.41$ & $4.33 \pm 0.41$ & $4.31 \pm 0.40$ & $3.65 \pm 0.30$ & $3.58 \pm 0.28$ & $3.18 \pm 0.33$ & $2.30 \pm 0.22$ & $1.25 \pm 0.17$ \\
\hline
\end{tabular}


A Bulk carriers

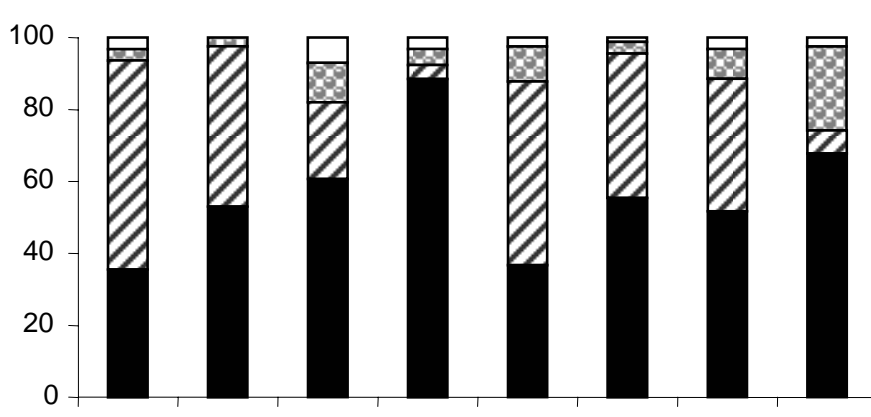

B Container vessels

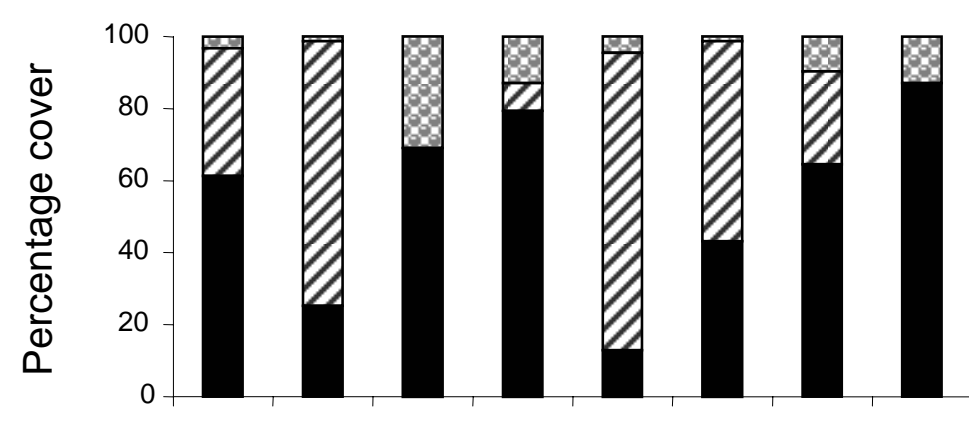

C "Other" vessels

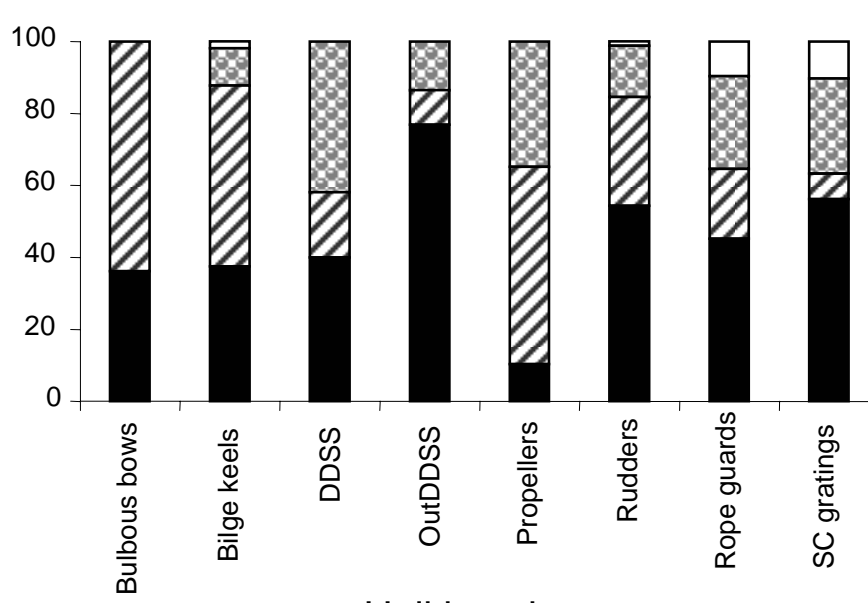

Hull location

Figure 10 Percentage covers of the four biofouling categories (see Table 4) within each hull location for the three vessel types used in the study. (DDSS = dry-docking support strips; OutDDSS = outside dry-docking support strips; SC gratings $=$ sea-chest gratings. Biofouling category: $\mathrm{A}=$ white, $\mathrm{B}=$ dots, $\mathrm{C}=$ strips and $\mathrm{D}=$ black.

\subsubsection{Multivariate analyses}

Multivariate analyses separated three vessels (6, 9, and 22) from the remaining 27 surveyed as these vessels each had the greatest degree of biofouling (richness and average percentage cover) of the 30 vessels surveyed (Table 5; Figure 11). Vessels 6 
and 9 were the two out-of-service vessels, and vessel 22 was classified as a domestic supply vessel, all mentioned previously. Cluster analysis revealed three main groupings of hull locations, which are consistent with the patterns observed in the percentage cover data: (1) propeller; (2) bulbous bow, bilge keel, rudder, and rope guard; and (3) OutDDSS, DDSS, and sea-chest gratings (Figure 12).

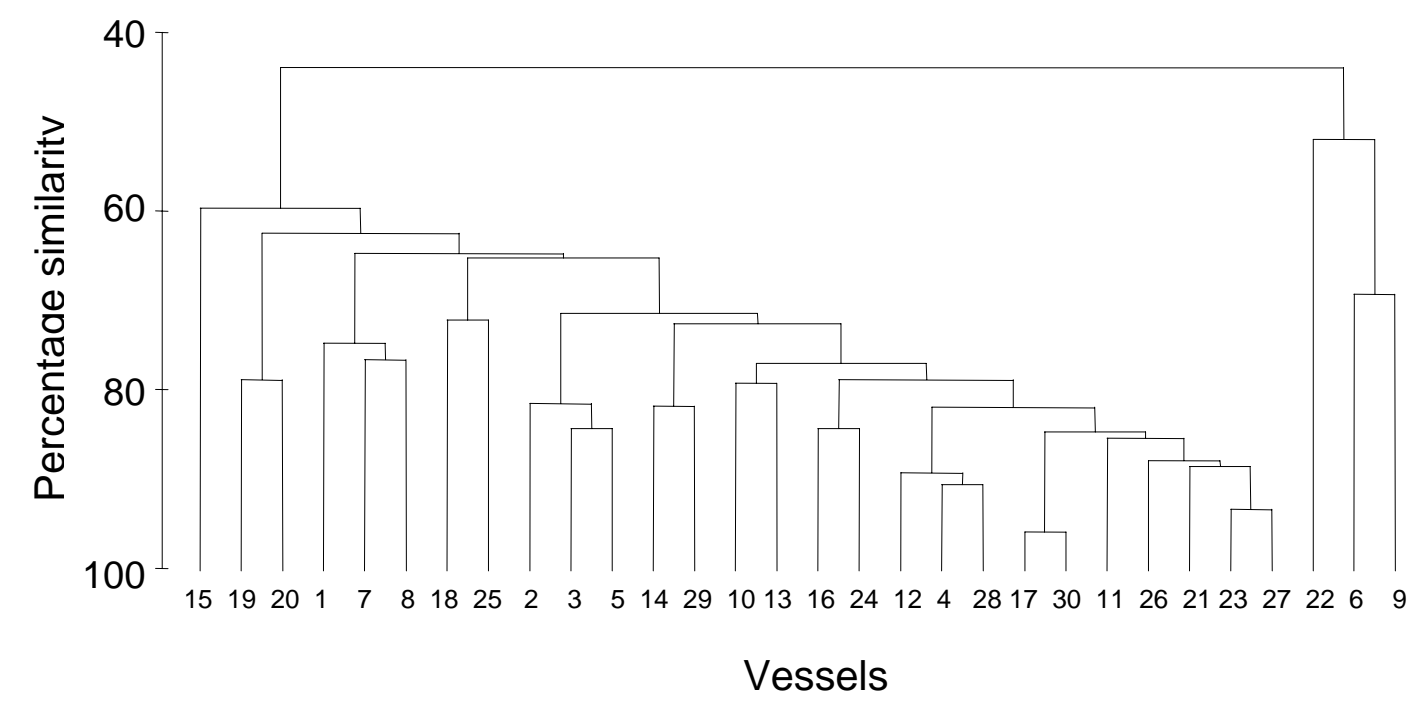

Figure 11 Dendogram showing the similarity in the average percentage cover per quadrat of bare metal, anti-fouling coating, and the 12 biofouling taxa for each of the 30 merchant vessels used in this study. See Table 5 for supporting data.

\subsubsection{Weighted percentage cover}

All three vessel types had a relatively high average weighted percentage cover (i.e. category C and D taxa) within DDSS, as did the propeller, rope guard, and sea-chest gratings for the "other" vessel types (Figure 13). The biofouling patterns within these hull locations for the "other" vessels contrasted with very little category C and D taxa within the bulbous bow location of these vessels. The final GLM for the weighted percentage cover data selected the vessel type and hull location interaction term $(P<$ 0.05 , d.f. $=14 / 198)$. Subsequent models for each vessel type resulted in marginally significant differences amongst hull locations for container vessels $(P=0.051$, d.f. $=$ 7/116), non-significant differences for bulk carriers $(P>0.10$, d.f. $=7 / 47)$ and highly significant differences for the "other" vessels $(P<0.001$, d.f. $=7 / 35)$. Pairwise comparisons of means resulted in significant differences between the bilge keel and seachest gratings for container vessels, and between the bulbous bow and the DDSS, propeller, and rope guard for the "other" vessels. 


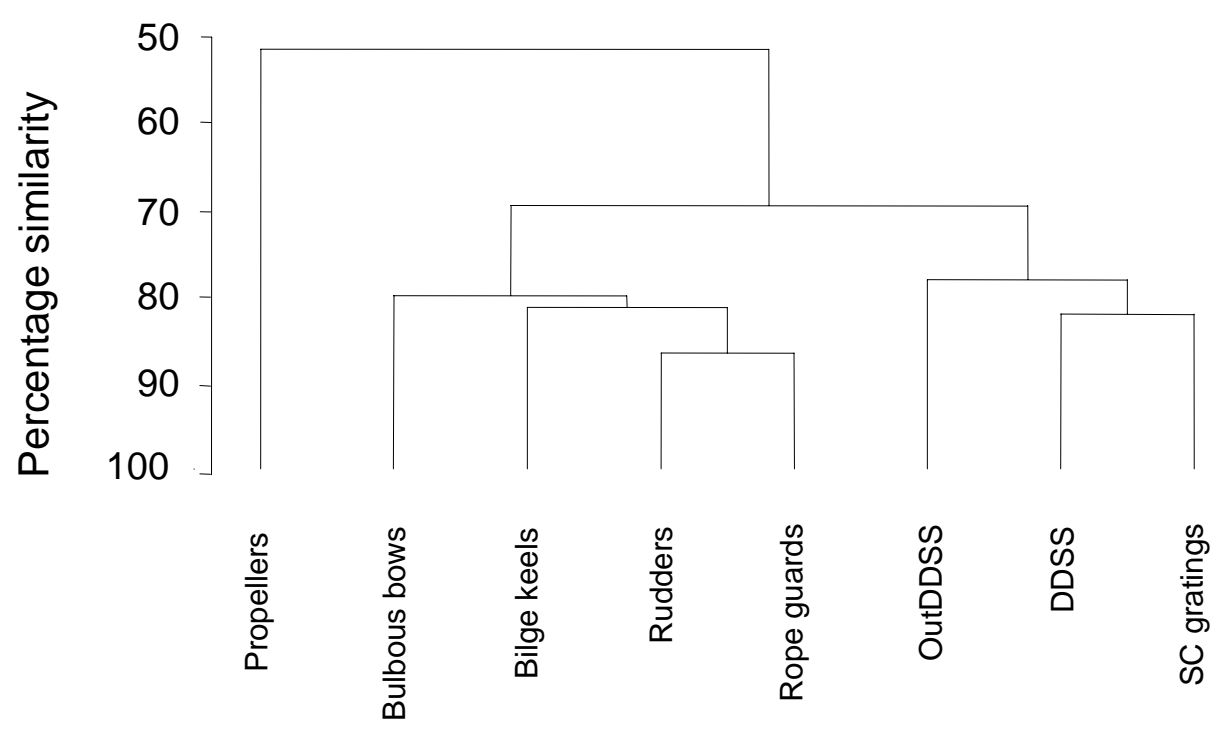

Hull location

Figure 12 Dendogram showing the similarity in the average percentage cover per quadrat of bare metal, anti-fouling coating, and the 12 biofouling taxa for each hull location used in this study. See Table 6 for supporting data. (DDSS = dry-docking support strips; OutDDSS = outside dry-docking support strips; SC gratings $=$ sea-chest gratings).

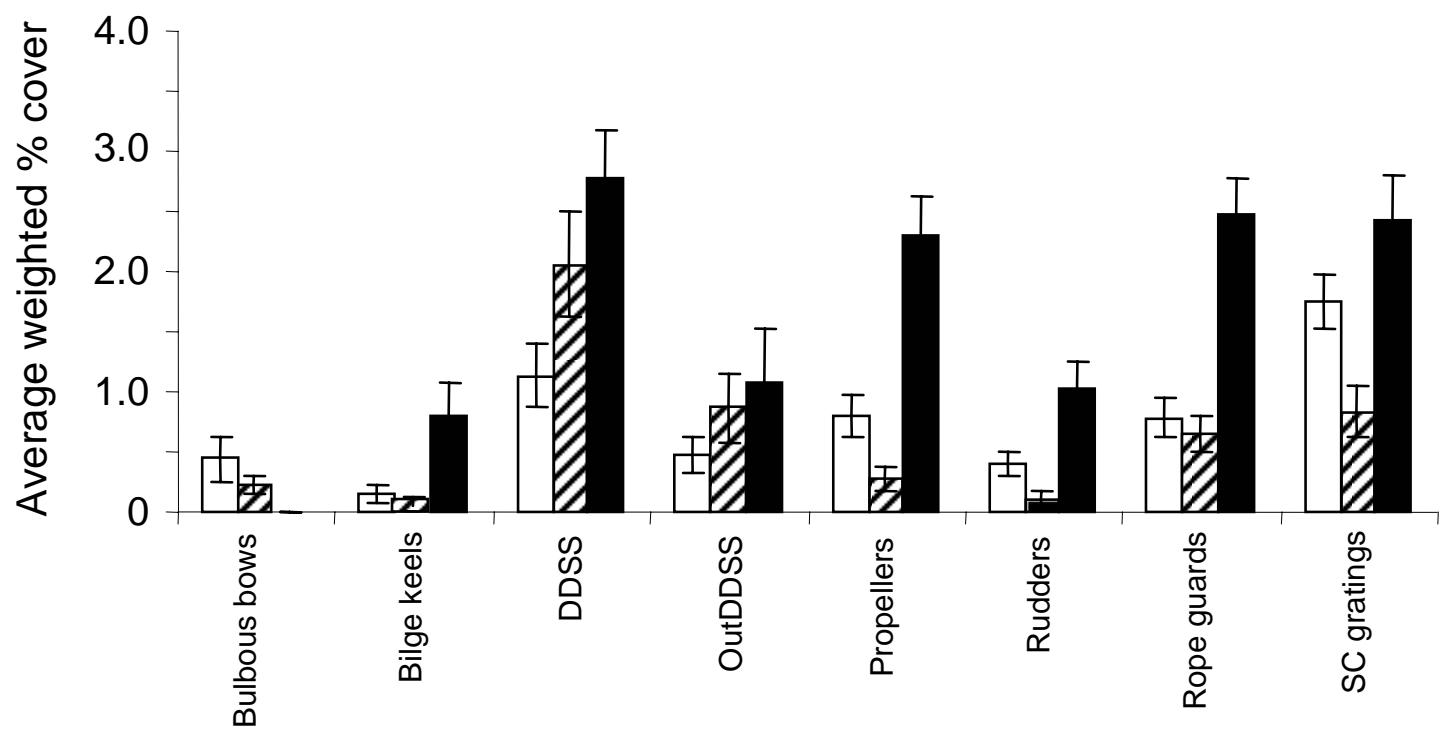

Hull location

Figure 13 Average ( $\pm 1 \mathrm{SE}$ ) weighted percentage cover within each hull location for the three vessel types used in the study. See materials and methods section for definitions of weighted percentage cover (DDSS = dry-docking support strips; OutDDSS = outside dry-docking support strips; SC gratings = sea-chest gratings. White bars = container vessels, striped $=$ bulk carriers, and black $=$ "other" vessels. 


\subsection{DISCUSSION}

\subsubsection{Richness and percentage cover}

The archived video footage of underwater hull assessments proved to be a cost-effective way of quantifying levels of biofouling taxa at selected hull locations on a wide range of merchant vessels in New Zealand waters. It is important, however, to note that at the time of their video survey, the majority of the 30 vessels analysed probably had antifouling coating in excess of 36 months old given that these vessels were either requiring an in-water hull clean or a dry-docking extension. Therefore, considering that the effectiveness of modern-day anti-fouling coatings at resisting biofouling declines with age, the levels of biofouling encountered in this study were probably approaching worst-case biofouling scenarios typical of merchant vessels.

In light of the above, it was not surprising that all 30 vessels surveyed were fouled with at least one of the 15 taxonomic groups found in the study. Of the three vessel types, the six vessels classified as "other" were the most fouled, having the highest average taxa richness (per vessel), average percentage cover, and average weighted percentage cover of biofouling taxa. All six vessels classified as "other" traded either domestically throughout New Zealand or across the Tasman Sea (between Australia and New Zealand). Also, all vessels with category D taxa present were domestic or trans-Tasman vessels. Skerman (1960) and Coutts (1999) also found domestic and trans-Tasman vessels to be heavily fouled in relation to "other" vessel types surveyed. Generally this is because vessels plying similar latitudes with relatively short voyage durations are known to possess higher levels of biofouling than vessels that visit ports separated by vast latitudinal distances (Visscher 1928; Woods Hole Oceanographic Institution 1952; Coutts 1999; James and Hayden 2000; Lewis 2002; Lewis et al. 2003). Biofouling organisms are capable of surviving on vessels remaining at similar latitudes owing to the relatively consistent ambient water temperatures (and sometimes salinity levels) at similar latitudes, and short voyages have little influence on the ability of biofouling organisms to feed and grow rapidly (Visscher 1928).

In contrast, many of the international container and bulk carrier vessels that had a relatively low average taxa richness and percentage cover of biofouling organisms were often restricted to category B and C taxa. Such international vessels generally expose 
biofouling organisms to relatively long voyages at fast speeds (i.e. $>18$ knots), as well as relative extremes in temperature and salinity levels. Hence, only the more hydrodynamic-insensitive (e.g. cosmopolitan algae, acorn barnacles, tubeworms, and encrusting bryozoans) are able to survive on such relatively fast-moving vessels. For instance, Allen (1953) found that the cosmopolitan serpulid Hydroides norvegica (Gunnerus) and the bryozoan Watersipora subtorquata (d'Orbigny 1842) (as $W$. cucullata (Busk)) were the only surviving organisms on a three month voyage through tropical, warm temperate, and cool temperate waters on which the vessel's speed reached 30 knots.

Two container vessels had the highest levels of biofouling across hull locations out of all the vessels surveyed, with category B, C, and D taxa being present. Significantly, these were also trans-Tasman vessels and each had spent a minimum of three months laid-up in Auckland Harbour since their last dry-docking. Considering most merchant vessels currently utilise self-polishing copolymer (SPC) coatings, which require water movement to expose a fresh surface from which the biocide is released, such extended inactivity results in insufficient biocide release to prevent biofouling and eventually enables a wide variety of biofouling communities to establish and mature. If operating conditions for a merchant vessel are optimal, SPC coatings are capable of maintaining a vessel free from macroscopic biofouling for up to five years (Christie and Dalley 1987). However, despite the uniform areas of the hull being relatively clean, significant biofouling can still be present in relatively protected areas such as the gratings, surrounding intake pipes, bow thruster tunnels, rope guards, and/or in areas that lack anti-fouling coating (Coutts 1999; James and Hayden 2000; Wonham et al. 2000; this study). This is likely to be a consequence of: 1) turbulent water flow (such as over gratings and hull protrusions) resulting in rapid polishing and anti-fouling "polishthrough"; or 2) low flow, as in static pockets, which would be similar to the situation with laid-up vessels. The net effect of both is inadequate biocide release to prevent biofouling.

Interestingly, SPC coatings are known to foul with some species of diatom, Amphora spp., and algal species such as Ulva, Ectocarpus, and Ulothrix spp., which are resistant to the copper and triorgano-tin biocides in the coating (Christie et al. 1976; Hall et al. 1979; Evans 1981; Reed and Moffat 1983; Callow 1986). Diatom and other algal 
species may also be able to colonise protected areas of vessels more readily than the more exposed areas of the hull (Callow 1986). This is because protected areas of vessels (e.g. bow thrusters, rudder recesses, and gratings) are subject to lesser hydrodynamic forces relative to the more laminar or uniform areas of the hull (Schulz and Swain 2000). These differences in flow regimes may result in lower leaching rates of the toxic biocides in the protected areas, which may enable various algal species to colonise them. Given that the biofouling process is often sequential, beginning with colonisation of the surface of the hull by bacteria followed by settlement of freeswimming algal spores and invertebrate larvae (e.g. Bishop et al. 1949; Woods Hole Oceanographic Institution 1952; Greene and Schoener 1982), early algal colonists and some invertebrates may provide a suitable non-toxic surface for a wide range of other biofouling organisms to attach and survive. This is supported by the fact that the protected areas on a number of the vessels surveyed were found to have category D taxa present.

The hulls of merchant ships are usually coated with SPC coatings that are designed to be most effective for a given vessel's optimal speed and the amount of time they propose to spend in port. For instance, fast moving vessels that spend minimal time in port are likely to adopt harder, slow polishing, anti-fouling coatings while slow vessels are likely to adopt softer, faster polishing, coatings (e.g. Lewis 2002). At present, it is common practice for the same type of coating to be applied to the entirety of a vessel's hull. However, some ships are now coated with different systems on different parts of the hull and this approach could be extended to better protect niche areas (John Lewis pers. comm.).

\subsubsection{Multivariate analyses}

Multivariate analysis revealed three main groups of hull locations: (1) propeller; (2) bulbous bow, bilge keel, rudder, and rope guard; and (3) OutDDSS, DDSS, and seachest gratings, according to similarities in the presence, absence, and abundance of bare metal, anti-fouling coating, and the 12 biofouling taxa encountered. We propose that variation in the patterns of biofouling between these hull locations can largely be explained by one or a combination of the following factors: (1) the presence, absence, or 
effectiveness of anti-fouling coating; (2) availability of sunlight; and (3) exposure to hydrodynamic flow.

Propellers for instance, are a unique hull location because they usually do not possess anti-fouling coating, just a non-toxic brass surface. However, the challenge for biofouling organisms is not to just colonise such a structure, but to survive the harsh turbulent environment while the propeller is in motion. This might explain the dominance of hydrodynamic-insensitive taxa with a high percentage cover (i.e. brown and green surface algae, acorn barnacles, tubeworms, and coralline algae), particularly towards the centre of the propeller where hydrodynamic forces are much less than at the extremities of the blades.

Bulbous bows, bilge keels, rope guards, and rudders formed the second grouping, primarily because of the presence and similar abundance of three algal taxa (i.e. fine brown, fine green, and filamentous green algae). Not surprisingly, this is largely explained by such locations receiving a plentiful supply of sunlight. Although bilge keels are often at depth, the angle of the bilge keels to the hull is such that the upper facing surface receives more available light than the adjacent flat surfaces. Furthermore, invertebrates were also noted living on the edges and on the undersides of the keels. One of the problems with bilge keel edges and weld seams is that the application of sprayed anti-fouling coating is often thinner on these areas, hence they are subjected to more turbulent flow and higher polishing rates making these surfaces susceptible to biofouling (Godwin and Eldredge 2001; John Lewis pers. comm.). Furthermore, the undersides of the bilge keels provide sheltered areas where polishing rates are slower, thus enabling various biofouling organisms to colonise and survive.

Interestingly, rope guards and rudders in particular also possessed a variety of invertebrate taxa. Similarly, although bulbous bows are probably subjected to some of the strongest hydrodynamic forces on merchant vessels, the anchor chains often remove the anti-fouling coating from this location, thus providing a non-toxic surface for biofouling organisms to colonise. Unfortunately, little can be done to prevent the removal of anti-fouling coating from bulbous bows by anchor chains. Anchor chains may also be responsible for de-fouling and introducing marine biofouling organisms. Usually only hydrodynamic-insensitive biofouling taxa that are morphologically suited 
are capable of surviving such harsh hydrodynamic environments (e.g. Koehl 1982; Denny 1988). Although, some hydrodynamic-sensitive taxa (e.g. Category B and C taxa) can colonise bulbous bows on vessels that have experienced prolonged periods of inactivity (e.g. vessels 6 and 9), it is unlikely that they would survive in this location if the vessel returned to service.

The third grouping of hull locations (i.e. OutDDSS, DDSS, and sea-chest gratings) was grouped together because of their relatively low abundance of algal taxa and high percentage cover of anti-fouling coating. This is because these locations, especially OutDDSS and DDSS, receive very little light because of the shading effects of bilge keels, hence limiting algal growth. Similarly, sea-chest gratings are usually located at the turn of the bilge and underneath the vessels where light is limited. OutDDSS were the least fouled hull location on average because of limited light availability coupled with the effective release of biocides as a result of their exposure to relatively normal hydrodynamic water flows. However, OutDDSS of the two most heavily fouled vessels (i.e. 6 and 9) were colonised by a range of biofouling taxa. As mentioned previously, their inactivity resulted in inadequate biocide release to prevent biofouling. In a similar context, Preiser and Ticker (1985) found that DDSS provided a nucleus for invertebrates to migrate into surrounding areas (OutDDSS) as a result of the leaching rates of the anti-fouling coatings declining with time.

Although DDSS may be subjected to relatively strong hydrodynamic forces, this location was often colonised by category $\mathrm{C}$ and $\mathrm{D}$ taxa, including a relatively high average weighted percentage cover for all three vessel types. Such areas usually possess old and ineffective anti-fouling coating, providing invertebrates with a suitable non-toxic surface to colonise. Sometimes, given DDSS are located at depth (e.g. 5-12 $\mathrm{m})$, they are not as frequently exposed to freshwater as upper regions of the hull (e.g. ports established in freshwater dominated environments), which may also contribute to the prolonged survivorship of particular biofouling organisms within this location (Visscher 1928; Apte et al. 2000). Rainer (1995) and Coutts (1999) also found DDSS of merchant vessels to possess a greater degree of biofouling than most other hull locations. Interestingly, James and Hayden (2000) generally found greater levels of biofouling organisms within DDSS of recreational craft compared with this location on merchant vessels. 


\subsubsection{Weighted percentage cover}

Variation in the weighted percentage cover data was shown to be dependent on vessel type with the "other" vessel category, which included the two trans-Tasman vessels, being particularly important. As stated previously, trans-Tasman vessels have been found to be more heavily fouled than vessels observed on most other pathways. DDSS, propeller, rope guard, sea-chest gratings, and rudder locations all had relatively high values for the "other" vessel type category, and DDSS had relatively high values for all three vessel types. DDSS and sea-chest gratings had the highest average weighted percentage cover of the higher taxonomic groups (i.e. categories $\mathrm{C}$ and $\mathrm{D}$ ), which suggests that these locations may have the greatest likelihood of housing NIMS. For instance, Coutts (1999) sampled the more uniform areas of merchant vessel hulls visiting Tasmanian waters, and found that DDSS had $89 \%$ of the taxa encountered (including NIMS). Furthermore, DDSS can represent $5 \%$ and $20 \%$ of the submerged area of the hull (Preiser and Ticker 1985), hence such areas are capable of housing high numbers of NIMS (Coutts 1999).

\subsubsection{Biosecurity risk}

The presence of certain taxa and relatively high levels of biofouling upon the hulls of merchant vessels does not necessarily equate to a significant biosecurity risk. The risk also depends on whether NIMS are present and their potential for establishment in the recipient location, whether or not the NIMS are already present there, and the extent of the potential negative (and positive) impacts (i.e. pest status). Clearly, the highest biosecurity risks of visiting international vessels visiting New Zealand are those carrying unwanted NIMS. Biosecurity New Zealand has so far listed six unwanted NIMS under their Biosecurity Act 1993 (i.e. Mediterranean fanworm Sabella spallanzanii, European green crab Carcinus maenas, northern Pacific seastar Asterias amurensis, Chinese mitten crab Eriocheir sinensis, green seaweed Caulerpa taxifolia and the Asian clam Potamocorbula amurensis) given they all had demonstrable ecological and economic impacts outside their native ranges (Mountfort 1998; Biosecurity Council 2003).

Of particular interest are the two heavily fouled trans-Tasman vessels that were laid up in Auckland for three months before the survey. If these vessels were put back into 
service, however, a key question is whether these well established biofouling communities would be more or less susceptible to invasion from NIMS during their visit to Australia. For instance, the classic hypothesis proposed by Elton (1958), which states that species diversity enhances community resistance to invasion by NIMS, would suggest that the biofouling communities on these vessels would be relatively immune to invasion by NIMS.

Alternatively, recent studies have shown that communities high in species diversity are more likely to be invaded by NIMS (e.g. Robinson et al. 1995; Planty-Tabacchi et al. 1996; Wiser et al. 1998; Levine and D’Antonio 1999; Lonsdale 1999; Stohlgren et al. 1999; Levine 2000). If this alternative hypothesis is accepted, then heavily fouled transTasman vessels may be more susceptible to invasion by NIMS and therefore capable of introducing unwanted species (e.g. S. spallanzanii, C. maenas, and A. amurensis) to New Zealand.

Many measures such as dry biomass, species or taxa richness, species diversity, and percentage cover of biofouling organisms upon a vessel's hull have been used to assess both the performance of anti-fouling coatings and to gain a better understanding of the biofouling processes (Visscher 1928; Pyefinch 1950; Woods Hole Oceanographic Institution 1952; Cologer and Preiser 1981), and to identify vessels and hull locations that present biosecurity risks (Skerman 1960; Huang et al. 1979; Rainer 1995; Coutts 1999; James and Hayden 2000; Godwin and Eldredge 2001; Gollasch 2002; Minchin and Gollasch 2003; this study).

The weighted percentage cover variable used in this study provides an alternative approach as it aims to take into account not only the nature and extent of the biofouling, but also the development and growth of the biofouling community. However, the variable is clearly simplistic and somewhat biased in terms of the information it provides on biosecurity risk (e.g. it does not consider the presence of NIMS, or the biosecurity risks associated with certain taxa such as fine and filamentous algae, and mobile invertebrate species). We recommend that future research should be undertaken to further develop the approach. This should include a revision of the taxonomic groupings applied in this study. Also, the weighted percentage cover variable used in this study might be further refined by applying a weighting scale better suited to the 
invasion history of each taxa (e.g. the taxonomic groups used in this study could have been weighted by the number of unwanted NIMS from a list such as that described above).

\subsubsection{Management}

New Zealand is in the process of developing mandatory biofouling requirements as an Import Health Standard under their Biosecurity Act 1993. Any border surveillance of merchant vessels for NIMS should focus primarily on niche areas, particularly DDSS and sea-chest gratings. It is also recommended that the inside of sea-chests be inspected for mobile organisms considering recent research has illustrated that such structures have the potential to disperse a variety of biofouling organisms (Richards 1990; Carlton et al. 1995; Coutts et al. 2003; Coutts and Dodshun 2007). In addition, given that Coutts (1999) found microscopic alternate life stages of macrothalloid brown algae (which were fruiting in some samples) at the waterline of merchant vessels, this hull location should also be sampled for potential non-indigenous algal species (e.g. the invasive Japanese kelp Undaria pinnatifida is known to be translocated via the hulls of vessels; Hay 1990).

Despite DDSS being an inevitable consequence of the dry-docking procedure, they can be managed simply by the judicious placement of the docking blocks at each docking to ensure they are in a different location at alternative dockings. Alternatively, Preiser and Ticker (1985) devised a way of applying adhesive anti-fouling coating pads to the docking blocks before a vessel's docking, so that when the vessel departed the dry-dock these normally unprotected areas were treated with anti-fouling coating. However, as far as the author is aware, this technology has not been pursued any further. Also, there are anti-fouling coatings that can be applied underwater, and these could be used to protect DDSS as well as damaged regions of the hull. Another, albeit expensive solution, might be to replace existing dry-docks with two sets of hydraulic docking blocks, so that anti-fouling coating can be applied to the entire bottom of the vessel using a two-stage operation.

A possible way of managing the biosecurity risks from propellers is to coat them with an anti-fouling coating resistant to cavitation where the propeller motion provides the

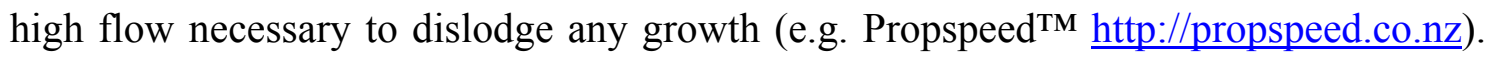


It is also significant to note that the use of the most effective anti-fouling coating produced to date, tributyltin (TBT) is now prohibited on vessels greater than 24 metres in length (International Convention on the Control of Harmful Anti-fouling Systems on Ships, 2001). This means that the application of anti-fouling coatings that have been specially formulated for use on various types of vessels and hull locations is of paramount importance from a biosecurity perspective (Lewis 2002).

\subsection{ADDENDUM}

Despite this Chapter being conducted over five years ago, this research or rather Coutts and Taylor (2004) has made a significant contribution towards further scientific studies in this area. The author is aware of eight studies in particular that have researched the nature and extent of biofouling and NIMS on merchant vessels (this includes reference to bulk carriers, chemical tankers, cargo, commercial, and container vessels) (see Table 7 for a summary). Of these, four papers (i.e. Drake and Lodge 2007; Farrapeira et al. 2007; Otani et al. 2007; Sylvester and MacIsaac 2010) adopted a similar experimental design to the present chapter and made special reference and comparisons with Coutts and Taylor (2004). Moreover, the unprecedented Biosecurity New Zealand vessel biofouling research program's vessel sampling design was also heavily influenced by the findings of Coutts and Taylor (2004) (see BLG 12/INF 4, 2007; Table 7).

All eight studies have further contributed significantly towards our understanding of the nature and extent of biofouling and non-indigenous aquatic species on merchant vessels. While the majority of their findings were consistent with that of Coutts and Taylor (2004), some findings were inconsistent (see also Table 7):

- Dry-docking support strips were relatively free of biofouling (i.e. Australian Shipowners Association 2006; Davidson et al. 2009; Sylvester and MacIsaac 2010). I am unable to explain this inconsistency.

- Leading and trailing edges of rudders appeared to accumulate the highest levels of biofouling (i.e. Davidson et al. 2009; Sylvester and MacIsaac 2010). The video recordings used during the Coutts and Taylor (2004) did not focus on these areas. 
- Time since dry-docking and time since the application with anti-fouling were not related to hull fouling variables (i.e. Mineur et al. 2007; Sylvester and MacIsaac 2010). The Mineur et al. (2007) study only focused on algae and many algal species are known to be resistant to copper biocides (e.g. Christie et al. 1976; Hall et al. 1979; Evans 1981; Reed and Moffat 1983; Callow 1986). Therefore, if such species are able to colonise relatively new anti-fouling coatings, then this might explain this result. The Sylvester and MacIsaac (2010) studied vessels that consistently exposed vessels to extreme salinity gradients (i.e. Great Lakes and open-ocean) that may have consistently limited the biofouling succession on such vessels and any notable correlation.

Some of the most interesting findings of these studies included (see also Table 7):

- Sylvester and MacIsaac (2010) noted a negative correlation between biofouling intensity and time spent operating in high latitude waters, and a positive correlation with time spent in ports on the Pacific coast of South America.

- Sylvester and MacIsaac (2010) used a custom designed scraping and vacuum system which is a significant advancement over the plastic bag and putty scraper method used by Coutts and Taylor (2004).

- Mineur et al. (2007) recorded the highest number of algal species, including NIMS on a vessel that used a non-toxic coating (Intersleek $757^{\circledR}$ silicone elastomer). Furthermore, they highlight the increase use of non-toxic coatings as a response of the AFS Convention and the biosecurity threat such a shift could have in the global dispersal of non-indigenous algal species. 
Table 7 Summary of known research that has focussed on biofouling and non-indigenous marine species on merchant vessels (this includes reference to bulk carriers, chemical tankers, cargo, commercial, and container vessels) since Coutts and Taylor (2004).

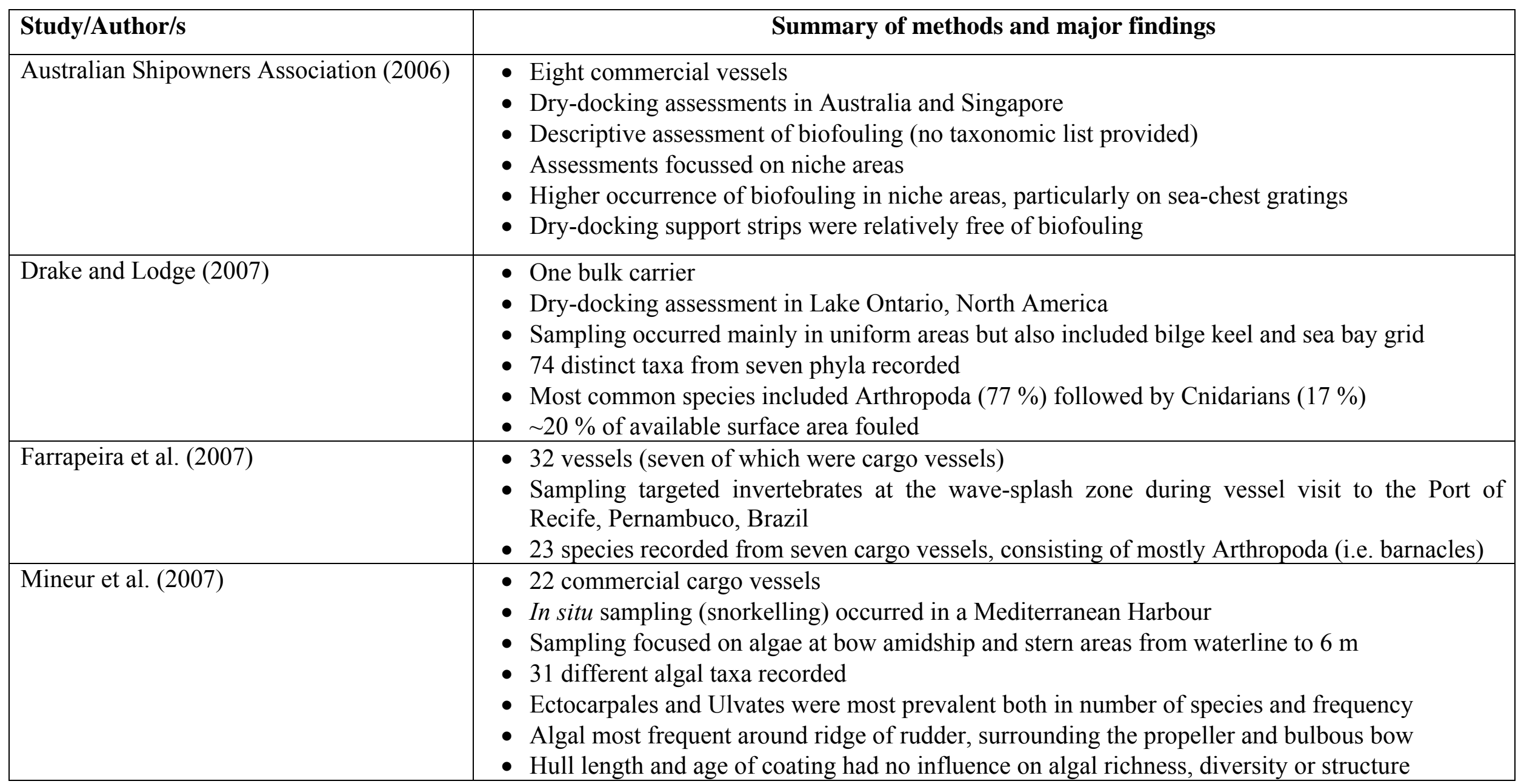


Table 7 Continued.

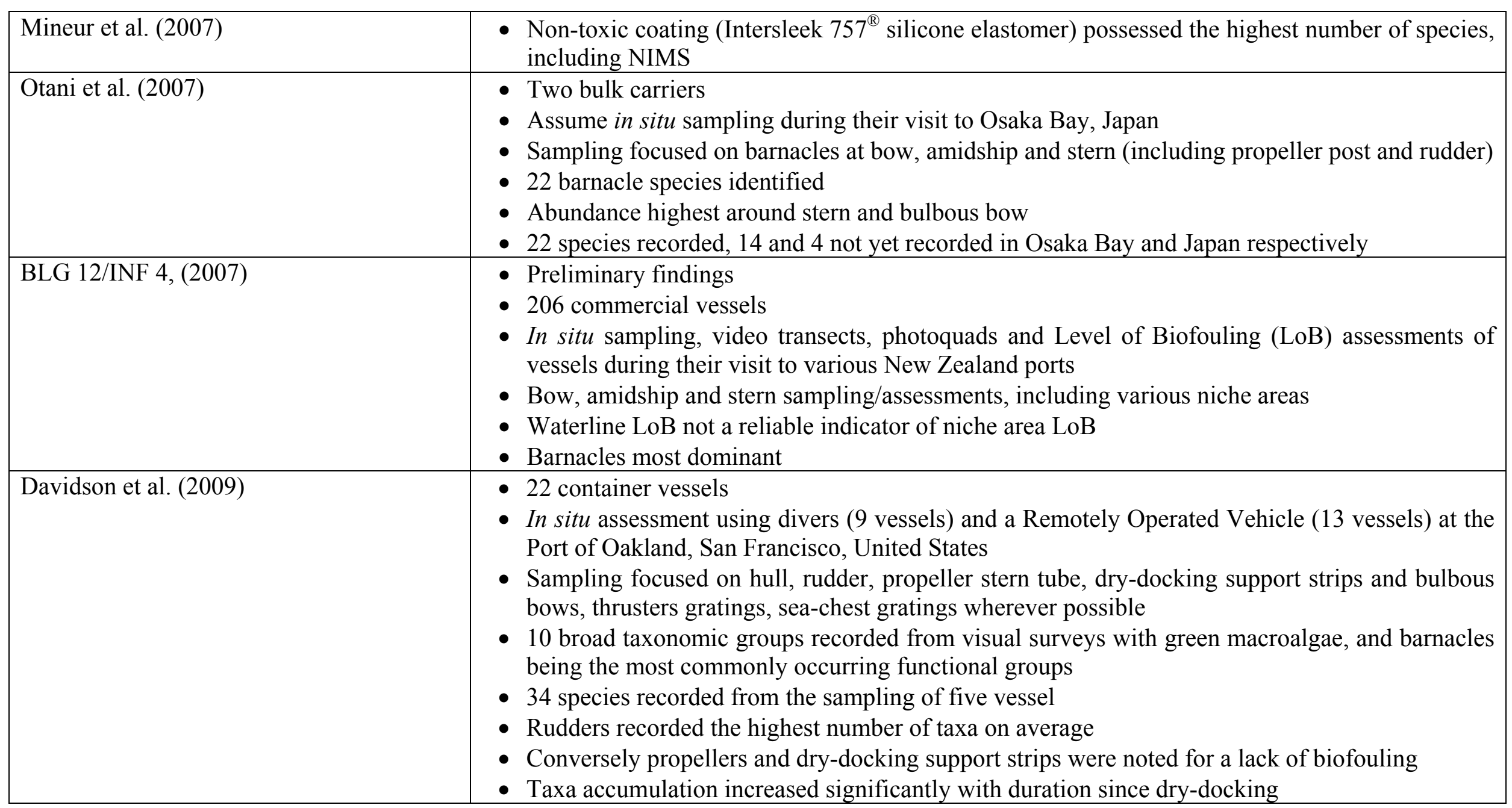


Table 7 Continued.

\begin{tabular}{|c|c|}
\hline Sylvester and MacIsaac (2010) & $\begin{array}{l}\text { - } 20 \text { commercial vessels ( } 16 \text { bulk carriers and } 4 \text { chemical tankers) } \\
\text { - In situ assessment using divers both Canadian (Clarkson, Hamilton) and United States } \\
\text { (Cleveland and Toledo) ports } \\
\text { - Replicated Chapter } 3 \text { (Coutts and Taylor } 2004) \text { sampling design } \\
\text { - Sampling used a custom designed scraping and vacuum system } \\
\text { - } 57 \text { different species were recorded } \\
\text { - Barnacles }(51 \%) \text {, cladocerans }(19 \%) \text {, bivalves }(12 \%) \text {, and amphipods ( } 11 \%) \text { were the most } \\
\text { - abundant } \\
\text { - } 21 \text { marine taxa recorded are not known to occur in the Great Lakes } \\
\text { - Leading edge of rudder and sea-chest grating accumulated the most species } \\
\text { - Leading and trailing edge of rudders and rope guard were among the most heavily fouled } \\
\text { locations } \\
\text { - Species richness and invertebrate abundance were also negatively correlated with sailing speed } \\
\text { - Negative correlation between biofouling intensity and time spent operating in high latitude } \\
\text { waters, and a positive correlation with time spent in ports on the Pacific coast of South America } \\
\text { - Time since dry-docking and time since painted with anti-fouling were not related to hull fouling } \\
\text { variables }\end{array}$ \\
\hline
\end{tabular}




\subsection{REFERENCES}

Allen, F. E., 1953. Distribution of marine invertebrates by ships. Australian Journal of Marine Freshwater Research 4: 307-316.

Apte, S., Holland, B. S., Godwin, L. S, Gardner, P. A., 2000. Jumping ship: a stepping stone event mediating transfer of non-indigenous species via a potentially unsuitable environment. Biological Invasions 2: 75-79.

Australian Shipowners Association, 2006. Assessment of introduced marine pest risks associated with niche areas in commercial shipping, June 2006. 24 p.

Biosecurity Council, 2003. Protect New Zealand: the biosecurity strategy for New Zealand. Wellington, Biosecurity Council. 63 p.

Bishop, M. W. H., Pyefinch, K. A., Spooner, M. F., 1949. The examination and interpretation of fouling samples from ships. Journal of Iron and Steel Institute 161: $35-40$.

BLG 12/INF. 4, 2007. Preliminary findings of a research programme to assess the risk of bio-fouling of ships arriving in New Zealand Paper presented by New Zealand to the Sub-Committee on Bulk Liquids and Gases, $12^{\text {th }}$ session, Agenda item 11, 30 November 2007.5 pp.

Bray, J. R., Curtis, J. T., 1957. An ordination of the upland forest communities of Southern Wisconsin. Ecological Monographs 27: 325-349.

Callow, M. E., 1986. Fouling algae from "In-service" ships. Botanica Marina 24: 351357.

Carlton, J. T., 1987. Patterns of transoceanic marine biological invasions in the Pacific. Bulletin of Marine Science 41: 452-465.

Carlton, J. T., Reid, D. M., van Leeuwen, H., 1995. Shipping study: the role of shipping in the introduction of non-indigenous aquatic organisms to the coastal waters of the United States (other than the Great Lakes) and an analysis of control options. United States Coast Guard, Connecticut, Department of Transportation, Washington District of Columbia. Pp. 1-213. 
Christie, A. O., Daley, R., 1987. Barnacle fouling and its prevention. Barnacle Biology: 419-433.

Clark, K. R., 1993. Non-parametric multivariate analyses of changes in community structure. Australian Journal of Ecology 18: 117-143.

Cohen, A. N., Carlton, J. T., 1995. Biological study. Nonindigenous aquatic species in a United States estuary: a case study of the biological invasions of the San Francisco Bay and Delta. United States Fish and Wildlife Service, Washington District of Columbia and the National Sea Grant College Program, Connecticut Sea Grant, NTIS No. PB96-166525.

Cologer, C. P., Preiser, H. S., 1981. Fouling and paint behavior on naval surface ships after multiple underwater cleaning cycles. In: Costlow, J. D; Tipper, R. C., (Eds). Proceedings of the Symposium on Marine Biodeterioration: an interdisciplinary study. Uniformed services. University of Health Sciences, 20-23 April 1981. Pp. 207-212.

Coutts, A. D. M., 1999. Hull fouling as a modern vector for marine biological invasions: investigation of merchant vessels visiting northern Tasmania. Unpublished MSc thesis, Australian Maritime College, Launceston, Australia. 283 p.

Coutts, A. D. M., 2002. A biosecurity investigation of a barge in the Marlborough Sounds. Cawthron Report No. 744.59 p.

Coutts, A. D. M., Taylor, M. D., 2004. A preliminary investigation of biosecurity risks associated with biofouling on merchant vessels in New Zealand. New Zealand Journal of Marine and Freshwater Research 38: 215-229.

Coutts, A. D. M, Dodgshun, T. J., 2007. The nature and extent of fouling in vessel seachests: a protected mechanism for marine bioinvasions. Marine Pollution Bulletin 54: 876-886.

Coutts, A. D. M., Moore, K. M., Hewitt, C. L., 2003. Ships'sea-chests: an overlooked transfer mechanism for non-indigenous marine species. Marine Pollution Bulletin 46: 1510-1512. 
Cranfield, H. J., Gordon, D. J., Willan, R. C., Marshall, B. C., Battershill, C. N., Francis, M. P., Nelson, W. A., Glasby, C. J., Read, G. B., 1998. Adventive marine species in New Zealand. NIWA Technical Report No. 34. 48 p.

Davidson, I., C., Brown, C. W., Sytsma, M. D., Ruiz, G. M., 2009. The role of containerships as transfer mechanisms of marine biofouling species, Biofouling 25: $645-655$

DeFelice, R. C., 1999. Fouling marine invertebrates on the floating dry dock USS Machinist in Pearl Harbour to its move to Apra Harbour, Guam. Hawai'i Biological Survey, Bernice P. Bishop Museum Honolulu, Hawaii. Contribution No. 1999-013 to the Hawaii Biological Survey.

Denny, M. W., 1988. Biology and the mechanics of wave-swept environments. New Jersey, Unites States, Princeton University Press. Pp.1-132.

Drake, J. M., Lodge, D. M., 2007. Hull fouling is a risk factor for intercontinental species exchange in aquatic ecosystems. Aquatic Invasions 2: 121-131.

Elton, C. S., 1958. The ecology of invasions by animals and plants. London, Methuen and Co Ltd. Pp. 1-181.

Evans, L. V., 1981. Marine algae and fouling: A review, with particular reference to ship-fouling. Botanica Mariner 24: 167-171.

Farrapeira, C. M. R., de Melo, A. V. O. M., Barbosa, D., F., da Silva, K. M. E., 2007. Ship hull fouling in the Port of Recife, Pernambuco. Brazilian Journal of Oceanography 55:207-221.

Field, D., 1999. Disaster averted? Black striped mussel outbreak in northern Australia. Fish Farming International 26: 30-31.

Foster, B. A., Willan, R. C., 1979. Foreign barnacles transported to New Zealand on an oil platform. New Zealand Journal Marine Freshwater Research 13: 143-149.

Godwin, L. S., Eldredge, L. G., 2001. South Oahu Marine Invasions Shipping Study (SOMISS). Technical Report No. 20. Honolulu. Hawaii Biological Survey, Bishop Museum. 104 p 
Gollasch, S., 2002. The importance of ship hull fouling as a vector of species introductions into the North Sea. Biofouling 18: 105-121.

Greene, C. H., Schoener, A., 1982. Succession on marine hard substrata. A fixed lottery. Oecologia 55: 289-297.

Hall, A., 1981. Copper accumulation in copper-tolerant and non-tolerant populations of marine fouling alga Ectocarpus siliculosus (dillw.) Lyngebye. Botanica Marina 24: $223-228$.

Hay, C. H., 1990. The dispersal of Undaria pinnatifida by coastal shipping in New Zealand, and implications for further dispersal of Undaria to France. British Phycological Journal 25: 301-313.

Hay, C. H., Dodgshun, T., 1997. Ecosystem transplant? The case of the Yefim Gorbenko. Seafood New Zealand, May 1997: 13-14.

Hewitt, C. L., 2002. The distribution and biodiversity of tropical Australian marine bioinvasions. Pacific Science 56: 213-222.

Hewitt, C. L., Campbell, M. L., Thresher, R. E., Martin R. B., 1999. Marine biological invasions of Port Phillip Bay, Victoria. Technical Report No. 20. Hobart, Australia, CSIRO Marine Research, Centre for Research on Introduced Marine Pests. 344 p.

Huang, X. M., Ni, W. Z., Lu, H. Q., Lui, K. D., 1979. A study of the interrelation between service condition of ships and fouling organisms. Oceanologia et Limnologia Sinica 10: 82-90.

James, P., Hayden, B., 2000. The potential for the introduction of exotic species by vessel hull fouling: a preliminary study. NIWA Technical Report No. 16.15 p.

Koehl, M. A. R., 1982. The interaction of moving water and sessile organisms. Science America 247: 124-134.

Levine, J. M., 2000. Species diversity and biological invasions: relating local processes to community pattern. Science $288: 852-854$. 
Levine, J. M., D’Antonio, C. M., 1999. Elton revisited: a review of evidence linking diversity and invasibility. Okos 87: 15-26.

Lewis, J., 2002. Hull fouling as a vector for the translocation of marine organisms. Phase I Study. Ballast Water Research Series. Report 14. Canberra. Australian Government Department of Agriculture, Fisheries and Forestry. 142 p.

Lewis, P. N., Hewitt, C. L., Riddle, M., McMinn, A., 2003. Marine introductions in the Southern Ocean: an unrecognised hazard to biodiversity. Marine Pollution Bulletin 46: 213-223.

Lonsdale, W. M., 1999. Concepts and synthesis: global patterns of plant invasions, and the concept of invasibility. Ecology 80: 1522-1536.

Marine Corrosion Sub-Committee, 1944. Fouling of ships' bottoms: identification of marine growths. Journal of Iron and Steel Institute 150: 143-156.

Minchin, D., Gollasch, S. 2002. Vectors-how exotics get around. In: Leppakoski, E.; Gollasch, S.; Olenin, S. ed. Invasive aquatic species of Europe: distribution, impact and management. London, Kluwer. Pp. 183-192.

Minchin, D., Gollasch, S., 2003. Fouling and ships' hulls: how changing circumstances and spawning events may result in the spread of exotic species. Biofouling 19: 111122.

Mineur, F., Johnson, M.P., Maggs, C.A., Stegenga, H., 2007. Hull fouling on commercial ships as a vector of macroalgal introduction. Marine Biology 151:1299-1307.

Mountfort, D. O., 1998. Current status of ballast water treatment research at Cawthron Institute, Nelson, New Zealand. Report prepared for Australian Quarantine and Inspection Services, Canberra, Australia. Cawthron Report No. 446.

Nehring, S., 2001. After the TBT era: alternative anti-fouling paints and their ecological risks. Senckenbergiana Maritime 3: 341-351. 
Otani, M., Oumi, T., Uwai, S., Hanyuda, T., Prabowo, R. E., Yamaguchi, T. and Kawai, H., 2007. Occurrence and diversity of barnacles on international ships visiting Osaka Bay, Japan, and the risk of their introduction. Biofouling 23: 277-286

Planty-Tabacchi, A., Tabacchi, E., Naiman, R. J., De-Ferrari, C., Decamps, H., 1996. Invasibility of species-rich communities in riparian zones. Conservation Biology 10: 598-607.

Preiser, H. S., Ticker. A., 1985. A novel system for preserving hull areas obscured by docking blocks for optimum fuel savings. United States Department of the Navy Report. Pp. 297-313.

Pyefinch, K. A., 1950. Notes on the ecology of ship-fouling organisms. Journal of Animal Ecology 19: 29-35.

Rainer, S., 1995. Potential for the introduction and translocation of exotic species by hull fouling: a preliminary assessment. Centre for Research on Introduced Marine Pests. Hobart, Tasmania. Technical Report No. 1.18 p.

Reed, R. H., Moffat, L., 1983. Copper toxicity and copper tolerance in Enteromorpha compressa (L.) Grev. Journal of Experimental Biology and Ecology 69: 85-103.

Richards, A., 1990. Murricids: a hazard to navigation? Hawaiian Malacological Society. Hawaii Shell News 38: 10.

Robinson, G. R., Quinn, F. J., Stanton, M. L., 1995. Invasion of experimental habitat islands in a California winter annual grassland. Ecology 76: 786-794.

Ruiz, G. M., Carlton, J. T., Grosholz, E. D., Hines, A. H., 1997. Global invasions of marine and estuarine habitats by non-indigenous species: mechanisms, extent, and consequences. American Zoologist 37: 621-632.

Ruiz, G. M., Fofonoff, P. W., Carlton, J. T., Wonham, M. J., Hines, A. H., 2000. Invasion of coastal marine communities in North America: apparent patterns, processes, and biases. Annual Reviews in Ecology and Systematics 31: 481-531.

SAS/STAT., 1990. Version 6.11. Cary, North Carolina, United States. SAS Institute Inc. 
Schormann, J., Carlton, J. T., Dochoda, M. R., 1990. The ship as a vector in biotic invasions. Marine Technology and the Environment 19: 147-152.

Schultz, M., Swain, G. W., 2000. The influence of biofilms on skin friction drag. Biofouling 15: 129-139.

Skerman, T. M., 1960. Ship-fouling in New Zealand waters: a survey of marine fouling organisms from vessels of the coastal and overseas trades. New Zealand Journal of Science 3: 620-48.

Stohlgren, T. J., Binkley, D., Chong, G. W., Kalkhan, M. A., Schell, L. D., Bull, K. A., Otsuki, Y., Newman, G., Bashkin, M., Son, Y., 1999. Exotic plant species invade hot spots of native plant diversity. Ecological Monographs 69: 25-46.

Sylvester, F., MacIsaac, H. J., 2009. Is vessel hull fouling an invasion threat to the Great Lakes? Diversity and Distributions 16: 132-143.

Thresher, R. E., 1999. Diversity, impacts and options for managing invasive marine species in Australian waters. Journal of Environmental Management 6: 137-148.

Thresher, R. E., Hewitt, C. L., Campbell, M. L., 1999. Synthesis: introduced and cryptogenic species in Port Phillip Bay. In: Hewitt, C. L., Campbell, M. L., Thresher, R. E, Martin, R. B. ed. Marine biological invasions of Port Phillip Bay, Victoria. Centre for Research on Introduced Marine Pests. Technical Report No. 20. Pp. 283-295.

Visscher, J. P., 1928. Nature and extent of fouling of ships bottoms. Bulletin Bureau of Fisheries 43: 193-252.

Wiser, S. K., Allen, R. B., Clinton, P. W., Platt, K. H., 1998. Community structure and forest invasion by an exotic herb over 23 years. Ecology 79: 2071-2081.

Wonham, M. J., Carlton, J. T., Ruiz, G. M., Smith, L. D., 2000. Fish and ships: relating dispersal frequency to success in biological invasions. Marine Biology 136: 11111121.

Woods Hole Oceanographic Institution, 1952. Marine fouling and its prevention. Annapolis, Maryland, United States Naval Institute. Pp. 1-388. 


\title{
Chapter 4 - A novel method for assessing the en route survivorship of biofouling organisms
}

\section{PREFACE}

In light of the previous two chapters, the logical progression was to assess the intrinsic survivorship of biofouling organisms on various vessels in different hull locations. This necessitated the development of a novel method of attaching and removing pre-fouled settlement plates to vessel hulls. This chapter describes the design, methods and results of the technique used to attach pre-fouled settlement plates to vessel hulls at different hull locations. This work has been published in a refereed journal and is presented below in identical form. The citation for the original publication is:

Coutts, A. D. M., Taylor, M. D., Hewitt, C. L., 2007. Novel method for assessing the en route survivorship of biofouling organisms on various vessel types. Marine Pollution Bulletin 54: 97-100.

\begin{abstract}
A novel method for attaching pre-fouled settlement plates to vessels' hulls was developed to assess the en route survivorship of biofouling organisms on various vessel types at different hull locations. Various prototypes were initially trialled on a RO/RO passenger ferry operating across the Cook Strait, New Zealand between Wellington (North Island) and Picton (South Island) between May and October 2004. The most successful prototype relied on a magnetically attached base plate ('MAGPLATE') onto which a settlement plate could be affixed. Further trials resulted in a total of 162 individual MAGPLATE being attached and successfully retrieved (100\% retrieval) from 18 voyages on various vessel types ranging from 3 to 22 knots and from 3 to $7 \mathrm{~h}$ voyage durations. The development of this tool enabled the next chapter to proceed.
\end{abstract}




\subsection{INTRODUCTION}

Shipping is considered the single largest vector for the human-mediated movement of non-indigenous marine species (NIMS) around the world (e.g. Ruiz et al. 1997; Minchin and Gollasch 2002). A variety of shipping mechanisms (e.g. ballast and bilge water discharges, biofouling, de-fouling, sea-chests, sea sieves, anchors, chain lockers and piping; see Carlton et al. 1995; Schormann et al. 1990) are capable of transporting NIMS to new locations.

Biofouling is now being acknowledged as one of the single most important dispersal mechanisms alongside ballast water (e.g. Cranfield et al. 1998; Thresher et al. 1999; Hewitt 2002; Gollasch 2002; Hewitt et al. 2004). It is not currently known, however, which vessel types, pathways or levels of biofouling (e.g. species richness, abundance, percentage cover, biomass, etc) constitute the greatest biosecurity risk to receiving locations. For example, barges, oil exploration rigs, floating dry-docks, decommissioned, or specialised vessels are renowned for accumulating relatively high levels of biofouling over their entire hull, often including widely recognised NIMS that are capable of surviving slow ocean voyages to new locations (e.g. Foster and Willan 1979; Hay 1990; Hay and Dodgshun 1997; Brock et al. 1999; Coles et al. 1999; DeFelice 1999; Field 1999; Apte et al. 2000; Godwin and Eldredge 2001; Coutts 2002; Godwin 2003). Alternatively, relatively high levels of biofouling, often including NIMS, have been observed on more active and faster-moving vessels such as merchant vessels in areas of the hull experiencing reduced flow or where anti-fouling coatings are damaged or have poor anti-fouling application (e.g. dry-docking support strips (DDSS), bow thrusters, bilge keels, rope guards, sea-chests, rudder posts) (Rainer 1995; Coutts 1999; James and Hayden 2000; Schultz and Swain 2000; Lewis et al. 2003; Coutts et al. 2003; Coutts and Taylor 2004).

Nevertheless, biosecurity risk largely depends on the survivorship of NIMS or unwanted biofouling species from a donor to recipient locations Our knowledge of the survivorship of NIMS and biofouling organisms on vessels is predominantly a result of researchers inspecting vessel post-voyage either in situ or dry-dock, and conducting retrospective analyses of survivorship relative to the vessel's operating speed, duration and/or route (see Lewis 2002 for summary). Relatively few studies have actually assessed the recruitment and en route survivorship of biofouling organisms on a vessel's hull (i.e. Carlton and Hodder 1995; Brock et al. 1999; Davidson et al. 2008) or 
have undertaken an experimental assessment of biofouling from a biological invasion perspective. In part, this is due to the constraints of accessing and manipulating biofouling communities in situ. Access to commercial vessels has hitherto been restricted to one-off evaluations in dry-dock or through significant efforts of individual researchers to overcome the occupational health and safety concerns and increased security precautions in port environments (e.g. Rainer 1995; Coutts 1999; James and Hayden 2000).

In order to undertake empirical evaluations, we have developed a novel method for attaching settlement plates to vessels' hulls to assess the en route survivorship of biofouling organisms on various vessel types at different hull locations. These settlement plates can be introduced to different regions of a hull and placed at various stages of community development. Moreover, unlike most other studies, the development of such a novel method has the potential to enable manipulative experiments that are capable of quantifying the survivorship of biofouling species with precision and accuracy. Here we describe the design and use of the settlement plate attachments and describe other potential applications. The challenge was to design a method of attaching settlement plates to a variety of vessel types at different hull locations that would not harm the integrity of the hull, yet provide a rapid, easy to use and reliable mechanism for affixing and retrieving settlement plates that does not significantly alter vessel operations.

\subsection{METHODS}

A variety of settlement plate prototypes and attachment methods were trialled between May and October 2004 on a Roll-On/Roll-Off (RO/RO) passenger ferry (14,588 gross weight tonnes) operating across the Cook Strait, New Zealand between Wellington (North Island) and Picton (South Island) - a return distance of $\sim 102$ nautical miles. With permission from the ferry operators and Port Marlborough New Zealand Limited, SCUBA divers attached the prototypes to the bow of the vessel on the portside during berthing in Picton Harbour. All prototypes were subjected to an average voyage speed of $\sim 18$ knots for $\sim 7 \mathrm{~h}$ and retrieved during the vessel's return to Picton Harbour. The most successful prototype relied on a magnetically attached base plate (hereinafter termed a 'MAGPLATE') onto which a settlement plate could be affixed. The MAGPLATE consisted of eight capped neodymium iron boron (NIB) magnets (52 Ø x 
7.4 with a $4.5 \mathrm{~mm}$ central hole) bolted to the underside of a stainless steel (316 marine grade) base plate measuring 275 × $200 \times 13.4 \mathrm{~mm}$ (Figure 14).

All surrounding edges of the stainless steel base plate were bevelled at an angle of $45^{\circ}$ to reduce hydrodynamic drag acting on the plates. The outside edge of the top of the base plates were fitted with an $8 \times 5 \mathrm{~mm}$ strip of stainless steel with a $45^{\circ}$ bevelled edge designed to house and protect a settlement plate made of black acrylic $(235 \times 160 \times 3$ $\mathrm{mm}$ ) attached via seven counter-sunk screws (Figure 14). The settlement plates were coated with non-toxic coating (plasti-kote ${ }^{\mathrm{TM}} \mathrm{T}-19$ Red Oxide Primer) to mimic the surface texture and colour of the most frequently used anti-fouling coatings adopted in the maritime industry.

In order to assess effectiveness, 162 settlement plates were hung approximately $3 \mathrm{~m}$ below the surface of spring low tide beneath a local wharf in Picton Harbour for $\sim 150$ days until sufficient biofouling (i.e. $\sim 100 \mathrm{~g}$ weight biomass weight) had accumulated on the settlement plates. On 7 October 2004, the first set of en route survivorship trials commenced on nine different vessels visiting or operating in Picton (e.g., recreational vessels; towed and motorised barges; $\mathrm{RO} / \mathrm{RO}$ passenger ferries) representing three arbitrary speed categories: slow (3-6 knots); medium (8-10 knots), and fast (14.5-22 knots). Each individual vessel trial involved divers firstly removing 15 pre-fouled settlement plates from underneath the wharf. Each plate was gently inserted into a specially designed rack to protect plates during transportation. Divers then transferred the rack with the 15 plates to a support vessel at the surface where each plate was attached to the MAGPLATEs. MAGPLATEs were then reinserted into the racks ready for each trial.

Prior to a vessel's departure, divers attached three replicate MAGPLATEs at three different hull locations: 1) bow region where en route biofouling survivorship was predicted to be relatively low due to strong hydrodynamic forces; 2) stern region where en route biofouling survivorship may be enhanced due to their protection from strong hydrodynamic forces; and 3) amidship DDSS representing areas where anti-fouling coatings are old/ineffective and where relatively high levels of biofouling are known to exist, but the en route survivorship of biofouling organisms is unknown. The remaining six MAGPLATEs (i.e. three with magnets and three without magnets) were hung beneath the wharf for the duration of each vessel trial to assess the influence of 
magnetism on biofouling organisms. On the 7 January 2005, a second set of en route survivorship trials commenced replicating the same methods described above.

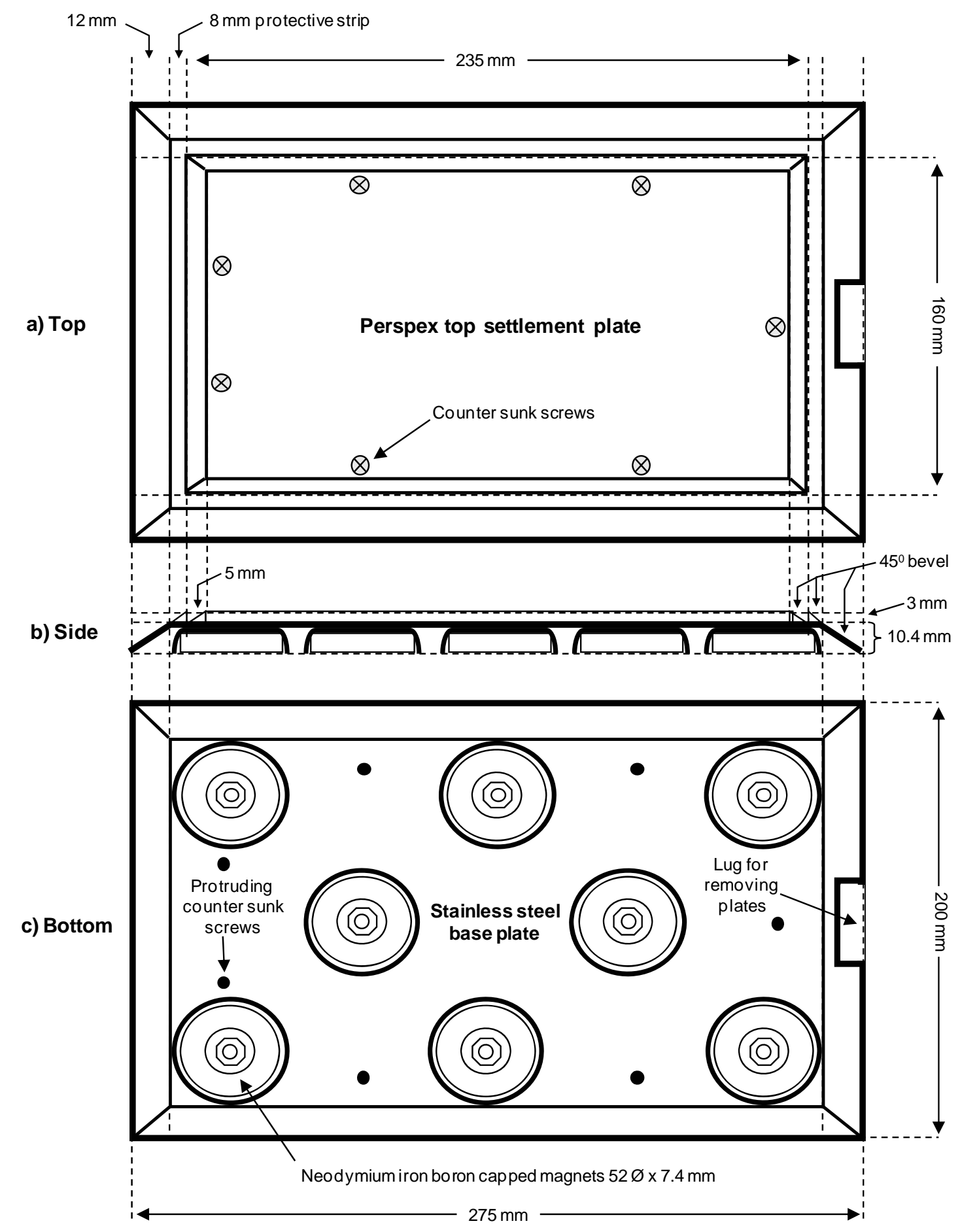

Figure 14 Diagram (not to scale) of the dimensions of the MAGPLATEs from a) top view, b) side view, and c) bottom view. 


\subsection{RESULTS AND DISCUSSION}

Of the 162 individual MAGPLATE trials, all have been successfully retrieved (100\% retrieval) from the 18 voyages on various vessel types ranging from 3 to 22 knots and from 3 to $7 \mathrm{~h}$ voyage durations. It took an average of $45.0 \pm 3.0 \mathrm{~min}( \pm 1 \mathrm{SE})$ to attach 15 settlement plates to the MAGPLATEs, an average of 3 min per plate. It took an average of only $23.0 \pm 3.0 \mathrm{~min}(\sim 2.5 \mathrm{~min}$ per plate) to attach nine MAGPLATEs to a vessel's hull and only $15.0 \pm 2.0 \mathrm{~min}(\sim 1.6 \mathrm{~min}$ per plate $)$ to retrieve them. Preliminary assessments have revealed that the NIB magnets used in the MAGPLATEs have had no noticeable influence on the persistence of the biofouling organisms on the settlement plates.

The final dimensions of the MAGPLATEs were a compromise between maximising adhesive strength to overcome the shear forces produced by a vessel travelling up to 22 knots, while simultaneously minimising the overall height or profile of the plates. For example, each NIB magnet produced a pull force of $7 \mathrm{~kg}$ or a total of $56 \mathrm{~kg}$ per MAGPLATE. However, this adhesive force necessitated an overall height of protrusion of $13.4 \mathrm{~mm}$ from the attachment surface. Hence, it is likely that the MAGPLATEs would protrude outside the boundary layer, particularly at the bow of faster moving vessels. We plan to further test MAGPLATEs in flume tanks to assess the hydrodynamic flow regime surrounding the plates at flow rates ranging from 3 to 22 knots. It might be possible to utilise thinner gauge stainless steel and NIB magnets to reduce the over height of the MAGPLATEs and protrusion from the hull. Moreover, their height could be significantly reduced if the trials were undertaken on slower moving vessels resulting in significantly lower shear forces enabling the use of smaller magnets and thinner materials.

Stainless steel (316 marine grade) was used for MAGPLATE construction to increase longevity in the marine environment while significantly reducing any magnetic effect on the biofouling organisms produced by the NIB magnets. However, the NIB magnets are susceptible to rusting, hence it is not currently known how long the MAGPLATEs could remain attached to a vessel's hull. Therefore, further research into methods of minimising or preventing the NIB magnets from rusting will be undertaken. MAGPLATEs provide an easy to use, safe and practical method of affixing and manipulating surfaces and biofouling communities on vessels. Cawthron is proposing to utilise the MAGPLATEs to undertake further trials to determine the en route 
survivorship and recruitment of biofouling organisms on different vessels types plying similar latitudes (e.g. between Australia and New Zealand); trans-equatorial routes (e.g. between Japan and New Zealand); and tropical to temperate routes and vice-versa (e.g. between Hawaii and New Zealand). MAGPLATEs may also be used to determine the en route survivorship of fouling organisms inside sea-chests and to test the efficacy of various treatment systems.

Presently, anti-fouling coatings are tested during in situ static trials and in rotary tanks. Some ship-based trials have been undertaken, however the coatings remain on the hull for the duration of the vessel's in-service period between successive dry-docks. MAGPLATEs could be used to test the performance of various anti-fouling coatings on different vessel types at various hull locations. Furthermore, MAGPLATEs could be used to assess the rates of recruitment and survivorship of biofouling organisms on various coating types on different vessel types at various hull locations.

\subsection{REFERENCES}

Apte, S., Holland, B. S., Godwin, L. S., Gardner, P. A., 2000. Jumping ship: a stepping stone event mediating transfer of non-indigenous species via a potentially unsuitable environment. Biological Invasions 2: 75-79.

Brock, R., Bailey-Brock, J. H., Goody, J., 1999. A case study of the efficacy of freshwater immersion in controlling introduction of alien marine fouling communities: the USS Missouri. Pacific Science 53: 223-231.

Carlton, J. T., Hodder, J., 1995. Biogeography and dispersal of coastal marine organisms: experimental studies on a replica of a $16^{\text {th }}$-century sailing vessel. Marine Biology 121: 721-730.

Carlton, J. T., Reid, D. M., van Leeuwen, H., 1995. Shipping Study: the Role of Shipping in the Introduction of Non-indigenous Aquatic Organisms to the Coastal Waters of the United States (other than the Great Lakes) and an Analysis of Control Options. United States Coast Guard, Connecticut, Department of Transportation, Washington District of Columbia. 213 pp. 
Coles, S. L., DeFelice, R. C., Godwin, L. S., 1999. The impact of nonindigenous marine species transported to Pearl Harbour on the hull of the USS Missouri. Hawaii Biological Survey Contribution No. 1999-014. Bernice Pauahi Bishop Museum, Honolulu, pp. 1-27.

Coutts, A. D. M., 1999. Hull fouling as a modern vector for marine biological invasions: Investigation of merchant vessels visiting Northern Tasmania. Unpublished M.Sc thesis, Australian Maritime College, Launceston, Australia. 283 pp.

Coutts, A. D. M., 2002. A biosecurity investigation of a barge in the Marlborough Sounds. Cawthron Report No. 744.59 pp.

Coutts, A. D. M., Taylor, M. D., 2004. A preliminary investigation of biosecurity risks associated with biofouling on merchant vessels in New Zealand. New Zealand Journal of Marine and Freshwater 38: 215-229.

Coutts, A. D. M., Moore, K. M., Hewitt, C. L., 2003. Ships' sea-chests: an overlooked transfer mechanism for non-indigenous marine species. Marine Pollution Bulletin 46: $1510-1512$.

Cranfield, H. J., Gordon, D. J., Willan, R. C., Marshall, B. C., Battershill, C. N., Francis, M. P., Nelson, W. A., Glasby, C. J., Read, G. B., 1998. Adventive marine species in New Zealand. NIWA Technical Report No. 34. 48 pp.

Davidson, I. C., McCann, L. D., Fofonoff, P. W., Sytsma, M. D., Ruiz, G. M., 2008. The potential for hull-mediated species transfers by obsolete ships on their final voyages. Diversity and Distributions 14: 518-529.

DeFelice, R. C., 1999. Fouling marine invertebrates on the floating dry dock USS Machinist in Pearl Harbour to its move to Apra Harbour, Guam. Hawai'i Biological Survey, Bernice P. Bishop Museum Honolulu, Hawaii. Contribution No. 1999-013 to the Hawaii Biological Survey.

Field, D., 1999. Disaster averted? Black striped mussel outbreak in northern Australia. Fish Farming International 26: 30-31. 
Foster, B. A., Willan, R. C., 1979. Foreign barnacles transported to New Zealand on an oil platform. New Zealand Journal Marine Freshwater Research 13: 143-149.

Godwin, L. S., 2003. Hull fouling of maritime vessels as a pathway for marine species invasions to Hawaiian Islands. Biofouling 19 (Supplement): 123-131.

Godwin, L. S., Eldredge, L. G., 2001. South Oahu Marine Invasions Shipping Study (SOMISS). Technical Report No. 20. Honolulu. Hawaii Biological Survey, Bishop Museum. 104 pp.

Gollasch, S., 2002. The importance of ship hull fouling as a vector of species introductions into the North Sea. Biofouling 18: 105-121.

Hay, C. H., 1990. The dispersal of Undaria pinnatifida by coastal shipping in New Zealand, and implications for further dispersal of Undaria to France. British Phycological Journal 25: 301-313.

Hay, C. H., Dodgshun, T. J., 1997. Ecosystem transplant? The case of the Yefim Gorbenko. Seafood New Zealand, May, 13-14.

Hewitt, C. L., 2002. The distribution and biodiversity of tropical Australian marine bioinvasions. Pacific Science 56: 213-222.

Hewitt, C. L., Campbell, M. L., Thresher, R. E., Martin, R. B., Boyd, S., Cohen, B. F., Currie, D. R., Gomon, M. F., Keogh, M. J., Lewis, J. A., Lockett, M. M., Mays, N., McArthur, M. A., O’Hara, T. D., Poore, G. C. B., Ross, D. J., Storey, M. J., Watson, J. E., Wilson, R. S., 2004. Introduced and cryptogenic species in Port Phillip Bay, Victoria, Australia. Marine Biology 144, 183-202.

James, P., Hayden, B., 2000. The potential for the introduction of exotic species by vessel hull fouling: A preliminary study. NIWA Technical Report No. 16.15 pp.

Lewis, J. A., 2002. Hull fouling as a vector for the translocation of marine organisms. Phase I Study: Hull fouling research. Department of Agriculture, Fisheries and Forestry Australia. Strategic Ballast Water Research and Development Program, Canberra, Report No. 1. 142 pp. 
Lewis, P. N., Hewitt, C. L., Riddle, M., McMinn, A., 2003. Marine introductions in the Southern Ocean: an unrecognised hazard to biodiversity. Marine Pollution Bulletin 46: $213-223$.

Minchin, D., Gollasch, S., 2002. Vectors - How exotics get around. In: Leppakoski, E., Gollasch, S., Olenin, S. (Eds.), Invasive Aquatic Species of Europe: Distribution, Impact and Management. Kluwer, London, pp. 183-192.

Rainer, S., 1995. Potential for the introduction and translocation of exotic species by hull fouling: A preliminary assessment. Technical Report No. 1. Hobart, Tasmania. Centre for Research on Introduced Marine Pests, $18 \mathrm{pp}$.

Ruiz, G. M., Carlton, J. T., Grosholz, E. D., Hines, A. H., 1997. Global invasions of marine and estuarine habitats by non-indigenous species: mechanisms, extent, and consequences. American Zoologist 37: 621-632.

Schormann, J., Carlton, J. T., Dochoda, M. R., 1990. The ship as a vector in biotic invasions. Marine Technology and the Environment 19: 147-152.

Schultz, M., Swain, G. W., 2000. The influence of biofilms on skin friction drag. Biofouling 15: 129-139.

Thresher, R. E., Hewitt, C. L., Campbell, M. L., 1999. Synthesis: introduced and cryptogenic species in Port Phillip Bay. In: Hewitt, C. L., Campbell, M. L., Thresher, R. E, Martin, R. B., (Eds), Marine Biological Invasions of Port Phillip Bay, Victoria. Centre for Research on Introduced Marine Pests. Technical Report No. 20, pp. 283-295. 


\section{Chapter 5 - The survivorship of biofouling organisms on various vessel types at different hull locations}

\section{PREFACE}

This chapter combines the results of the previous two chapters to determine the survivorship of biofouling organisms on different vessel types at various hull locations. I was responsible for collecting, processing and analysing the data, although Michael Taylor and Richard Piola had considerable input into the methods used to analyse the data. I was also responsible for writing the majority of the chapter, although Richard Piola had considerable input into reviewing and re-writing certain parts. An abbreviated version of this chapter has been published in the international peer-reviewed journal Biofouling according to the following citation:

Coutts, A. D. M., Piola, R. F., Taylor, M. D., Hewitt, C. L., Gardner, J. P. A., 2010. The effect of vessel speed on the survivorship of biofouling organisms at different hull locations. Biofouling 26: 539-553.

\footnotetext{
ABSTRACT

This study used a specially designed MAGPLATE system to quantify the en route survivorship and post-voyage recovery of biofouling assemblages subjected to short voyages ( $<12$ hours) across a range of vessel speeds (slow, medium, fast; in the range 4.0 to 21.5 knots). The effect of hull location (bow, amidships and stern) was also examined. While no significant differences were evident in en route survivorship of biofouling organisms amongst hull locations, biofouling cover and richness was markedly reduced on faster vessels relative to slower craft. Therefore, potential inoculum size and pool (species richness) of non-indigenous marine species is likely to be reduced for vessels that travel at faster speeds ( $>14$ knots), which may reduce the
} 
chances of successful introductions. Despite this, the magnitude of the introductions in biofouling on fast vessels can be considered minor, especially for species richness where $90 \%$ of source-port species were recorded at destinations.

\subsection{INTRODUCTION}

Shipping is considered to be the most important vector for the human-mediated movement of non-indigenous marine species (NIMS) around the world (e.g. Ruiz et al. 1997; Minchin and Gollasch 2002; Hewitt and Campbell 2008). However, the accumulation of marine growth on vessel hulls (biofouling) is recognised to be one of the single most important dispersal mechanisms for NIMS (e.g. Cranfield et al. 1998; Thresher et al. 1999; Hewitt 2002; Gollasch 2002; Hewitt et al. 2004; Hewitt and Campbell 2008). In 2009, the International Maritime Organisation's Sub-Committee on Bulk Liquids and Gases (BLG) agreed to develop international measures for minimising the transfer of invasive aquatic species through biofouling of ships (BLG 14/9). Furthermore, Australia, New Zealand and the State of California are also in the process of developing their own biofouling policies and requirements (e.g. MEPC 56/INF.11; Biosecurity New Zealand 2009; AB 740 2007). Such developments are hindered, however, by a continued lack of understanding as to which vessel types, pathways or levels of biofouling (e.g. species richness, abundance, percentage cover, biomass, etc) constitute the greatest biosecurity risk for the dispersal of NIMS.

Invasion success is generally thought to be positively associated with the quality and quantity of "inocula" (e.g. gametes, larvae, adult individuals) of organisms that are being transported to recipient locations (Ruiz and Carlton 2003; Lockwood et al. 2007). However, many factors influence the quality and quantity of inocula, including: type of vessel; the presence/absence, age and type of anti-fouling coating; port residency period; voyage speed, duration, route; environmental symmetry between source and recipient ports; settlement location on the vessel; and type/morphology of biofouling organism (e.g. Coutts 1999; Lewis 2002; Floerl 2005; Piola et al. 2009). Voyage speed in particular is possibly one of the most important factors for the survivorship of biofouling organisms (e.g. Coutts 1999; Coutts et al. 2010). 
Our knowledge of the survivorship of biofouling organisms on vessels is dominated by post-voyage in situ or dry-dock inspections, with retrospective analyses of survivorship relative to the vessel's operating speed, duration and route (see Lewis 2002 for summary). Hence, there have been few studies that have actually assessed the recruitment and en route survivorship of biofouling organisms on a vessel's hull. Of those studies that have been conducted, their observations are restricted to one off isolated occurrences on predominantly slow-moving vessels that travelled between 4.06.5 knots (Carlton and Hodder 1995; Brock et al. 1999; Davidson et al. 2008, but see also Lewis et al. 2004).

Coutts et al. (2010) experimentally compared the effect of different vessel voyage speeds on the survival of a range of biofouling organisms in situ, using a custom built hydrodynamic keel attached to the bottom of a $6 \mathrm{~m}$ powerboat. The study established a positive correlation between increasing voyage speed (5, 10 and 18 knots) and the loss of species richness and percentage cover (i.e. potential inocula). The duration of these voyage trials was only 20 minutes and as noted by the authors, the hydrodynamic flow regimes acting on the keel could only be compared to those experienced by biofouling organisms towards the bow of a vessel (Coutts et al. 2010). In reality, survivorship of biofouling organisms is likely to be greater in niche areas protected from harsh hydrodynamic forces (e.g. Coutts and Taylor 2004; Australian Shipowners Association 2006).

The development of a specially designed MAGPLATE system has permitted the quantification of the effect of hydrodynamic forces on the survivorship of biofouling at different hull locations, on a range of vessel types, travelling at different speeds (Coutts et al. 2007). This system enables pre-fouled settlement plates to be attached to steelhulled vessels, allowing for direct comparison of biofouling assemblage composition before and after a voyage. Utilising the MAGPLATE technology, the specific aims of this study were to: a) quantify the en route survivorship and post-voyage recovery of biofouling organisms after being subjected to various voyage speeds at different hull locations; and b) compare patterns of survival and post-voyage recovery among different morphological characteristics (i.e. growth form, profile and structure) of biofouling organisms. We then used the results of this study to assess NIMS risks and policy implications. 


\subsection{METHODS}

\subsubsection{Voyage trials}

Two series of experimental trials on the effects of hull location and vessel speed on biofouling assemblages were conducted from Picton Harbour, Marlborough Sounds, New Zealand (Figure 15). Voyage trials were conducted using assemblages of commonly occurring biofouling organisms often associated with vessel biofouling (e.g. ascidians, barnacles, bryozoans, hydroids, tubeworms, sponges, etc). Experimental units of black acrylic settlement plates $(235 \times 160 \times 3 \mathrm{~mm})$ were treated with three coats of non-toxic paint (plasti-kote ${ }^{\circledR} \mathrm{T}-19$ Red Oxide Primer) to mimic surface texture and colour of the most frequently used maritime anti-fouling coatings. In May 2004, 162 settlement plates were hung vertically between wharf piles in Picton Harbour, $\sim 3 \mathrm{~m}$ below the spring low water mark, for use during "Trial 1" (hereafter referred to as T1). A further 162 settlement plates were hung beneath the same wharf in the same manner in November 2004, for use during "Trial 2" assessment trials (i.e. T2). T1 plates were retrieved after 5 months (during the austral winter) and T2 plates after 2 months (austral summer). T1 trials were conducted between 7 and 30 October 2004, while T2 trials occurred between 14 January and 21 February 2005. During each trial period, nine vessels were randomly chosen from the various vessels operating in the Picton region, representing five different vessel types (a dumb barge, yacht, launch, and three each of motorised barges and Roll-On/Roll-Off (RO/RO) passenger ferries).

A total of 18 experimental pre-fouled settlement plates were used during each vessel survivorship trial. Three experimental assemblage plates were left hanging undisturbed beneath the wharf to act as undisturbed controls. Divers removed the remaining 15 assemblage plates from beneath the wharf. Each plate was gently inserted into a specially designed rack to protect biofouling assemblages during transportation. Divers then transferred the rack with the 15 plates to a support vessel at the surface where each plate was attached to the MAGPLATEs. MAGPLATEs were then reinserted into the racks ready for each trial (see Chapter 4; Section 4.2).

Prior to each vessel's departure, divers attached three replicate MAGPLATEs at each of three different hull locations (a total of nine plates) comprising: 1) an "exposed" area at the bow region where biofouling survivorship was predicted to be relatively low due to 
strong hydrodynamic forces; 2) inside a dry-docking support strip "DDSS" at amidships where anti-fouling coatings are old/ineffective and where relatively high levels of biofouling are known to exist, but biofouling survivorship is unknown; and 3) a "protected" area around the stern region in a relatively protected location where biofouling survivorship may be enhanced due to their protection from strong hydrodynamic forces.

The remaining six MAGPLATEs (comprising three MAGPLATEs with magnets intact and three MAGPLATEs with magnets removed) were attached to a control panel (500 $\mathrm{x}$ $1000 \times 5 \mathrm{~mm}$ ) and re-suspended vertically beneath the wharf for the duration of each vessel trial. These served as procedural controls to assess any handling effects and potential influence of magnetism on biofouling organisms. The depth and illumination of plates within vessels relative to their controls may have varied, particularly for the $\mathrm{RO} / \mathrm{RO}$ passenger ferries (i.e. plates were $\sim 5 \mathrm{~m}$ deep and consequently more shaded on the ferries), although this was not considered significant given the voyage trials were less than 12 hours.

Before the start of each voyage, the 15 MAGPLATEs (nine on the vessel and six controls) and three undisturbed controls were photographed in situ, to provide a baseline against which future changes in assemblage composition and cover could be assessed (i.e. hereafter termed "pre-voyage"). All settlement plates were again photographed in situ immediately upon each vessel's return to port to assess the "postvoyage" survivorship of biofouling organisms. Divers then retrieved the 15 MAGPLATEs and transported them using the specially designed racks to the support vessel where the settlement plates were removed and returned to their place of origin beneath the wharf where the original three undisturbed controls were maintained. The 18 settlement plates used for each trial were photographed 7 days later to assess the post-voyage recovery and loss of biofouling organisms (i.e. hereafter referred to as " $7 \mathrm{~d}$ post-voyage"). The survivorship of biofouling organisms was determined by examining organisms under a dissecting microscope on a random selection of plates immediately after voyage trials and at the completion of the $7 \mathrm{~d}$ assessments. Criteria established by Woods et al. (2007) were used for assessing the viability of organisms. 


\subsubsection{Voyage details and environmental conditions}

ONSET StowAway TidbiT temperature data loggers and a handheld YSI 85 multimeter were used to record seawater temperature and salinity adjacent to the control plates beneath the wharf and at random locations throughout each voyage. A questionnaire was also completed by the vessel operator after each trial to determine the voyage route, total voyage duration, time spent steaming/stationary, relative voyage conditions (i.e., calm $=0 \mathrm{~m}$, choppy $=0.25 \mathrm{~m}$, very choppy $=>0.5 \mathrm{~m}$ wave height) and maximum vessel speed. Data pertaining to the hydrodynamic accelerative forces/speeds acting on the biofouling organisms at the various hull locations during each vessel trial could not be obtained. Vessels were grouped into one of three voyage speed categories: slow (4.0-6.5); medium (8.0-9.0); and fast (14.0-21.5 knots) based on the maximum voyage speed achieved during each trial. While it is acknowledged that vessel speeds, routes, distances and durations may have varied within and among each vessel category and could be considered confounded, these differences are unlikely to detract from the overall findings of the study.

\subsubsection{Classification of taxa}

Biofouling species greater than $1 \mathrm{~mm}$ in size were identified to the lowest practical taxonomic level based on available literature and identification records. Organisms were classified as native (an organism that originates in New Zealand) and nonindigenous (a foreign organism that has established in New Zealand) according to Cranfield et al. (1998). Organisms only able to be identified to genus level or higher were classified as status "unknown". Assessment of the effect of voyage speed on the survivorship of biofouling organisms was achieved by recording the number of species and their percentage cover per plate present in the pre-voyage, post-voyage and $7 \mathrm{~d}$ post-voyage photographs. Estimates of the number of species and their percentage cover data were derived from a uniform grid of 50 point counts (Drummond and Connell 2005) that was aligned in an identical position over the plate during each assessment. A $20 \mathrm{~mm}$ perimeter along the edge of each plate/photograph was omitted from counting to control for possible boundary effects. No recruitment of new organisms was observed during the assessment of $7 \mathrm{~d}$ post-voyage assemblages. 
To determine links between an organism's survival and basic morphology characteristics, all organisms were classified according to seven discrete morphological groups, including; growth form (solitary or colonial), profile (erect or encrusting) and structure (soft, hard or flexible). Species richness and percentage cover for each of the seven morphological groups was then recalculated for each quadrat to determine the effect of voyage speed on the prevalence and abundance of each morphological group.

\subsubsection{Analyses}

Multivariate analyses of assemblage composition and cover were performed using PRIMER V6.1.11 (PRIMER-E Ltd, Lutton, Ivybridge, United Kingdom). All data were square-root transformed so that highly dominant species did not cause undue bias at the expense of less dominant taxa (Clarke and Warwick 2001). Cluster analysis and twodimensional non-metric multi-dimensional scaling (nMDS) ordinations were produced from Bray-Curtis similarity matrices. Using group average clustering, treatment groupings that formed at 75-90 \% Bray-Curtis similarity thresholds illustrated patterns of interested and were superimposed on the nMDS ordination plots (Clarke 1993). Where feasible, SIMPER analyses (Similarity/distance percentage analysis; see Clark 1993) were then used to identify the major taxa explaining trends on the nMDS plots.

All univariate analyses used a repeated measures analysis of variance (RM-ANOVA) in STATISTICA 7. Differences in the composition and percentage cover of biofouling organisms on control assemblages (i.e. undisturbed vs MAGPLATEs without magnets and MAGPLATEs with magnets vs MAGPLATEs without magnets) were compared to those of pre-voyage and post-voyage assemblages to determine possible handling and magnetic effects. All control assemblages were not significantly different to each other before and after voyages, and were therefore omitted from further analyses. Furthermore, no differences were detected between pre-voyage treatment panels.

\subsection{RESULTS}

\subsubsection{Voyage profiles and environmental conditions}

Maximum voyage speeds per vessel type ranged from 4.0 knots (dumb barge) through to 21.5 knots (Ferry 3) with slow, medium and fast vessels averaging $5.6 \pm 0.3,8.4 \pm$ 0.2 , and $17.9 \pm 1.3$ knots, respectively (Table 8 ). Total voyage durations varied amongst 
the three vessel speed categories with slow vessels spending an average of $7.8 \pm 0.8$ hours away from berth, medium $6.6 \pm 0.4$ and fast $8.4 \pm 0.5$ hours. Similarly, the time spent steaming and stationary during their voyages varied amongst vessel categories with fast vessels spending the longest average steaming periods $(6.7 \pm 0.2$ hours $)$ and the shortest average stationary periods $(1.7 \pm 0.3$ hours $)$. Vessels in the slow and medium categories spent similar average periods steaming and stationary (i.e., slow $=$ $4.9 \pm 0.5$ steaming, $3.0 \pm 0.5$ stationary; medium $=3.8 \pm 0.3$ steaming, $2.8 \pm 0.4$ hours stationary).

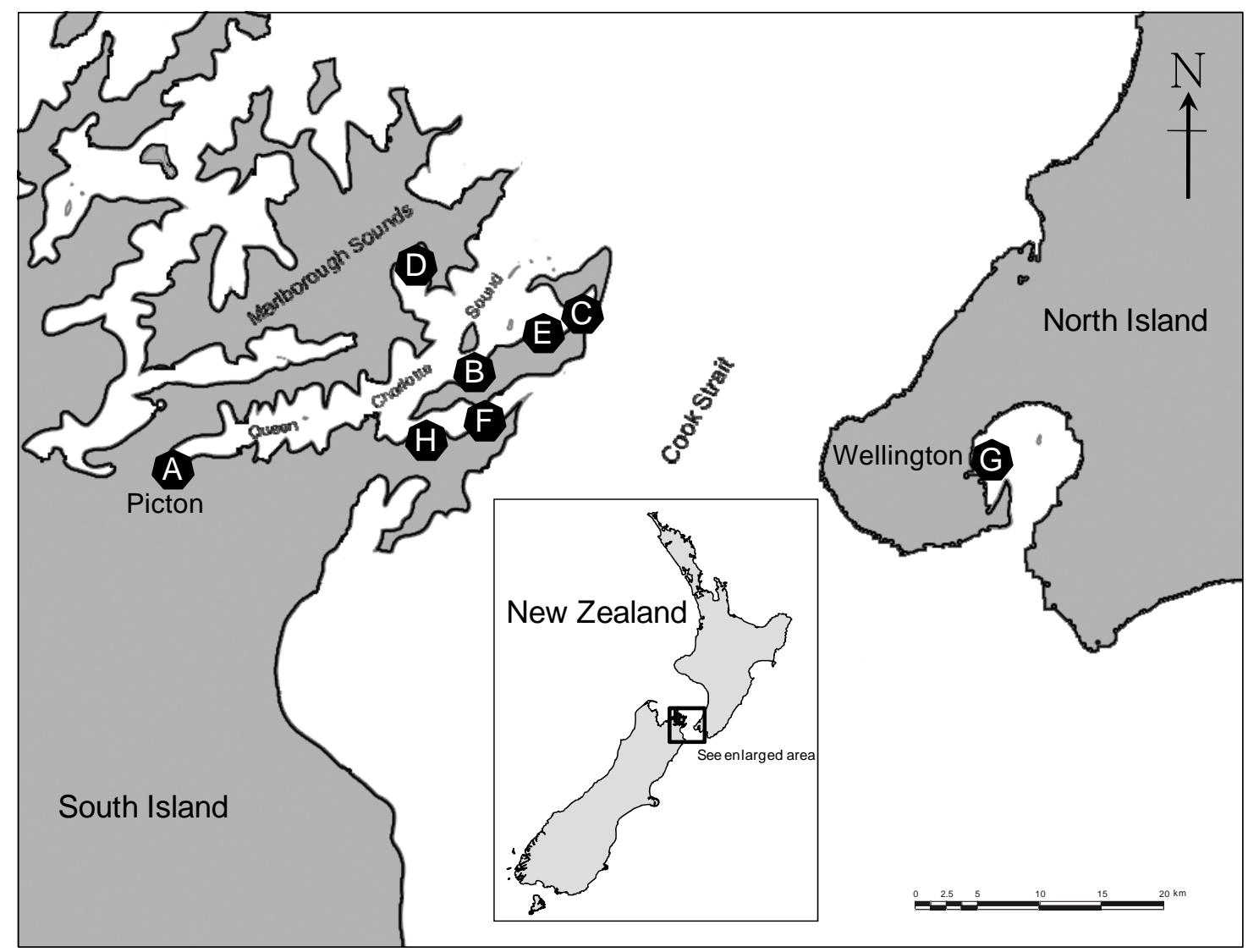

Figure 15 Voyage trials were conducted on vessels that operated from Picton Harbour (South Island) throughout the Queen Charlotte Sound and across Cook Strait to Wellington (North Island), New Zealand. Use in conjunction with Table 8. 
Table 8 A summary of the vessel voyage trials and conditions experienced by biofouling organisms relative to controls.

\begin{tabular}{|c|c|c|c|c|c|c|c|c|c|c|c|}
\hline Trial & Vessel trial & $\begin{array}{c}\text { Max } \\
\text { voyage } \\
\text { speed } \\
\text { (knots) }\end{array}$ & $\begin{array}{l}\text { Speed } \\
\text { category }\end{array}$ & $\begin{array}{l}\text { Steaming/ } \\
\text { stationary } \\
\text { duration } \\
\text { (hours) }\end{array}$ & \begin{tabular}{|c|} 
Total \\
voyage \\
duration \\
(hours)
\end{tabular} & $\begin{array}{c}\begin{array}{c}\text { Distance } \\
\text { travelled } \\
(\mathrm{nm})\end{array} \\
\text { Figure } 15\end{array}$ & $\begin{array}{c}\text { Voyage } \\
\text { conditions }\end{array}$ & $\begin{array}{c}\text { Temp } \\
\text { range } \\
\text { (Controls) } \\
\left({ }^{0} \mathrm{C}\right) \\
(\mathrm{min} / \mathrm{max})\end{array}$ & $\begin{array}{c}\text { Temp } \\
\text { range } \\
\text { (Voyage) } \\
\left({ }^{0} \mathrm{C}\right) \\
(\mathrm{min} / \mathrm{max})\end{array}$ & $\begin{array}{c}\text { Salinity } \\
\text { range } \\
\text { (Controls) } \\
\text { (ppt) } \\
\text { (min/max) }\end{array}$ & $\begin{array}{l}\text { Salinity } \\
\text { range } \\
\text { (Voyage) } \\
\text { (ppt) } \\
\text { (min/max) }\end{array}$ \\
\hline $\mathbf{T 1}$ & $\begin{array}{l}\text { Dumb barge } \\
\text { Yacht } \\
\text { Motorised barge } 1 \\
\text { Launch } \\
\text { Motorised barge } 2 \\
\text { Motorised barge } 3 \\
\text { Ferry } 1 \\
\text { Ferry } 2 \\
\text { Ferry } 3\end{array}$ & $\begin{array}{l}5.5 \\
5.8 \\
6.0 \\
8.0 \\
8.0 \\
9.0 \\
14.5 \\
18.5 \\
20.5\end{array}$ & $\begin{array}{l}\text { Slow } \\
\text { Slow } \\
\text { Slow } \\
\text { Medium } \\
\text { Medium } \\
\text { Medium } \\
\text { Fast } \\
\text { Fast } \\
\text { Fast }\end{array}$ & $\begin{array}{c}5.0 / 3.0 \\
6.0 / 2.0 \\
5.0 / 3.0 \\
3.75 / 2.0 \\
3.0 / 4.0 \\
3.0 / 2.5 \\
7.25 / 2.5 \\
6.75 / 1.75 \\
6.0 / 1.0\end{array}$ & $\begin{array}{c}8.0 \\
8.0 \\
8.0 \\
5.75 \\
7.0 \\
5.5 \\
9.75 \\
8.5 \\
7.0\end{array}$ & $\begin{array}{l}27(\mathrm{~A}-\mathrm{B}) \\
31(\mathrm{~A}-\mathrm{C}) \\
26(\mathrm{~A}-\mathrm{B}) \\
27(\mathrm{~A}-\mathrm{D}) \\
30(\mathrm{~A}-\mathrm{E}) \\
27(\mathrm{~A}-\mathrm{F}) \\
102(\mathrm{~A}-\mathrm{G}) \\
102(\mathrm{~A}-\mathrm{G}) \\
102(\mathrm{~A}-\mathrm{G})\end{array}$ & $\begin{array}{c}\text { Calm } \\
\text { Choppy } \\
\text { Very choppy } \\
\text { Calm } \\
\text { Calm } \\
\text { Calm } \\
\text { Calm } \\
\text { Calm } \\
\text { Choppy }\end{array}$ & $\begin{array}{l}13.1 / 13.7 \\
13.8 / 14.4 \\
12.8 / 13.4 \\
12.9 / 13.1 \\
13.1 / 13.7 \\
11.6 / 12.7 \\
12.6 / 13.8 \\
13.5 / 14.2 \\
13.5 / 13.8\end{array}$ & $\begin{array}{l}12.8 / 13.9 \\
13.0 / 14.4 \\
12.6 / 13.9 \\
12.8 / 13.6 \\
13.1 / 14.5 \\
11.6 / 12.7 \\
11.6 / 13.8 \\
11.8 / 14.2 \\
13.2 / 14.6\end{array}$ & $\begin{array}{l}32.4 / 32.5 \\
32.5 / 32.5 \\
32.5 / 32.7 \\
32.3 / 32.8 \\
32.4 / 32.6 \\
32.5 / 32.7 \\
32.5 / 32.7 \\
32.3 / 32.5 \\
31.9 / 34.2\end{array}$ & $\begin{array}{l}32.7 / 33.1 \\
32.5 / 33.2 \\
32.1 / 32.7 \\
32.5 / 33.1 \\
32.4 / 33.1 \\
32.6 / 33.2 \\
32.5 / 33.2 \\
32.7 / 33.3 \\
31.9 / 33.4\end{array}$ \\
\hline $\mathbf{T} 2$ & $\begin{array}{l}\text { Dumb barge } \\
\text { Yacht } \\
\text { Motorised barge } 1 \\
\text { Launch } \\
\text { Motorised barge } 2 \\
\text { Motorised barge } 3 \\
\text { Ferry } 1 \\
\text { Ferry } 2 \\
\text { Ferry } 3\end{array}$ & $\begin{array}{c}4.0 \\
6.0 \\
6.0 \\
8.0 \\
8.5 \\
9.0 \\
14.0 \\
18.5 \\
21.5\end{array}$ & $\begin{array}{l}\text { Slow } \\
\text { Slow } \\
\text { Slow } \\
\text { Medium } \\
\text { Medium } \\
\text { Medium } \\
\text { Fast } \\
\text { Fast } \\
\text { Fast }\end{array}$ & $\begin{array}{c}6.0 / 5.0 \\
3.0 / 1.5 \\
4.5 / 3.25 \\
4.0 / 2.75 \\
4.25 / 3.75 \\
4.5 / 2.0 \\
7.25 / 2.25 \\
6.75 / 1.75 \\
6.0 / 1.0\end{array}$ & $\begin{array}{l}11.0 \\
4.5 \\
7.5 \\
6.75 \\
8.0 \\
6.5 \\
9.5 \\
8.5 \\
7.0\end{array}$ & $\begin{array}{c}27(\mathrm{~A}-\mathrm{B}) \\
26(\mathrm{~A}-\mathrm{F}) \\
26(\mathrm{~A}-\mathrm{H}) \\
27(\mathrm{~A}-\mathrm{D}) \\
24(\mathrm{~A}-\mathrm{F}) \\
26(\mathrm{~A}-\mathrm{F}) \\
102(\mathrm{~A}-\mathrm{G}) \\
102(\mathrm{~A}-\mathrm{G}) \\
102(\mathrm{~A}-\mathrm{G})\end{array}$ & $\begin{array}{c}\text { Choppy } \\
\text { Choppy } \\
\text { Calm } \\
\text { Very choppy } \\
\text { Calm } \\
\text { Calm } \\
\text { Calm } \\
\text { Calm } \\
\text { Calm }\end{array}$ & $\begin{array}{l}17.3 / 17.5 \\
17.3 / 17.8 \\
15.9 / 17.3 \\
16.8 / 17.6 \\
16.2 / 16.7 \\
17.7 / 18.8 \\
16.7 / 17.1 \\
16.9 / 17.3 \\
16.4 / 17.2\end{array}$ & $\begin{array}{l}14.6 / 17.5 \\
14.7 / 17.8 \\
14.6 / 17.3 \\
15.5 / 17.6 \\
14.5 / 16.7 \\
14.5 / 18.8 \\
14.4 / 16.7 \\
14.5 / 17.3 \\
14.5 / 20.1\end{array}$ & $\begin{array}{l}34.5 / 34.6 \\
34.4 / 34.6 \\
34.4 / 34.4 \\
34.4 / 34.6 \\
34.3 / 34.3 \\
34.4 / 34.6 \\
34.4 / 34.4 \\
34.4 / 34.4 \\
34.5 / 34.7\end{array}$ & $\begin{array}{l}34.5 / 34.7 \\
34.4 / 34.7 \\
34.4 / 34.7 \\
34.4 / 34.8 \\
34.3 / 34.5 \\
34.4 / 34.8 \\
34.4 / 35.1 \\
34.4 / 35.2 \\
34.5 / 35.4\end{array}$ \\
\hline $\begin{array}{l}\text { Summary } \\
\bar{X}( \pm 1 \mathrm{SE})\end{array}$ & $\begin{array}{l}\text { Slow } \\
\text { Medium } \\
\text { Fast }\end{array}$ & $\begin{array}{c}5.6 \pm 0.3 \\
8.4 \pm 0.2 \\
17.9 \pm 1.3\end{array}$ & $\begin{array}{l}- \\
- \\
-\end{array}$ & $\begin{array}{l}4.9 \pm 0.5 / 3.0 \pm 0.5 \\
3.8 \pm 0.3 / 2.8 \pm 0.4 \\
6.7 \pm 0.2 / 1.7 \pm 0.3\end{array}$ & $\begin{array}{l}7.8 \pm 0.8 \\
6.6 \pm 0.4 \\
8.4 \pm 0.5\end{array}$ & $\begin{array}{c}27.2 \pm 0.8 \\
26.8 \pm 0.8 \\
102.0 \pm 0.0\end{array}$ & $\begin{array}{l}\text { T1 } \\
\text { T2 }\end{array}$ & $\begin{array}{l}13.0 \pm 0.2 / 13.6 \pm 0.2 \\
16.8 \pm 0.2 / 17.5 \pm 0.2\end{array}$ & $\begin{array}{l}12.5 \pm 0.2 / 14.0 \pm 0.2 \\
14.6 \pm 0.1 / 17.8 \pm 0.4\end{array}$ & $\begin{array}{l}32.4 \pm 0.1 / 32.8 \pm 0.2 \\
34.4 \pm 0.0 / 34.5 \pm 0.0\end{array}$ & $\begin{array}{l}32.4 \pm 0.1 / 33.1 \pm 0.1 \\
34.4 \pm 0.1 / 34.9 \pm 0.1\end{array}$ \\
\hline
\end{tabular}


Fast vessels travelled the longest distance during the trials, plying an average of $102 \pm$ $0.0 \mathrm{~nm}$ between Picton (South Island) and Wellington (North Island), while the slow and medium vessels remained within the Queen Charlotte Sound and travelled an average of $27.2 \pm 0.8$ and $26.8 \pm 0.8 \mathrm{~nm}$ respectively (Table 8; Figure 15). Biofouling organisms experienced water temperatures ranging from a minimum of $11.6^{\circ} \mathrm{C}$ during $\mathrm{T} 1$ to a maximum of $20.1^{\circ} \mathrm{C}$ during $\mathrm{T} 2$ (Table 8). On average, treatment assemblages experienced higher and lower water temperatures $(\min \mathrm{T} 1=12.5 \pm 0.2, \mathrm{~T} 2=14.6 \pm 0.1$; $\max \mathrm{T} 1=14.0 \pm 0.2, \mathrm{~T} 2=17.8 \pm 0.4)$ relative to control assemblages $(\min \mathrm{T} 1=13.0 \pm$ $0.2, \mathrm{~T} 2=16.8 \pm 0.2 ; \max \mathrm{T} 1=13.6 \pm 0.2, \mathrm{~T} 2=17.5 \pm 0.2$; Table 1). Salinity levels ranged from 31.9 PSU during T1 up to 35.4 PSU during T2 trials. Generally biofouling organisms on vessels had a tendency to experience slightly higher salinity levels as they moved towards the open ocean. Most of the trials were conducted in calm (12) to choppy (4) conditions, while two vessel voyages experienced very choppy conditions (Table 8).

\subsubsection{Pre-voyage assemblage composition}

Preliminary analyses identified significant differences in the species richness and percentage cover estimates between starting assemblages used during T1 and T2 trial periods $\left(F_{[1,192]}=36.90, P<0.001\right)$. This was likely due to differences in assemblage development time (5 versus 2 months for T1 and T2 respectively) and differential seasonal recruitment patterns (winter versus spring/summer). As such, data from T1 and T2 trials were analysed separately unless otherwise stated. There was no detectable effect of handling $\left(F_{[1,34]}=0.240, P=0.627\right)$ or magnetism $\left(F_{[1,34]}=0.374, P=0.544\right)$ on percentage cover.

A total of 34 different sessile taxa were identified consisting of two plant species and ten animal phyla: Porifera (2), Cnidaria (1), Mollusca (2), Bryozoa (14), Annelida (5), Arthropoda (Crustacea) (1) and Chordata (Ascidiacea) (6) (Table 9). This included eight (24\%) native species, nine non-indigenous species (26\%) and 17 (50\%) species of unknown origins (Table 9). T1 pre-voyage settlement plates were dominated by the non-indigenous erect hydroid, Obelia longissima and the bryozoan, Bugula flabellata with an average percentage cover of $36.7 \pm 4.0$ and $36.8 \pm 4.8$ per plate respectively. The non-indigenous encrusting colonial ascidian, Diplosoma listerianum, and the native 
Table 9 Summary of biofouling organisms identified amongst settlement plates used for the vessel survivorship trials over two trials (T1 and T2); including their status in New Zealand waters, morphological characteristics, average percentage cover ( \pm 1 SE) during pre-, post-, and $7 \mathrm{~d}$ postvoyage assessment periods for each of three vessel speed categories (slow, medium and fast). - refers to a species absence on settlement plates.

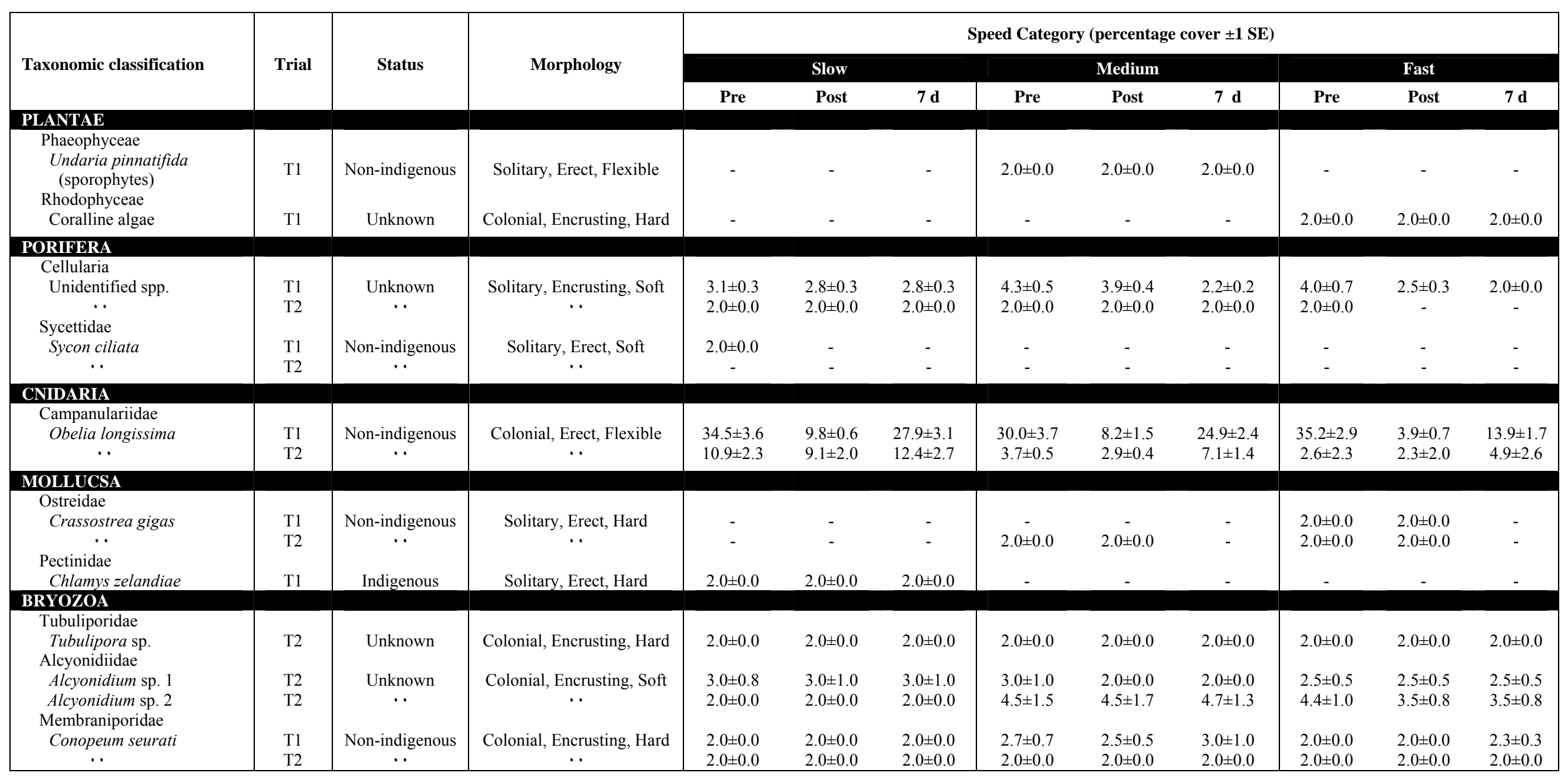


Table 9. Continued.

\begin{tabular}{|c|c|c|c|c|c|c|c|c|c|c|c|c|}
\hline \multirow{3}{*}{ Taxonomic classification } & \multirow{3}{*}{ Trial } & \multirow{3}{*}{ Status } & \multirow{3}{*}{ Morphology } & \multicolumn{9}{|c|}{ Speed Category } \\
\hline & & & & \multicolumn{3}{|c|}{ Slow } & \multicolumn{3}{|c|}{ Medium } & \multicolumn{3}{|c|}{ Fast } \\
\hline & & & & Pre & Post & $7 \mathrm{~d}$ & Pre & Post & $7 \mathrm{~d}$ & Pre & Post & $7 \mathrm{~d}$ \\
\hline \multicolumn{13}{|l|}{ BRYOZOA } \\
\hline $\begin{array}{l}\text { Electridae } \\
\text { Electra tenella } \\
\text { Buoulidae }\end{array}$ & $\mathrm{T} 1$ & Non-indigenous & Colonial, Encrusting, Hard & $2.0 \pm 0.0$ & $2.0 \pm 0.0$ & $2.0 \pm 0.0$ & - & - & - & - & - & - \\
\hline Bugula flabellata & $\mathrm{T} 1$ & Non-indigenous & Colonial, Erect, Flexible & $36.0 \pm 4.5$ & $25.7 \pm 3.4$ & $35.2 \pm 4.2$ & $35.7 \pm 3.9$ & $27.6 \pm 3.3$ & $32.8 \pm 3.0$ & $36.0 \pm 4.5$ & $25.7 \pm 3.4$ & $35.2 \pm 4.2$ \\
\hline Beaniidae & $\mathrm{T} 2$ & .. & $\cdots$ & $3.0 \pm 1.0$ & $2.0 \pm 0.0$ & $2.0 \pm 0.0$ & $7.2 \pm 1.5$ & $5.2 \pm 0.8$ & $4.8 \pm 1.0$ & $2.0 \pm 0.0$ & - & - \\
\hline Beania sp. & $\mathrm{T} 1$ & Unknown & Colonial, Erect, Hard & $2.8 \pm 0.4$ & $2.8 \pm 1.2$ & $2.6 \pm 0.6$ & $4.0 \pm 1.1$ & $3.7 \pm 1.0$ & $2.6 \pm 0.6$ & $2.7 \pm 0.3$ & $2.5 \pm 0.5$ & $2.0 \pm 0.0$ \\
\hline $\begin{array}{c}\text {.. } \\
\text { Eurystomellidae }\end{array}$ & $\mathrm{T} 2$ & .. & .. & $9.1 \pm 1.4$ & $9.0 \pm 1.3$ & $9.3 \pm 1.4$ & $7.8 \pm 1.4$ & $7.7 \pm 1.3$ & $8.3 \pm 1.5$ & $8.9 \pm 1.2$ & $8.3 \pm 1.3$ & $8.1 \pm 1.3$ \\
\hline $\begin{array}{l}\text { Eurystomella foraminigera } \\
\text { Hippothoidae }\end{array}$ & $\mathrm{T} 2$ & Unknown & Colonial, Encrusting, Hard & - & - & - & - & - & - & $2.0 \pm 0.0$ & $2.0 \pm 0.0$ & $2.0 \pm 0.0$ \\
\hline $\begin{array}{l}\text { Celleporella bathamae } \\
\text { Archnopusiidae }\end{array}$ & $\mathrm{T} 2$ & Indigenous & Colonial, Encrusting, Hard & $2.0 \pm 0.0$ & $2.0 \pm 0.0$ & $2.0 \pm 0.0$ & $2.7 \pm 0.6$ & $2.7 \pm 0.6$ & $2.7 \pm 0.6$ & $2.7 \pm 0.6$ & $2.7 \pm 0.6$ & $2.7 \pm 0.6$ \\
\hline $\begin{array}{l}\text { Arachnopusia unicornis } \\
\text { Bitectiporidae }\end{array}$ & $\mathrm{T} 1$ & Indigenous & Colonial, Encrusting, Hard & $4.0 \pm 1.4$ & $4.0 \pm 1.4$ & $4.0 \pm 0.8$ & $2.8 \pm 0.4$ & $2.4 \pm 0.4$ & $2.5 \pm 0.5$ & $2.0 \pm 0.0$ & $2.0 \pm 0.0$ & $2.0 \pm 0.0$ \\
\hline Bitectipora rostrata & $\mathrm{T} 1$ & Unknown & Colonial, Encrusting, Hard & - & - & - & $3.0 \pm 1.0$ & $3.0 \pm 1.0$ & $3.0 \pm 1.0$ & $2.0 \pm 0.0$ & $2.0 \pm 0.0$ & $2.0 \pm 0.0$ \\
\hline $\begin{array}{c}\cdots \\
\text { Watersiporidae }\end{array}$ & $\mathrm{T} 2$ & .. & . & $2.0 \pm 0.0$ & $2.0 \pm 0.0$ & $2.0 \pm 0.0$ & $2.0 \pm 0.0$ & $2.0 \pm 0.0$ & $2.0 \pm 0.0$ & $2.4 \pm 0.4$ & $2.4 \pm 0.4$ & $2.4 \pm 0.4$ \\
\hline Watersipora subtorquata & $\begin{array}{l}\mathrm{T} 1 \\
\mathrm{~T} 2\end{array}$ & $\begin{array}{c}\text { Non-indigenous } \\
. .\end{array}$ & $\begin{array}{c}\text { Colonial, Encrusting, Hard } \\
. .\end{array}$ & $\begin{array}{l}2.3 \pm 0.3 \\
5.8 \pm 1.0\end{array}$ & $\begin{array}{l}2.3 \pm 0.3 \\
5.8 \pm 1.0\end{array}$ & $\begin{array}{l}2.5 \pm 0.5 \\
5.8 \pm 1.0\end{array}$ & $\begin{array}{l}2.0 \pm 0.0 \\
5.0 \pm 0.8\end{array}$ & $\begin{array}{l}2.0 \pm 0.0 \\
5.1 \pm 0.8\end{array}$ & $\begin{array}{l}2.0 \pm 0.0 \\
5.6 \pm 0.9\end{array}$ & $\begin{array}{l}2.2 \pm 0.2 \\
5.1 \pm 0.6\end{array}$ & $\begin{array}{l}2.2 \pm 0.2 \\
5.1 \pm 0.6\end{array}$ & $\begin{array}{l}2.2 \pm 0.2 \\
5.3 \pm 0.7\end{array}$ \\
\hline Cyclicoporidae & & & & & & & & & & & & \\
\hline Cyclicopora longipora & $\mathrm{T} 1$ & Unknown & Colonial, Encrusting, Hard & $2.5 \pm 0.5$ & $2.5 \pm 0.5$ & $3.0 \pm 1.0$ & - & - & - & $2.0 \pm 0.0$ & $2.0 \pm 0.0$ & $2.0 \pm 0.0$ \\
\hline Microporelliidae & $\mathrm{T} 2$ & . & . & $2.5 \pm 0.3$ & $2.5 \pm 0.3$ & $2.5 \pm 0.3$ & $2.0 \pm 0.0$ & $2.0 \pm 0.0$ & $2.0 \pm 0.0$ & $2.3 \pm 0.3$ & $2.3 \pm 0.3$ & $2.3 \pm 0.3$ \\
\hline $\begin{array}{l}\text { Microporella agonistes } \\
. .\end{array}$ & $\begin{array}{l}\mathrm{T} 1 \\
\mathrm{~T} 2\end{array}$ & $\begin{array}{c}\text { Unknown } \\
. .\end{array}$ & $\begin{array}{c}\text { Colonial, Encrusting, Hard } \\
. .\end{array}$ & $\begin{array}{c}- \\
2.0 \pm 0.0\end{array}$ & $\stackrel{-}{2.0 \pm 0.0}$ & $\begin{array}{c}- \\
2.0 \pm 0.0\end{array}$ & $\begin{array}{l}2.0 \pm 0.0 \\
2.5 \pm 0.5\end{array}$ & $\begin{array}{l}2.0 \pm 0.0 \\
2.5 \pm 0.5\end{array}$ & $\begin{array}{c}- \\
2.5 \pm 0.5\end{array}$ & $\begin{array}{l}2.0 \pm 0.0 \\
2.0 \pm 0.0\end{array}$ & $\begin{array}{l}2.0 \pm 0.0 \\
2.0 \pm 0.0\end{array}$ & $\begin{array}{c}- \\
2.0 \pm 0.0\end{array}$ \\
\hline \multicolumn{13}{|l|}{$\begin{array}{l}\text { ANNELIDA } \\
\text { Terebellidae }\end{array}$} \\
\hline $\begin{array}{c}\text { Terebellidae } \\
\text { Unidentified sp. } \\
\ldots . \\
\text { Serpulidae }\end{array}$ & $\begin{array}{l}\mathrm{T} 1 \\
\mathrm{~T} 2\end{array}$ & $\begin{array}{c}\text { Unknown } \\
. .\end{array}$ & $\begin{array}{c}\text { Solitary, Erect, Soft } \\
. .\end{array}$ & $\begin{array}{l}2.2 \pm 0.2 \\
2.9 \pm 0.4\end{array}$ & $\begin{array}{l}2.2 \pm 0.2 \\
2.0 \pm 0.0\end{array}$ & $\begin{array}{c}2.5 \pm 0.5 \\
-\end{array}$ & $2.0 \pm 0.0$ & $\begin{array}{l}2.0 \pm 0.0 \\
2.0 \pm 0.0\end{array}$ & $\begin{array}{c}2.0 \pm 0.0 \\
-\end{array}$ & $\begin{array}{c}2.0 \pm 0.0 \\
-\end{array}$ & $\begin{array}{l}- \\
-\end{array}$ & $\begin{array}{l}- \\
-\end{array}$ \\
\hline $\begin{array}{c}\text { Hydroides elegans } \\
\quad .\end{array}$ & $\begin{array}{l}\mathrm{T} 1 \\
\mathrm{~T} 2\end{array}$ & $\begin{array}{c}\text { Non-indigenous } \\
. .\end{array}$ & $\begin{array}{c}\text { Solitary, Encrusting, Hard } \\
. .\end{array}$ & $\begin{array}{l}3.3 \pm 0.5 \\
6.2 \pm 0.7\end{array}$ & $\begin{array}{l}3.3 \pm 0.5 \\
6.2 \pm 0.7\end{array}$ & $\begin{array}{l}3.3 \pm 0.5 \\
6.2 \pm 0.7\end{array}$ & $\begin{array}{l}3.5 \pm 0.4 \\
6.1 \pm 1.0\end{array}$ & $\begin{array}{l}3.5 \pm 0.4 \\
6.1 \pm 1.0\end{array}$ & $\begin{array}{l}3.5 \pm 0.4 \\
6.1 \pm 1.0\end{array}$ & $\begin{array}{l}5.4 \pm 0.7 \\
4.3 \pm 0.7\end{array}$ & $\begin{array}{l}5.4 \pm 0.7 \\
4.3 \pm 0.7\end{array}$ & $\begin{array}{l}5.4 \pm 0.7 \\
4.4 \pm 0.7\end{array}$ \\
\hline Pomatocerus caeruleus & $\mathrm{T} 1$ & Indigenous & Solitary, Encrusting, Hard & $4.7 \pm 0.6$ & $4.7 \pm 0.6$ & $4.7 \pm 0.6$ & $5.4 \pm 0.6$ & $5.4 \pm 0.6$ & $5.4 \pm 0.6$ & $7.4 \pm 0.8$ & $7.4 \pm 0.8$ & $7.4 \pm 0.8$ \\
\hline. & $\mathrm{T} 2$ & $\because$ & .. & $11.2 \pm 1.5$ & $11.2 \pm 1.5$ & $11.2 \pm 1.5$ & $11.2 \pm 1.1$ & $11.2 \pm 1.1$ & $11.2 \pm 1.1$ & $10.1 \pm 1.8$ & $10.1 \pm 1.8$ & $10.1 \pm 1.8$ \\
\hline Gaelolaria hystrix & $\mathrm{T} 1$ & Indigenous & Solitary, Encrusting, Hard & $4.4 \pm 0.5$ & $4.3 \pm 0.4$ & $4.2 \pm 0.5$ & $4.0 \pm 0.5$ & $4.3 \pm 0.6$ & $4.6 \pm 0.6$ & $7.5 \pm 1.1$ & $7.5 \pm 1.1$ & $7.5 \pm 1.1$ \\
\hline .. & $\mathrm{T} 2$ & .. & .. & $6.2 \pm 0.7$ & $6.2 \pm 0.7$ & $6.2 \pm 0.7$ & $6.1 \pm 1.0$ & $6.1 \pm 1.0$ & $6.1 \pm 1.0$ & $4.3 \pm 0.7$ & $4.3 \pm 0.7$ & $4.4 \pm 0.7$ \\
\hline
\end{tabular}


Table 9. Continued.

\begin{tabular}{|c|c|c|c|c|c|c|c|c|c|c|c|c|}
\hline \multirow{3}{*}{ Taxonomic classification } & \multirow{3}{*}{ Trial } & \multirow{3}{*}{ Status } & \multirow{3}{*}{ Morphology } & \multicolumn{9}{|c|}{ Speed Category } \\
\hline & & & & \multicolumn{3}{|c|}{ Slow } & \multicolumn{3}{|c|}{ Medium } & \multicolumn{3}{|c|}{ Fast } \\
\hline & & & & Pre & Post & $7 \mathrm{~d}$ & Pre & Post & $7 \mathrm{~d}$ & Pre & Post & $7 \mathrm{~d}$ \\
\hline \multicolumn{13}{|l|}{ ANNELIDA } \\
\hline Spirorbidae & & & & & & & & & & & & \\
\hline Unidentified spp. & $\mathrm{T} 1$ & Unknown & Solitary, Encrusting, Hard & $3.6 \pm 0.7$ & $3.6 \pm 0.7$ & $3.6 \pm 0.7$ & $2.7 \pm 0.5$ & $2.7 \pm 0.5$ & $2.7 \pm 0.5$ & $2.9 \pm 0.4$ & $2.9 \pm 0.4$ & $2.9 \pm 0.4$ \\
\hline . & $\mathrm{T} 2$ & .. & . & $4.5 \pm 0.6$ & $4.5 \pm 0.6$ & $4.5 \pm 0.6$ & $4.6 \pm 1.1$ & $4.6 \pm 1.1$ & $4.6 \pm 1.1$ & $6.8 \pm 0.8$ & $6.8 \pm 0.8$ & $6.8 \pm 0.8$ \\
\hline \multicolumn{13}{|l|}{ CRUSTACEA } \\
\hline $\begin{array}{l}\text { Balanidae } \\
\text { Austrominius modestus }\end{array}$ & $\mathrm{T} 1$ & Indigenous & Solitary, Encrusting, Hard & $2.0 \pm 0.0$ & $2.0 \pm 0.0$ & $2.0 \pm 0.0$ & - & - & - & $2.0 \pm 0.0$ & $2.0 \pm 0.0$ & $2.0 \pm 0.0$ \\
\hline \multicolumn{13}{|l|}{ CHORDATA } \\
\hline \multirow{2}{*}{\multicolumn{13}{|c|}{$\begin{array}{l}\text { Urochordata } \\
\text { Polyclinidae }\end{array}$}} \\
\hline & & & & & & & & & & & & \\
\hline Aplidium sp. & $\mathrm{T} 1$ & Unknown & Colonial, Encrusting, Soft & $12.0 \pm 0.0$ & $12.0 \pm 0.0$ & - & - & - & - & $4.0 \pm 0.0$ & - & - \\
\hline$\ldots$ & $\mathrm{T} 2$ & . & $\ldots$ & - & - & - & - & - & - & $2.0 \pm 0.0$ & $2.0 \pm 0.0$ & $2.0 \pm 0.0$ \\
\hline \multicolumn{13}{|l|}{ Didemnidae } \\
\hline Didemпит sp. 1 & $\mathrm{~T} 1$ & Unknown & Colonial, Encrusting, Soft & $3.1 \pm 0.6$ & $3.1 \pm 0.6$ & $4.5 \pm 1.0$ & $4.8 \pm 0.7$ & $4.7 \pm 0.7$ & $6.1 \pm 1.3$ & $4.1 \pm 0.6$ & $4.0 \pm 0.7$ & $3.7 \pm 0.7$ \\
\hline .. & $\mathrm{T} 2$ & . & $\cdots$ & $2.7 \pm 0.2$ & $2.7 \pm 0.3$ & $2.5 \pm 0.2$ & $2.8 \pm 0.4$ & $2.8 \pm 0.4$ & $2.6 \pm 0.4$ & $2.3 \pm 0.2$ & $2.4 \pm 0.4$ & $2.0 \pm 0.0$ \\
\hline Didemпит sp. 2 & $\mathrm{~T} 1$ & Unknown & Colonial, Encrusting, Soft & $2.0 \pm 0.0$ & $2.0 \pm 0.0$ & - & - & - & - & $2.0 \pm 0.0$ & $2.0 \pm 0.0$ & $2.0 \pm 0.0$ \\
\hline .. & $\mathrm{T} 2$ & . & 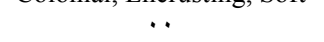 & $8.0 \pm 4.0$ & $8.0 \pm 4.0$ & $8.0 \pm 4.0$ & - & - & - & - & - & - \\
\hline \multicolumn{13}{|l|}{ Pyuridae } \\
\hline Pyura ragata & $\mathrm{T} 1$ & Indigenous & Solitary, Encrusting, Soft & $2.0 \pm 0.0$ & $2.0 \pm 0.0$ & $2.0 \pm 0.0$ & $6.0 \pm 0.0$ & $6.0 \pm 0.0$ & $6.0 \pm 0.0$ & - & - & - \\
\hline Microcosmus australis & $\mathrm{T} 1$ & Indigenous & Solitary, Encrusting, Soft & - & - & - & $2.0 \pm 0.0$ & $2.0 \pm 0.0$ & - & $2.0 \pm 0.0$ & $2.0 \pm 0.0$ & - \\
\hline .. & $\mathrm{T} 2$ & .. & .. & - & - & - & $4.0 \pm 0.0$ & $2.0 \pm 0.0$ & - & - & - & - \\
\hline Diplosoma listerianum & $\mathrm{T} 1$ & Non-indigenous & Solitary, Encrusting, Soft & - & - & - & $6.0 \pm 0.0$ & $6.0 \pm 2.3$ & $8.0 \pm 2.3$ & $3.0 \pm 0.7$ & $2.8 \pm 0.8$ & $2.0 \pm 0.0$ \\
\hline .. & $\mathrm{T} 2$ & .. & . & $23.8 \pm 4.2$ & $22.1 \pm 4.0$ & $18.3 \pm 3.0$ & $31.8 \pm 5.2$ & $31.4 \pm 5.2$ & $26.9 \pm 4.8$ & $27.1 \pm 5.5$ & $21.9 \pm 5.2$ & $6.0 \pm 0.0$ \\
\hline & & & Total Richness & 28 & 27 & 26 & 24 & 24 & 22 & 28 & 27 & 25 \\
\hline SUMMARY & & & Average \% cover ( \pm 1 SE) & $81.1 \pm 2.0$ & $61.8 \pm 2.0$ & $73.3 \pm 1.8$ & $79.0 \pm 2.0$ & $62.5 \pm 2.3$ & $71.6 \pm 2.0$ & $72.7 \pm 2.8$ & $44.5 \pm 1.9$ & $43.4 \pm 1.9$ \\
\hline
\end{tabular}


tubeworm, Pomatocerus caeruleus were the most abundant organisms detected on the T2 pre-voyage settlement plates with an average percentage cover of $23.6 \pm 4.3$ and $11.2 \pm 1.5$ per plate respectively (Table 9$)$.

\subsubsection{Multivariate analysis}

Multivariate analysis of $\mathrm{T} 1$ assemblage composition and dominance showed that fast vessel post- and $7 \mathrm{~d}$ post-voyage assemblages had markedly different compositions from fast pre-voyage treatments, as well as to pre-, post- and $7 \mathrm{~d}$ post-voyage communities on slow and medium vessels ( $\geq 75 \%$ Bray-Curtis similarity; Figure 16). SIMPER analysis indicated this was largely a result of increased bare space on fast plates on post- and $7 \mathrm{~d}$ post-voyage plates, in addition to the complete removal of the bryozoan Bugula flabellata, and the reduction in cover (and subsequent slow recovery) of Obelia longissima (Table 9; Figure 1).

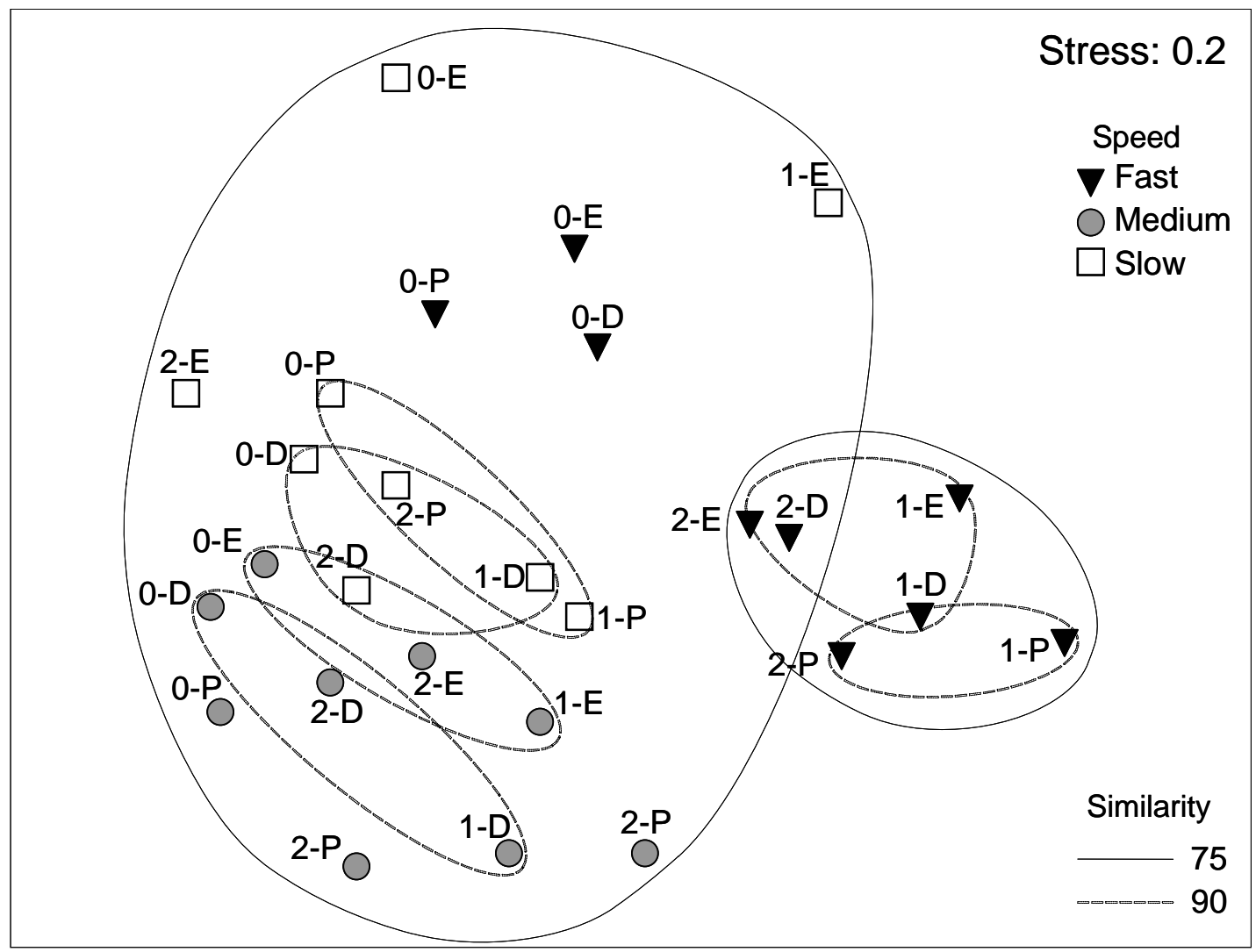

Figure 16 nMDS plots of the T1 pre- (0), post- (1) and $7 \mathrm{~d}$ post-voyage (2) composition and dominance of biofouling organisms on plates subjected to slow, medium and fast vessel voyage speeds at three different hull locations $(\mathrm{E}=$ exposed, $\mathrm{D}=\mathrm{DDSS}$, and $\mathrm{P}=$ protected). Each point represents the average composition and dominance of biofouling organisms within a given hull location. Lines encircle treatment groups having a BrayCurtis similarity of $\geq 75 \%$ and $\geq 90 \%$. 
Analysis of communities from T2 trials showed that all pre-, post- and $7 \mathrm{~d}$ post-voyage fast vessel assemblages differed from those exposed to medium and slow vessel speeds ( $\geq 80 \%$ Bray-Curtis similarity; Figure 17). SIMPER analysis indicated this was primarily a result of a decrease in the abundance and dominance of the colonial ascidian Diplosoma listerianum (Table 9) and the increase in bare space on fast plates relative to slow and medium plates. Pre-voyage treatment plates were different between T2 trials, particularly between fast vessels relative to slow and medium pre-treatment plates. This could be explained by biofouling communities advancing rapidly over the 5 week summer period trial period. While vessel trials were conducted in a random order, the three fast vessel trials occurred towards the end of all trials allowing biofouling communities to advance the most. However, the effect of speed and magnitude of change between pre- post- and $7 \mathrm{~d}$ points remains the greatest for fast vessels compared to other speeds at each location (Figure 17). Distinct patterns were again observed with respect to hull location, with all exposed, DDSS and protected assemblages being consistently separated out at $\geq 90 \%$ Bray-Curtis similarity across all vessels speeds (Figure 17). However, given that these hull location groupings were unique for each vessel speed, determination of which specific taxa contributing to the dissimilarity observed between groups proved difficult using SIMPER analyses.

\subsubsection{Species richness}

A significant Time (i.e. assessment period) $\mathrm{x}$ Speed interaction was observed which explained variation in species richness in both trial periods (T1: $F_{[4,144]}=2.886, P=0.024$ and T2: $\left.F_{[4,144]}=5.525, P<0.001\right)$. During $\mathrm{T} 1$ trials, this interaction contributed to a significant decrease in species richness on fast plates over each successive time period (Tukey's HSD, $P \leq 0.001$; Figure 18a), in contrast to a marked decline in species richness in medium and slow treatment assemblages only after $7 \mathrm{~d}$ post-voyage (Tukey's HSD, $P<0.001$; Figure 18a). During T2 trials, species richness on fast treatment plates again decreased significantly at each recorded time period (Tukey's HSD, $P<0.05$; Figure 18b), with $7 \mathrm{~d}$ post-voyage assemblages having significantly decreased species richness relative to slow and medium plates (Tukey's HSD, $P<0.05$ ). Slow and medium assemblage species richness remained largely unchanged (Figure 18b). 


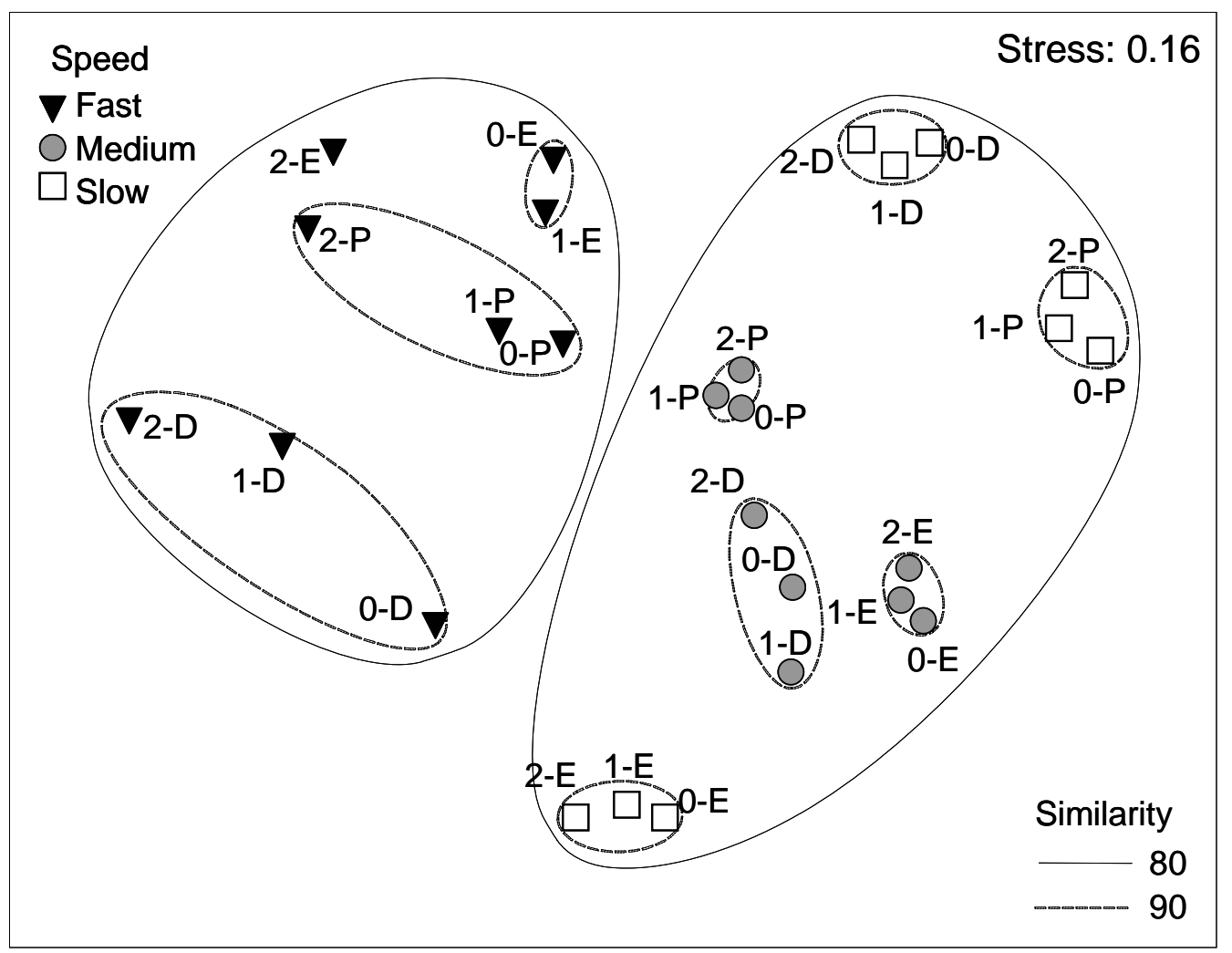

Figure $17 \mathrm{nMDS}$ plots of the T2 pre- (0), post- (1) and $7 \mathrm{~d}$ post-voyage (2) composition and dominance of biofouling organisms on plates subjected to slow, medium and fast vessel voyage speeds at three different hull locations $(\mathrm{E}=$ exposed, $\mathrm{D}=\mathrm{DDSS}$, and $\mathrm{P}=$ protected). Each point represents the average composition and dominance of biofouling organisms within a given hull location. Lines encircle treatment groups having a BrayCurtis similarity of $\geq 80 \%$ and $\geq 90 \%$. 

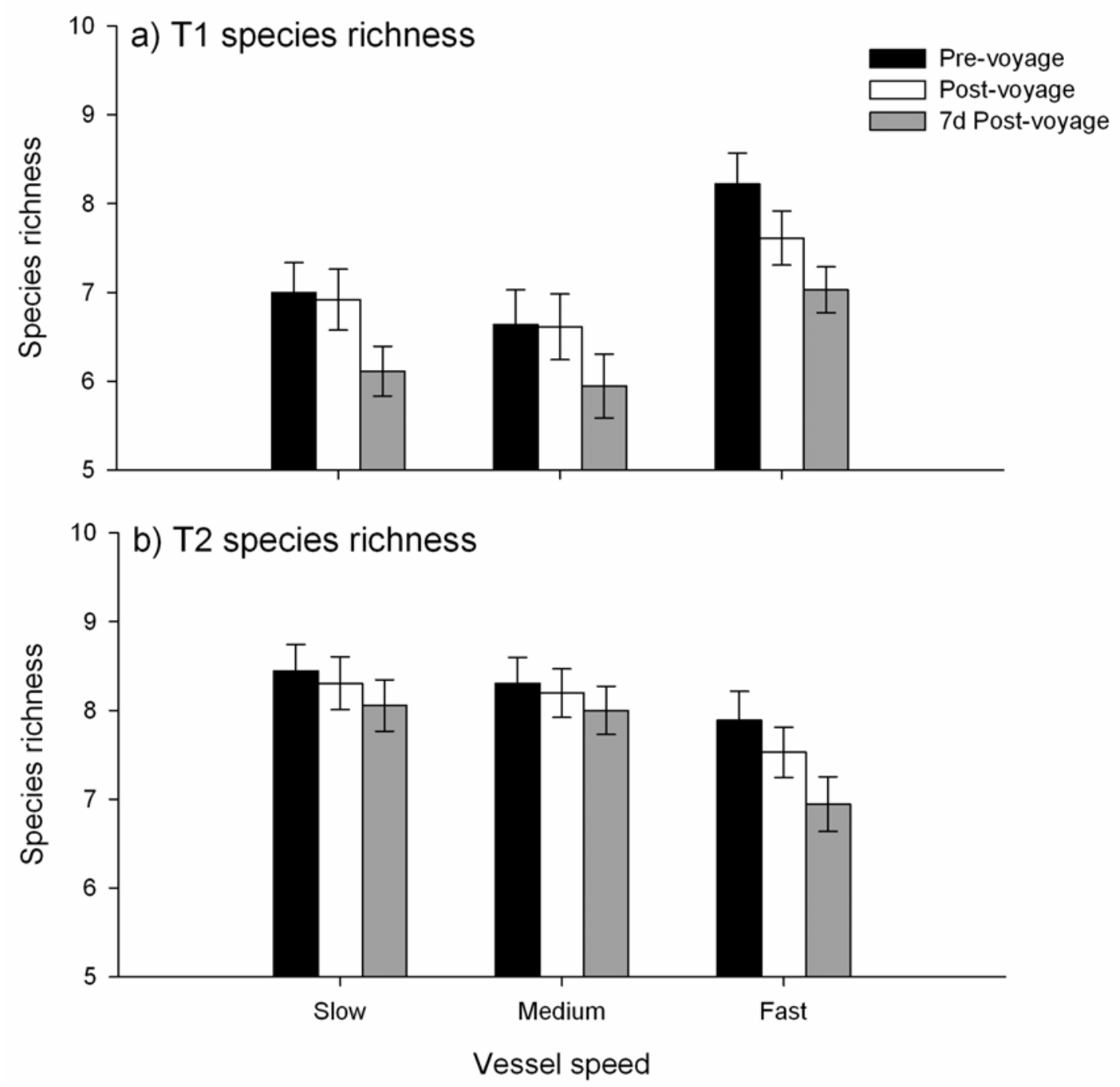

Figure 18 Average percentage changes and $( \pm 1 \mathrm{SE})$ in species richness recorded during pre-, post- and $7 \mathrm{~d}$ post-voyage assessments over three vessel voyage speeds (slow, medium, and fast) for both trials a) T1 and b) T2.

Across both $\mathrm{T} 1$ and $\mathrm{T} 2$ trials, decreases in species richness in fast treatment assemblages were largely due to the removal of numerous bryozoan species (unknown: Beania sp., and non-indigenous: Bitectipora rostrata, Bugula flabellata, Conopeum seurati), several ascidians (unknown: Didemnum sp.1, native Microcosmos australis, and non-indigenous: Diplosoma listerianum), an unidentified sponge (Porifera) and a Terebellid species (Table 9; Figure 19c and Figure 20c). Many of these same species contributed to declines in species richness in T1 medium and slow assemblages (Figure 19b). The prevalence of species on T2 slow and medium plates remained largely unchanged across all time periods (Figure 20a and b). 

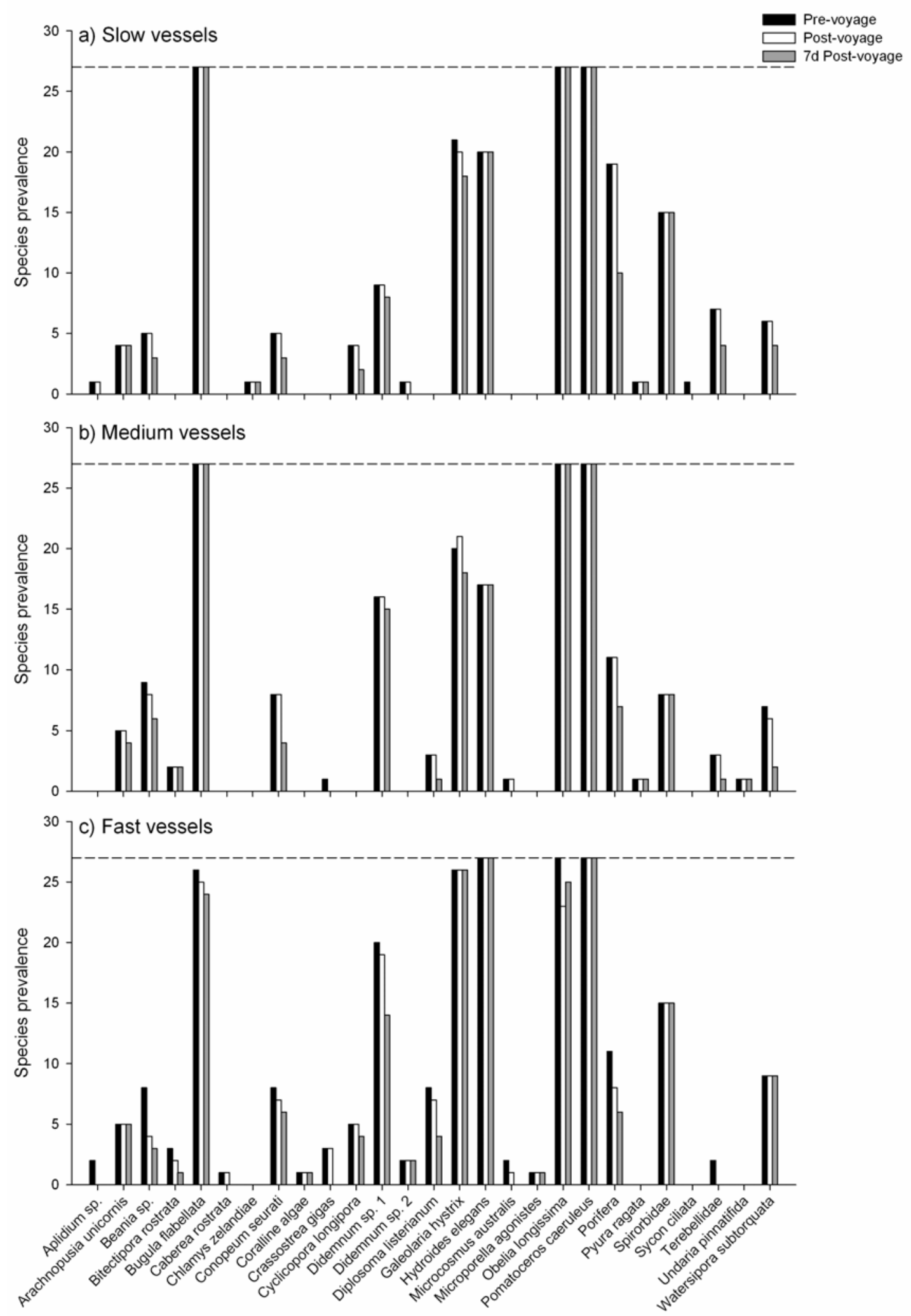

Figure 19 Prevalence of various biofouling organisms encountered on settlement plates during the T1 trials amongst three vessel voyage speeds: a) slow, b) medium, and c) fast during pre-, post- and $7 \mathrm{~d}$ post-voyage assessments. The dashed line refers to the total number of settlement plates used per trial (i.e. three vessels $\mathrm{x}$ three hull locations $\mathrm{x}$ three replicate plates $=27$ ). 

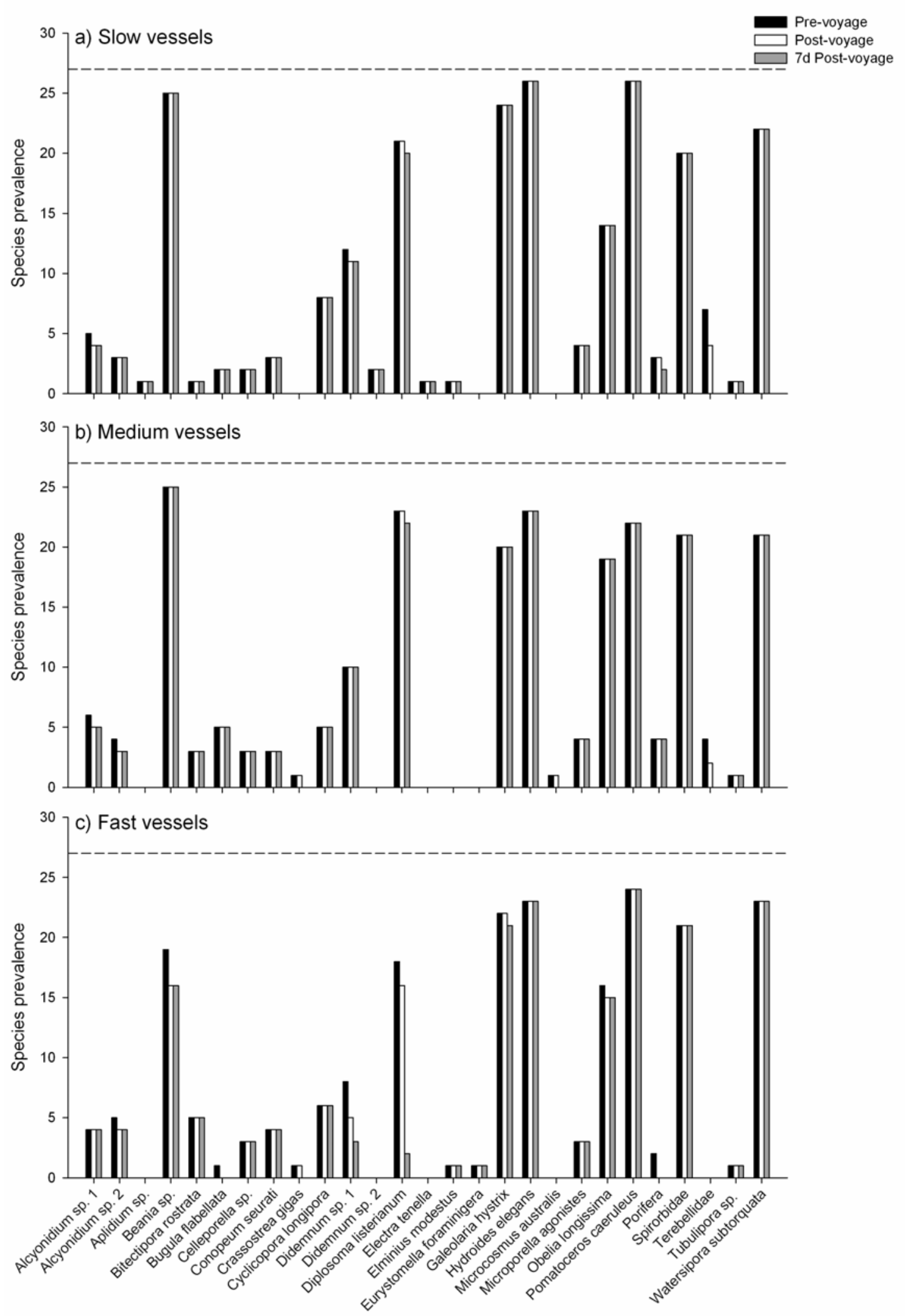

Figure 20 Prevalence of various biofouling organisms encountered on settlement plates during the T2 trials amongst three vessel voyage speeds: a) slow, b) medium, and c) fast during pre-, post- and $7 \mathrm{~d}$ post-voyage assessments. The dashed line refers to the total number of settlement plates used per trial (i.e. three vessels $\mathrm{x}$ three hull locations $\mathrm{x}$ three replicate plates $=27$ ). 


\subsubsection{Species percentage cover}

Analysis of assemblage percentage cover for $\mathrm{T} 1$ treatments showed a significant Time $\mathrm{x}$ Speed interaction $\left(F_{[4,144]}=20.621, P<0.001\right)$, with dramatic declines $(23-37 \%)$ in cover observed across all speed treatments post-voyage, but significantly greater $7 \mathrm{~d}$ postvoyage recovery in medium and slow assemblages relative to fast $7 \mathrm{~d}$ post-voyage treatments (Tukey's HSD, $P<0.001$; Figure 21a). A Time x Speed interaction was also observed for T2 assemblages $\left(F_{[4,144]}=3.472, P=0.009\right)$, this time characterised by a significant and persistent decline in species cover on fast treatment plates across all time periods (Tukey's HSD, $P \leq 0.05$ ), but largely no change in recorded cover for medium and slow assemblages irrespective of sampling time (Figure 21b). In addition, a Time x Location interaction was observed during T2 trials $\left(F_{[4,144]}=3.321, P=0.012\right)$ as a result of decreased $7 \mathrm{~d}$ post-voyage percentage cover of biofouling within exposed and DDSS hull locations relative to their respective pre-voyage states (Tukey's HSD, $P<0.05$ ).
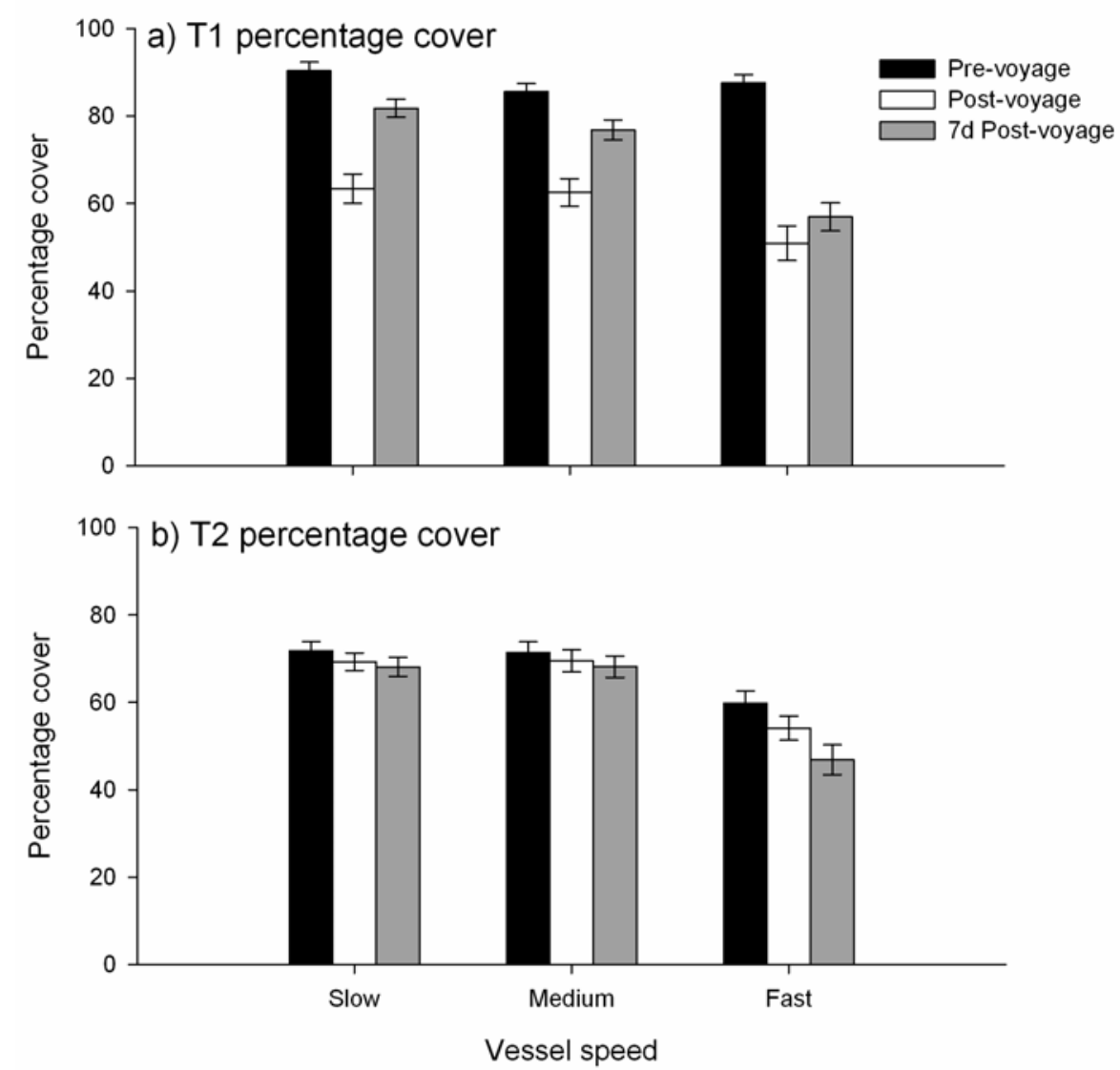

Figure 21 Changes in species percentage cover recorded during pre-, post- and $7 \mathrm{~d}$ post-voyage assessments over three vessel voyage speeds (slow, medium, and fast) for both trials a) T1 and b) T2. 
During T1 trials, $7 \mathrm{~d}$ post-voyage recovery was consistently observed for the nonindigenous aborescent bryozoan $B$. flabellata, the hydroid O. longissima, and the unknown colonial ascidian Didemnum sp. 1 (Table 9; Figure 22). In comparison, the only species to display consistent post-voyage recovery during T2 trials was $O$. longissima. Interestingly, two non-indigenous species, $B$. flabellata and the colonial ascidian $D$. listerianum, showed consistently reduced post-voyage percentage cover across all speeds during T2 trials (Table 9; Figure 23), with $D$. listerianum in particular exhibiting significant loss in abundance between the post-voyage $(21.9 \pm 5.2)$ and $7 \mathrm{~d}$ post-voyage assessment $(6.0 \pm 0.0)$. The unknown bryozoan Alcyonidium sp.1 and the Terebellid species also showed slight declines in percentage cover following fast voyages (Table 9; Figure 23c).

\subsubsection{Morphology}

A significant Speed x Morphology interaction was observed for comparisons of colonial versus solitary, soft versus hard and hard versus flexible morphologies $(P \leq 0.05$; Table 10). These interactions were due to a decrease in the post-voyage occurrence of colonial, flexible and soft species in fast treatments relative to solitary and hard species, combined with little change in the prevalence of any specific morphological group in medium and slow treatments. Fast voyages significantly reduced the occurrence of both erect and encrusting species with respect to each other $\left(F_{[2,313]}=10.851, P<0.001\right)$, as well as soft-bodied taxa relative to flexible species (Table 10a).

While significant changes in percentage cover occurred amongst all morphological comparisons (i.e. colonial > solitary; erect $>$ encrusting; flexible $>$ soft; soft $>$ hard; flexible $>$ hard), this was independent of vessel speed (Table 10b). Species that were most susceptible to voyage speed and responsible for contributing most to the changes in these comparisons included the colonial/erect/flexible species $O$. longissima and $B$. flabellata, and the colonial/encrusting/soft D. listerianum (Table 9 and Table 10). 

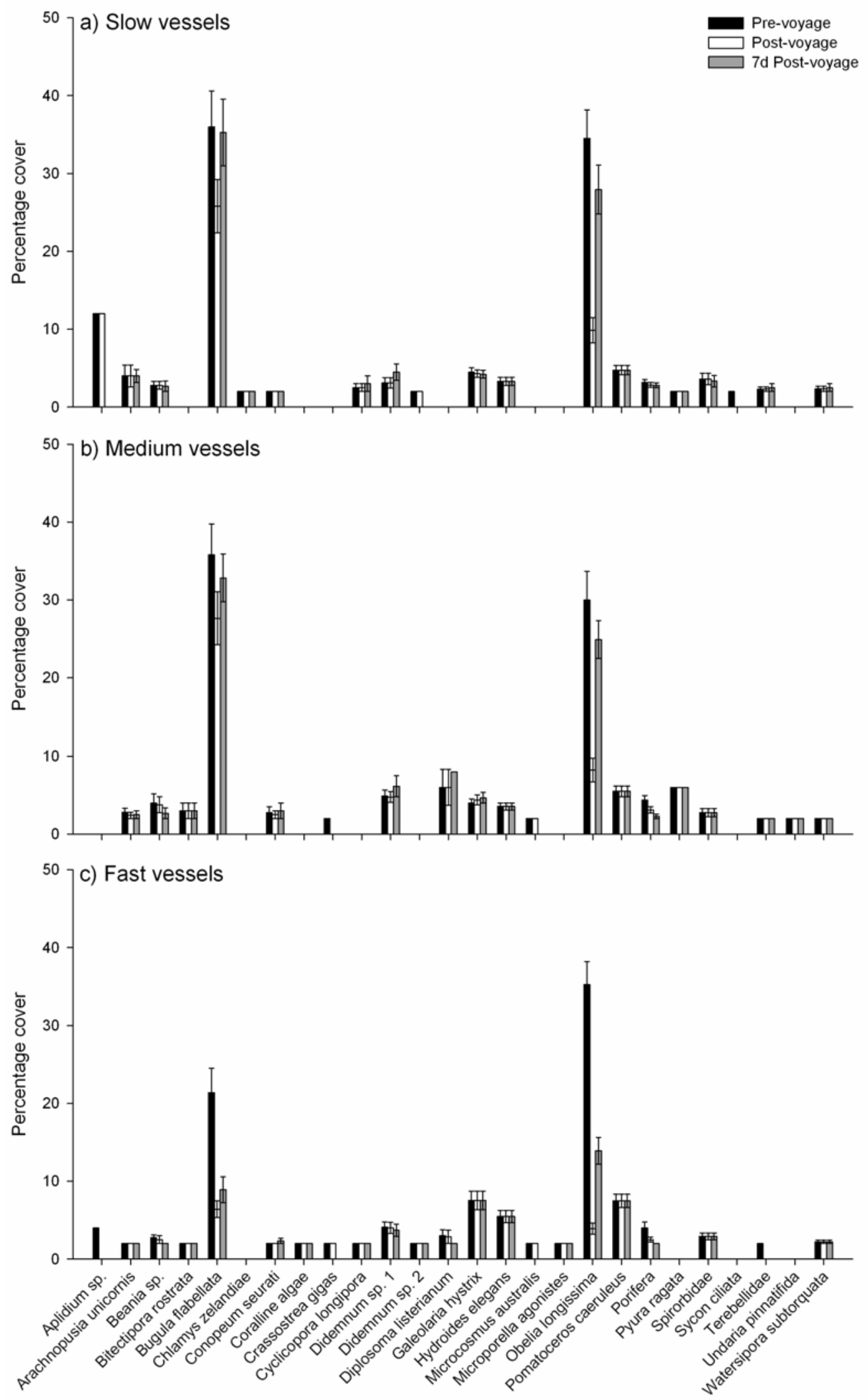

Figure 22 Average percentage cover of various biofouling organisms encountered on settlement plates during the T1 trials amongst three vessel voyage speeds: a) slow, b) medium, and c) fast during pre-, post- and $7 \mathrm{~d}$ post-voyage assessments. 

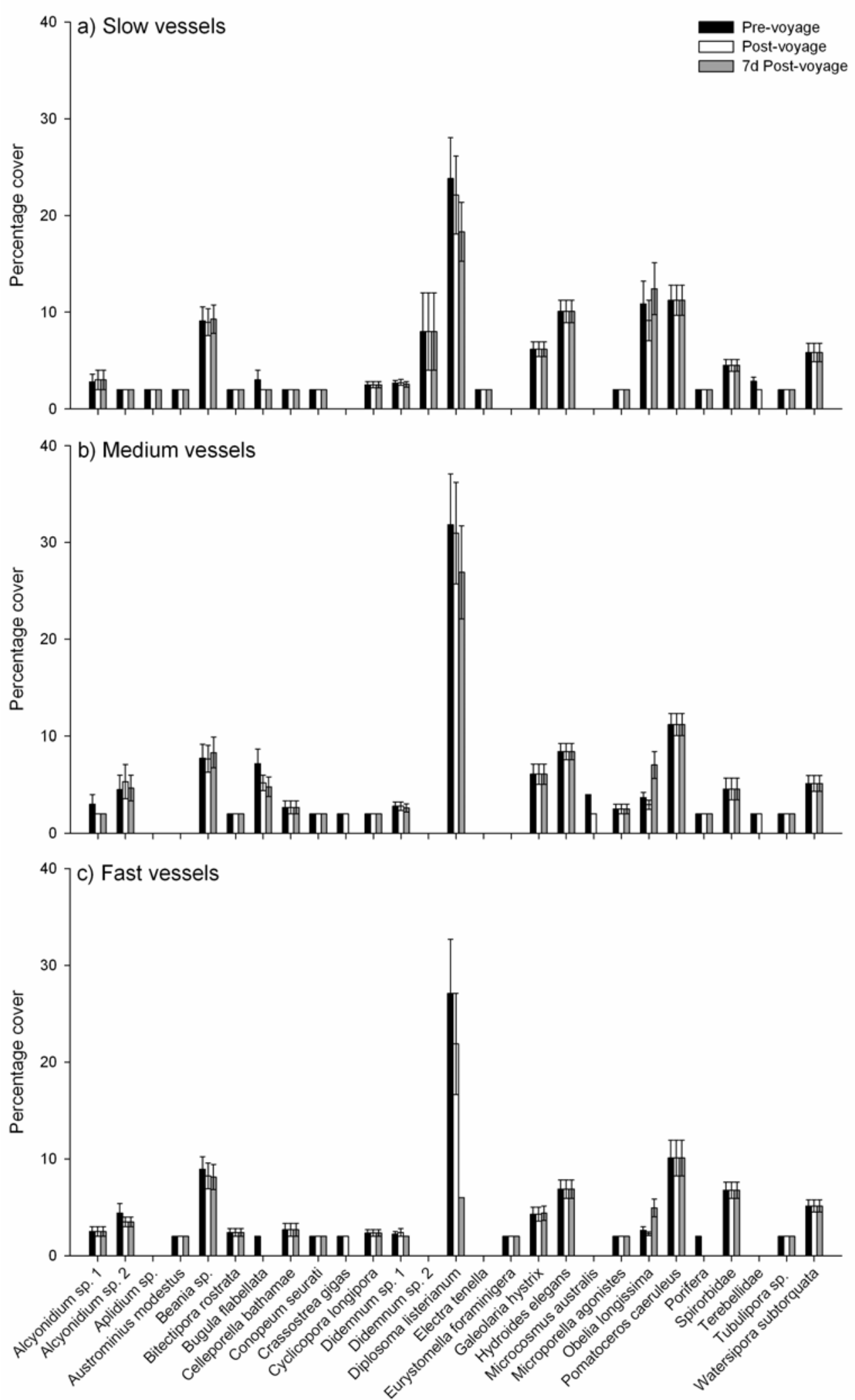

Figure 23 Average percentage cover of various biofouling organisms encountered on settlement plates during the T1 trials amongst three vessel voyage speeds: a) slow, b) medium, and c) fast during pre-, post- and $7 \mathrm{~d}$ post-voyage assessments. 
Table 10 Summary of two-way analysis of variance of the effect of voyage speed on the change in: a) species richness; and b) percentage cover between pre- and postvoyage data (with $\mathrm{T} 1$ and $\mathrm{T} 2$ pooled) relative to species morphological characteristics.

\begin{tabular}{|c|c|c|c|c|c|c|c|c|}
\hline & \multicolumn{3}{|c|}{ a) Richness } & \multicolumn{5}{|c|}{ b) Percentage cover } \\
\hline Source & df & MS & $\mathbf{F}$ & $\boldsymbol{P}$ & df & MS & $\mathbf{F}$ & $\boldsymbol{P}$ \\
\hline $\begin{array}{l}\text { Solitary vs colonial } \\
\text { Speed treatment } \\
\text { Morphology } \\
\text { Speed x morphology } \\
\text { Error } \\
\end{array}$ & $\begin{array}{r}2 \\
1 \\
2 \\
316 \\
\end{array}$ & $\begin{array}{l}0.101 \\
0.056 \\
0.051 \\
0.007 \\
\end{array}$ & $\begin{array}{r}14.314 \\
7.976 \\
7.261\end{array}$ & $\begin{array}{r}<0.001 \\
0.005 \\
<0.001\end{array}$ & $\begin{array}{r}2 \\
1 \\
2 \\
316 \\
\end{array}$ & $\begin{array}{l}0.035 \\
7.464 \\
0.039 \\
0.042 \\
\end{array}$ & $\begin{array}{r}0.840 \\
174.516 \\
0.923\end{array}$ & $\begin{array}{r}0.432 \\
<\mathbf{0 . 0 0 1} \\
0.398\end{array}$ \\
\hline $\begin{array}{l}\text { Erect vs encrusting } \\
\text { Speed treatment } \\
\text { Morphology } \\
\text { Speed x morphology } \\
\text { Error }\end{array}$ & $\begin{array}{r}2 \\
1 \\
2 \\
313 \\
\end{array}$ & $\begin{array}{l}0.085 \\
0.014 \\
0.000 \\
0.007 \\
\end{array}$ & $\begin{array}{r}10.851 \\
1.806 \\
0.025\end{array}$ & $\begin{array}{r}<0.001 \\
0.179 \\
0.974\end{array}$ & $\begin{array}{r}2 \\
1 \\
2 \\
313 \\
\end{array}$ & $\begin{array}{l}0.029 \\
6.253 \\
0.001 \\
0.056 \\
\end{array}$ & $\begin{array}{c}0.520 \\
110.85 \\
0.019\end{array}$ & $\begin{array}{r}0.594 \\
<0.001 \\
0.980\end{array}$ \\
\hline $\begin{array}{l}\text { Soft } v \text { s flexible } \\
\text { Speed treatment } \\
\text { Morphology } \\
\text { Speed x morphology } \\
\text { Error }\end{array}$ & $\begin{array}{r}2 \\
1 \\
2 \\
272\end{array}$ & $\begin{array}{l}0.364 \\
0.254 \\
0.048 \\
0.027\end{array}$ & $\begin{array}{r}13.327 \\
9.313 \\
1.764\end{array}$ & $\begin{array}{r}<0.001 \\
0.002 \\
0.173\end{array}$ & $\begin{array}{r}2 \\
1 \\
2 \\
272\end{array}$ & $\begin{array}{l}0.072 \\
5.587 \\
0.078 \\
0.077\end{array}$ & $\begin{array}{r}0.934 \\
72.362 \\
1.018\end{array}$ & $\begin{array}{r}0.393 \\
<\mathbf{0 . 0 0 1} \\
0.362\end{array}$ \\
\hline $\begin{array}{l}\text { Soft } v s \text { hard } \\
\text { Speed treatment } \\
\text { Morphology } \\
\text { Speed x morphology } \\
\text { Error }\end{array}$ & $\begin{array}{r}2 \\
1 \\
2 \\
313 \\
\end{array}$ & $\begin{array}{l}0.229 \\
0.404 \\
0.150 \\
0.019\end{array}$ & $\begin{array}{r}11.556 \\
20.314 \\
7.575\end{array}$ & $\begin{array}{l}<0.001 \\
<0.001 \\
<0.001\end{array}$ & $\begin{array}{r}2 \\
1 \\
2 \\
313 \\
\end{array}$ & $\begin{array}{l}0.029 \\
6.253 \\
0.001 \\
0.056\end{array}$ & $\begin{array}{r}0.520 \\
110.853 \\
0.019\end{array}$ & $\begin{array}{c}0.594 \\
<0.001 \\
0.980\end{array}$ \\
\hline $\begin{array}{l}\text { Hard vs flexible } \\
\text { Speed treatment } \\
\text { Morphology } \\
\text { Speed x morphology } \\
\text { Error }\end{array}$ & $\begin{array}{r}2 \\
1 \\
2 \\
287 \\
\end{array}$ & $\begin{array}{l}0.058 \\
0.009 \\
0.023 \\
0.007 \\
\end{array}$ & $\begin{array}{l}7.749 \\
1.312 \\
3.107\end{array}$ & $\begin{array}{r}<0.001 \\
0.252 \\
0.046\end{array}$ & $\begin{array}{r}2 \\
1 \\
2 \\
287 \\
\end{array}$ & $\begin{array}{r}0.001 \\
12.171 \\
0.007 \\
0.048 \\
\end{array}$ & $\begin{array}{r}0.276 \\
251.104 \\
0.160\end{array}$ & $\begin{array}{c}0.758 \\
<0.001 \\
0.851\end{array}$ \\
\hline
\end{tabular}

\subsection{DISCUSSION}

The development of MAGPLATE technology has enabled the first consistently applied empirical evaluation of the en route and post-voyage survivorship of biofouling organisms across different hull locations on a range of vessel types. Vessel operating speed was observed to be the primary determinant of species survival and assemblage composition. Communities transported on fast-moving vessels contained fewer species at the completion of a voyage compared to pre-voyage states, with species richness declining still further after $7 \mathrm{~d}$. In contrast, biofouling assemblages on medium and slow-moving vessels displayed minimal reductions in species numbers pre- and post voyage, although some $7 \mathrm{~d}$ post-voyage declines were evident during one trial period. With respect to biofouling cover, treatment assemblages on fast vessels experienced the greatest reductions, with extended post-voyage recovery either minor (T1) or nonexistent (T2). Changes in assemblage cover for medium and slow voyages were similar 
throughout all trials, with remaining cover either recovering rapidly $7 \mathrm{~d}$ post-voyage (T1) or remaining unchanged across all sampling periods (T2). Differing morphological characteristics appeared to be a major factor in the removal of species and cover, with specific growth forms (colonial), profiles (erect) and structures (soft, flexible) being most susceptible to removal.

This study has mimicked real-world scenarios of vessels that have remained stationary in a port or coastal waters for between two and five months prior to setting sail for a relatively short return voyage (i.e. 3.0-7.25 hours voyage duration). Of relevance here is the fact that the recent global economic downturn has resulted in an unprecedented number of vessels being anchored for long periods in ports and harbours around the world (Floerl and Coutts 2009; Wingrove 2009). Lay-up periods of 2-5 months may provide ample opportunity for biofouling organisms to colonise areas of vessels where anti-fouling coatings may be absent, spent, and/or damaged (Piola and Johnson 2009). The results of this study demonstrate that while fast-moving vessels (14.0-21.5 knots) may be capable of reducing species richness and percentage cover (i.e. potential inocula) of biofouling, the majority of species still survived. These results are even more pronounced for slow and medium voyage speeds where assemblage compositions and abundances remain largely unchanged pre- and post-voyage.

Of the 33 different biofouling species encountered in this study, only three failed to survive post- and/or $7 \mathrm{~d}$ post-voyages. These were the native sponge Sycon ciliata, juvenile non-indigenous Pacific oysters Crassostrea gigas and the native solitary ascidian Microcosmus australis. It should be noted, however, these species were considered 'rare', constituting and average of just two (S. ciliate and C. gigas) and four (M. australis) percentage cover per plate. Furthermore, S. ciliata was the only species to not complete a voyage, with $C$. gigas and $M$. australis recorded as absent only after 7 d post-voyage. In contrast, $90 \%$ of biofouling organisms survived the voyage trials, with some colonial species (e.g. the non-indigenous hydroid O. longissima) displaying significant recovery within $7 \mathrm{~d}$ despite large reductions in post-voyage percentage cover. This is consistent with Carlton and Hodder's (1995) observations of the en route survivorship of biofouling organisms during their $800 \mathrm{~km}$ voyage down the west coast of the United States on the Golden Hinde II. They recorded equivalent levels of species 
survival (90-95\%) in addition to the rapid post-voyage regeneration of similar colonial species (e.g. hydroids).

\subsubsection{Voyage speed and morphology}

The three voyage speed groupings used in this study, namely slow $(5.6 \pm 0.3)$, medium $(8.4 \pm 0.2)$ and fast $(17.9 \pm 1.3$ knots $)$ closely resemble those used by Coutts et al. (2010) (i.e. 5, 10 and 18 knots) during their towed keel study. Not surprisingly, the overall results of the two studies were very similar, with species richness and percentage cover decreasing as vessel speed increased, particularly at fast voyage speeds. Unexpectedly, however, Chapter 2 reported greater losses in species richness $(50 \%)$ and average percentage cover $(85 \%)$ at 18 knots than was recorded by the present study (i.e. $4 \%$ and $44 \%$ for richness and cover, respectively). This difference could simply be attributable to differences in species composition in assemblages used during the two studies (Chapter 2 worked in Tasmania, Australia). Alternatively, differential hydrodynamic stresses may have been acting upon the test assemblages in each study. For example, the protrusive shape of the MAGPLATEs (compared to the streamline design of the towed keel) may have resulted in more extensive boundary layers or unstable turbulent flows around test assemblages in this study, effectively reducing the magnitude of shear force stresses acting on the organisms.

The effects of voyage speed on the percentage cover of species classified based on various morphological characteristics varied slightly between this study and that of Chapter 2. Chapter 2 recorded greater reductions in percentage cover amongst solitary species compared with colonials, and flexible taxa compared with soft, and no differences were observed between hard and flexible morphologies. In contrast, patterns of species removals based on morphology recorded were the opposite, with colonial cover reduced more than solitary, soft more than flexible, and flexible more than hard. It is likely that these contrasting results were largely due to differences in baseline community compositions.

However, despite the observed differences in biofouling survivorship between the two studies, I predicted that biofouling survival is likely to be consistently higher for species with the following morphological characteristics: solitary/encrusting/hard; colonial/encrusting/soft; and colonial/erect/flexible. For example, many soft-bodied 
encrusting colonial organisms (e.g. colonial ascidians) typically protrude only several millimetres from the substratum (Chapter 2) and most likely reside within the boundary layer of the hull. As stated in Chapter 2, while such taxa may be vulnerable to "peeling away" from the substratum if moving water is able to get beneath a leading edge, removal would also depend upon the strength of the colony tissues and adhesive "glue" anchoring them, and the surface texture of the settlement substratum (Edlund and Koehl 1998). Hard encrusting taxa, such as encrusting bryozoans, bivalves and serpulid polychaetes have the advantage of a calcareous body structure that can afforded protection and rigidity against acting hydrodynamic forces. The flexibility offered by the colonial branching morphologies (e.g. hydroids, arborescent bryozoans) would likely resulted in a state of anisotropy (i.e. conforming to the direction of hydrodynamic flow) in the colony when the vessel was in motion, thereby reducing drag and perhaps allowing the organisms to reside (at least partially) within the keel boundary layer (Koehl 1984; Denny et al. 1985; Denny et al. 1998).

It should be noted, the circumstances governing the development of the "biofouling assemblages" presented in this study do not hold true for all real-world vessels. For many vessels, biofouling accumulation is generally a gradual process which occurs over the duration of a vessels operational life, not during a 2-3 month stationary period. As such, the average operating speed of vessel would likely have an influence on the composition of the resident biofouling community present, both at its inception and throughout is developmental growth. For example, faster vessels are likely to 'select for' biofouling communities tolerant of greater hydrodynamic forces (e.g. hard, solitary, encrusting taxa), while slower vessel assemblages would likely be dominated by soft, colonial, erect taxa (Coutts 1999; Otani et al. 2007; Davidson et al. 2009; Sylvester and MacIsaac 2009). Given this, the propensity for speed to reduce the overall inoculum pressure (biomass, abundance and/or richness) of any given biofouling community would likely be less than observed in this study, as the biofouling present has already been 'selected' for suitability to that vessels particular operating parameters and mode of use.

This study demonstrates that faster vessels can be expected to deliver fewer propagules to recipient locations than their slower counterparts. And while vessel operating speed cannot solely be considered to be a reliable management option for reducing the 
biosecurity risks associated with biofouling on vessel hulls, these findings do support the view that slower vessels should be targeted for greater management attention relative to faster craft. Ultimately, however, increased speed only acts to reduce potential inoculum pressure (i.e. the overall biomass of biofouling present or abundance of individual species) on vessels, rather than reduce the diversity of possible invaders, and on-going management focus is required for all vessels types, albeit to differing degrees.

\subsubsection{Hull location}

Surprisingly, hull location had no obvious effect on species richness or percentage cover of treatment assemblages. This is largely attributable to a combination of: 1) a limited choice of suitable protected hull areas in which to affix the MAGPLATEs; and 2) issues with the final selection of a "protected" hull location. Many recognised protected niche areas that exist on vessel hulls (e.g. rope guards, keels, sea-chests) were either not conducive to attachment of MAGPLATEs (e.g. too narrow, curved surfaces) or were inaccessible to divers. As such, the protected location ultimately chosen for this study was toward the stern of the vessel where the hull narrows prior to reaching the propeller shaft and rudder. This area was expected to experience less hydrodynamic forces relative to those acting on the bow and amidships of the hull. Unfortunately, all vessels employed during these trials (with the exception of the Dumb Barge) used reverse-thrust to manoeuvre their vessel during berthing. As a result, MAGPLATEs in protected locations were subjected to considerable propeller wash at the start or end of each journey, or both.

It is likely that the hydrodynamic forces exerted by the propeller wash were sufficiently strong to be akin to those acting on the exposed and DDSS areas of the hull during transit, resulting in no detectable differences in assemblage structure among these locations. However, no detectable differences in species richness or percentage cover were observed amongst hull locations of the dumb barge either. This is possibly due to the slow speeds travelled by the vessel during each trial (maximum of 4.0-5.5 knots), resulting in insufficient hydrodynamic forces to cause any detectable differences between hull locations. We maintain that survivorship of biofouling organisms is likely to be higher in "protected" locations of merchant vessels in the real world given that many rely on bow thrusters and tugs during berthing rather than relying on reverse 
thrust. This view is supported by real-world assessments of biofouling distribution and abundance on merchant vessels (e.g. James and Hayden 2000; Coutts and Taylor 2004; Australian Shipowners Association 2006; Davidson et al 2009).

\subsubsection{Environmental factors and conditions}

All voyage trials subjected biofouling organisms to greater ranges of seawater temperatures and salinity relative to the procedural controls at the wharf in Picton Harbour. In general, biofouling organisms experienced slightly elevated salinity levels (up to 1.5 PSU) on vessels as they travelled through Queen Charlotte Sound towards the open ocean. It has been suggested that under more extreme salinity fluctuations, greater operating speeds of modern vessels may be responsible for the spread of low-salinity and brackish water species, because of the decreased exposure time of these species to full-strength seawater (Roos 1979; Lewis 2002; Minchin and Gollasch 2003). While salinity-tolerance is unlikely to have been a major contributor to the survival of organisms in this present study, it may nonetheless be a contributing factor in the transport of euryhaline (and some steno-haline) species by vessels berthing in estuarine or river-based ports, or both (Brock et al. 1999; Apte et al. 2000).

Test assemblages in this study experienced markedly lower seawater temperatures relative to controls, particularly during the summer trials. During one voyage, seawater temperature experienced by biofouling assemblages ranged from $14.5^{\circ} \mathrm{C}$ to $20.1^{\circ} \mathrm{C}$ over a $7 \mathrm{~h}$ period. While it is more likely that hydrodynamic forces played a greater influence in the en route survivorship of biofouling organisms during the trials, fluctuations in seawater temperature are known to induce spawning events in some marine invertebrate species (e.g. Apte et al. 2000). In some temperate regions, an increase of less than $2^{\circ} \mathrm{C}$ in seawater temperature can cause prolific spawning of several taxa (Minchin 1992). This raises the possibility that any species able to survive a vessel voyage may be induced to spawn upon arrival in a new location simply as a result of variations in temperature experienced en route.

The propensity for some biofouling organisms to endure rapid and considerable fluctuations in temperature and salinity may combine with physical attributes of receiving environments giving them an increased chance of establishment and spread. Ports and harbours are highly modified environments that are often characterised by 
large fluctuations in parameters such as temperature and salinity (Minchin and Gollasch 2003). Given that these areas are also the primary hotspots and dispersal hubs for marine introductions (Carlton 1987; Ruiz et al. 2000), it is likely that biofouling organisms tolerant to significant en route fluctuations in temperature and salinity may be well suited to establishment in these physicochemically variable environments (Dafforn et al. 2009).

While the majority of species recovered slightly from the trials in terms of increased percentage cover $7 \mathrm{~d}$ post-voyage, the non-indigenous colonial ascidian $D$. listerianum suffered considerable losses in post- and $7 \mathrm{~d}$ post-voyage percentage cover. This was especially apparent amongst settlement plates that were subjected to fast voyage speeds. This reduction in cover could in part be explained by fish predation as the first author witnessed spotties (Notolabrus celidotus) feeding on only those settlement plates subjected to the fast and medium voyage trials. When these plates were observed upon completion of the $7 \mathrm{~d}$ post-voyage assessment under a microscope, grazing marks were present where $D$. listerianum once existed. In contrast, no active predation was observed on static control assemblages. This increased predation pressure might have been induced by visual and/or chemical cues resulting from physical damage sustained by the biofouling species during voyages (e.g. through hydrodynamic forces). It is also possible that protective canopy-cover organisms (e.g. arborescent bryozoans, hydroids) that were removed from the assemblage during the voyage, allowed predators access to previously hard-to-get to primary-cover species such as D. listerianum (Russ 1980).

\subsubsection{Inoculum pressure and NIMS risks}

This study demonstrated that different vessel speeds have the potential to change NIMS inoculum pressure on recipient environments, with slow and medium vessels more likely to transport the highest levels of biofouling and therefore are most likely to pose the greatest risk on a vessel by vessel scale. This reduced inoculum pressure primarily a result of reductions in biofouling biomass with increasing speed, as their change was recorded in overall biofouling assemblage richness or percentage cover across speed categories. The presence of biofouling organisms after the voyage trials does not necessarily guarantee survivorship, reproduction or establishment in a new region, however, a greater diversity and percentage cover of organisms means a greater potential for successful translocation to occur (i.e. higher risk). This study demonstrates 
the ability of a range of coastal vessel types to spread NIMS domestically and highlights the need for internal border management measures (e.g. Wasson et al. 2001; Forrest et al. 2009), especially for slow and medium speed craft.

\subsubsection{Limitations and future research}

While every attempt was made to construct the MAGPLATEs as thin as possible, adhesive strength necessitated an overall height of protrusion of $13.4 \mathrm{~mm}$ from the hull surface (Coutts et al. 2007). Unfortunately, characterisation of the hydrodynamic flow regime over and around the MAGPLATEs at different speeds and hull locations could not be achieved. Therefore, it is possible that the MAGPLATEs and biofouling organisms protruded beyond realistic boundary layers of the vessels, particularly towards the bow of fast-moving vessels. This may have resulted in biofouling organisms being subjected to different hydrodynamic flow regimes relative to the hull surface. For example, it is conceivable that the leading edge of the MAGPLATEs may have induced and subjected biofouling organisms to unstable turbulent flows. Arguably the results of this study could therefore be considered conservative and survivorship of biofouling organisms attached to the hull proper could be greater in the real world.

The en route survivorship of biofouling organisms in this study were related to the maximum voyage speed of vessels and the resultant unidirectional hydrodynamic flow over the vessel hulls (i.e. bow-to-stern). However, it is important to acknowledge that biofouling organisms, particularly at the bow would have experienced multi-directional accelerative hydrodynamic forces (i.e. when vessels punch or slam through waves) well beyond the vessels respective maximum voyage speed. It is possible that the fate of some biofouling organisms may have been decided by acute accelerative forces rather than prolonged unidirectional hydrodynamic forces.

\subsection{REFERENCES}

AB 740, 2007. California Legislature 2007-2008 Regular Session. Assembly Bill No. 740. Amended in Assembly April 17, 2007.

Apte, S., Holland, B. S., Godwin, L. S, Gardner, P. A., 2000. Jumping ship: a stepping stone event mediating transfer of non-indigenous species via a potentially unsuitable environment. Biological Invasions 2: 75-79. 
Ashton, G., Boos, K., Shucksmith, R., Cook, E., 2006. Risk assessment of hull fouling as a vector for marine non-natives in Scottland. Aquatic Invasions 1: 214-218.

Australian Shipowners Association, 2006. Assessment of introduced marine pest risks associated with niche areas in commercial shipping, June 2006. 24 p.

Biosecurity New Zealand, 2010. Import health standard for vessel biofouling. Biosecurity New Zealand, April 2010.

BLG 14/9, 2009. Development of international measures for minimising the transfer of invasive aquatic species through bio-fouling of ships. Submitted by New Zealand, Sub-Committee on Bulk Liquids and Gases, 14th Session, Agenda item 9, 9 November 2009.

Brock, R., Bailey-Brock, J. H., Goody, J., 1999. A case study of efficacy of freshwater immersion in controlling introduction of alien marine fouling communities: The USS Missouri. Pacific Science 53: 223-231.

Carlton, J. T., 1987. Patterns of transoceanic marine biological invasions in the Pacific. Bulletin of Marine Science 41: 452-465.

Carlton, J. T., Hodder, J. 1995. Biogeography and dispersal of coastal marine organisms: experimental studies on a replica of a 16th-century sailing vessel. Marine Biology 121: 721-730.

Clarke, K. R., 1993. Non-parametric multivariate analyses of changes in community structure. Australian Journal of Ecology 18: 117-143.

Clarke, K. R., Warwick, R. M., 2001. Change in marine communities: an approach to statistical analysis and interpretation. 2nd Edition. PRIMER-E, Plymouth, United Kingdom, 172 pp.

Coutts, A. D. M., 1999. Hull fouling as a modern vector for marine biological invasions: investigation of merchant vessels visiting northern Tasmania. Unpublished MSc thesis, Australian Maritime College, Launceston, Australia. 283 p. 
Coutts, A. D. M., Taylor, M. D., 2004. A preliminary investigation of biosecurity risks associated with biofouling on merchant vessels in New Zealand. New Zealand Journal of Marine and Freshwater Research 38: 215-229.

Coutts, A. D. M., Taylor, M. D., Hewitt, C. L. 2007. Novel method for assessing the en route survivorship of biofouling organisms on various vessel types. Marine Pollution Bulletin 54: 97-100.

Coutts, A. D. M., Piola, R. F., Hewitt, C. L., Connell, S. D., Gardner, J. P. A., 2010. Effects of vessel voyage speed on survival of biofouling organisms: implications for translocation of non-indigenous marine species. Biofouling 26: 1-13.

Cranfield, H. J., Gordon, D. J., Willan, R. C., Marshall, B. C., Battershill, C. N., Francis, M. P., Nelson, W. A., Glasby, C. J., Read, G. B., 1998. Adventive marine species in New Zealand. NIWA Technical Report No. 34. 48 p.

Dafforn, K. A., Glasby, T. M., Johnston, E. L., 2009. Links between estuarine condition and spatial distributions of marine invaders. Diversity and Distributions 15: 807821.

Davidson, I. C., McCann, L. D., Fofonoff, P. W., Sytsma, M. D., Ruiz, G. M., 2008. The potential for hull-mediated species transfers by obsolete ships on their final voyages. Diversity and Distributions 14: 518-529.

Davidson, I. C., Brown, C. W., Sytsma, M. D., Ruiz, G. M., 2009. The role of containerships as transfer mechanisms of marine biofouling species. Biofouling 25: 645-655.

Denny, M. W., Daniel, T. L., Koehl, M. A. R., 1985. Mechanical limits to size in waveswept organisms. Ecological Monographs 55: 69-102.

Denny, M. W., Gaylord, B. P., Helmuth, B., Daniel, T. L., 1998. The menace of momentum: dynamic forces on flexible organisms. Limnology Oceanography 43: 955-968.

Drummond, S. P., Connell, S. D., 2005. Quantifying percentage cover on subtidal organisms on rocky coasts: a comparison of the costs and benefits of standard methods. Marine and Freshwater Research 56: 865-876. 
Edlund, A. F., Koehl, M. A., 1998. Adhesion and reattachment of compound ascidians to various substrata: weak glue can prevent tissue damage. Journal of Experimental Biology 201: 2397-2402.

Floerl, O., 2002. Intracoastal spread of fouling organisms by recreational vessels. $\mathrm{PhD}$ thesis. James Cook University, Townsville. p. 283.

Floerl O. 2005. Factors that influence hull fouling on ocean going vessels. In: Godwin, L. S., (Ed). Hull fouling as a mechanism for marine invasive species introductions. Proceedings of a workshop on current issues and potential management strategies, 12-13 February 2003, Honolulu, Hawaii. Bishop Museum. p. 6-13.

Floerl, O., Coutts, A. D. M., 2009. Potential ramifications of the global economic crisis on human-mediated dispersal of marine non-indigenous species. Marine Pollution Bulletin 58: 1595-1598.

Forrest, B. M., Gardner, J. P. A., Taylor, M. D., 2009. Internal borders for managing invasive marine species. Journal of Applied Ecology 46: 46-54.

Gollasch, S., 2002. The importance of ship hull fouling as a vector of species introductions into the North Sea. Biofouling 18: 105-121.

Hewitt, C. L., 2002. The distribution and biodiversity of tropical Australian marine bioinvasions. Pacific Science 56: 213-222.

Hewitt, C. L., Campbell, M. L., Thresher, R. E., Martin, R. B., Boyd, S., Cohen, B. F., Currie, D. R., Gomon, M. F., Keogh, M. J., Lewis, J. A., Lockett, M. M., Mays, N., McArthur, M. A., O’Hara, T. D., Poore, G. C. B., Ross, D. J., Storey, M. J., Watson, J. E., Wilson, R. S., 2004. Introduced and cryptogenic species in Port Phillip Bay, Victoria, Australia. Marine Biology 144: 183-202.

Hewitt, C. L., Campbell, M. L., 2008. Assessment of relative contribution of vectors to the introduction and translocation of marine invasive species. Report for the Department of Agriculture, Fisheries and Forestry. National Centre for Marine Conservation and Resource Sustainability Australian Maritime College, an institute of the University of Tasmania. p. 45. 
James, P., Hayden, B., 2000. The potential for the introduction of exotic species by vessel hull fouling: a preliminary study. NIWA Technical Report No. 16.15 p.

Koehl, M. A. R., 1984. How do benthic organisms withstand moving water? American Zoologist 24:57-70.

Lewis, J. A., 2002. Hull fouling as a vector for the translocation of marine organisms. Phase I Study: Hull fouling research. Department of Agriculture, Fisheries and Forestry Australia. Strategic Ballast Water Research and Deveopment Program, Canberra, Report No. 1. 142 pp.

Lewis, P. N., Riddle, M. J., Hewitt, C. L., 2004. Management of exogenous threats to Antarctica and the sub-Antarctic Islands: balancing risks from TBT and nonindigenous marine organisms. Marine Pollution Bulletin 49: 999-1005.

Lockwood, J. L., Hoopes, M. F., Marchetti, M. P., 2007. Invasion ecology. Oxford: Blackwell Scientific Press. 304 p.

MEPC 56/INF. 11. 2007. [Internet]. Management of biofouling risks on vessels entering Australian waters. Submitted by Australia to the $56^{\text {th }}$ session of the Marine Environment Protection Committee, Agenda Item 13, 4 ${ }^{\text {th }}$ May 2007 (cited 2010 May 25). Available at: http://www.sjofartsverket.se/pages/10805/56-INF11.pdf.

Minchin, D., 1992. Multiple species, mass spawning events in an Irish Sea lough: the effect of temperatures on spawning and recruitment of invertebrates. Invertebrate Reproductive and Development 22: 229-238.

Minchin, D., Gollasch, S., 2002. Vectors-how exotics get around. In: Leppakoski, E.; Gollasch, S.; Olenin, S., (Eds). Invasive aquatic species of Europe: distribution, impact and management. London, Kluwer. Pp. 183-192.

Minchin, D., Gollasch, S., 2003. Fouling and ships' hulls: how changing circumstances and spawning events may result in the spread of exotic species. Biofouling 19: 111122.

Otani, M., Oumi, T., Uwai, S., Hanyuda, T., Prabowo, R. E., Yamaguchi, T., Kawai, H., 2007. Occurrence and diversity of barnacles on international ships visiting Osaka Bay, Japan, and the risk of their introduction. Biofouling 23: 277-286. 
Piola, R. F., Dafforn, K. A., Johnston, E. L., 2009. The influence of antifouling practices on marine invasions. Biofouling 25: 633-644.

Roos, P. J., 1979. Two stage life cycle of a Cordylophora population in the Netherlands. Hydrobiologia 62: 231-239.

Ruiz, G. M., Carlton, J. T., 2003. Invasion vectors: a conceptual framework for management. In: Ruiz, G. M., Carlton, J. T., (Eds). Invasive species: vectors and management strategies. Washington: Island Press. p. 459-504.

Ruiz, G. M., Carlton, J. T., Grosholz, E. D., Hines, A. H., 1997. Global invasions of marine and estuarine habitats by non-indigenous species: mechanisms, extent, and consequences. American Zoologist 37: 621-632.

Ruiz, G. M., Fofonoff, P. W., Carlton, J. T., Wonham, M. J., Hines, A. H., 2000. Invasion of coastal marine communities in North America: apparent patterns, processes, and biases. Annual Reviews in Ecology and Systematics 31: 481-531.

Russ, G. R., 1980. Effects of predation by fishes, competition, and structural complexity of the substratum on the establishment of a marine epifaunal community. Journal of Experimental Marine Biology and Ecology 42: 55-69.

Sylvester, F., MacIsaac, H. J., 2009. Is vessel hull fouling an invasion threat to the Great Lakes? Diversity Distributions 16:132-143.

Thresher, R. E., Hewitt, C. L., Campbell, M. L., 1999. Synthesis: introduced and cryptogenic species in Port Phillip Bay. In: Hewitt, C. L., Campbell, M. L., Thresher, R. E, Martin, R. B., (Eds). Marine biological invasions of Port Phillip Bay, Victoria. Centre for Research on Introduced Marine Pests. Technical Report No. 20. Pp. 283-295.

Wasson, K. Zabin, C. J., Bedinger, L., Diaz, M. C., Pearse, J. S., 2001. Biological invasions of estuaries without international shipping: the importance of intraregional transport. Biological Conservation 102: 143-153.

Wingrove, M., 2009. Demand slump for oil, gas puts more rigs into lay-up. Lloyds List DCN, International News, November 12, 2009. 
Woods, C., Floerl, O., Fitridge, I., Johnston, O., Robinson, K., Rupp, D., Davey, N., Rush, N., Smith, M., 2007. Evaluation of the seasonal efficacy of hull cleaning methods. MAF Biosecurity New Zealand Technical Report ZBS2005-22. 119 pp. 


\section{Chapter 6 - A preliminary assessment of the nature and extent of biofouling inside vessel sea-chests}

\section{PREFACE}

Although the previous two chapters determined that there are niche areas on vessels that are more likely retain NIMS, neither study looked inside sea-chests. I chose to undertake a preliminary assessment of the nature and extent of biofouling inside seachests to complete the story as I had previously hypothesized that many mobile NIMS were dispersed via vessel biofouling rather than via ballast water.

Given logistical difficulties and occupational health and safety constraints associated with in-water inspections, an arrangement was made with personnel at the Nelson slipway and Auckland and Lyttelton dry-docks to collect representative samples of biofouling species inside sea-chests from as many vessels as possible. Tim Dodgshun co-ordinated the freighting of samples to Cawthron and maintain contact with the three vessel maintenance facilities. I indentified all the biofouling organisms with assistance from Rod Asher (Cawthron's resident taxonomist) and other taxonomic experts as needed. I also analysed and wrote the chapter with assistance and guidance from my supervisor Michael Taylor. An abbreviated version of this chapter has been published in the international peer-reviewed journal Marine Pollution Bulletin according to the following citation:

Coutts, A. D. M, Dodgshun, T. J., 2007. The nature and extent of organisms in vessel sea-chests: A protected mechanism for marine bioinvasions. Marine Pollution Bulletin 54: 876-886. 


\begin{abstract}
A total of 150 different organisms, including one plant species and 12 animal phyla were identified from sea-chests of 42 vessels visiting or operating in New Zealand between May 2000 and November 2004. Forty-nine percent of organisms were sessile, $42 \%$ mobile adults and the remaining $9 \%$ sedentary. Decapods were the most represented group with 19 species present among $79 \%$ of vessels. Forty percent of organisms were indigenous to New Zealand, $15 \%$ introduced, $10 \%$ non-indigenous, and $35 \%$ of unknown origin. Sea-chests have the potential to 1) transfer nonindigenous organisms between countries across oceanic boundaries; and 2) disperse both indigenous and introduced organisms domestically. The occurrence of adult mobile organisms is particularly significant and indicates that sea-chests may be of greater importance than ballast water or biofouling for dispersing certain marine species. These findings emphasise the need to assess and manage biosecurity risks for entire vessels rather than different mechanisms (i.e. ballast water, vessel biofouling, sea-chests, etc.) in isolation.
\end{abstract}

\title{
6.1. INTRODUCTION
}

Human-mediated introductions of non-indigenous marine species (NIMS) into regions where they did not formally exist have had positive commercial and even ecological benefits (e.g. Galil 2000; Sinner et al. 2000; Hayes and Sliwa 2003; Wonhom et al. 2005). However, many of these organisms have resulted in adverse ecological, economic, and social consequences (Carlton 1996, 2001; Pimentel et al. 2000; Hewitt 2003). A variety of vectors are responsible for translocating NIMS around the world and along coastlines domestically, including shipping, fisheries, mariculture and the aquarium trade (e.g. Carlton 1985, 1987, 1992; Cohen and Carlton 1995; Hewitt et al. 1999, 2004; Thresher et al. 1999; Ruiz et al. 2000; Minchin and Gollasch 2002). However, international shipping is generally considered to be responsible for the majority of inadvertent NIMS introductions (Carlton 1987; Cranfield et al. 1998; Minchin and Gollasch 2002; Nehring 2002).

A variety of shipping-related mechanisms are recognised, including ballast and bilge water discharges, vessel biofouling, sea-chests, sea-sieves, anchors, chain lockers, and piping (Schormann et al. 1990; Carlton 1995; Lewis 2002; Coutts et al. 2003). Of these, particular attention has been given to ballast water and vessel biofouling as key 
mechanisms, particularly for larval stages and adult sessile organisms (e.g. Carlton 1995; Cranfield et al. 1998; Hewitt et al. 1999, 2004; Ruiz et al. 2000; Fofonoff et al. 2003). However, the importance of ballast water and vessel biofouling relative to other shipping-related mechanisms remains poorly understood. Furthermore, emerging evidence suggests that other mechanisms, in particular vessel sea-chests, may explain the global distribution of organisms for which transport via ballast water or vessel biofouling is questionable (Coutts et al. 2003).

Sea-chests are recesses built into a vessel's hull below the waterline that house the intake pipes for sea-water used for ballast, engine cooling and fire fighting. Sea-chest systems as potential dispersal mechanisms for marine organisms have been recognised in the scientific literature for several decades (e.g. Newman 1963; Hoese 1973; Carlton 1985; Slack-Smith and Brearly 1987; Richards 1990; Carlton et al. 1995; Cohen and Carlton 1995; Carlton 2001; Lewis 2002; Davis and Davis 2004). However, the potential for sea-chests to disperse NIMS was probably first highlighted when Coutts et al. (2003) documented the occurrence of two recognised pest species, the European clam Corbula gibba and the European green crab Carcinus maenas, inside the seachests of a passenger ferry in southern Australia. Despite such findings, a better understanding of the potential for sea-chests to house and disperse aquatic organisms has not yet emerged. Therefore the aim of this study was to determine the nature and extent of organisms inside sea-chests of vessels in New Zealand and to establish their role as a dispersal mechanism for marine species.

\subsection{METHODS}

\subsubsection{Characteristics of sea-chests}

The size and number of sea-chests varies with vessel size and type. For example, a small 500 gross weight tonne (GWT) fishing vessel may only possess a single $0.5 \mathrm{~m}^{3}$ sea-chest while a 30,000 GWT bulk carrier could have several sea-chests $>2 \mathrm{~m}^{3}$ in volume. Furthermore, most large vessels generally have an upper and lower sea-chest (Figure 24). Each is covered with a flush fitting steel grille with either round holes 15$25 \mathrm{~mm}$ in diameter, or slots $20-35 \mathrm{~mm}$ wide by $\sim 250 \mathrm{~mm}$ long. The gratings prevent large debris from entering the sea-chests during ballast pumping, although this does not preclude the entry of small marine organisms. Sea-sieves or strainers are located 
between the sea-chests and the pumps and are designed to retain objects $>5 \mathrm{~mm}$ (Figure 24). While sea-sieves are accessible from inside the vessel, sea-chests are normally only accessible from the outside of the vessel after the gratings are removed, usually during slipping or dry-docking.

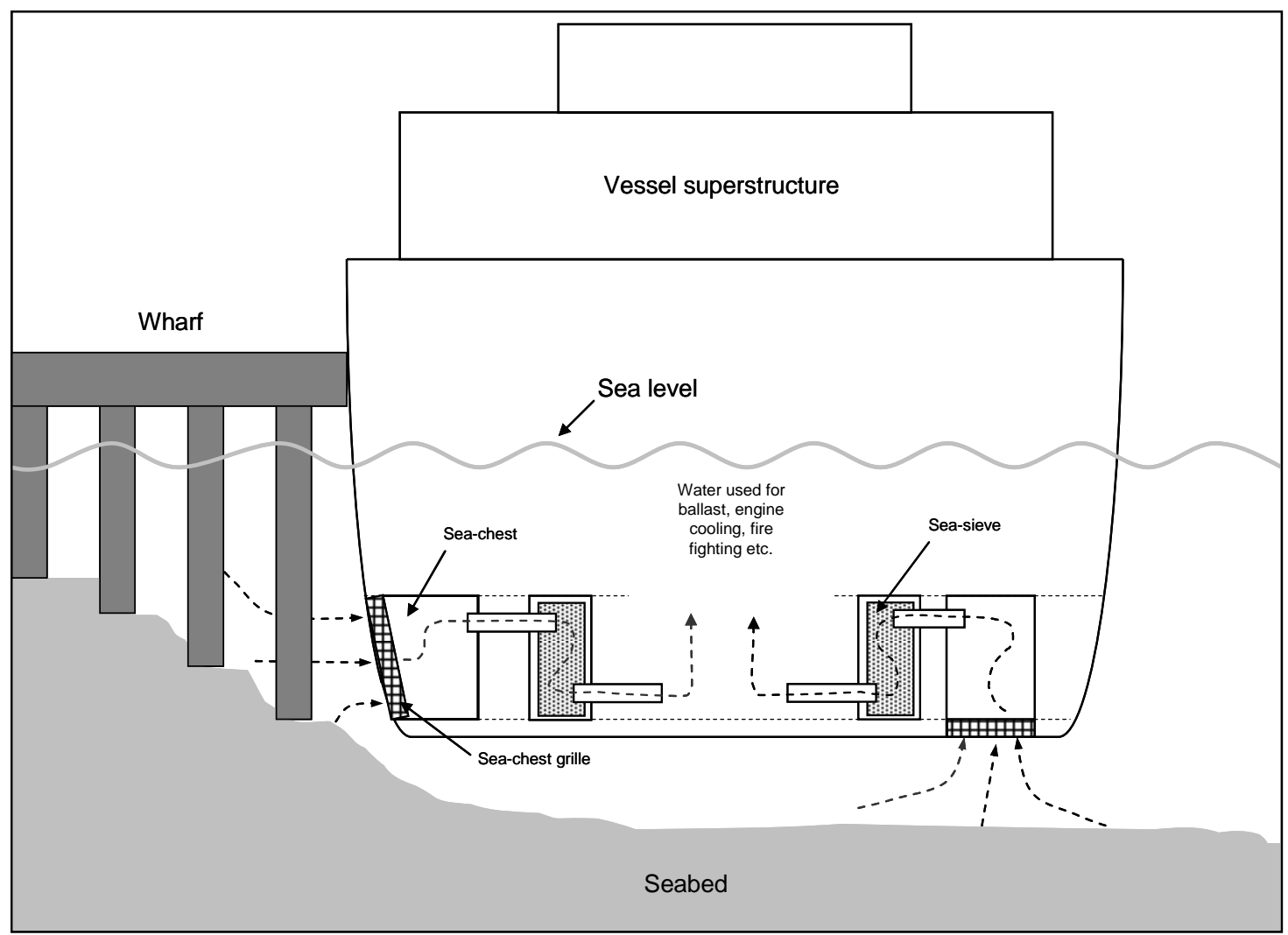

Figure 24 Schematic diagram of a vessel's sea-chest system.

\subsubsection{Sample collection and processing}

A total of 53 sea-chests were sampled from 42 vessels at three vessel maintenance facilities around New Zealand (Auckland, Nelson and Lyttelton) between May 2000 and November 2004. A questionnaire was used to obtain as much information as possible about each vessel (e.g. vessel size, vessel type, maintenance history, voyage history, etc.). Vessels sampled included fishing vessels (27); bulk carriers (3); research vessels (3); passenger ferries (2); and a cruise ship, cable layer, container, dredge, frigate, tanker and tug boat ranging in size from 135 to 13,621 GWT. As many seachests were sampled from each vessel as possible prior to the commencement of maintenance work. Single sea-chests were sampled from 38 vessels, while four vessels 
had several sea-chests sampled. Vessels were sampled after an average in-service period (i.e. period of time between visiting vessel maintenance facilities) of 822 days. Twenty four vessels were classified as domestic (100\% of their in-service period in New Zealand waters), and nine each of semi-international ( $>75 \%$ of their in-service period outside New Zealand waters) and international vessels (100\% of their time outside New Zealand waters, but visited maintenance facilities in New Zealand at the completion of their in-service period). Thirteen of the vessels and their 20 associated sea-chests were retrofitted with sea-chest treatment systems (e.g. CHLOROPAC ${ }^{\circledR}$, Cathelco, Chem-Free ${ }^{\mathrm{TM}}$, etc.) designed to reduce the accumulation of organisms.

To sample each sea-chest, a putty scraper was used to remove biofouling attached to the internal surfaces and representative samples of all other organisms were collected by hand. All organisms $>1 \mathrm{~mm}$ in size (dead and alive) were identified to the lowest taxonomic level practical. Organisms were classified as indigenous (an organism that originates in New Zealand); introduced (a foreign organism that has established in New Zealand); and non-indigenous (a foreign organism not previously recorded in New Zealand) according to Cranfield et al. (1998). Organisms only identified to genus level or higher were classified as unknown. Organisms were also classified as sessile (permanently attached to the substratum), sedentary (attached to the substratum but capable of limited movement), or mobile (capable of spontaneous movement).

\subsubsection{Data processing and analysis}

EstimateS 8.2 software (Colwell et al. 2004) was used to compute species accumulation (sample-based rarefaction) curves to evaluate sampling effectiveness for vessels from the various geographical regions of operation (i.e. all vessels combined, domestic, semiinternational, international as described previously). Two methods using 100 resampling simulations were used to generate: 1) expected species accumulation curves using a Monte Carlo simulation with Mao Tau $95 \%$ confidence intervals (Colwell et al. 2004); and 2) Chao 2 nonparametric richness estimators (Longino et al. 2002). The PRIMER V5.2.2 software package was used for all other statistical analyses. A species (taxa)-area curve analysis was undertaken to evaluate sampling effectiveness for vessels from the various geographical regions of operation (i.e. domestic, semi-international, international as described above). A Bray-Curtis similarity matrix based on the presence/absence of organisms detected in sea-chests was created for all vessels, and a 
cluster analysis and dendrogram used to explore similarities between patterns of seachest occupancy in relation to the three regions of vessel operation. We recognised that this overall analysis is potentially confounded by different types of vessels operating in the three regions, because sea-chest usage will differ among vessel type, which may affect occupancy. The range of vessels sampled did not allow us to look at the effect of vessel type within each region of operation, however we were able to undertake a separate analysis of sea-chest occupancy for 27 fishing vessels (the most represented vessel type) that were represented across five different regions (all of New Zealand, southern New Zealand, world-wide, Pacific and South Pacific). For this purpose, organisms were aggregated into 22 higher taxonomic groups (i.e. Division, Phylum, or Class) to explore the main patterns in sea-chest composition among vessels from the different regions of operation. Results are displayed using a 2-dimensional non-metric multi-dimensional scaling (nMDS) ordination.

Analysis of Similarity (ANOSIM; Clark 1993) based on the presence/absence of all organisms was used to examine: 1) the similarities of organisms in sea-chests within and between vessels; and 2) factors influencing the nature and extent of organisms in sea-chests such as age of anti-fouling coating and sea-chest treatment systems, particularly with respect to organism life-habits (i.e. sessile, sedentary, mobile).

\subsection{RESULTS}

\subsubsection{Occurrence of organisms in sea-chests}

A total of 150 different organisms were identified from sea-chests consisting of one plant species (mangrove seeds Avicennia marina) and 12 animal phyla: Porifera (4 species); Cnidaria (13); Platyhelminthes (1); Nemertea (1); Nematoda (1); Mollusca (30); Ectoprocta (11); Annelida (19); Sipuncula (2); Anthropoda (43); Echinodermata (3); and Chordata (21) (Table 11). The species accumulation curve analysis illustrated that the full nature and extent of organisms inside sea-chests relative to geographical regions of operation was not realised because none of the curves reached an asymptote (Figure 25a, c, e, g). Therefore, a greater range of species would have been encountered if sampling of additional vessels and sea-chests had been undertaken. While the Chao2 nonparametric analysis demonstrated that variability decreased as more vessels were 
sampled, namely semi-domestic and international vessels (Figure $25 f$ and $h$ ), increasingly variability increased as more domestic vessels were sampled (Figure 25d).

a). All vessels

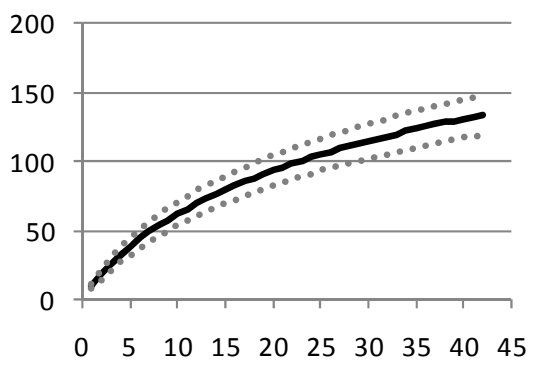

\section{c). Domestic vessels}

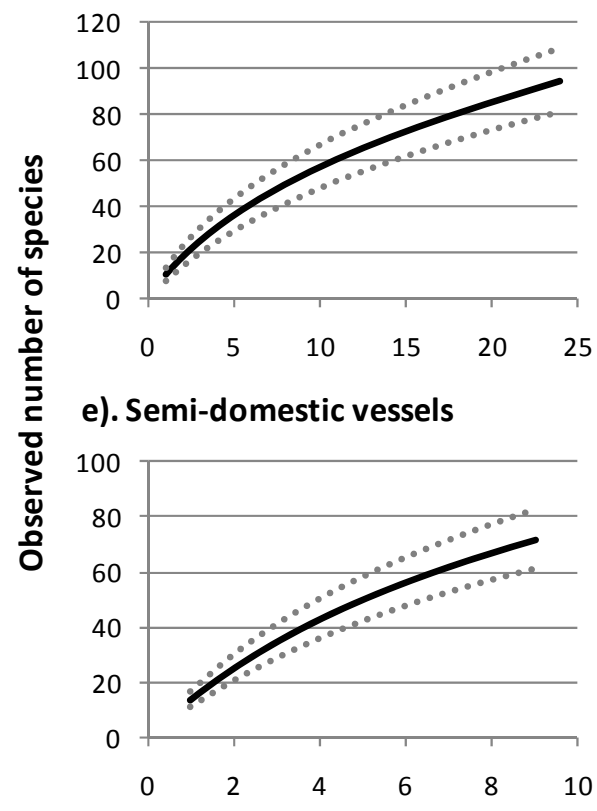

g). International vessels

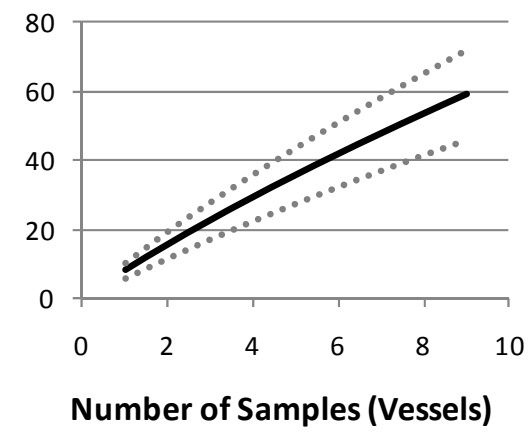

b).

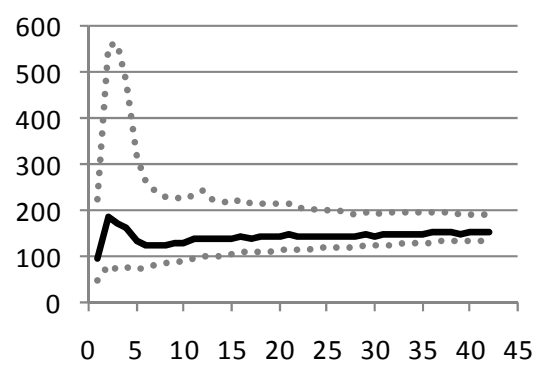

d).

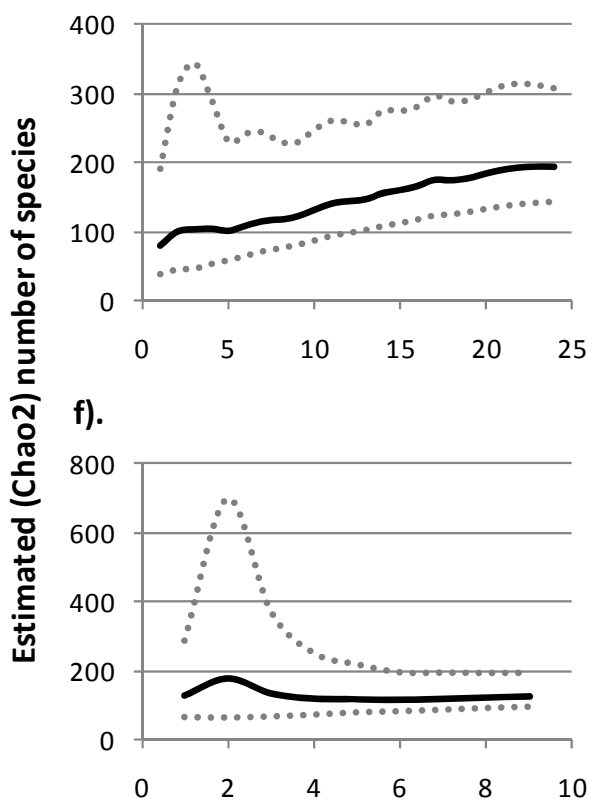

h).

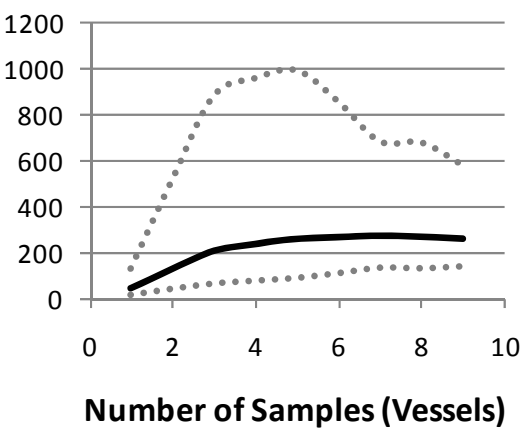

Figure 25 Species accumulation curves for: all 42 vessels (a and b); 24 domestic vessels ( $c$ and $d$ ); nine semi-international vessels (e and $f$ ); and nine international vessels ( $g$ and $h$ ). Left hand side grafts are expected species accumulation curves using Monte Carlo simulations (solid lines) with Mao Tau $95 \%$ confidence intervals (dashed lines). Right hand side graphs are Chao 2 nonparametric richness estimators (solid lines with $95 \%$ confidence intervals (dashed lines). 
Table 11 Organisms identified inside 53 sea-chests from 42 vessels sampled in New Zealand; Origin: Organisms classified according to their origin relative to New Zealand waters as classified by Cranfield et al. (1998). Life-habit: Organisms' life-habit at the time of collection. $N$ refers to the number of vessels with the organism present. $\dagger$ refers to only shells of the organisms present.

\begin{tabular}{|c|c|c|c|c|}
\hline Phylum/Class/Family & Genus/species & Origin & Life-habit & $\mathbf{N}$ \\
\hline $\begin{array}{l}\text { PLANTAE } \\
\text { Avicenniaceae }\end{array}$ & Avicennia marina (seeds) & Indigenous & Sessile & 3 \\
\hline \multicolumn{5}{|l|}{ PORIFERA } \\
\hline \multicolumn{4}{|l|}{ Demospongiae } & 2 \\
\hline Callyspongiidae & Callyspongia sp. & Unknown & Sessile & 2 \\
\hline Crellidae & $\begin{array}{l}\text { Crella incrustans } \\
\text { Unidentified spp. }\end{array}$ & $\begin{array}{l}\text { Indigenous } \\
\text { Unknown }\end{array}$ & $\begin{array}{l}\text { Sessile } \\
\text { Sessile }\end{array}$ & $\begin{array}{l}1 \\
2\end{array}$ \\
\hline \multicolumn{5}{|l|}{ CNIDARIA } \\
\hline Hydrozoa & Unidentified spp. & Unknown & Sessile & 4 \\
\hline Sertulariidae & Amphisbetia bispinosa & Indigenous & Sessile & 2 \\
\hline Campanulariidae & $\begin{array}{l}\text { Unidentified spp. } \\
\text { Obelia } \text { sp. } \\
\text { Obelia dichotoma (=australis) }\end{array}$ & $\begin{array}{l}\text { Unknown } \\
\text { Unknown } \\
\text { Introduced }\end{array}$ & $\begin{array}{l}\text { Sessile } \\
\text { Sessile } \\
\text { Sessile }\end{array}$ & $\begin{array}{l}2 \\
4 \\
1\end{array}$ \\
\hline Haleciidae & $\begin{array}{l}\text { Halecium sp. } \\
\text { Halecium corrugatis }\end{array}$ & $\begin{array}{l}\text { Unknown } \\
\text { Indigenous }\end{array}$ & $\begin{array}{l}\text { Sessile } \\
\text { Sessile }\end{array}$ & $\begin{array}{l}1 \\
1\end{array}$ \\
\hline Tubulariidae & $\begin{array}{l}\text { Ectopleura sp. } \\
\text { Ectopleura larynx }\end{array}$ & $\begin{array}{l}\text { Introduced } \\
\text { Introduced }\end{array}$ & $\begin{array}{l}\text { Sessile } \\
\text { Sessile }\end{array}$ & $\begin{array}{l}9 \\
3\end{array}$ \\
\hline $\begin{array}{l}\text { Anthozoa } \\
\text { Actiniidae }\end{array}$ & $\begin{array}{l}\text { Actiniaria spp. } \\
\text { Actinozoa zoantharia } \\
\text { Isactina olivacea } \\
\text { Anthothoe albocincta }\end{array}$ & $\begin{array}{l}\text { Unknown } \\
\text { Indigenous } \\
\text { Indigenous } \\
\text { Indigenous }\end{array}$ & $\begin{array}{l}\text { Sedentary } \\
\text { Sedentary } \\
\text { Sedentary } \\
\text { Sedentary }\end{array}$ & $\begin{array}{l}7 \\
1 \\
1 \\
1\end{array}$ \\
\hline PLATYHELMINTHES & Unidentified spp. & Unknown & Mobile & 2 \\
\hline NEMERTEA & Unidentified spp. & Unknown & Mobile & 3 \\
\hline NEMATODA & Unidentified spp. & Unknown & Mobile & 7 \\
\hline \multicolumn{5}{|l|}{ MOLLUCSA } \\
\hline Gastropoda & Unidentified spp. & Unknown & Mobile & 1 \\
\hline Fissurellidae & Diodora sp. $\dagger$ & Non-indigenous & Mobile & 1 \\
\hline \multirow[t]{4}{*}{ Cypraeidae } & Cypraea sp. & Non-indigenous & Mobile & 1 \\
\hline & Cypraea cf. arabica $\dagger$ & Non-indigenous & Mobile & 1 \\
\hline & Cypraea cf. vitellus $\dagger$ & Non-indigenous & Mobile & 1 \\
\hline & Cypraea cf. marginalis $\dagger$ & Non-indigenous & Mobile & 1 \\
\hline \multirow[t]{2}{*}{ Ranellidae } & Cymatium sp. & Unknown & Mobile & 1 \\
\hline & Cymatium gemmatum & Indigenous & Mobile & 1 \\
\hline Cassinae & Galeodea triganceae & Indigenous & Mobile & 1 \\
\hline Buccinidae & Cominella sp. $\dagger$ & Non-indigenous & Mobile & 1 \\
\hline Cavoliniidae & Cavolina inflexa & Indigenous & Mobile & 1 \\
\hline Nudibranchia & Unidentified spp. & Unknown & Mobile & 2 \\
\hline Dendrodorididae & Dendrodoris citrina & Indigenous & Mobile & 1 \\
\hline Bivalvia & Unidentified sp. & Unknown & Sedentary & 2 \\
\hline Arcidae & Unidentified sp. & Unknown & Sessile & 1 \\
\hline \multirow[t]{3}{*}{ Mytilidae } & Mytilus spp. & Introduced & Sedentary & 15 \\
\hline & Perna canaliculus & Indigenous & Sedentary & 19 \\
\hline & Aulacomya atra maoriana & Indigenous & Sedentary & 20 \\
\hline \multirow[t]{3}{*}{ Ostreidae } & Unidentified spp. & Unknown & Sessile & 2 \\
\hline & Ostrea chilensis & Indigenous & Sessile & 3 \\
\hline & Crassostrea gigas & Introduced & Sessile & 3 \\
\hline \multirow[t]{3}{*}{ Pectinidae } & Chlamys sp. & Unknown & Sedentary & 1 \\
\hline & Talochlamys gemmulata & Indigenous & Sedentary & 3 \\
\hline & Mesopeplum convexum & Indigenous & Sedentary & 1 \\
\hline Anomiidae & Anomia trigonopsis & Indigenous & Sessile & 1 \\
\hline Ungulinidae & Diplodonta globus & Indigenous & Sessile & 1 \\
\hline Carditidae & Unidentified sp. & Unknown & Sessile & 1 \\
\hline Gaimardiidae & Gaimardia trapezina $\dagger$ & Non-indigenous & Sessile & 1 \\
\hline Hiatellidae & Hiatella arctica & Indigenous & Sessile & 13 \\
\hline Veneridae & Ruditapes largillierti & Indigenous & Sessile & 3 \\
\hline BRYOZOA & Unidentified sp. & Unknown & Sessile & 4 \\
\hline Electridae & Electra tenella & Introduced & Sessile & 1 \\
\hline \multirow{3}{*}{ Bugulidae } & Bugula sp. & Unknown & Sessile & 1 \\
\hline & Bugula sp. & Unknown & Sessile & 1 \\
\hline & Bugula flabellata & Introduced & Sessile & 6 \\
\hline
\end{tabular}


Table 11. Continued.

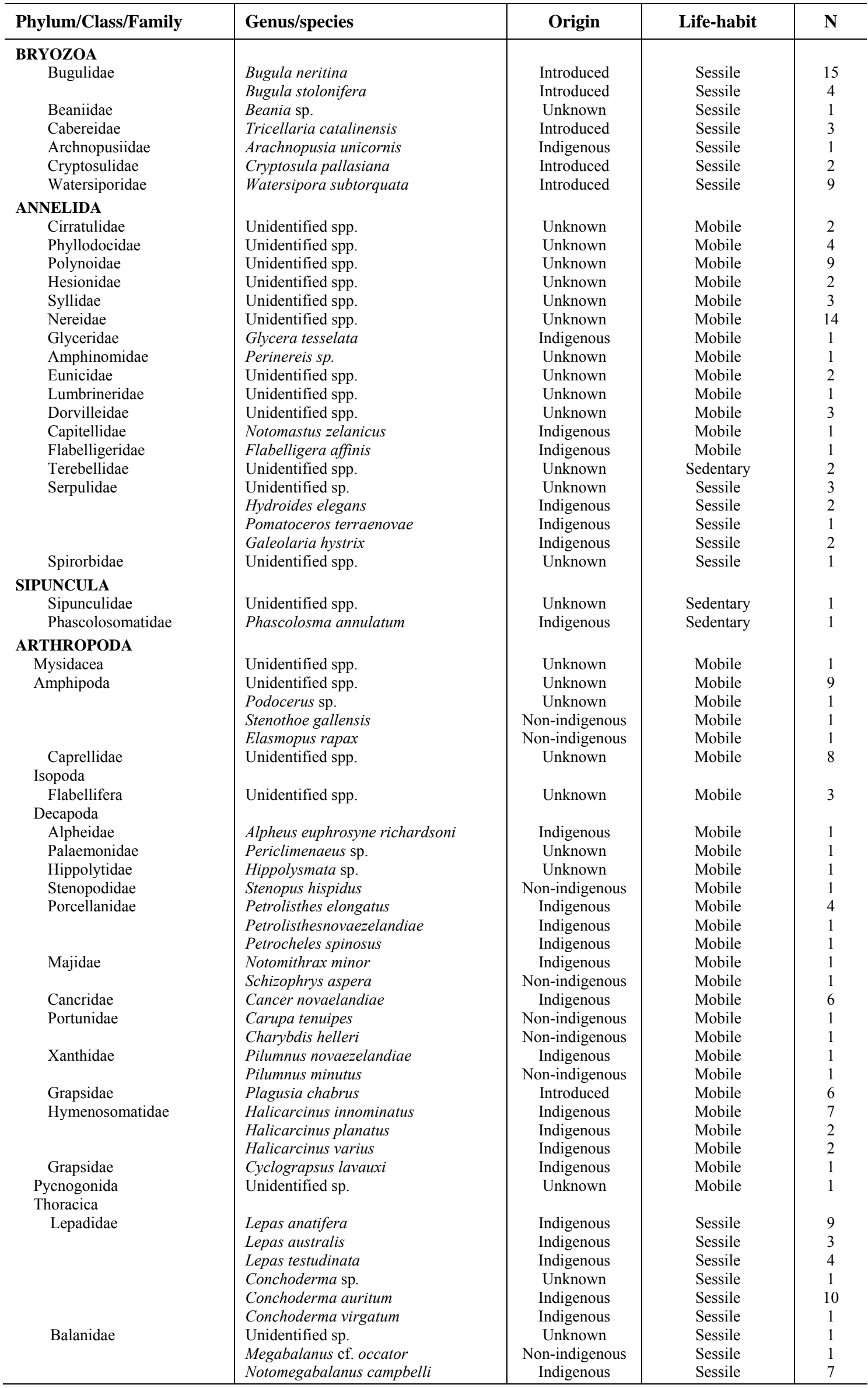


Table 11. Continued.

\begin{tabular}{|c|c|c|c|c|}
\hline Phylum/Class/Family & Genus/species & Origin & Life-habit & $\mathbf{N}$ \\
\hline Balanidae & $\begin{array}{l}\text { Notomegabalanus decorus } \\
\text { Megabalanus tintinnabulum linzei } \\
\text { Amphibalanus sp. } \\
\text { Amphibalanus amphitrite } \\
\text { Amphibalanus reticulatus } \\
\text { Amphibalanus trigonus } \\
\text { Elminus modestus }\end{array}$ & $\begin{array}{l}\text { Indigenous } \\
\text { Indigenous } \\
\text { Unknown } \\
\text { Introduced } \\
\text { Non-indigenous } \\
\text { Introduced } \\
\text { Indigenous }\end{array}$ & $\begin{array}{l}\text { Sessile } \\
\text { Sessile } \\
\text { Sessile } \\
\text { Sessile } \\
\text { Sessile } \\
\text { Sessile } \\
\text { Sessile }\end{array}$ & $\begin{array}{c}4 \\
3 \\
3 \\
12 \\
1 \\
4 \\
10\end{array}$ \\
\hline $\begin{array}{l}\text { ECHINODERMATA } \\
\text { Echinometridae } \\
\text { Holothuroidea } \\
\text { Asteriidae }\end{array}$ & $\begin{array}{l}\text { Evechinus chloroticus } \\
\text { Unidentified sp. } \\
\text { Coscinasterias calamaria }\end{array}$ & $\begin{array}{l}\text { Indigenous } \\
\text { Unknown } \\
\text { Indigenous }\end{array}$ & $\begin{array}{l}\text { Mobile } \\
\text { Mobile } \\
\text { Mobile }\end{array}$ & $\begin{array}{l}1 \\
1 \\
1\end{array}$ \\
\hline $\begin{array}{l}\text { CHORDATA } \\
\text { Urochordata } \\
\text { Polyclinidae } \\
\text { Cionidae } \\
\text { Didemnidae } \\
\text { Rhodosomatidae } \\
\text { Botrylliinae } \\
\text { Styelinae } \\
\\
\text { Pyuridae }\end{array}$ & $\begin{array}{l}\text { Unidentified sp. } \\
\text { Aplidium } \text { sp. } \\
\text { Aplidium phortax } \\
\text { Aplidium quadriverium } \\
\text { Ciona intestinalis } \\
\text { Didemnum } \text { sp. } \\
\text { Corella } \mathrm{sp} . \\
\text { Corella eumyota } \\
\text { Botrylloides } \mathrm{sp} . \\
\text { Cnemidocarpa bicornuata } \\
\text { Styela } \text { clava } \\
\text { Asterocarpa } \text { sp. } \\
\text { Asterocarpa humilis } \\
\text { Pyura pachydermatina } \\
\text { Pyura rugata } \\
\text { Pyura subtorquata } \\
\text { Pyura suteri }\end{array}$ & $\begin{array}{l}\text { Unknown } \\
\text { Unknown } \\
\text { Introduced } \\
\text { Indigenous } \\
\text { Introduced } \\
\text { Unknown } \\
\text { Unknown } \\
\text { Introduced } \\
\text { Introduced } \\
\text { Indigenous } \\
\text { Introduced } \\
\text { Unknown } \\
\text { Introduced } \\
\text { Indigenous } \\
\text { Indigenous } \\
\text { Indigenous } \\
\text { Indigenous }\end{array}$ & $\begin{array}{l}\text { Sessile } \\
\text { Sessile } \\
\text { Sessile } \\
\text { Sessile } \\
\text { Sessile } \\
\text { Sessile } \\
\text { Sessile } \\
\text { Sessile } \\
\text { Sessile } \\
\text { Sessile } \\
\text { Sessile } \\
\text { Sessile } \\
\text { Sessile } \\
\text { Sessile } \\
\text { Sessile } \\
\text { Sessile } \\
\text { Sessile }\end{array}$ & $\begin{array}{l}3 \\
2 \\
1 \\
1 \\
6 \\
3 \\
1 \\
2 \\
1 \\
1 \\
2 \\
2 \\
3 \\
8 \\
1 \\
1 \\
1\end{array}$ \\
\hline $\begin{array}{l}\text { Vertebrata } \\
\text { Eleotrididae } \\
\text { Tripterygiidae } \\
\text { Engraulinae }\end{array}$ & $\begin{array}{l}\text { Grahamichthys radiata } \\
\text { Forsterygion varium } \\
\text { Forsterygion malcolmi } \\
\text { Engraulis australis }\end{array}$ & $\begin{array}{l}\text { Indigenous } \\
\text { Indigenous } \\
\text { Indigenous } \\
\text { Indigenous }\end{array}$ & $\begin{array}{l}\text { Mobile } \\
\text { Mobile } \\
\text { Mobile } \\
\text { Mobile }\end{array}$ & $\begin{array}{l}1 \\
1 \\
1 \\
1\end{array}$ \\
\hline
\end{tabular}

Between 1 and 33 organisms were recorded per sea-chest, with an average of $10.7 \pm 7.1$ (average $\pm \mathrm{SD}$ ). The most frequently encountered taxonomic groups included Anthozoa (45 \% vessels), Bivalvia (74\%), Ectoprocta (57\%), Annelida (55\%), Decapoda (79 $\%$ ), Thoracica (67\%), and Urochordata (45\%) (Table 11). Seventy-three (49\%) of organisms found in sea-chests were sessile, 63 (42\%) mobile adults and the remaining $14(9 \%)$ sedentary (Table 11$)$. Sessile organisms were present inside sea-chests of 41 (99 \%) vessels, an average of $5.6 \pm 4.2$ per vessel. Mobile organisms were present among sea-chests of $35(83 \%)$ of vessels with an average of $3.3 \pm 3.6$ per vessel while sedentary organisms were present inside sea-chests of $23(55 \%)$ vessels with an average of $1.8 \pm 1.5$ per vessel.

Sixty (40\%) organisms found in sea-chests were indigenous to New Zealand, 22 (15\%) introduced, $16(10 \%)$ non-indigenous, and $52(35 \%)$ were of unknown origin (Table 11). The majority of the 60 indigenous organisms were present in sea-chests of 
domestic vessels, but many were also found in sea-chests of semi-international and international vessels (Figure 26). Introduced organisms were particularly prevalent in sea-chests on semi-international vessels. There was a high incidence of unknown organisms among vessels from all origins. Non-indigenous organisms were most prevalent among international vessels, with 15 of the 16 taxa present in sea-chests of seven vessels from the Pacific/South Pacific region. These vessels only visited New Zealand waters at the completion of their in-service period to renew their anti-fouling coatings at vessel maintenance facilities. Note that only 10 of the 15 NIMS from these international vessels were alive at the time of sampling, with five consisting of empty shells of Cominella sp., Diodora sp., Cypraea cf. arabica, C. cf. vitellus and C. cf. marginalis (Table 11). These shells were of greater size than the grille aperture of each sea-chest, suggesting that they were alive at the time of initial occupancy.

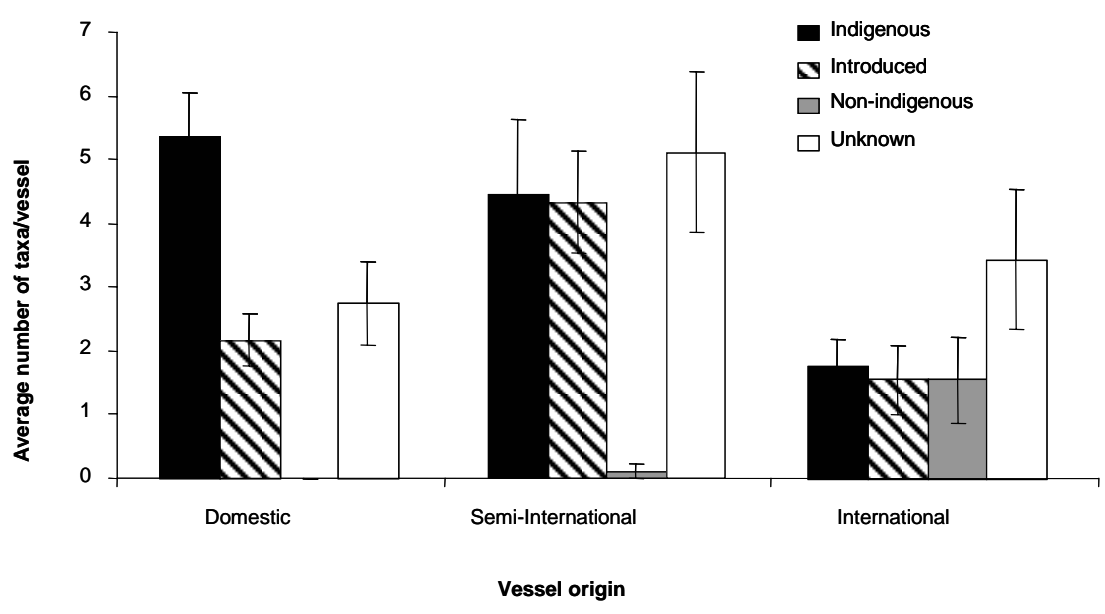

Figure 26 Average $( \pm 1 \mathrm{SE})$ number of indigenous, introduced, non-indigenous and unknown organisms according to vessel origin (domestic, semi-international and international).

\subsubsection{Community composition of organisms in sea-chests}

The composition of organisms inside sea-chests was highly diverse among vessels from different origins (Figure 27), but relatively similar among sea-chests sampled from the same vessels than between different vessels (ANOSIM, $R=0.770, P=0.001$ ). Furthermore, composition of organisms in sea-chests was more similar for vessels that operated in similar geographic regions than for vessels from different regions (ANOSIM, $R=0.169, P=0.016$ ) (Figure 28). 


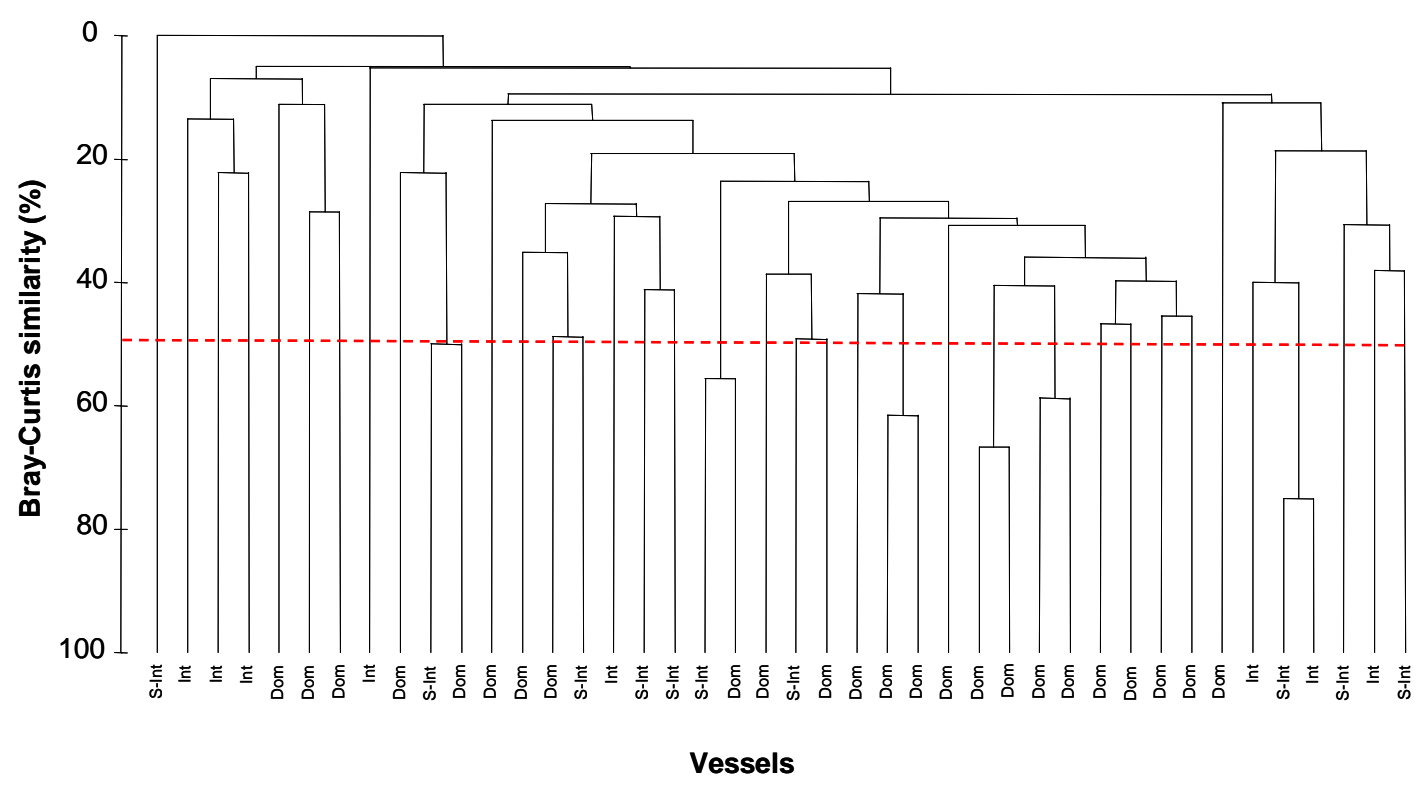

Figure 27 Dendrogram illustrating the Bray-Curtis percentage similarity between the community composition of organisms in sea-chests of the 42 vessels surveyed. The dashed line represents the $50 \%$ similarity threshold. Int $=$ international vessels; S-Int $=$ semi-international vessels; Dom $=$ domestic vessels.

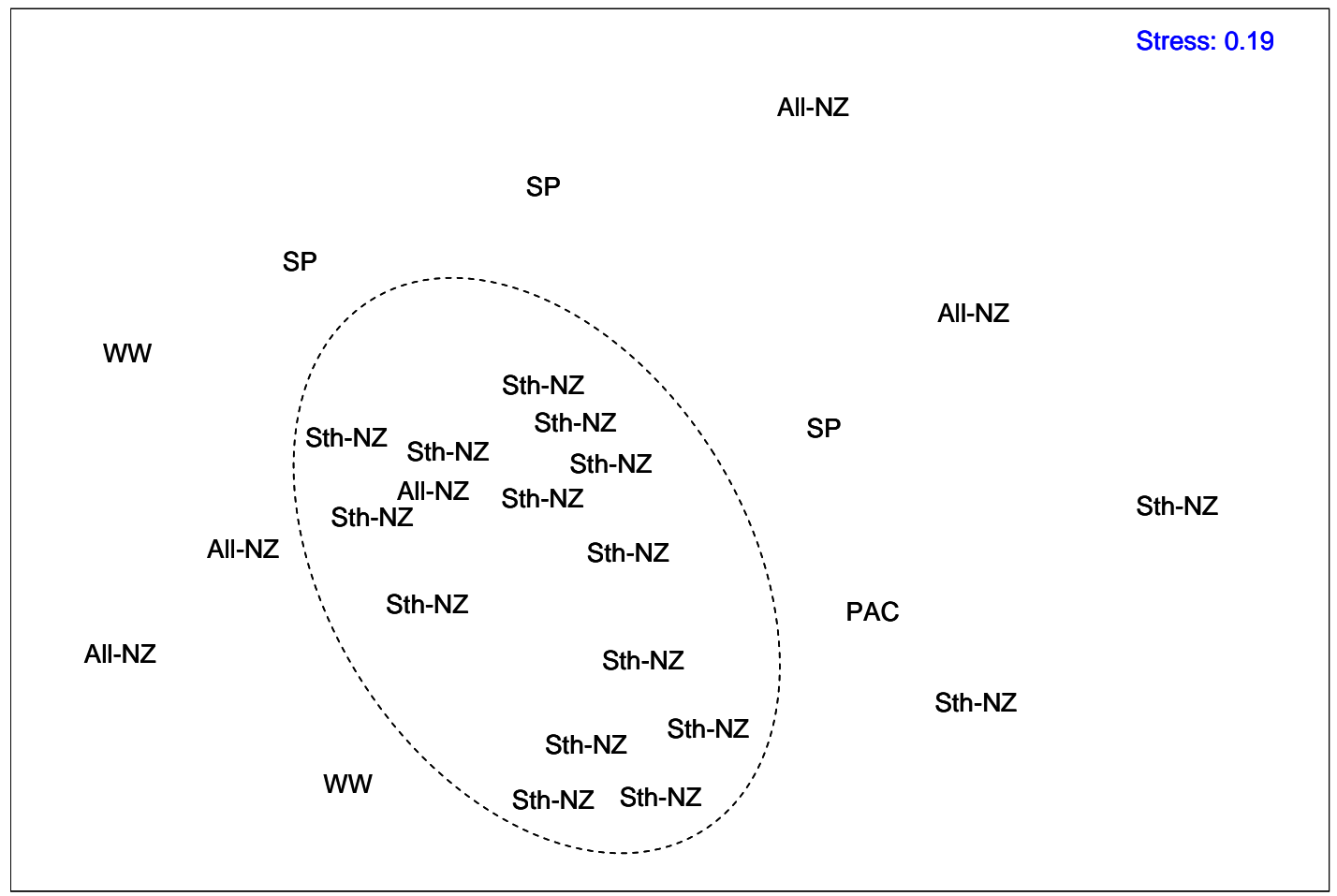

Figure 28 Multi-dimensional scaling plot illustrating the similarity between patterns of organisms (reclassified into 22 higher taxonomic groups) in sea-chests of 27 fishing vessels relative to geographical area of operation (e.g. Sth-NZ = southern New Zealand, All-NZ = all of New Zealand, WW= world-wide, PAC $=$ Pacific Ocean, SP $=$ South Pacific). The dashed circle represents a group of vessels that operated in a similar geographical area. 
The composition of organisms in sea-chests among the 27 fishing vessels was highly variable, although there was some evidence of greater community similarity in the fishing vessels that remained in southern New Zealand waters (Figure 28). Age of antifouling coating and greater in-service period appeared to have a significant influence on sea-chest communities, with older coatings and longer in-service periods associated with greater numbers of organisms (ANOSIM, $R=0.223, P=0.030$ ). Sea-chests with treatment systems contained fewer organisms on average $(7.0 \pm 1.1)$ than untreated seachests $(11.0 \pm 1.1)$. While treatment systems appeared to significantly influence community composition (ANOSIM, $R=0.233, P=0.009$ ), they failed to completely eliminate organisms. Furthermore, treatment systems had a significant effect on composition of both sessile (ANOSIM, $R=0.128, P=0.013$ ) and sedentary organisms (ANOSIM, $R=0.221, P=0.003$ ), but did not significantly affect the occurrence of mobile organisms in sea-chests (ANOSIM, $R=0.028, P=0.710$ ).

\subsection{DISCUSSION}

\subsubsection{Factors influencing patterns of occupancy inside sea-chests}

The discovery of 150 different organisms in sea-chests of a range of vessel types from various geographical regions supports Carlton's (1992) suggestion that "sea-chests are the modern-day equivalent to the deep, sheltered cavities created by shipworms in pre20th century (wooden) vessels that provided havens for a wide diversity of adult mobile organisms". The occurrence of such diversity in sea-chests is a consequence of a variety of factors. Firstly, unlike the settlement of sessile organisms on vessel hulls, many sessile, sedentary and mobile organisms are likely to be involuntarily 'vacuumed' into sea-chests from neighbouring wharf piles, the surrounding water column and even the seabed, especially when sea-chests are in close proximity to such substrata (authors unpubl. data; Figure 24).

Secondly, anti-fouling paints in sea-chests are unable to perform as well as they do on uniform areas of the hull because they are subjected to extremes in water-flow that compromise their effectiveness. Consequently, sessile organisms are capable of establishing in areas where the paints have prematurely worn due to excessive waterflow or in static pockets where insufficient water-flow results in the paint remaining inactive. Moreover, diverse communities of sessile organisms can conceivably develop 
and provide suitable habitats for other organisms, particularly mobile species (e.g. amphipods, annelids, decapods, echinoderms, gastropods and isopods). Such explanations are consistent with our observations that greater numbers of organisms were evident in sea-chests that possessed older anti-fouling paints or longer in-service periods.

Sea-chest treatment systems also significantly influenced the composition of the seachest communities. However, this was most evident for both sessile and sedentary organisms, with treatment having little influence on the occurrence of mobile organisms. Interestingly, other researchers have also documented the inefficacy of seachest treatment systems to eliminate the abundance of organisms (e.g. Lewis and Smith 1991; Lewis et al. 1998). Once organisms are established in sea-chests, they are likely to encounter favourable conditions for growth as they are subject to a continuous supply of food and oxygen and often elevated water temperatures (the latter due to the transfer of heat from the vessel's engine which could facilitate the survivorship of tropical organisms). Moreover, many of the mobile taxa are capable of feeding on dead organisms such as fish entrained in the sea-sieves (author's unpublished data). Most importantly, organisms inside sea-chests are protected from the unforgiving hydrodynamic flows experienced by fouling organisms on the exterior of the hull.

Our finding that the composition of organisms inside sea-chests was more similar among sea-chests sampled from the same vessel than among sea-chests from different vessels indicates that the pattern of occupancy on each vessel is relatively unique. In addition to the variety of factors that influence occupancy as described above, such findings can also be explained by the different source pool of organisms among the different regions of vessel operation. In this respect, the species accumulation curve analysis highlighted the need for sampling more vessels of various types, geographical regions and origins (particularly of international origin) to capture the true nature and extent of organisms in sea-chests. Notwithstanding this need, it should be recognised that sampling effort that targets a greater source pool of organisms is likely to lead to taxonomic difficulties that may undermine the benefits of more extensive sampling. In the present study, $35 \%$ of organisms were classified as having an unknown origin because they could not be definitely described to species level. 


\subsubsection{Biosecurity risk}

The presence of 144 live adult organisms inside seachests clearly illustrates the potential for a range of taxa, particularly mobile species, to be dispersed via this mechanism. Prior to the observations made during this research, the dispersal of the 63 mobile and 14 of the sedentary organisms identified inside sea-chests in this study was assumed more likely to occur via ballast water. Interestingly, $95 \%$ of the mobile organisms were small enough to fit between the grilles and escape from the sea-chests sampled. Furthermore, some species such as the non-indigenous amphipods, Elasmopus rapax and Stenthoe gallensis included females with broods of developing embryos and newly hatched juveniles. Moreover, ovigerous females of decapods were also found, including six Halicarcinus innominatus and one each of Notominthrax minor, Pilumnus minutus and Plagusia chabrus.

The occurrence of 19 different species of decapod found alive in sea-chests of 33 (79 $\%$ ) of the vessels suggests that sea-chests are a significant candidate for the dispersal of this group of organisms. In particular, vessels operating in the Indo-Pacific and South Pacific regions may pose a significant risk of introducing decapods while visiting maintenance facilities in New Zealand. For instance, New Zealand is already host to two Indo-Pacific decapods, the red rock crab Plagusia chabrus and the swimming crab Charybdis japonica (Cranfield et al. 1998; Webber 2001). Furthermore, five nonindigenous decapod species were found alive in the sea-chests of three vessels of tropical origin (Table 11) despite the vessels visiting maintenance facilities at temperate New Zealand ports (Nelson and Lyttelton) during winter. Hence it is conceivable that some of these organisms could establish in northern New Zealand waters. Moreover, there is potential for mature adult decapods to also disperse non-indigenous parasites, pathogens and viruses that may be associated with them (e.g. Carcinonemertes epialti, Sacculina spp., White Spot Syndrome Baculovirus).

Trans-Tasman vessels have the potential to introduce high profile pests from Australia to New Zealand via sea-chests. Prime candidates include the Mediterranean fanworm Sabella spallanzanii, the European green crab C. maenas and the Northern Pacific seastar Asterias amurensis, especially given that the latter two species have been previously recorded in sea-chests of vessels in Australia (Coutts et al. 2003; R. Thresher, pers. comm.). Conversely, international vessels are equally capable of 
donating indigenous New Zealand species to other regions. For example, sea-chests of trans-Tasman vessels may have contributed to the transport of the pie-crust crab (Cancer novaezelandiae), the pill-box crab (H. innominatus), the New Zealand halfcrab (Petrolisthes elongatus) and the variable triplefin (Forsterygion varium) to Australia, especially given that these species were all found alive inside sea-chests during this study.

The occurrence of F. varium and other fish species (e.g. Grahamichthys radiata, F. malcolmi, and Engraulis australis) inside sea-chests is of considerable interest. The introduction of many fish species, particularly in the gobiidae and blenniidae around the world has largely been attributed to ballast water (Hoese 1973; Springer and Gomon 1975; Al-Hassan and Miller 1987; Pollard and Hutchings 1990; Willis et al. 1999; Francis et al. 2003). However, very few ballast water surveys to date have actually collected fishes (e.g. Middleton 1982; Williams et al. 1988; Carlton and Geller 1993; Ruiz and Hines 1997; Smith et al. 1999). This is not surprising considering well maintained sea-sieves should prevent the passage of such macro-organisms into ballast tanks. Therefore, although, many fish may have escaped prior to sampling conducted during this study, the presence of several fish species in our samples provides compelling evidence to suggest that sea-chests may have contributed to the dispersal of such organisms around the world. Finally, as well as presenting a risk in the international transfer of NIMS, sea-chests may also be responsible for the spread of both indigenous and introduced species to new locations throughout New Zealand waters, and in fact throughout the domestic waters of other coastal nations. For example, a variety of domestic fishing and coastal vessels frequently travel between New Zealand ports and have the potential to disperse high profile pests such as $\mathrm{C}$. japonica and the recently discovered (i.e. August 2005) clubbed tunicate Styela clava (Gust et al. 2005; Davis and Davis 2006).

\subsubsection{Management measures for sea-chests}

Active anti-fouling coatings and the utilisation of effective sea-chest treatment systems are currently the best defence for mitigating the accumulation of unwanted marine growth and the biosecurity risk of sea-chest systems. A variety of treatment systems involving the release of toxic chemicals (e.g., CHLOROPAC ${ }^{\circledR}$, Cathelco, Chem-Free ${ }^{\mathrm{TM}}$, etc.) are currently available, however they are relatively expensive and may present 
some environmental risk. Furthermore, our study indicates that while such treatments appear to reduce the occurrence of both sessile and sedentary organisms, they are less effective against mobile organisms such as decapods. Clearly, the treatment of biosecurity risks associated with sea-chests will require approaches that are effective against the full range of organisms that may be present. For this purpose we are currently investigating the utility of heat treatment as the most practical way forward. The feasibility of heat treatment arises from the fact that heat can be readily generated as hot water or steam that is circulated from a vessel's engine cooling system or steam generating system. Our initial enquiries suggest that such a system would be relatively straightforward to retrofit many vessel types. For example, 'ice-class' vessels operating in high latitudes are required to recirculate engine cooling water into at least one seachest to avoid freezing (e.g. Finnish-Swedish Maritime Administrations 2005). Alternatively sea-chest hygiene could be managed via a system developed by Miko Marine AS (Norway) that enables engineers to access sea-chests from inside the vessel, thus facilitating regular in-water surveys and maintenance.

\subsubsection{Conclusions and recommendations}

This study clearly illustrates that a wide variety of organisms are capable of surviving inside sea-chests, highlighting the potential for this mechanism to introduce NIMS and disperse indigenous and other pest organisms. The occurrence of adult mobile stages is particularly significant and indicates that sea-chests may be of greater importance than ballast water or hull fouling for dispersing certain marine species. The actual occupancy of the seachests we sampled is probably even greater than reflected in our data given that many smaller organisms $(<1 \mathrm{~mm})$ would not have been detected and many mobile species could have escaped prior to sampling. Nonetheless, our findings emphasise the importance of managing the vessel as a whole rather than different mechanisms (i.e. ballast water, hull fouling, sea-chests, etc.) in isolation, especially if the reduction of NIMS transfer via shipping is to be a realistic goal. To further elucidate the true extent of occupancy in sea-chests we encourage researchers to undertake investigations at other maintenance facilities around the world, and to investigate a variety of other vessel types (e.g. larger ocean-going vessels) operating on different trade routes. 


\subsection{REFERENCES}

Al-Hassan, L. A. J., Miller, P. A., 1987. Rhinogobius brunneus (Gobiidae) in the Arabian Gulf. Japanese Journal of Ichthyology 33: 405-408.

Carlton, J. T., 1985. Transoceanic and interoceanic dispersal of coastal marine organisms: the biology of ballast water. Oceanography and Marine Biology: An Annual Review 23: 313-371.

Carlton, J. T., 1987. Patterns of transoceanic marine biological invasions in the Pacific Ocean. Bulletin of Marine Science 41: 452-465.

Carlton, J. T., 1992. Blue immigrants: The marine biology of maritime history. The Log of Mystic Seaport 44: 31-36.

Carlton, J. T., 1996. Pattern, process, and prediction in marine invasion ecology. Biological Conservation 78: 97-106.

Carlton, J. T., 2001. Introduced species in US coastal waters: environmental impacts and management priorities, Arlington, Viriginia, United States, Pew Oceans Commission, p. 28.

Carlton, J. T., Geller, B., 1993. Ecological roulette: The global transport of nonindigenous marine organisms. Science 261: 78-82.

Carlton, J. T., Hodder, J., 1995. Biogeography and dispersal of coastal marine organisms: experimental studies on a replica of a $16^{\text {th }}$-century sailing vessel. Marine Biology 121: 721-730.

Carlton, J. T., 2001. Introduced species in U. S. coastal waters: environmental impacts and management priorities, Arlington, Viriginia, United States, Pew Oceans Commission, p. 28.

Carlton, J. T., Reid, D. M., van Leeuwen, H., 1995. Shipping study: The role of shipping in the introduction of nonindigenous aquatic organisms to the coastal waters of the United States (other than the Great Lakes) and an analysis of control options. U.S. Coast Guard, Connecticut, Department of Transportation, Washington, D.C. 
Clark, K. R., 1993. Non-parametric multivariate analyses of changes in community structure. Australian Journal of Ecology 18: 117-143.

Cohen, A. N., Carlton, J. T., 1995. Nonindigenous aquatic species in a United States Estuary: A case study of the biological invasions of the San Francisco Bay and Delta. A report for the United States Fish and Wildlife Services, Washington D. C. and The National Sea Grant College Program, Connecticut Sea Grant. 175.

Colwell, R. K., Mao, C. X., Chang. J., 2004. Interpolating, extrapolating, and comparing incidence-based species accumulation curves. Ecology 85: 2717-2727.

Coutts, A. D. M., Moore, K. M., Hewitt, C. L., 2003. Ships'sea-chests: an overlooked transfer mechanism for non-indigenous marine species? Marine Pollution Bulletin 46: 1504-1515.

Cranfield, H. J., Gordon, D. P., Willan, R. C., Marshall, B. A., Battershill, C. N., Francis, M. P., Nelson, W. A., Glasby, C. J., Read, G. B., 1998. Adventive marine species in New Zealand. National Institute of Water and Atmospheric Research, Technical Report 34, Wellington, New Zealand, p. 48.

Davis, M. H., Davis, M. E., 2004. The role of man-aided dispersal in the spread of the immigrant Styela clava Herdman, 1882. Journal of Marine Science and Environment 1: 18-24.

Davis, M. H., Davis, M. E., 2006. Styela clava (Tunicata: Ascidiacea) a new edition to the fauna of New Zealand. Porcupine Marine Natural History Society Newsletter 20: $23-28$.

Finnish-Swedish Maritime Administrations, 2005. Finnish-Swedish Maritime Administration Ice Classes and Requirements http://www.fma.fi/e/services/informationservices/publications/bulletin/hae.php?l=e $\underline{\text { nands }=\mathrm{v}}$.

Fofonoff, P. W., Ruiz, G. M., Steves, B., James, J. T., 2003. In ships or on ships? Mechanisms of transfer and invasion for nonnative species to the coasts of north America. In: Ruiz, G., Carlton, J. (Eds.), Invasive Species: Vectors and Management Strategies. Island Press, Washington, pp. 152-182. 
Francis, M. P., Walsh, C., Morrison, M. A., Middleton, C., 2003. Invasion of the Asian goby, Acentrogobius pflaumii, into New Zealand, with new locality records of the introduced bridled goby, Arenigobius bifrenatus. New Zealand Journal of Marine and Freshwater Research 37: 105-112.

Galil, B., 2000. A sea under siege - alien species in the Mediterranean. Biological Invasions 2: 177-186.

Gust, N., Floerl, O., Inglis, G., Miller, S., Fitridge, I., Hurren, H., 2005. Rapid delimitation survey of Styela clava in the Viaduct Harbour and Freemans Bay, Auckland. NIWA Client Report CHC2005-147, National Institute of Water and Atmospheric Research Ltd, Christchurch, p. 45.

Gust, N., Inglis, G. J., 2006. Adaptive multi-scale sampling to determine an invasive crab's habitat usage and range in New Zealand. Biological Invasions 8: 339-353.

Hayes, K. R., Sliwa, C., 2003. Identifying potential marine pests - a deductive approach applied to Australia. Marine Pollution Bulletin 46: 91-98.

Hewitt, C. L., 2002. The distribution and diversity of tropical Australian marine bioinvasions. Pacific Science 56: 213-222.

Hewitt, C.L., 2003. The diversity of likely impacts of introduced marine species in Australian waters. Records of the South Australian Museum Monograph Series 7: $3-10$.

Hewitt, C. L., Campbell, M. L., Thresher, R. E., Martin R. B., 1999. Marine biological invasions of Port Phillip Bay, Victoria. Technical Report No. 20, Hobart, Australia, CSIRO Marine Research, Centre for Research on Introduced Marine Pests, p. 344.

Hewitt, C. L., Campbell, M. L., Thresher, R. E., Martin, R. B., Boyd, S., Cohen, B. F., Currie, D. R., Gomon, M. F., Keogh, M. J., Lewis, J. A., Lockett, M. M., Mays, N., McArthur, M. A., O’Hara, T. D., Poore, G. C. B., Ross, D. J., Storey, M. J., Watson, J. E., Wilson, R. S., 2004. Introduced and cryptogenic species in Port Phillip Bay, Victoria, Australia. Marine Biology 144: 183-202.

Hoese, D. F., 1973. The introduction of the gobiid fishes Acanthogobius flavimanus and Tridentiger trigonocephalus into Australia. Koolewong 2: 3-5. 
Lewis, J. A., 2002. Hull fouling as a vector for the translocation of marine organisms. Phase 1: Hull fouling research. Ballast Water Research Series, Report No. 14 Department of Agriculture, Fisheries and Forestry Australia, Canberra, 142 pp.

Lewis, J. A., Smith, B. S., Taylor, R. J., Batten, J. J., 1998. Fouling of RAN submarine seawater systems and a comparison of electro-chemical control methods. In: Proceedings of the $8^{\text {th }}$ International Naval Corrosion Conference, Plymouth, United Kingdom, April 1998, Paper No. 7. 1-19.

Lewis, J. A., Smith, B. S., 1991. Hydroides settlement in Sydney Harbour (Australia) and its control in sea-water cooling systems. In: Rossmoore, H. W., (Ed.). Biodeterioration and biodegradation 8. Elsevier Applied Science, London. Pg 464466.

Longino, J. T., Coddington, J., Colwell, R. K., 2002. The ant fauna of a tropical rainforest: Estimating species richness three different ways. Ecology 83: 689-702.

Middleton, M. J., 1982. The oriental goby, Acanthogobius flavimanus (Temminck and Schlegel), an introduced fish in the coastal waters of New South Wales, Australia. Journal of Fish Biology 21: 513-523.

Minchin, D., Gollasch, S., 2002. Vectors - how exotics get around. In: Leppa“koski, E., Gollasch, S., Olenin, S. (Eds.), Invasive Aquatic Species of Europe: Distribution, Impacts and Management. Kluwer Academic Publishers, Netherlands, pp. 183192.

Newman, W., 1963. On the introduction of an edible Oriental shrimp (Caridea, Palaemonidae) to San Francisco Bay. Crustaceana 5: 119-132.

Pimentel, D., Lach, L., Zuniga, R., Morrison, D., 2000. Environmental and economic costs of non-indigenous species in the United States. BioScience 50: 53-65.

Pollard, D. A., Hutchings, P. A., 1990. A review of exotic marine organisms introduced to the Australian region. II. Invertebrates and algae. Asian Fisheries Science 3: 223-250.

Richards, A., 1990: Muricids: A Hazard to Navigation? Hawaiian Shell News May, pp 10. 
Ruiz, G. M., Hines, A. H., 1997. The risk of nonindigenous species invasion in Prince William Sound associated with oil tanker traffic and ballast water management: pilot study. Regional Citizens' Advisory Council of Prince William Sound, Valdez, Alaska (Rep. No. 632f.97.1).

Ruiz, G. M., Fofonoff, P. W., Carlton, J. T., Wonham, M. J., Hines, A. H., 2000. Invasion of coastal marine communities in North America: apparent patterns, processes, and biases. Annual Reviews in Ecology and Systematics 31: 481-531.

Slack-Smith, S. M., Brearly, A., 1987. Musculista senhousia (Benson, 1842); a mussel recently introduced into the Swan River estuary, Western Australia (Mollusca: Mytilidae). Records of the Western Australian Museum 13: 225-230.

Sinner, J., Forrest, B. M., Taylor, M. D., 2000. A Strategy for Managing the Asian Kelp Undaria: Final Report. Cawthron Report, 578, Cawthron Institute, Nelson, New Zealand, 122p.

Smith, L. D., Wonham, M. J., McCann, L. D., Ruiz, G. M., Hines, A. H., Carlton, J. T., 1999. Invasion pressure to a ballast-flooded estuary and an assessment of inoculant survival. Biological Invasions 1: 67-87.

Springer, V. G., Gomon, M. F., 1975. Revision of the Blennid fish genus Omobrachus with descriptions of three new species and notes on other species of the tribe Omobranchini. Smithonian Contributions to Zoology 177: 1-135.

Thresher, R. E., Hewitt, C. L., Campbell, M. L., 1999. Introduced and cryptogenic species in Port Phillip Bay. In: Hewitt, C. L., Campbell, M. L., Thresher, R. E., Martin, R. B. (Eds.), Marine Biological Invasions of Port Phillip Bay, Victoria. Centre for Research on Introduced Marine Pests Technical Report No. 20 CSIRO Marine Research, Hobart, 283-295.

Webber, R., 2001. Space invaders, crags that turn up in New Zealand unannounced. Seafood New Zealand, November 2001, 80-84.

Williams, R. J., Griffiths, F. B, van der Waal, E. J., Kelly, J., 1988. Cargo vessel ballast water as a vector for the transport of non-indigenous marine species. Estuarine and Coastal Shelf Science 26: 409-420. 
Willis, T. J., Saunders, J. E. H., Blackwood, D. L., Archer, J. E., 1999. First New Zealand record of the Australian bridled goby, Arenigobius bifrenatus (Pisces: Gobiidae). New Zealand Journal of Marine and Freshwater Research 33: 189-192.

Wonhom, M. J., O’Connor, M., Harley, C. D. G., 2005. Positive effects of a dominant invader on introduced and native mudflat species. Marine Ecology Progress Series 289: 109-116. 


\section{Chapter 7 - General discussion and recommendations}

\subsection{INTRODUCTION}

At the time of commencing this thesis, the likelihood of non-indigenous marine species (NIMS) being dispersed via biofouling on modern-day vessels was only just beginning to receive international attention. Furthermore, there was a considerable lack of knowledge surrounding which levels of biofouling, type of vessels and vessel characteristics posed the greatest risk of dispersing NIMS.

For almost three decades prior to this, ballast water was thought to be the primary vector for the dispersal of NIMS (e.g. Medcof 1975; Carlton 1982; Carlton and Geller 1993; Locke et al. 1993; Carlton et al. 1995). However, in the space of a decade, vessel biofouling has been increasingly identified as an equal, if not greater risk than ballast water in some parts of the world (e.g. Hewitt et al. 1999, 2004; Thresher 2000; Hewitt 2002, 2003; Gollasch 2002; Fofonoff et al. 2003; Lewis et al. 2003; Lewis et al. 2004; Minchin 2006, 2007; Schaffelke et al. 2006; Schaffelke and Hewitt 2007; Hewitt and Campbell 2008; Hewitt et al. 2009).

This thesis has made a fundamental contribution towards improving our understanding of the biosecurity risks associated with vessel biofouling. To illustrate this, the most significant findings of each chapter have been summerised followed by a discussion surrounding how these results contribute to our understanding of the biofouling invasion process. Furthermore, I will demonstrate how these findings have contributed to the development of biofouling management measures that have, or are being developed around the world. Given biofouling management is in its infancy, I also offer a pragmatic biofouling risk assessment method that could be used to manage high risk vessels. Finally, I conclude this thesis by identifying important knowledge gaps and offer recommendations for further research and biofouling management regimes. 


\subsection{SUMMARY OF THESIS FINDINGS}

Before discussing how the results of this thesis have contributed to our understanding of the biofouling invasion process, the key findings of each chapter are worth reiterating.

\subsubsection{Chapter 2 - Effect of vessel voyage speed on the survival and translocation of biofouling organisms}

- Species morphology is a strong determinant for organismal survivorship during the faster speed trials. Organisms most resilient to hydrodynamic forces included those with low-profile encrusting forms, hard calcareous protection, and/or flexible morphologies. Furthermore, colonial morphotypes have a further advantage over solitary morphotypes given their propensity for asexual reproduction from as little as a single surviving zooid.

- While faster moving (10-18 knots) vessels are capable of translocating biofouling species, it is slower moving vessels that travel $<5$ knots that translocate both larger numbers of organisms and a greater number of species, including soft-bodied organisms that may be less resilient to transfer at higher vessel speeds.

- Theoretically if survivorship is greater on slow-moving vessels, which in turn increases inoculum pressure in ports and harbours, slow-moving vessels will pose the greatest risk on a vessel by vessel scale.

- This chapter highlights the important need for suitable anti-fouling coatings and cleaning strategies on all vessels, given that once biofouling organisms colonise and establish on a vessel hull, voyage speed alone will not eliminate biofouling risk.

\subsubsection{Chapter 3 - Which hull locations are more likely to contain non-indigenous marine species}

- The archived video footage of underwater hull assessments proved to be a costeffective way of quantifying levels of biofouling taxa and potential biosecurity risk of housing NIMS at selected hull locations on a wide range of merchant vessels.

- Out-of-service vessels and vessels plying trans-Tasman routes possessed greater levels of biofouling than more active vessels. 
- Dry-docking support strips and sea-chest gratings generally had the highest levels of biofouling and may pose relatively high biosecurity risks.

- The distribution and abundance of biofouling on vessels is likely to be a consequence of submerged surfaces possessing old, damaged, ineffective and/or no anti-fouling coatings.

- Any future biosecurity surveillance should target niche areas, dry-docking support strips and sea-chests in particular for NIMS.

- Dry-docks should be retrofitted with two sets of hydraulic docking blocks so that anti-fouling coating can be applied to the entire bottom of the vessel using a two-stage operation.

\subsubsection{Chapter 4 - A novel method for assessing the en route survivorship of biofouling organisms}

- The novel MAGPLATE system proved to be an innovative tool for empirically assessing the en route survivorship of biofouling organisms at different hull locations on various vessel types.

- MAGPLATEs could be used to determine the en route survivorship and recruitment of biofouling organisms on different vessels types plying similar latitudes (e.g. between Australia and New Zealand); trans-equatorial routes (e.g. between Japan and New Zealand); and tropical to temperate routes and vice-versa (e.g. between Hawaii and New Zealand).

- MAGPLATEs could be used to test the performance of various anti-fouling coatings on different vessel types at various hull locations. Furthermore, MAGPLATEs could be used to assess the rates of recruitment and survivorship of biofouling organisms on various coating types on different vessel types at various hull locations.

\subsubsection{Chapter 5 - The survivorship of biofouling organisms on various vessel types at different hull locations}

- No significant differences in en route survivorship amongst biofouling organisms were evident amongst hull locations. 
- While fast-moving vessels may be capable of reducing species richness and percentage cover (i.e. potential inocula) of biofouling, $90 \%$ of species survived.

- Vessel operating speed cannot be considered a reliable management option for reducing the biosecurity risks associated with biofouling on vessel hulls.

- Nevertheless, en route survivorship is still likely to be greater on slow-moving vessels, which in turn has the potential to increase inoculum pressure, and therefore are more likely to pose the greatest risk on a vessel by vessel scale.

- This study clearly demonstrates the ability of coastal vessels to spread NIMS domestically and reinforces the need for the development of internal border management.

\subsubsection{Chapter 6 - A preliminary assessment of the nature and extent of biofouling inside vessel sea-chests}

- A total of 150 different organisms, including one plant species and 12 animal phyla were identified from sea-chests.

- Forty-nine percent of organisms were sessile, $42 \%$ mobile adults and the remaining $9 \%$ sedentary.

- Decapods were the most represented group with 19 species present among $79 \%$ of vessels.

- Forty percent of organisms were indigenous to New Zealand, $15 \%$ introduced, $10 \%$ non-indigenous, and $35 \%$ of unknown origin.

- Age of anti-fouling coating and greater in-service period appeared to have a significant influence on sea-chest communities, with older coatings and longer in-service periods associated with greater numbers of organisms.

- Sea-chest treatment systems had a significant effect on composition of both sessile and sedentary organisms, but did not significantly affect the occurrence of mobile organisms in sea-chests.

- Sea-chests have the potential to: 1) transfer non-indigenous organisms between countries across oceanic boundaries; and 2) disperse both indigenous and introduced organisms domestically. 
- The occurrence of adult mobile organisms is particularly significant and indicates that sea-chests may be of greater importance than ballast water or vessel biofouling for dispersing certain marine species.

- These findings emphasise the need to assess and manage biosecurity risks for entire vessels rather than different mechanisms (i.e. ballast water, biofouling, sea-chests, etc.) in isolation.

- Engine cooling water could be re-circulated into sea-chests as a cost-effective management measure.

\subsection{ADVANTAGES OF THIS THESIS OVER PREVIOUS STUDIES}

At the time of commencing this thesis, the majority of studies that investigated the nature and extent of biofouling on vessel hulls had conducted their surveys during vessel dry-dockings (e.g. Woods Hole Oceanographic Institution 1952; Skerman 1960; Gollasch 2002). Such assessments tend to encounter vessels at the completion of their in-service period when anti-fouling coatings are spent and levels of biofouling are at their worst, thus resulting in over-estimates or worst-case senarios. Furthermore, assessments are likely to unestimate the significance of mobile taxa as a result of them departing the hull prior to sampling (e.g. Coutts et al. 2010c). Conversely the advantage of in-situ assessments such as Chapter $\mathbf{3}$ is they are capable of capturing more realistic representations of the nature and extent of biofouling on vessels throughout their inservice periods. Moreover, most hull locations (apart from inside sea-chests) can be readily accessed and with a correct sampling method/regime (e.g. vacuum system) is capable collecting all biofouling organisms present. While the video analysis technique used in chapter 3 was obviously unable to sample biofouling organisms, it proved to be an innovative way of retrospectively assessing the nature and extent of biofouling on various vessel types in a cost-effective manner.

Prior to commencing this thesis, very few studies had investigated the survivorship of biofouling organisms. As far as the author is aware, only three studies have attempted to quantify the pre- and post-voyage survivorship of various biofouling organisms on vessel hulls (i.e. Carlton and Hodder 1995; Brock et al. 1999; Davidson et al. 2008). While these studies were extremely insightful, they were largely opportunistic assessments of biofouling survivorship on single slow-moving vessels ( $\sim 4.0$ to 6.5 
knots), albeit over extended voyage durations ( $>2$ weeks), including exposure to freshwater environments (e.g. Columbia River and Panama Canal). The advantage of Chapters 2 and 5 over these studies is they were able assess the acute and chronic survivorship across different vessels and hull locations while controlling many covariates. The only limitations of these studies were the treatments were conducted over short durations (i.e. 20 minutes to 11 hours). Clearly longer voyage durations are likely to result in greater loses of species richness and abundance.

Arguably one of the most significant findings of this thesis was Chapter 6's discovery of such a diverse range of biofouling organisms inside vessel sea-chests. Interestingly, dispite several authors discussing the potential for sea-chest systems to house and disperse marine organisms and NIMS for several decades (e.g. Newman 1963; Hoese 1973; Carlton 1985; Slack-Smith and Brearly 1987; Richards 1990; Carlton et al. 1995; Cohen and Carlton 1995; Carlton 2001; Lewis 2002; Davis and Davis 2004; Coutts et al. 2003), this is the first comprehensive assessment. Many of the sedentary and mobile taxa discovered in sea-chests have never been recorded from vessel hulls, particularly of active fast-moving vessels, to the author's knowledge. As a consequence such taxa were previously thought to be only dispersed via ballast water.

\subsection{PUTTING THESIS FINDINGS IN PERSPECTIVE WITH THE WIDER LITERATURE}

The following section draws upon the wider literature in an attempt to explain the nature, extent and survivorship of biofouling organisms on vessel hulls.

\subsubsection{Colonisation}

The moment a vessel is immersed in seawater, the biofouling process beings (e.g. Woods Hole Oceanographic Institution 1952; Wahl 1989; 1997; Lewis 1998; Railkin 2004). Every square centimetre of a vessel's submerged hull is potentially under constant exploration and colonisation pressure from algal propagules and invertebrate larvae. While the adoption of anti-fouling coatings are generally effective at resisting colonisation over much of the submerged surface, as stated in Chapters 2, 3 and 5, all vessels possess hull locations that either possess old, damaged, ineffective and/or no anti-fouling coatings. For example, self-polishing copolymer anti-fouling coatings are one of the most popular coatings used amongst vessel owners/operators today. Such 
coatings are designed to polish, ablate or exfoliate during transit so that fresh biocides are exposed at the surface to inhibit settlement. However, often the polishing rates vary across the hull, particularly within niche areas resulting in coatings polishing either too quickly (e.g. bulbous bow, sea-chest grilles, leading edges of bilge keels and rudders) or too slowly (e.g. inside sea-chests, rope guards). The net result is coatings become ineffective and allow colonisation to occur.

While such niche areas could be colonised by biofouling purely by chance, some species of larvae are capable of actively seeking and exploring surfaces in pursuit of a favourable location to settle (e.g. hydroids: Walters and Wethey 1996; Lemire and Bourget 1996; bryozoans: Walters 1992a; 1992b; Walters and Wethey 1996; barnacles: Miron et al., 1996; Lemire and Bourget 1996; Walters and Wethey 1996; crabs: Lee et al. 2004). Small-scale surface topography is also known to influence larval settlement of certain species such as barnacles (Mullineaux and Butman 1991; Hills and Thomason 1998; Wright and Boxshall 1999; Skinner and Coutinho 2005), polychaetes (Hurlbut 1991; Walters et al. 1997), bivalves (Bologna and Heck 2000; Czarnoleski et al. 2004), and crabs (Lee et al. 2004). Furthermore, given the majority of niche areas on vessels are at depth and receive limited light (e.g. thrusters tunnels, bilge keels, DDSS, seachests, rope guards, etc), some invertebrate larvae are known to display phototaxis and geotaxis behaviour prior to settlement. For example, many colonial ascidian larvae initially swim towards the surface (i.e. towards the light and/or against gravity) before swimming away from the light and with gravity seeking shaded crevices or overhangs such as niche areas (Grave 1920, 1926; Mast 1921; Grave and Woodbridge 1924; Hurlbut 1991). Similarly, the invasive bryozoans, Bugula neritina is photosensitive during the larval stage, although it becomes indifferent to light prior to metamorphosis (Lynch 1947). Interestingly, some researchers have found more NIMS associated with floating pontoons and fixed wharf piles than natural substrates (e.g. Glasby et al. 2007).

The occurrence of biofouling outside niche areas on the more uniform areas of vessel hulls is becoming more common on copper based anti-fouling coatings now that the highly effective, but toxic tributyltin coatings have been banned. For example, numerous biofouling species associated with vessel hulls have shown significant tolerance to copper, including calcareous tubeworms (Johnston and Keough 2003; Dafforn et al. 2008), barnacles (Weiss 1947), hydroids (Stebbing 2002), bryozoans 
(Floerl et al. 2004; Piola and Johnston 2006), bivalves (Lee and Chown 2007) and algae (Russell and Morris 1970, 1972; Reed and Moffat 1983; Correa et al. 1996; JelicMrcelic et al. 2006; Han et al. 2008). The establishment of such copper-tolerant species in turn provides non-toxic surfaces for other species to settle, which in turn could facilitate the transfer of less tolerant NIMS (e.g. Wisely 1958; Floerl et al. 2004). As such, the use of copper-based anti-foulants on vessel hulls has the potential to select for the settlement and transport of NIMS with a high tolerance to metal pollution (e.g. Dafforn et al. 2008; Piola et al. 2009).

Once an anti-fouling coating fails and a biofouling community develops, the Reynolds shear stresses encountered by larvae settling into biofouling communities varies. More advanced biofouling communities are likely to produce turbulent flows over the rough surfaces relative to smooth substrata (e.g. reviewed in Nowell and Jumars 1984; Ligrani 1989). Hence, larvae are more likely to be caught in micro-eddies and settle amongst advanced communities. Furthermore, when rough substrata are subjected to waves (as are surfaces in harbours exposed to wind chop and ship wakes), these micro-eddies and effects of bed roughness are enhanced (Grant and Madsen 1986).

Anti-fouling coating technologists have been trying to develop cost-effective environmentally friendly coatings for over 25 years. Arguably, one of the most successful of these to date includes the fouling release coatings like silicone or teflon based coatings. Such coatings do not prevent biofouling, but rather limit the adhesive strength resulting in the biofouling being washed off during transit, particularly on fastmoving vessels (i.e. $>15$ knots). While such coatings might appear to be the solution, they are extremely expensive and difficult to repair if damaged (Callow and Callow 2002). Furthermore, such coatings could selectively translocate a variety of different types of biofouling species. For example, Mineur et al. (2007) sampled algal species from 22 vessels and found that the only vessel that was coated with a fouling release coating also possessed the highest number of NIMS and had six times the richness of the other vessels. The use of copper-based anti-fouling coatings, particularly on recreational craft in San Diego Bay, California is being phased out for non-toxic coatings (e.g. Johnson and Gonzalez 2004). However, such coatings are required to be scrubbed every 2-4 weeks. In light of Mineur et al. (2007) and the risks associated with 
in-water cleaning (e.g. Hopkins and Forrest 2008), it will be interesting to note if any new algal species suddenly appear within their marinas.

Finally, it is also important to acknowledge that not all recruitment of biofouling organisms on vessel hulls is a passive or voluntary process. As outlined in Chapter 6, large quantities of larvae are capable of being involuntary recruited from the surrounding water column into sea-chests. More importantly, juvenile and even adult sessile, sedentary and mobile organisms are capable of being 'vacuumed' from neighbouring wharf piles or the seabed. Once inside, species can enjoy a warmer environment (due to the radiated heat through shell plating from a vessel's engineroom), with a consistent food-source (dead organisms trapped inside the sea strainers), that is protected from harsh external hydrodynamic forces.

\subsubsection{Survivorship}

Once biofouling organisms settle on a hull, the ultimate distribution, abundance and potential inoculum pressure that arrives in a donor region is influenced by many factors such as: residency period prior to departure and upon arrival, type of reproductive growth, adhesive strength and morphology of organisms, type of anti-fouling coating, hull location, voyage speed, duration and pathway (Chapter 1; Figure 1). One of the most influential factors is the residency period of vessels. Vessels that have short residency periods firstly inhibit newly settled organisms from advancing (e.g. becoming sexually maturing), hence they are more vulnerable during transit and their ability to reproduce in donor regions is also reduced if residency periods are also short. Conversely, vessels that have prolonged residency periods in both donor and recipient locations are more likely to allow species to develop, reach sexual maturity and reproduce. However, extended residency periods can have an adverse effect on biofouling organisms if they grow too large and exhibit isotropical ontogeny (i.e. relatively uniform growth in all directions). Hence, their survival during transit will be dependent on the voyage speed, duration, pathway, the organism's morphology and their settlement location on the hull.

Once biofouling organisms are established, some species are capable of increasing their chances of survival during transportation. As discussed in Chapters 2 and 5, the shape, size and texture of biofouling organisms will determine which hydrodynamic forces act 
upon them during transit (i.e. drag, lift and acceleration) (Denny 1985; Denny et al. 1985; Gerard 1987; Johnson and Koehl 1994). Such effects on survival and morphology occur in response to the effect of flow on drag; the magnitude of the drag is proportional to the velocity of the flow (i.e. vessel speed, and the length of the object), and gets larger as organisms increase in size or encounter faster flows.

Some biofouling organisms are capable of morphological plasticity or adopting a morphology that increases flexibility and reduces drag in high flow environments (e.g. Fowler-Walker et al. 2006). As illustrated in Chapters 2 and 5, species with erect/flexible characteristics (e.g. aborescent bryozoans and hydroids) are well adapted to coping with harsh hydrodynamic forces considering they are capable of flattening and aligning with the direction of hydrodynamic flow, thus reducing drag and allowing the organisms to reside (at least partially) in the boundary layer (Koehl 1984; Denny et al. 1985, 1998). The most resilient species, however, are barnacles, encrusting bryozoa, serpulids, spirorbids and oysters owing to their low encrusting profiles, hard structures and superior adhesive cements (e.g. Callow and Callow 2002). Therefore, it is not surprising that such species are the most frequently occurring species on vessel hulls, particularly fast-moving merchant vessels (e.g. Coutts 1999; James and Hayden 2000; Lewis 2002; Coutts and Taylor 2004; Otani et al. 2007). Conversely, erect soft-bodied organisms like sponges, ascidians, anemones, sabellid worms are the most vulnerable to hydrodynamic flows and are largely confined to slow-moving vessels or within protected niche areas of faster-moving vessels. However, unlike many sessile species, some soft-bodied colonial species could theoretically recover from a single zooid through asexual reproduction. Clearly, the hydrodynamic forces of wave-swept shore environments have obviously been an instrumental and critical selective force on the evolution of body shapes and biomechanical designs of biofouling organisms.

Interestingly, Chapters 2, 3 and 5 documented the nature, extent and survivorship of sessile biofouling organisms on the exposed external surfaces of vessel hulls. Chapter 6 was arguably one of the first studies in the world to investigate the nature and extent of biofouling inside vessel hulls (i.e. sea-chests). This chapter clearly illustrated that a wide diversity of biofouling organisms, in particular sedentary (9\%) and mobile taxa (42\%) are capable of persisting inside sea-chests (e.g. gastropoda, nudibranchia, annelida, sipuncula, decapoda, pycnogonida, echinodermata, and vertebrata) which 
were historically only thought to be transportable as larvae in ballast water. More importantly, it appears that fast-moving vessels are still capable of supporting and transporting a wide diversity of taxa.

The type of anti-fouling coating also plays an important role in determining the distribution, abundance and potential inoculum pressure of NIMS. As discussed previously, many fast-moving merchant vessels adopt superior self-polishing copolymers that are designed to polish, ablate or exfoliate their outer layer of the coating during transit. However, the hydrodynamic flow regime around some niche areas such bilge keels, thrusters tunnels, sea-chests and grilles, rope guards, etc are very different to the mainstream areas of the hull. So biofouling organisms are more likely to survive in niche areas as a consequence of the differential polishing rates (i.e. Chapter 3). Similarly, biofouling organisms are more likely to persist within niche areas where the necessary hydrodynamic forces needed to wash way the biofouling are less. However, biofouling organisms, particularly low profile, encrusting acorn barnacles, bryozoans, serpulids, spirorbids are capable of surviving on conventional or contact leaching coating outside niche areas because they of the nature of the coatings (e.g. Coutts 1999; James and Hayden 2000; pers obs).

The degree to which biofouling organisms are able to survive during transit is also dependent on their ability to feed during transit. The quantity of food available during an oceanic voyage is appreciably less than coastal waters, hence it may be impossible for some species to feed, thus stunting their growth or in extreme cases causing them to die when voyage durations are long (e.g. Walton-Smith 1946; Pyefinch 1950). However, fast-moving vessels are capable of minimising the exposure of biofouling organisms to oceanic waters and variations in temperature and salinity (e.g. across the equator or passage through the Panama Canal) which in turn could theoretically deliver healthier taxa and subsequent colonisation and propagule pressure (e.g. Roos 1971).

Once biofouling organisms arrive in a donor location there are many factors that dictate whether they will transfer, colonise and establish (Chapter 1; Figure 1), but this is beyond the scope of this thesis. Prevention is clearly better than a cure, hence the correct application and maintenance of suitable anti-fouling coatings to the entire submerged hull surface of vessel hulls, including niche areas is the most cost-effective 
of minimising the unwanted translocation of biofouling organisms and NIMS. However, the results of this thesis demonstrate that if biofouling organisms colonise and establish on a vessel's hull, voyage speed alone is not capable of providing a reliable second level of defence against the unwanted arrival of NIMS. Clearly, the survivorship of biofouling organisms was highest amongst vessels that travelled at slow and medium speeds (e.g. <10 knots). Therefore, given the accumulation of biofouling follows a successional process and NIMS are more likely to be associated with higher levels of biofouling, vessels that travel at slow and medium speeds are likely to pose the greatest risk of translocating NIMS on a vessel by vessel scale. However, despite the ability of fast vessels at reducing the diversity, quantity and quality of sessile biofouling organisms in laminar flow areas of the hull, a wide range of sessile, sedentary and mobile organisms were still cable of survival in niche areas, particularly sea-chests.

\subsection{APPLICATION OF THESIS FINDINGS}

International recognition of biofouling as a mechanism for the unwanted dispersal of NIMS prompted the $56^{\text {th }}$ session of the International Maritime Organization (IMO) Marine Environment Protection Committee (MEPC) in July 2007 to consider a request from several member States and observers for vessel biofouling to be included in the agenda of the IMO work plan ${ }^{6}$. The paper stated that "There are currently no international measures in place addressing the risks of the introduction of invasive aquatic species in biofouling of ships ${ }^{7 "}$. The paper further noted that "it is consistent with the IMO's objectives that new issues that might adversely affect the marine environment, such as biofouling, should be identified at the earliest feasible stage and action taken to avoid or mitigate such effects ${ }^{8}$ ( (See also Roberts and Tsamenyi 2008).

At the time of writing, the IMO's Sub-Committee on Bulk Liquids and Gases (BLG) are in the process of developing international measures for minimising the transfer of invasive aquatic species through biofouling of ships (BLG 14/9). Chapters 3 and 6 (i.e. Coutts and Taylor 2004; Coutts and Dodgshun 2007) in particular have had

\footnotetext{
${ }^{6}$ IMO paper MEPC 56/19/3, Development of international measures for minimizing the translocation of invasive aquatic species through biofouling of ships. Submitted by New Zealand, Australia, UK, Friends of the Earth International and the World Conservation Union (IUCN), 5 April 2007.

${ }^{7}$ MEPC 56/19/3 (see footnote 3), paragraph 7.

${ }^{8}$ MEPC 56/19/3 (see footnote 3), paragraph 16.
} 
considerable input into the drafting of these measures. While such measures will make a significant contribution towards changing vessel owner's/operator's behaviour and minimise the dispersal of NIMS via vessel biofouling, they will only apply to vessels greater than 400 gross weight tonnes. Barges and associated support vessels, fishing vessels and recreational craft fall outside of the IMO's mandate (Roberts and Tsamenyi 2008).

Some countries such as Australia, New Zealand and the State of California are already in the process of developing mandatory biofouling management requirements which are likely to be implemented within the next two years (i.e. 2010-2012). Interestingly, each country has adopted a different approach towards assessing the risk posed by vessel biofouling before developing their policies and management requirements.

\subsection{NEW ZEALAND GOVERNMENT}

In 2004, MAF Biosecurity New Zealand (MAFBNZ) commission the National Institute of Water and Atmospheric Research, Cawthron Institute, Golder and Associates Pty Ltd (formally Kingett Mitchell Ltd) and New Zealand Diving and Salvage Pty Ltd to representatively sample international merchant vessels, fishing vessels, cruise vessels, recreational yachts, barges, tugs, and petroleum exploration related infrastructure upon arrival in New Zealand waters (Biosecurity New Zealand 2005). Chapter 3 (Coutts and Taylor 2004) provided valuable insight into which hull locations should be sampled in order to detect NIMS (i.e. sampling of niche areas). Moreover, the simplistic level of biofouling concept developed in Chapter 3 prompted MAFBNZ to further develop a more quantitative tool so that consistent assessment of levels of biofouling could be achieved by contractors when sampling different vessel types (e.g. Floerl et al. 2005). The outcomes of this research will underpin the development of MAFBNZ's biofouling policy and amendments to the Biosecurity Act 1993 in order to facilitate the implementation of future biofouling management requirements (e.g. Biosecurity New Zealand 2009). Such requirements are likely to be implemented within the next two years (2010-2012).

\subsection{AUSTRALIAN GOVERNMENT}

In 2008, the Department of Agriculture, Fisheries and Forestry's (DAFF) Invasive Marine Species Program commissioned the University of Tasmania, Australian 
Maritime College's National Centre for Marine Conservation and Resource Sustainability and Aquenal Pty Ltd to conduct a desktop assessment of the marine pest risk associated with vessel biofouling. Vessel visit datasets were obtained from the Australian Quarantine and Inspection Service (AQIS), the Australian Fisheries Management Authority (AFMA) and the Lloyds Maritime Intelligence Unit, including wherever possible the previous and past ten ports of call and for each vessel entering an Australian port between 2002 and 2007.

DAFF has recognised that any proposed biofouling regulations could be considered a Sanitary and Phytosanitary (SPS) Measure (http://www.daff.gov.au/market-accesstrade/sps). SPS measures are subject to rules set under the World Trade Organization (WTO). In particular, the use of SPS measures is governed by the provisions of the WTO Agreement on the Application of Sanitary and Phytosanitary Measures (the SPS Agreement) ${ }^{9}$. Furthermore, given that any proposed biofouling regulations are likely to directly or indirectly affect international trade, a SPS Measure must be developed and applied in accordance with the rights and obligations in the SPS Agreement irrespective of pursuance of IMO standards. Therefore, in the absence of an international standard for vessel biofouling, signatories are required to undertake a science-based risk assessment before notifying the WTO SPS Secretariat of the proposed measures.

As part of conducting the biofouling risk assessment in accordance with SPS Agreement, Chapters 2, 5 and 6 (i.e. Coutts and Dodgshun 2007; Coutts et al. 2010a and b) played significant roles during the pest categorisation phase when conducting the hazard analysis to identify biofouling species of concern (i.e. species known or capable of being translocated as biofouling on vessel hulls), and determining their likelihood of translocation or survival (potential inoculation) to Australia as biofouling organisms. Chapter 6 was instrumental in determining which species are capable of being translocated as biofouling organisms as prior to this work, many sedentary and mobile taxa were thought to be dispersed via ballast water discharge rather than biofouling (e.g. Fofonoff et al. 2003). Furthermore, Chapters 2 and 5 played an important role when determining the transport survival based on physical and physiological stress during the

\footnotetext{
${ }^{9}$ According to Annex A(1)(a) and (d) of the SPS Agreement an SPS Measure is considered any measure applied: a) to protect animal or plant life or health within the territory of the Member from risks arising from the entry, establishment or spread of pests, diseases, disease-carrying organisms or disease-causing organisms; and d) to prevent or limit other damage within the territory of the Member from the entry, establishment or spread of pests.
} 
voyage. It was hoped that vessel speed could be incorporated into the risk assessment for determining the survival of biofouling organisms amongst different vessel types. However, the results of Chapters 2 and $\mathbf{5}$ established that while voyage speed is capable of reducing potential inoculum pressure, particularly in laminar flow areas, speed is unlikely to affect the survival of biofouling organisms in niche areas (i.e. Chapters 3 and 6). For this reason, vessel speed could not be incorporated into the likelihood assessment. Such requirements are likely to be implemented within the next two years (2010-2012).

\subsection{STATE OF CALIFORNIA}

Amendments to the Marine Invasive Species Act of 2003 required the California State Lands Commission (Commission) to analyze and evaluate the risk of non-indigenous species release from commercial vessel mechanisms other than ballast water (essentially vessel biofouling), in consultation with a Technical Advisory Group (TAG). I was an active member of the TAG which began in May 2005 with a one-day workshop held in San Francisco followed by a further three meetings in August, October and December 2005 in Sacramento, California. Chapters 3 and 6 played important roles during these discussions when analysing and evaluating the risk of NIMS release from commercial vessels (see Gonzalez and Johnson 2005; Takaka et al. 2006).

The Commission recommended that legislation be developed to reduce the introduction of NIMS into California's coastal waters through increased regulation of large commercial vessels entering California ports. The Assembly Bill 740 (AB 740) was developed and requires masters, owners, and/or operators of vessels over 300 gross weight tonnes that visit a Californian port or place as of 1 January 2008 to report information to the commission surrounding the application of anti-fouling coatings and hull husbandry activities. The State Lands Commission (SLC) in consultation with the U.S. Coast Guard are also required to develop and adopt regulations governing the management of hull fouling on vessels arriving at Californian ports before 1 January 2012 (http://www.slc.ca.gov/Spec_Pub/MFD/Ballast_Water/Documents/ab_740.pdf).

\subsection{STATES AND NORTHERN TERRITORY OF AUSTRALIA}

Given the Australian Government has yet to implement national biofouling requirements, States and Northern Territory have started amending their existing 
legislation, predominantly Fisheries Acts and Regulations in an attempt to protect their coastal waters against the arrival of NIMS (Biofouling Solutions 2009). At the time of writing, all State and Territory jurisdictions have the powers to manage the arrival of NIMS of concern via vessel biofouling, however none of them appear to have released a formal policy communicating their powers, which NIMS they are concern about, and which vessels they will target for inspection. For example, some jurisdictions such as New South Wales and Northern Territory have amended their legislation to define specific NIMS of concern relevant to biofouling, while other jurisdictions such as Western Australia have simply stated that they are capable of acting against any “aquatic, noxious or exotic species" (Biofouling Solutions 2009). However, Northern Territory and Western Australia to date have targeted and refused entry to a variety of contaminated vessels such as international recreational vessels, dredges, barges and petroleum related infrastructure (e.g. DeFelice 1999; Apte et al. 2000; Lewis 2002; Godwin and Eldredge 2001; Coutts 2002; Wells and Jones 2003; Lewis et al. 2003).

The Commonwealth in conjunction with the States/Territory jurisdictions are also capable of managing the introduction of species of concern via vessels using the Petroleum (Submerged Lands) Act 1967 (PLSA) and the associated Petroleum (Submerged Lands) (Management of Environment) Regulations 1999 and 'Schedule of Specific Requirements as to Offshore Petroleum Exploration and Production (2005)'. As part of this legislation, an Environmental Plan (EP) or Environmental Management Plan (EMP) is developed in consultation with the petroleum industry that specifies agreed environmental performance objectives and standards which could request that vessels/infrastructure are free of species of concern. Under CommonwealthState/Territory agreements, the States and Territory governments administer an Environmental Management application and approvals process relating to petroleum activities in the Commonwealth waters that lie beyond their respective State and Territory waters. As a result, one of the large petroleum companies, Woodside Energy Limited, has developed their own biofouling management strategy and contractor resource kit to ensure their contracted vessels and infrastructure are free of invasive marine species of concern $^{10}$ (Woodside 2009).

\footnotetext{
${ }^{10}$ Woodside Energy Limited prefer to use invasive marine species of concern rather than NIMS.
} 


\subsection{AN URGENT NEED FOR FURTHER BIOFOULING MANAGEMENT MEASURES}

Despite the intentions of IMO, New Zealand, Australia, and State of California to implement mandatory biofouling requirements within the next two years (2010-2012), there is a potential risk looming on the horizon. The global economic downturn has forced the long-term anchorage of unprecedented numbers of vessels and infrastructure in ports and harbours around the world such as Indonesia, Singapore, Malaysia, Philippines, etc (Floerl and Coutts 2009; Wingrove 2009). Such prolonged residency periods are likely to result in vessels and infrastructure accumulating high levels of biofouling, including many high risk NIMS that are known to occur in these waters (e.g. Asian Green mussel, Perna viridis; Asian bag mussel, Musculista senhousia; Black striped mussel, Mytilopsis sallei; Lady crab, Charybdis japonica).

The concern is that if/when the economy recovers and these vessels are re-engaged, there will not be enough dry-docks to accommodate the demand for cleaning and maintenance. Owners/operators may resort to in-water cleaning; however in-water cleaning is: a) being increasingly banned around the world; or 2) if permitted, is likely to focus on reducing hydrodynamic drag (to increase operational efficiency) and neglect niche areas where NIMS are likely to be more prevalent. It is therefore possible that unprecedented levels of biofouling and NIMS maybe translocated around the world.

Marine biosecurity authorities/regulators are encouraged to develop biofouling policies and regulations as soon as possible to manage this potential threat. Given that the development of such policies and requirements can be costly and time-consuming, a pragmatic decision-tree (hereafter referred to as a risk assessment) is proposed in Section 7.10 to assist with identifying and managing high risk vessels (Figure 29). This approach could be used in lieu of or until comprehensive biofouling risk assessments and policies are developed.

\subsection{A PROPOSED RISK ASSESSMENT FOR TARGETING HIGH RISK VESSELS}

\subsubsection{Determining which vessels to target}

Presently it is still not known which vessels pose the greatest biofouling risk. For example, in 2002, there were c. 3421 international vessel visits to New Zealand: 2581 
merchant vessels, 794 pleasure craft, 34 passenger ships, and 12 barges/tugs (Biosecurity Council 2003). Clearly any one of these vessels could pose a biosecurity risk and to inspect every vessel that arrives at the border is unrealistic. Therefore, a cost-effective approach is needed to target those vessels that have the highest likelihood of being contaminated with NIMS. Based on the findings of Chapters 2, 3 and 5, higher levels of biofouling accumulate on vessels that have the longest residency periods (i.e. remain stationary), and en route survival is likely to be higher on slowmoving vessels (e.g. $<10$ knots). Theoretically, therefore, if survivorship is greater on slow-moving vessels, which in turn increases inoculum pressure in ports and harbours, slow-moving vessels will pose the greatest risk on a vessel by vessel scale. Furthermore, such vessels have been implicated with successfully translocating NIMS around the world (e.g. Foster and Willan 1979; Hay 1990; Hay and Dodgshun 1997; DeFelice 1999; Field 1999; Apte et al. 2000; Godwin and Eldredge 2001; Coutts 2002; Lewis et al. 2006; Wells and Jones 2003; Anderson et al. 2006).

Many slow-moving vessels tend to have prolonged residency periods and are required to renew anti-fouling coatings within 2.5 years. Conversely, active vessels like merchant vessels tend to adopt superior self-polishing copolymer coatings that are capable of maintaining relatively clean hulls for close to 5 years (their in-service period). Therefore, vessels that travel $<10$ knots, predominantly spend prolonged periods stationary and/or have in-service periods ${ }^{11}$ of $<2.5$ years could be targeted, such as:

- Recreational vessels (yachts)

- Barges and tugs

- Fishing vessels

- Dredges

- Pipe-laying barges/vessels

- Mobile Offshore Drilling Units (e.g. jack-up barges, semi-submersibles)

- Offshore supply/anchor handling/diving support vessels

- Heavy-lift vessels

\footnotetext{
${ }^{11}$ In-service period refers to the period of time a vessel usually remains in the water between successive out of water cleaning
} 
- Seismic survey/research vessels

- Tallships

- Defence vessels (although sovereign immunity may apply)

\subsubsection{How to use the risk assessment}

The basis of the proposed risk assessment is it could be used by a quarantine officer to identify potentially high risk vessels overseas prior to their arrival or at the border upon arrival. Given the risk assessment is likely to be used on already potentially targeted high risk vessel types, the risk assessment is extremely conservative and provides criteria for granting or refusing a vessel's entry based on its pre-arrival hygiene practices (Figure 29). The assumption is made that high levels of biofouling are more likely to possess NIMS. The Australia Government has devised a simplistic, but pragmatic method of assessing the risk and likelihood of vessels/infrastructure containing NIMS of concern largely based on the level of approach developed in Chapter 3 (see Text Box 1 for more information). Therefore, vessels found with high levels of secondary or any tertiary levels of biofouling have a relatively higher likelihood of being contaminated with NIMS and should be refused entry or managed appropriately.

\subsubsection{Explanatory notes}

Step 1: Has the vessel/structure been removed from the water and cleaned prior to departure?

The risk of vessels accumulating NIMS is largely dependent on the time elapsed since their previous out of water clean. Therefore, Step 1 is designed to identify vessels that have been thoroughly cleaned (including niche areas) out of the water in vessel maintenance facilities prior to departure to the area of interest (Figure 29). Vessels that provide authentic supporting documentation proceed to Step 3. Vessels that did not meet the criteria or cannot produce authentic supporting documentation proceed to Step 2 (Figure 29). 
Step 1

Has the vessel/structure been removed

from the water and cleaned immediately

prior to departure to the area of interest

for this voyage
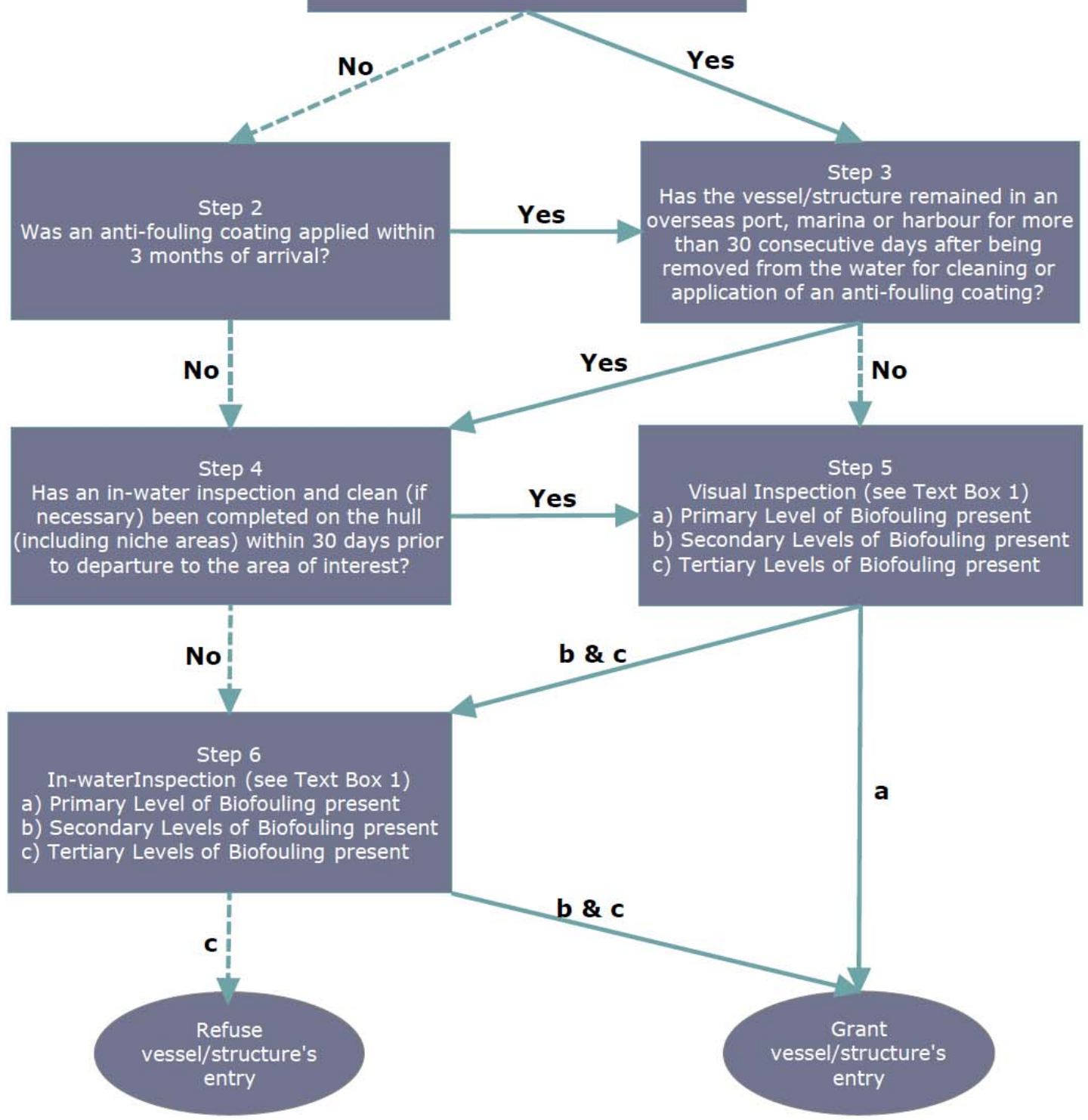

Figure 29 A proposed decision-tree for risk assessing high risk or targeting vessels for non-indigenous marine species. Yes also requires vessel owners/operators supplying authentic documentation to support their answers. No could mean the condition was met, but no authentic supporting documentation is produced. 


\section{Step 2: Was an anti-fouling coating applied within 3 months of arrival?}

Generally, the efficacy of most biocidal ${ }^{12}$ anti-fouling coatings at resisting the settlement of biofouling and NIMS declines with age (e.g. Chapter 3 and 6). Furthermore, there are many niche areas are often not coated with anti-fouling, hence provide non-toxic surfaces for biofouling and NIMS to accumulate (i.e. Chapters 3, 5 and 6). Given tertiary levels of biofouling and NIMS are capable of establishing on nontoxic surfaces within only a few months, vessels that have been anti-fouled within 3 months of arrival and have authentic documentation to support this proceed to Step 3. Vessels that have an anti-fouling coating older than 3 months upon arrival or are unable to supply authentic documentation proceed to Step 4 (Figure 29). Naturally the 3 month time period could be adjusted as necessary.

Step 3: Has the vessel/structure remained in an overseas port, marina or harbour for more than 30 consecutive days after being removed from the water for cleaning or application of anti-fouling or non-toxic coating?

This question is designed to capture the residual risk of vessels being contaminated after being thoroughly cleaned out of water prior to arrival (i.e. originating via Step 1) or possessing anti-fouling coatings less than 3 months old (i.e. originating via Step 2). The 30 consecutive day residency period is rather arbitrary, but based on the settlement rates observed while undertaking Chapters 2 and 5. If yes, or without authentic supporting documentation, they proceed to Step 4. No, or with authentic supporting information proceeds to Step 5 (Figure 29).

Step 4: Has an in-water inspection and clean (if necessary) been completed on the hull (including niche areas) within 30 days prior to departure?

This question is designed to give vessels a second chance to manage their biofouling risk if they possess an anti-fouling coating older than 3 months (i.e. originating via Step 2) or have remained in an overseas port, marina or harbour for more than 30 consecutive days (i.e. originating via Step 3) (Figure 29). Hence, in such circumstances vessels could reduce their biofouling risk by having their hull inspected, and if necessary in-water cleaned (including niche areas) within 30 days of departure. Such inspections could be conducted by trained and approved inspectors to provide a higher

\footnotetext{
${ }^{12}$ Biocidal anti-fouling coatings refer to those that rely on toxic chemicals incorporated in the coating to deter or kill the settlement of larvae and propagules.
} 
level of certainty or assurance. Yes, with (an approved inspector present) and/or authentic supporting documentation proceed to Step 5. No, or without authentic supporting documentation proceeds to Step 6 (Figure 29).

\section{Step 5: Visual inspection}

This step requires a visual inspection for biofouling at the waterline to largely verify the decision making undertaken at Steps 3 and 4. Vessels at this point should only possess primary levels of biofouling (See Text Box; Figure 30) and therefore likely to pose a low and acceptable level of risk and should be granted entry. Alternatively, if secondary or tertiary biofouling is witnessed, then they should proceed to Step 5 and undergo an in-water inspection.

\section{Step 6: In-water inspection}

While cameras on a stick such as Snake-Eye III, Titan Video Stick, SCUBAR, etc could be used to inspect shallow drafted recreational vessels, scientific or commercial divers would be required to inspect larger vessels. Inspections should focus on niche areas as outlined in Chapter 3. Vessels that possess only primary levels of biofouling are likely to pose a low and acceptable level of risk and should be granted entry. Alternatively, vessels with excessive levels of secondary biofouling outside niche areas or the presence of any tertiary levels of biofouling pose an increased likelihood of NIMS being present and vessels should not be granted entry (see Text box; Figure 30).

\subsection{OTHER CONSIDERATIONS}

The main advantage with the Australian Government level of biofouling approach is it avoids the need to identify specific NIMS of concern and is focussed more on a level of biofouling hygiene. Although there are significant challenges surrounding the decision upon which NIMS of concern need to be considered, their detection on vessels and their positive identification. However, the enforceability of such a standard within existing legislation needs to considered and may require changing legislation and regulations or adopting a species based approach. Furthermore, serious consideration should be given to deciding whether the implementation and enforceability of any biofouling measures is a SPS measure and constitutes notifying WTO. 


\section{Text box 1- Levels of biofouling}

The Australia Government has devised a simple, but pragmatic method of assessing the risk and likelihood of vessels/infrastructure containing NIMS of concern. The colonisation and accumulation of biofouling on surfaces submerged in sea water follows a very complex process from the time of settlement of the initial microscopic organisms to the establishment of macroscopic biofouling organisms. In its simplest form, the biofouling process that occurs over a period of time (e.g. such as the in-service period of a vessel/structure) can be classified into three main categories that can be used to assess a biofouling community at the time of observation (i.e. primary, secondary, and tertiary levels of biofouling; Figure 30). The levels of biofouling proposed in Chapter 3 (i.e. Coutts and Taylor 2004) were used as the basis of the Australian Government's approach (i.e. B = primary, C = secondary, and $D=$ tertiary). However, it is important to emphasise that these three categories are not entirely definitive as they are represent a successional continuum.

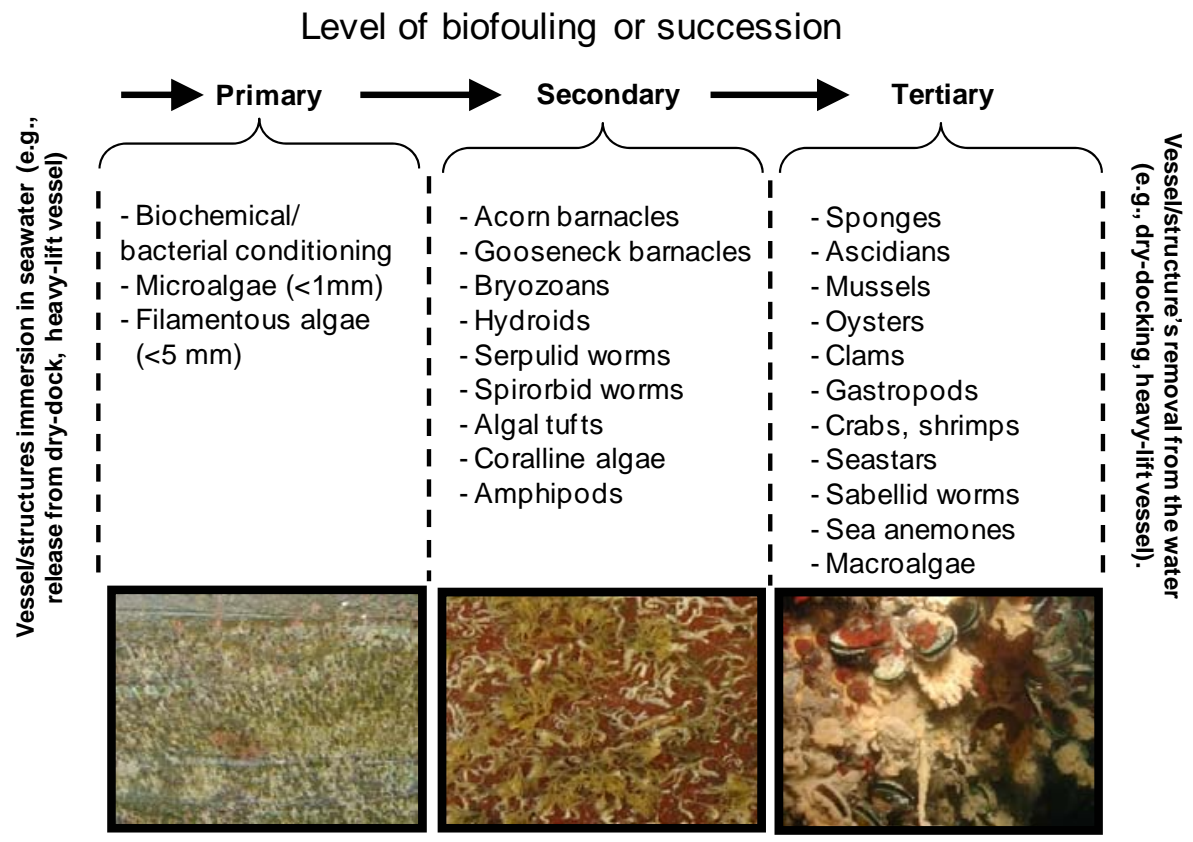

Figure 30 The simplistic, but pragmatic approach to assessing biofouling risk using three levels of biofouling or succession. Source Coutts et al. (2010c).

Primary biofouling begins the moment a vessel/structure's hull is submerged in sea water with the immediate biochemical and bacterial conditioning followed by bacterial, diatom, protozoan and multicellular colonisation. Such conditioning and colonisation of microscopic organisms provides an ideal substratum for more visible organisms such as fine filamentous algae, some of which are resistant to the toxic biocides contained in anti-fouling coatings. The establishment of these organisms tends to provide a suitable, but not necessarily mandatory substratum for the settlement of secondary biofouling organisms, which tend to be the most dominant and frequently encountered biofouling organisms on vessel/structure hulls. Secondary biofouling communities are more likely to progress towards tertiary biofouling, particularly in niche areas of vessels/structures that are protected from strong hydrodynamic forces, when vessels remain stationary for long periods of time, or simply the longer the in-service period.

While NIMS are capable of colonising a vessel hull during the secondary biofouling stage, they are more often associated with tertiary levels of biofouling (Figure 30). Therefore, the presence of high levels of secondary biofouling or any level of tertiary biofouling provides a simplistic, but pragmatic indicator for determining the likelihood that a vessel/structure may be contaminated with NIMS. 


\subsection{RECOMMENDATIONS}

The following recommendations are made based on both the specific outcomes of this thesis and foreseeable issues associated with the gradual implementation of vessels biofouling requirements around the world.

\subsubsection{Anti-fouling coatings}

All vessels should adopt effective anti-fouling coatings suited to their vessel's proposed activity. This also includes the coating of niche areas.

\subsubsection{Pragmatic risk assessments and vessel biofouling management requirements}

Biofouling is a natural phenomenon and every vessel will accumulate biofouling during its in-service period. Therefore, future biofouling management requirements should be realistic, pragmatic and adopt an Acceptable Level of Protection.

\subsubsection{Vessel maintenance facilities}

There is a significant lack of vessel maintenance facilities around the world. More state of the art dry-docks capable of containing/processing all defouled/waste material are required. Furthermore, new and existing vessel maintenance facilities should adopt a system for managing dry-docking support strips (e.g. alternating hydraulic docking blocks).

\subsubsection{In-water cleaning or incursion response capability}

The implementation of vessel biofouling management requirements around the world will inevitably result in significant numbers of vessels being refused entry into certain locations. Therefore, significant investment in environmentally-friendly in-water cleaning or incursion response technologies is required.

\subsubsection{Sea-chest treatment systems}

All vessels should adopt sea-chest treatment systems (aka Marine Growth Prevention Systems), preferably environmentally-friendly systems. Re-circulating engine cooling water into sea-chests like northern hemisphere ice-class vessels could be a costeffective tool for minimising the accumulation of NIMS. 


\subsection{REFERENCES}

AB 740, 2007. California Legislature 2007-2008 Regular Session. Assembly Bill No. 740. Amended in Assembly April 17, 2007.

Anderson, L. E., Melville, F., Alquezar, R., 2006. An investigation into a marine pest incursion in Port Curtis. Centre for Environmental Management, Central Queensland University. 12 p.

Apte, S., Holland, B. S., Godwin, L. S., Gardner, J. P. A., 2000. Jumping ship: a stepping stone event mediating transfer of non-indigenous species via a potentially unsuitable environment. Biological Invasions 2: 75-79.

Biofouling Solutions, 2009. An inspection of the Rem Etive for invasive marine species of concern. Biofouling Solutions report for TSMarine, November 2009. 109 pp.

Biosecurity Council, 2003. Protect New Zealand: the biosecurity strategy for New Zealand. Wellington, Biosecurity Council. 63 p.

Biosecurity New Zealand, 2009. Review of key parts of the Biosecurity Act 1993. Prepared by Biosecurity, Policy and Risk Directorate. MAF Biosecurity New Zealand Information Paper No. 2009/06, November 2009.

Biosecurity New Zealand, 2005. Vessel biofouling research to measure marine biosecurity risk. Biosecurity New Zealand. Issue 58, pp 8-9.

Bologna, P. A. X., Heck, K. L., 2000. Impacts of seagrass habitat architecture on bivalve settlement. Estuaries 23: 449-457.

BLG 14/9, 2009. Development of international measures for minimising the transfer of invasive aquatic species through bio-fouling of ships. Submitted by New Zealand, Sub-Committee on Bulk Liquids and Gases, $14^{\text {th }}$ Session, Agenda item 9, 9 November 2009.

Brock, R., Bailey-Brock, J. H., Goody, J., 1999. A case study of efficacy of freshwater immersion in controlling introduction of alien marine fouling communities: the USS Missouri. Pacific Science 53: 233-231. 
Callow, M. E., Callow, J. E., 2002. Marine biofouling: a sticky problem. Biologist 49: $1-5$.

Carlton, J. T., 1982. Final report of seawater ballast studies aboard the Martha R. Ingram. In: Mann, R. (Ed). Biology of ship's ballast water: the role of ballast water in the transoceanic dispersal of marine organisms. Chapter D-VI, from "Final project report. National foundation division of applied research" Grant No. DAR8008450 Woods Hole Oceanographic Institute, Massachusetts, USA.

Carlton, J. T., 1985. Transoceanic and interoceanic dispersal of coastal marine organisms: the biology of ballast water. Oceanography and Marine Biology: An Annual Review 23: 313-371.

Carlton, J. T., 2001. Introduced species in US coastal waters: environmental impacts and management priorities, Arlington, Viriginia, United States, Pew Oceans Commission, p. 28.

Carlton, J. T., Geller, J. B., 1993. Ecological roulette: the global transport of nonindigenous marine organisms. Science 261: 78-82.

Carlton, J. T., Hodder, J., 1995. Biogeography and dispersal of coastal marine organisms: experimental studies on a replica of a 16th-century sailing vessel. Marine Biology 121: 721-730.

Carlton, J. T., Reid, D. M., van Leeuwen, H., 1995. Shipping study: the role of shipping in the introduction of non-indigenous aquatic organisms to the coastal waters of the United States (other than the Great Lakes) and an analysis of control options. U.S. Coast Guard, Connecticut, Department of Transportation, Washington, D.C.: 1213.

Cohen, A. N., Carlton, J. T., 1995. Nonindigenous aquatic species in United States Estuary: a case study of the biological invasions of the San Francisco Bay and Delta. A report for the United States Fish and Wildlife Services, Washington, DC and The National Sea Grant College Program, Connecticut Sea Grant. 175. 
Correa, J., Gonza' lez, P., Sa' nchez, P., Muñ oz, J., Orellana, M., 1996. Copper-algae interactions: inheritance or adaptation? Environmental Monitoring Assessment 40: 41-54.

Coutts, A. D. M., 1999. Hull fouling as a modern vector for marine biological invasions: investigation of merchant vessels visiting northern Tasmania (MSc thesis). Launceston, Australia: Australian Maritime College; 283 pp.

Coutts, A. D. M., 2002. A biosecurity investigation of a barge in the Marlborough Sounds. Cawthron Report No. 744. 59 pp.

Coutts, A.D.M., Moore, K.M., Hewitt, C.L., 2003. Ships' sea-chests: an overlooked transfer mechanism for non-indigenous marine species? Marine Pollution Bulletin 46: 1504-1515.

Coutts, A. D. M., Taylor, M. D., 2004. A preliminary investigation of biosecurity risks associated with biofouling on merchant vessels in New Zealand. New Zealand Journal of Marine and Freshwater Research 38:215-229.

Coutts, A. D. M, Dodgshun, T. J., 2007. The nature and extent of organisms in vessel sea-chests: A protected mechanism for marine bioinvasions. Marine Pollution Bulletin, 54: 876-886.

Coutts, D. M., Piola, R. F., Hewitt, C. L., Connell, S. D., Gardner, J. P. A., 2010a. Effect of vessel voyage speed on survival of biofouling organisms: implications for translocation of non-indigenous marine species. Biofouling 26:1-13.

Coutts, A. D. M., Piola, R. F., Taylor, M. D., Hewitt, C. L., Gardner, J. P. A., 2010b. The effect of vessel speed on the survivorship of biofouling organisms at different hull locations. Biofouling 26: 539-553.

Coutts, A. D. M., Valentine, J. P., Edgar, G. J., Davey, A., Burgess-Wilson, B., 2010c. Removing vessels from the water for biofouling treatment has the potential to introduce mobile non-indigenous marine species. Marine Pollution Bulletin 60: 1533-1540.

Czarnoleski, M., Michalczyk, L., Pajdak-Stos, A., 2004. Substrate preference in settling zebra mussels Dreissena polymorpha. Archaeological Hydrobiology 159: 263-270. 
Dafforn, K. A., Glasby, T. M., Johnston, E. L., 2008. Differential effects of tributyltin and copper antifoulants on recruitment of non-indigenous species. Biofouling 24: 23-33.

Davidson, I. C., McCann, L. D., Fofonoff, P. W., Sytsma, M. D., Ruiz, G. M., 2008. The potential for hull-mediated species transfers by obsolete ships on their final voyages. Diversity and Distributions 14: 518-529.

Davis, M. H., Davis, M. E., 2006. Styela clava (Tunicata: Ascidiacea) a new edition to the fauna of New Zealand. Porcupine Marine Natural History Society Newsletter $20,23-28$.

Denny, M. W., 1985. Wave forces on intertidal organisms: a case study. Limnology Oceanography 30: 1171-1187.

Denny, M. W., Daniel, T. L., Koehl, M. A. R., 1985. Mechanical limits to size in waveswept organisms. Ecological Monographs 55: 69-102.

Denny, M. W., Gaylord, B. P., Helmuth, B., Daniel, T. L., 1998. The menace of momentum: dynamic forces on flexible organisms. Limnology Oceanography 43: $955-968$.

DeFelice, R. C., 1999. Fouling marine invertebrates on the floating drydock USS Machinist in Pearl Harbour to its move to Apra Harbour, Guam. Hawai'i Biological Survey, Bernice P. Bishop Museum Honolulu, Hawaii. Contribution No. 1999-013 to the Hawaii Biological Survey.

Field, D., 1999. Disaster averted? Black striped mussel outbreak in northern Australia. Fish Farming International 26: 30-31.

Floerl, O., Coutts, A. D. M., 2009. Potential ramifications of the global economic crisis on human-mediated dispersal of marine non-indigenous species. Marine Pollution Bulletin 58: 1595-1598.

Floerl, O., Pool, T. K., Inglis, G. J., 2004. Positive interactions between nonindigenous species facilitate transport by human vectors. Ecological Application. 14: 17241736. 
Floerl, O., Inglis, G. J., Hayden, B. J., 2005. A risk-based predictive tool to prevent accidental introductions of nonindigenous marine species. Environmental Management 35: 765-778.

Fofonoff, P. W., Ruiz, G. M., Stevens, B., Carlton, J. T., 2003. In ships or on ships? Mechanisms of transfer and invasion for non-native species to the coasts of north America. In: Ruiz, G. M., Carlton, J. T., (Eds), Invasive species: vectors and management strategies, Island Press, pp. 152-183.

Foster, B. A., Willan, R. C., 1979. Foreign barnacles transported to New Zealand on an oil platform. New Zealand Journal Marine Freshwater Research 13: 143-149.

Fowler-Walker, M. J., Wernberg, T., Connell, S. D., 2006. Differences in kelp morphology between wave sheltered and exposed localities: morphologically plastic or fixed traits? Marine Biology 148: 755-767.

Gerard, V. A., 1987. Hydrodynamic streamlining of Laminaria saccharina Lamour in response to mechanical stress. Journal of Experimental Marine Biology and Ecology 107: 237-244.

Glasby, T. M., Connell, S. D., Holloway, M. G., Hewitt, C. L., 2007. Nonindigenous biota on artificial structures: could habitat creation facilitate biological invasions? Marine Biology 151: 887-895.

Godwin, L. S., Eldredge, L. G., 2001. South Oahu Marine Invasions Shipping Study (SOMISS). Technical Report No. 20. Honolulu. Hawaii Biological Survey, Bishop Museum. 104 p.

Gollasch, S., 2002. The importance of ship hull fouling as a vector of species introductions into the North Sea. Biofouling 18: 105-121.

Gonzalez, J. A., Johnson, L. T., 2005. Managing hull transport of aquatic invasive species. Proceedings of May 11, 2005 workshop in San Francisco, California. California State Lands Commission. 53 p.

Grant, W. D., Madsen, O. S., 1986. Continental-shelf bottom boundary layer. Annual Review of Fluid Mechanics 18: 265-305. 
Grave, C., 1920. Amaroucium pellucidum (Leidy) form constellatum (Verrill). I. The activities and reactions of the tadpole larva. Journal of Experimental Marine Biology and Ecology 30: 239-257

Grave, C., 1926. Molgula citrina (Alder and Hancock). Activities and structure of the free-swimming larva. Journal of Morphology 42: 453-471

Grave, C., Woodbridge, H., 1924. Botryllus schlosseri (Pallas): the behaviour and morphology of the freeswimming larva. Journal of Morphology 39: 207-247.

Han, T., Kang, S. H., Park, J. S., Lee, H. K., Brown, M., 2008. Physiological responses of Ulva pertusa and U. armoricana to copper exposure. Aquatic Toxicology 86: $176-184$.

Hay, C. H., 1990. The dispersal of Undaria pinnatifida by coastal shipping in New Zealand, and implications for further dispersal of Undaria to France. British Phycological Journal 25: 301-313.

Hay, C. H., Dodgshun, T. J., 1997. Ecosystem transplant? The case of the Yefim Gorbenko. Seafood New Zealand, May 1997, 13-14.

Hewitt, C. L., 2002. The distribution and diversity of tropical Australian marine bioinvasions. Pacific Science 56: 213-222.

Hewitt, C. L., 2003. The diversity of likely impacts of introduced marine species in Australian waters. Records of the South Australian Museum Monograph Series 7: $3-10$.

Hewitt, C. L., Campbell, M. L., 2008. Assessment of relative contribution of vectors to the introduction and translocation of marine invasive species. Report for the Department of Agriculture, Fisheries and Forestry. National Centre for Marine Conservation \& Resource Sustainability Australian Maritime College, an institute of the University of Tasmania. p. 45.

Hewitt, C. L, Campbell, M.L., Thresher, R. E., Martin, R. B., 1999. Marine Biological Invasions of Port Phillip Bay, Victoria. Centre for Research on Introduced Marine Pests, Technical Report No. 20, CSIRO Marine Research Hobart, Australia. 344pp. 
Hewitt, C. L, Campbell, M.L., Thresher, R. E., Martin, R. B., Boyd, S., Cohen, B. F., Currie, D. R., Gomon, M. F., Keogh, M. J., Lewis, J. A., Lockett, M. M., Mays, N., McArthur, M.A., O’Hara, T. D., Poore, G. C. B., Ross, D. J., Storey, M. J., Watson, J. E., Wilson, R. S., 2004. Introduced and cryptogenic species in Port Phillip Bay, Victoria, Australia. Marine Biology 144: 182-202.

Hewitt, C. L., Gollasch, S., Minchin, D., 2009. Chapter 6 - Ballast water, sediments and hull fouling. In: Rilov, G., Crooks, J., (Eds), Biological Invasions in Marine Ecosystems: Ecology, Conservation and Management Perspectives. Springer, Heidelberg, Germany, pp 117-129.

Hills, J. M., Thomason, J. C., 1998. The effect of scales of surface roughness on the settlement of barnacle (Semibalanus balanoides) cyprids. Biofouling 12: 57-69.

Hoese, D. F., 1973. The introduction of the gobiid fishes Acanthogobius flavimanus and Tridentiger trigonocephalus into Australia. Koolewong 2: 3-5.

Hopkins, G. A., Forrest, B. M., 2008. Management options for vessel hull fouling: an overview of risks posed by in-water cleaning. ICES Journal of Marine Science. 65: 811-815.

Hurlbut, C. J., 1991. Community recruitment: settlement and juvenile survival of seven co-occurring species of sessile marine invertebrates. Marine Biology 109: 507-515.

James, P., Hayden, B., 2000. The potential for the introduction of exotic species by vessel hull fouling: a preliminary study. NIWA Technical Report No. 16; 15 pp.

Jelic-Mrcelic, G., Sliskovic, M., Antolic, B., 2006. Biofouling communities on test panels coated with TBT and TBT-free copper based antifouling paints. Biofouling 22: 293-302.

Johnson, A. J., Koehl, M. A. R., 1994. Maintenance of dynamic strain similarity and environmental stress factor in different flow habitats: thallus allometry and material properties of a giant kelp. Journal of Experimental Biology 195: 381-410.

Johnston, E. L., Keough, M. J., 2003. Competition modifies the response of organisms to toxic disturbance. Marine Ecology Progress Series. 251: 15-26. 
Koehl, M. A. R., 1984. How do benthic organisms withstand moving water? American Zoolology 24:57-70.

Lee, J. E., Chown, S. L., 2007. Mytilus on the move: transport of an invasive bivalve to the Antarctic. Marine Ecology Progress Series 339: 307-310.

Lee, J. T., Widdows, J., Jones, M. B., Coleman, R. A., 2004. Settlement of megalopae and early juveniles of the velvet swimming crab Necora puber (Decapoda: Portunidae) in flow conditions. Marine Ecology Progress Series 272: 191-202.

Lemire, M., Bourget, E., 1996. Substratum heterogeneity and complexity influence micro-habitat selection of Balanus sp and Tubularia crocea larvae. Marine Ecology Progress Series 135: 77-87.

Lewis, J. A., 1998. Marine biofouling and its prevention on underwater surfaces. Materials Forum 22: 41-61.

Lewis, J. A., 2002. Hull fouling as a vector for the translocation of marine organisms. Phase I Study: Hull fouling research. Department of Agriculture, Fisheries and Forestry Australia. Strategic Ballast Water Research and Development Program, Canberra, Report No. 1. 142 pp.

Lewis, P. N., Hewitt, C. L., Riddle, M., McMinn, A., 2003. Marine introductions in the Southern Ocean: an unrecognised hazard to biodiversity. Marine Pollution Bulletin 46: 213-223.

Lewis, P. N., Riddle, M., Hewitt, C. L., 2004. Management of exogenous threats to Antarctica and the sub-Antarctic Islands: balancing risks from TBT and nonindigenous marine organisms. Marine Pollution Bulletin 49: 999-1005.

Lewis, P. N., Bergstrom, D. M., Whinam, J., 2006. Barging in: a temperate marine community travels to the subantarctic. Biological Invasions 8: 787-795.

Ligrani, P. M., 1989. Structure of turbulent boundary layers. In: Cheremisinoff NP, editor. Encyclopedia of fluid mechanics. Houston: Gulf Professional Publishing. pp 121-187. 
Locke, A., Reid, D. M., van Leeuwen, H. C., Sprules, W. G., Carlton, J. T., 1993. Ballast water exchange as a means of controlling discharge of freshwater organisms by ships. Canadian Journal of Fisheries Aquatic Science 50: 2086-2093.

Lynch, W. F., 1947. The behaviour and metamorphosis of the larvae of Bugula neritina (Linnaeus): experimental modification of the length of the free-swimming period and the responses of larvae to light and gravity. Biological Bulletin, Woods Hole 92: $115-50$.

Mast, S. O., 1921. Reactions to light in the larvae of the ascidians, Amaroucium constellatum, Amaroucium pellucidum with special reference to photic orientation. Journal of Experimental Zoology 34: 149

Medcof, J. C., 1975. Living marine animals in ship's ballast water. Proceedings of the Natural Shellfisheries Association 65: 11-12.

Minchin, D., 2006. The transport and the spread of living aquatic species. In: Davenport, J., Davenport, J. L. (Eds.). The Ecology of Transportation: Managing Mobility for the Environment. Springer. p $77-97$.

Minchin, D., 2007. Aquaculture and transport in a changing environment: overlap and links in the spread of alien biota. Marine Pollution Bulletin 55: 302-313.

Mineur, F., Johnson, M., Maggs, C., Stegenga, H., 2007. Hull fouling on commercial ships as a vector of macroalgal introduction. Marine Biology. 151: 1299-1307.

Miron, G., Bourget, E., Archambault, P., 1996. Scale of observation and distribution of adult conspecifics: their influence in assessing passive and active settlement mechanisms in the barnacle Balanus crenatus (Brugiere). Journal of Experimental Marine Biology and Ecology 150: 131-147.

Mullineaux, L. S., Butman, C. A., 1991. Initial contact, exploration, and attachment of barnacle (Balanus amphitrite) cyprids settling in flow. Marine Biology 110: 93103.

Newman, W., 1963. On the introduction of an edible Oriental shrimp (Caridea, Palaemonidae) to San Francisco Bay. Crustaceana 5: 119-132. 
Nowell, A. R. M., Jumars, P. A., 1984. Flow environments of aquatic benthos. Annual Review of Ecology and Systematics 15: 303-328.

Otani, M., Oumi, T., Uwai, S., Hanyuda, T., Prabowo, R. E., Yamaguchi, T., Kawai, H., 2007. Occurrence and diversity of barnacles on international ships visiting Osaka Bay, Japan, and the risk of their introduction. Biofouling 23: 277-286.

Piola, R. F., Johnston, E. L., 2006. Differential resistance to extended copper exposure in four introduced bryozoans. Marine Ecology Progress Series 311: 103-114.

Piola, R. F., Dafforn, K. A., Johnston, E. L., 2009. The influence of antifouling practices on marine invasions. Biofouling 25: 633-644.

Pyefinch, K. A. 1950. Notes of the ecology of ship-fouling organisms. Journal of Animal Ecology. 19: 29-35.

Railkin, A. I., 2004. Marine biofouling: colonization process and defenses. CRC Press. New York. 303 pp.

Reed, R. H., Moffat, L., 1983. Copper toxicity and copper tolerance in Enteromorpha compressa (L.) Grev. Journal of Experimental Marine Biology and Ecology 69: 85-103.

Richards, A., 1990. Muricids: A Hazard to Navigation? Hawaiian Shell News, May, p. 10.

Roberts, J., Tsamenyi, M., 2008. International legal options for the control of biofouling on international vessels. Marine Policy 32: 559-569.

Roos, P. J., 1979. Two stage life cycle of a Cordylophora population in the Netherlands. Hydrobiologia 62: 231-239.

Russell, G., Morris, O. P., 1970. Copper tolerance in the marine fouling alga Ectocarpus siliculosus. Nature 228: 288-289.

Russell, G., Morris, O. P., 1972. Ship-fouling as an evolutionary process. In: Acker, R. F, Brown, B. F., DePalma, J. R., Iverson, W. P. (Eds). Proceedings of the third international congress on marine corrosion and fouling. Gaithersburg (MD): National Bureau of Standards. p. 719-730. 
Schaffelke, B., Hewitt, C. L., 2007. Impacts of introduced macroalgae. Botanica Marina 50: 397-417.

Schaffelke, B., Smith, J., Hewitt, C. L., 2006. Introduced macroalgae - growing problems. Journal of Applied Phycology 18: 529-541.

Skerman, T. M., 1960. Ship-fouling in New Zealand waters: A survey of marine fouling organisms from vessels of the coastal and overseas trades. New Zealand Journal of Science 3: 620-48.

Skinner, L. F., Coutinho, R., 2005. Effect of microhabitat distribution and substrate roughness on barnacle Tetraclita stalactifera (Lamarck, 1818) settlement. Brazilian Archives of Biology and Technology 48: 109-113.

Slack-Smith, S. M., Brearly, A., 1987. Musculista senhousia (Benson, 1842); a mussel recently introduced into the Swan River estuary, Western Australia (Mollusca: Mytilidae). Records of the Western Australian Museum 13: 225-230.

Stebbing ARD. 2002. Tolerance and hormesis - increased resistance to copper in hydroids linked to hormesis. Marine Environmental Research 54: 805-809.

Takaka, L., Falkner, M., Gilmore, S., 2006. Commercial vessel fouling in California: analysis, evaluation, and recommendations to reduce nonindigenous species release from the non-ballast water vector. California State Lands Commission Report, Marine Facilities Division, April 2006, 76 pp.

Thresher, R. E., 2000. Key threats from marine bioinvasions: a review of current and future issues. pp. 24-36. In: Pederson, J. (Ed.) Marine Bioinvasions, Proceedings of the First National Conference, January 24-27, 1999. Massachusetts Institute of Technology, Sea Grant College Program, Boston.

Wahl, M., 1989. Marine epibiosis. I. Fouling and antifouling: some basic aspects. Marine Ecological Progress Series 58: 175-189.

Wahl, M., 1997. Living attached: aufwuchs, fouling, epibiosis. In: Nagabhushanam, R., Thompson, M. F. (Eds.), Fouling organisms of the Indian Ocean: Biology and control Technology. A. A. Balkema, Rotterdam, The Netherlands, pp. 31-83. 
Walters, L. J., 1992a. Field settlement locations on subtidal marine hard substrata: is active larval exploration involved? Limnology Oceanography 37: 1101-1107.

Walters, L. J., 1992b. Post settlement success of the arborescent bryozoan Bugula neritina (L) - the importance of structural complexity. Journal of Experimental Marine Biology and Ecology 164: 55-71.

Walters, L. J., Wethey, D. S., 1996. Settlement and early post settlement survival of sessile marine invertebrates on topographically complex surfaces: the importance of refuge dimensions and adult morphology. Marine Ecology Progress Series 137: $161-171$

Walters, L. J., Hadfield, M. G., del Carmen, K. A., 1997. The importance of larval choice and hydrodynamics in creating aggregations of Hydroides elegans (Polychaeta: Serpulidae). Invertebrate Biology 116: 102-114.

Walton-Smith, F. G., 1946. Effects of water currents upon the attachment and growth of barnacles. Biological Bulletin of Marine Laboratory. 90: 51-70.

Weiss, C. M., 1947. The comparative tolerances of some fouling organisms to copper and mercury. Biological Bulletin 93:56-63.

Wells, F. E., Jones, D. S. 2003. Survey of berth 5 for species possibly introduced into Geraldton Harbour by the vessel 'Leonardo Da Vinci'. Report prepared by Western Australian Museum, Perth Western Australia for the Geraldton Port Authority. 12 p.

Wingrove, M., 2009. Demand slump for oil, gas puts more rigs into lay-up. Lloyds List DCN, International News, November 12, 2009.

Wisely, B., 1958. The settling and some experimental reactions of a bryozoan larva, Watersipora cucullata (Busk). Australian Journal of Marine Freshwater Research 9: 362-371.

Woods Hole Oceanographic Institution. 1952. Marine fouling and its prevention. United States Naval Institute, Annapolis, Maryland. 1-388. 
Woodside, 2009. Contractor Information Pack Management of Invasive Marine Species. Woodside Energy Limited. 30 p.

Wright, J., Boxshall, A., 1999. The influence of small-scale flow and chemical cues on the settlement of two congeneric barnacle species. Marine Ecology Progress Series 183: 179-187. 